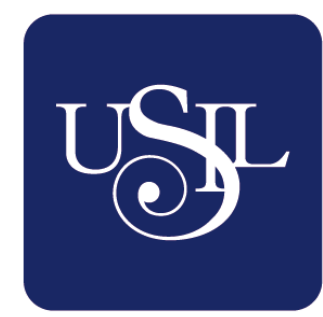

UNIVERSIDAD

SAN IGNACIO

DE LOYOLA

FACULTAD DE CIENCIAS EMPRESARIALES

Carrera de International Business

\title{
RELACIÓN ENTRE LAS ESTRATEGIAS DE NEGOCIO Y EL RENDIMIENTO DE LAS EXPORTACIONES DE EMPRESAS PERUANAS FABRICANTES DE MÁQUINAS PARA LA INDUSTRIA PANADERA DEL 2014 AL 2018
}

Tesis para optar el Título Profesional de Licenciado en International Business

JEANNETTE CECILIA SALAZAR VASQUEZ ANDREA GABRIELA ZUZUNAGA SERNA

Asesor:

Ph.D. Frida Rosa Coaquira Nina

Lima - Perú

2020 


\section{Dedicatoria}

A nuestros padres por habernos apoyado en cada paso de nuestra vida universitaria, por ser parte de todos nuestros logros incluyendo este y por siempre habernos inculcado el respeto y la superación.

A Dios por ser nuestra guía en cada paso que damos y cada decisión que tomamos. 


\title{
Resumen
}

La presente investigación busca determinar si la estrategia de negocios se relaciona con el rendimiento de las exportaciones de las empresas peruanas fabricantes de máquinas para la industria panadera (2014 - 2018). El enfoque es de tipo cuantitativo, de diseño no experimental transversal y de tipo correlacional. Se utilizó el censo a las 11 empresas que cumplieron con los criterios de haber tenido actividad de exportación con valor mayor a US $\$ 10000$ FOB en el periodo 2014 - 2018, que actualmente existan y que no sean empresas unipersonales. El instrumento utilizado para medir las variables estrategias de negocios y rendimiento de las exportaciones fue el cuestionario desarrollado por Knight y Cavusgil (2004). Los resultados mostraron que existe una relación positiva y significativa entre las variables estrategia de negocios y rendimiento de las exportaciones.

Palabras clave: Estrategia de Negocios, Rendimiento de las Exportaciones, Competencia Tecnológica Global, Enfoque en la Calidad

\begin{abstract}
This research seeks to determine if the business strategy is related to the export performance of Peruvian companies that manufacture machines for the bakery industry (2014 - 2018). The approach type is quantitative, with a non-experimental and transversal design and a correlational type. The research required a census of 11 companies that met the criteria of having had export activity with a greater value than US\$10 000 FOB in the 2014 - 2018 period, that currently exist and that are not one-person companies. The instrument used to measure the variables of business strategies and export performance was the questionnaire developed by Knight and Cavusgil (2004). The results showed that there is a positive and significant relationship between the variables business strategy and export performance.
\end{abstract}

Keywords: Business Strategy, Export Performance, Global Technological Competence, Quality Focus 


\section{Índice de Contenido}

Dedicatoria .. i

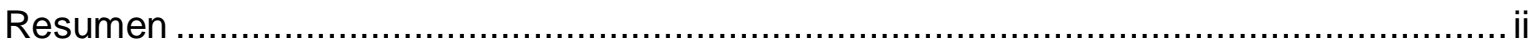

Índice de Contenido ................................................................................................. ii

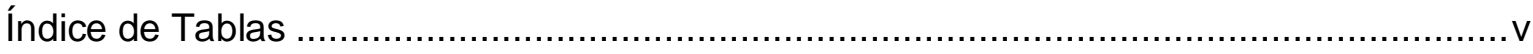

Índice de Figuras ........................................................................................... viii

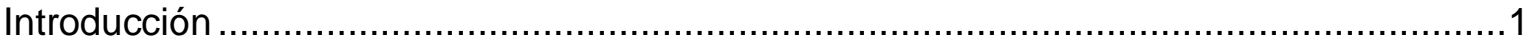

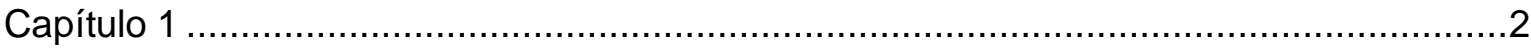

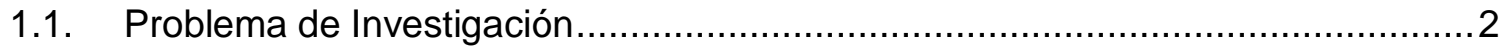

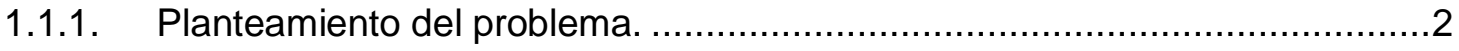

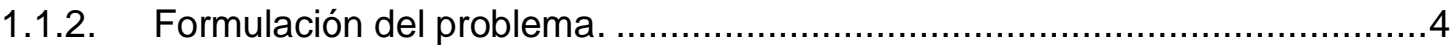

1.1.3. Justificación de la investigación...........................................................

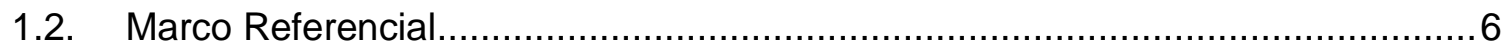

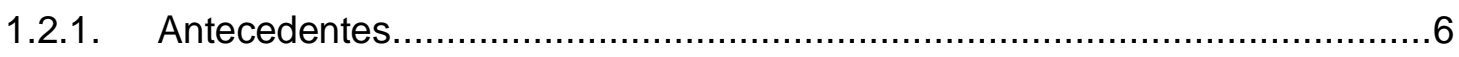

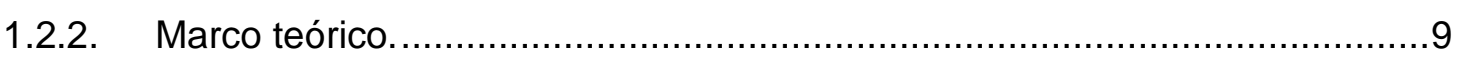

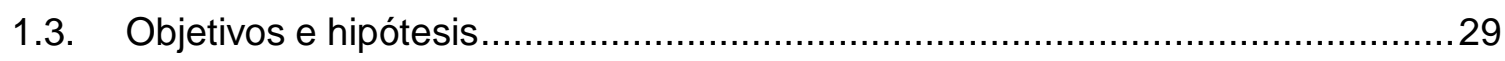

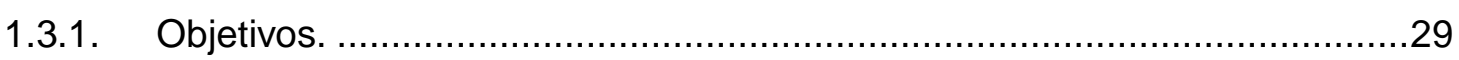

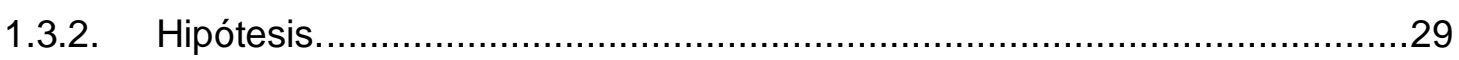

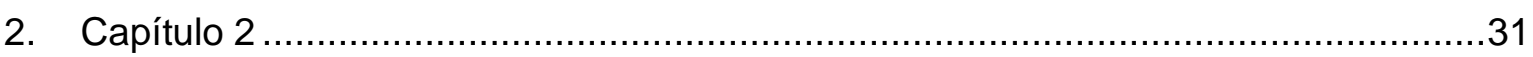

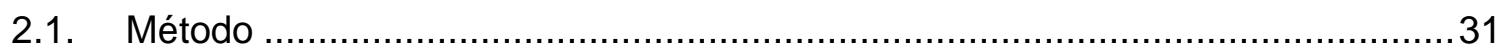

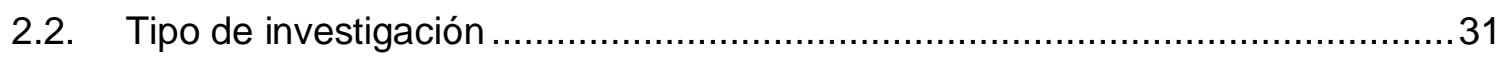

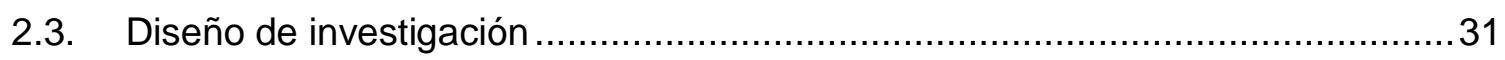

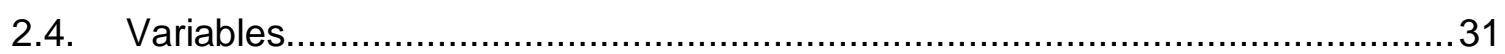

2.4.1. Variable Independiente: Estrategias de Negocios....................................31

2.4.2. Variable Dependiente: Rendimiento de las exportaciones........................33

2.4.3. Operacionalización de las variables.........................................................33

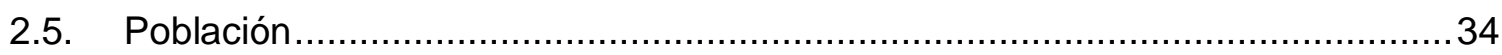

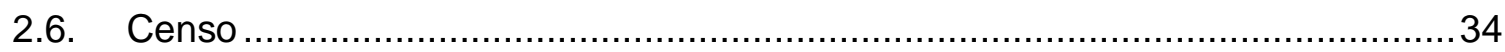

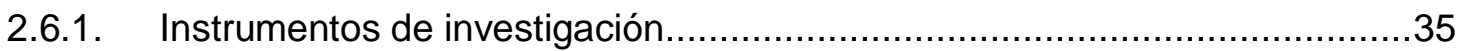

2.6.2. Procedimientos de recolección de datos..................................................36

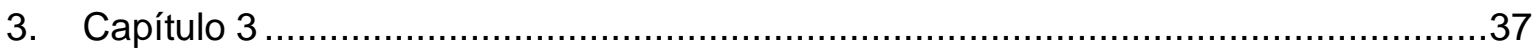

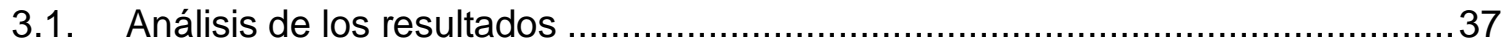

3.1.1. Análisis de Estrategia de Negocios........................................................ 73

3.1.2. Análisis de Competencia Tecnológica Global. .........................................74 
3.1.3. Análisis de Desarrollo de Productos Únicos...............................................75

3.1.4. Análisis de Enfoque de Calidad........................................................76

3.1.5. Análisis de Competencias de los Distribuidores.....................................77

3.1.6. Análisis de Rendimiento de las Exportaciones.........................................78

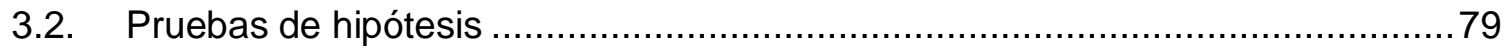

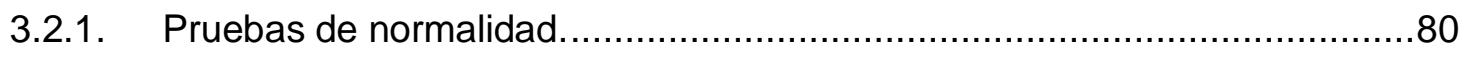

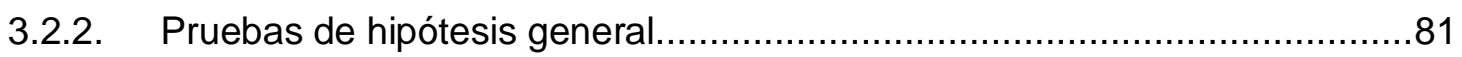

3.2.3. Pruebas de hipótesis específica 1 ...................................................... 82

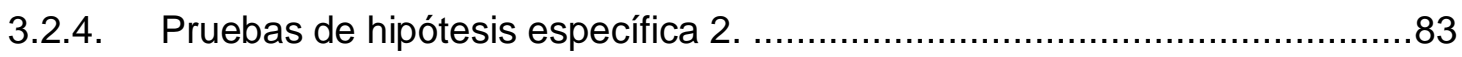

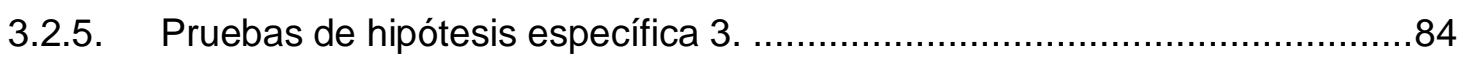

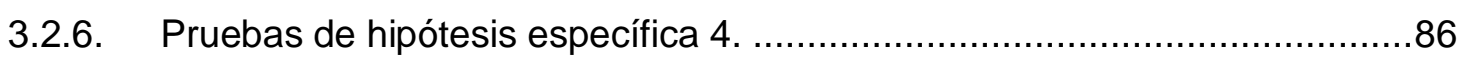

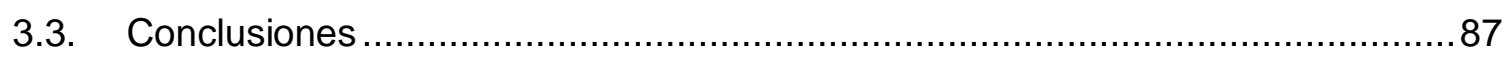

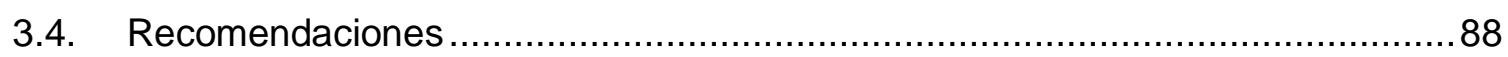

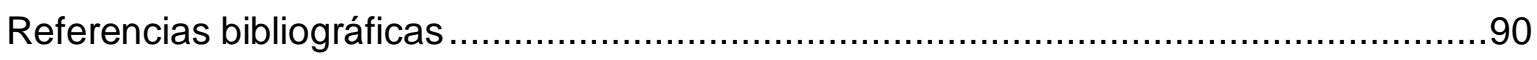

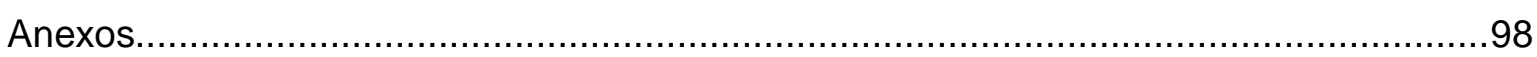

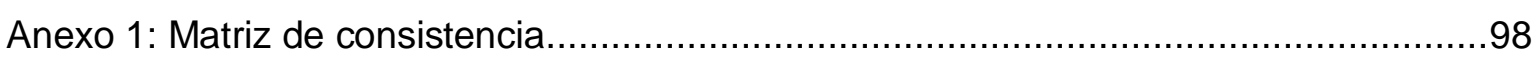

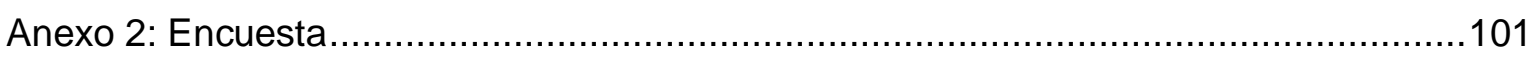

Anexo 3: Principales Exportadores por Subpartida Nacional $(2014-2018) \ldots \ldots \ldots \ldots \ldots \ldots . . . . . .107$

Anexo 4. Análisis factorial exploratorio de la variable Estrategia de Negocios ................110

Anexo 5. Análisis factorial exploratorio de la variable Rendimiento de las exportaciones

Anexo 6: Alfa de Cronbach Estrategia de negocios ................................................114

Anexo 7: Alfa de Cronbach Rendimiento de las exportaciones .....................................114

Anexo 8: Instrumento para validez de contenido - Juicio de Expertos .............................115

Anexo 9. Coeficiente V de Aiken ....................................................................... 143 


\section{Índice de Tablas}

Tabla 1. Principales 20 empresas exportadoras de máquinas de panificación..................14

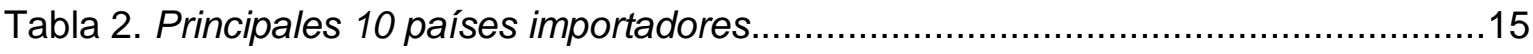

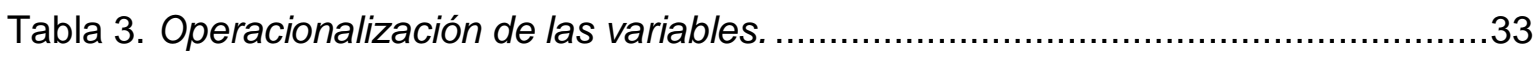

Tabla 4. A1. La empresa está a la vanguardia tecnológica de la industria en el mercado.

Tabla 5. A2. La empresa inventa mucha de la tecnología incorporada en sus productos. 39 Tabla 6. A3. En comparación con los competidores locales, a menudo la empresa es de las primeras en introducir innovaciones de productos o nuevos enfoques operativos......40 Tabla 7. A4. Somos reconocidos en nuestro principal mercado de exportación de productos tecnológicamente superiores.

Tabla 8. A5. La marca es muy apreciada por su experiencia técnica entre los miembros del canal en el mercado.

Tabla 9. A6. En el diseño y fabricación de este producto, emplean a algunos de los especialistas más calificados de la industria.

Tabla 10. Su principal producto de exportación satisface una necesidad especializada que es difícil para sus competidores.

Tabla 11. A8. En la industria, sus productos representan un enfoque nuevo e innovador para abordar las necesidades básicas del cliente.

Tabla 12. A9. En comparación con las ofertas de sus principales competidores, su producto es único con respecto al diseño clientes y la competencia.

Tabla 13. A10. En comparación con las ofertas de sus principales competidores, sus productos son únicos con respecto a la tecnología.

Tabla 14. A11. En comparación con las ofertas de sus principales competidores, sus productos son únicos con respecto al rendimiento.

Tabla 15. A12. Enfatizar la calidad del servicio al cliente es importante para la estrategia de la empresa en el mercado.

Tabla 16. A13. Enfatizar la calidad del producto es importante para la estrategia de la empresa en el mercado.

Tabla 17. A14. Para nosotros, el éxito en el mercado está impulsado por la verdadera satisfacción de las necesidades de nuestros clientes allí.

Tabla 18. A15. El rendimiento de los productos realmente cumple con las expectativas de los clientes en el mercado.

Tabla 19. A16. El servicio brindado con los productos realmente cumple con las expectativas de los clientes en el mercado. 
Tabla 20. A17. Los distribuidores cumplen con las expectativas en cuanto a establecimiento de precios locales.

Tabla 21. A18. Los distribuidores cumplen con las expectativas en cuanto a venta local.55 Tabla 22. A19. Los distribuidores cumplen con las expectativas en cuanto a publicidad local. .56

Tabla 23. A20. Los distribuidores cumplen con las expectativas en cuanto a servicio .....57 Tabla 24. A21. Los distribuidores cumplen con las expectativas en cuanto a recopilación de información del mercado local.

Tabla 25. A22. Los distribuidores cumplen con las expectativas en relación con el gobierno local.

Tabla 26. A23. Los distribuidores cumplen con las expectativas en cuanto a cultivar nuevos negocios / expansión.

Tabla 27. A24. Los distribuidores cumplen con las expectativas en cuanto a modificación del producto (si existe).

Tabla 28. A25. Los distribuidores cumplen con las expectativas en cuanto a organización del envío internacional.

Tabla 29. A26. Los distribuidores cumplen con las expectativas en cuanto a organización del envío local.

Tabla 30. A27. Los distribuidores cumplen con las expectativas en cuanto a relaciones públicas locales.

Tabla 31. A28. Los distribuidores cumplen con las expectativas en cuanto a soporte técnico al cliente / capacitación.

Tabla 32. A29. Los distribuidores cumplen con las expectativas en cuanto a traducción de literatura de ventas, instrucciones de uso o etiquetas.

Tabla 33. A30. Durante el periodo 2014-2018, la empresa ha estado satisfecha con el rendimiento del producto con respecto a la cuota de mercado.

Tabla 34. A31. Durante el periodo 2014-2018, la empresa ha estado satisfecha con el rendimiento del producto con respecto al crecimiento de ventas en el mercado.

Tabla 35. A32. Durante el periodo 2014-2018, la empresa ha estado satisfecha con el rendimiento de sus productos con respecto a la rentabilidad antes de impuestos en el mercado.

Tabla 36. A33. Durante el periodo 2014-2018, la empresa ha estado satisfecha con el crecimiento de las ventas en su principal mercado de exportación en comparación con sus principales competidores.

Tabla 37. Durante el periodo 2014-2018, la empresa ha estado satisfecha con el éxito de sus productos en su principal mercado de exportación. 
Tabla 38. A35. Durante el periodo 2014-2018, la empresa ha estado satisfecha con el rendimiento total de inversión (ROI) de sus productos en su principal mercado de

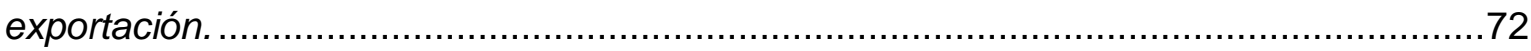

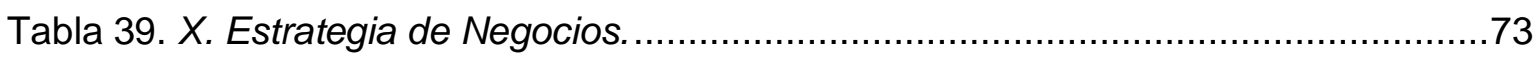

Tabla 40. X1. Competencia Tecnológica Global. .......................................................... 74

Tabla 41. X2. Desarrollo de Productos Únicos.......................................................... 75

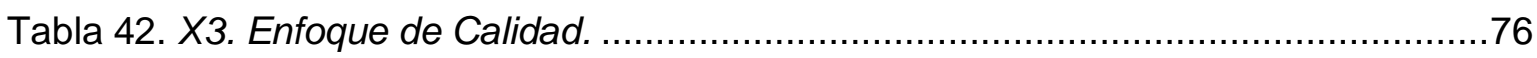

Tabla 43. X4. Competencias de los Distribuidores................................................77

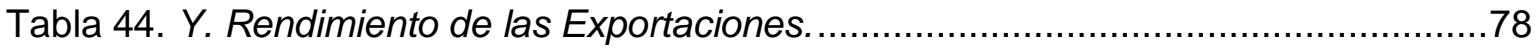

Tabla 45. Criterios para interpretar la correlación..................................................................

Tabla 47. Correlación de Pearson entre estrategias de negocio y el rendimiento de las exportaciones.

Tabla 48. Correlación de Pearson entre la competencia tecnológica global y el rendimiento de las exportaciones.

Tabla 49. Correlación de Pearson entre el desarrollo de productos únicos y el rendimiento de las exportaciones.

Tabla 50. Correlación de Pearson entre el enfoque de calidad y el rendimiento de las exportaciones. .85

Tabla 51. Correlación de Pearson entre las competencias de los distribuidores y el

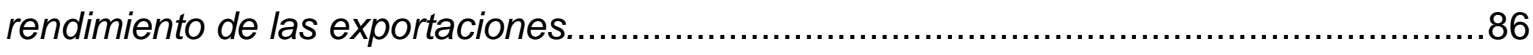

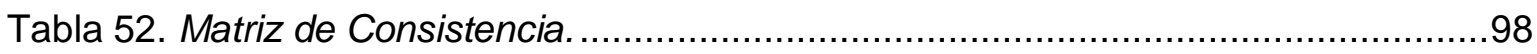

Tabla 53. Exportaciones FOB hornos (PA: 8417209000) 2014 - 2018......................... 107

Tabla 54. Exportaciones FOB maquinas en general (PA: 8438101000) $2014-2018 \ldots 108$

Tabla 55. Exportaciones FOB máquinas (ambas partidas) $2014-2018 \ldots \ldots \ldots \ldots \ldots \ldots . . . . . . . . . .109$

Tabla 56. Matriz de correlaciones para la variable Estrategia de negocios. ....................110

Tabla 57. Varianza total explicada para la variable estrategia de negocios.....................111

Tabla 58. Matriz de componente rotado para la variable Estrategia de negocios...........112

Tabla 59. Prueba de KMO y Bartlett variable Rendimiento de las exportaciones ............113

Tabla 60. Varianza total explicada variable Rendimiento de las exportaciones. .............113

Tabla 61. Matriz de componente rotado para la variable Rendimiento de las exportaciones

Tabla 62. Alfa de cronbach para la variable Estrategia de negocios ..............................114

Tabla 63. Alfa de cronbach para la variable Rendimiento de las exportaciones.............114 


\section{Índice de Figuras}

Figura 1. Innovación, capacidades organizacionales y empresas Born Global - Modelo Conceptual

Figura 2. Capacidades de relación, calidad e innovación como determinantes del

desempeño de las exportaciones - Modelo Conceptual.

Figura 3. Determinantes internos y externos del desempeño de las exportaciones Modelo conceptual.

Figura 4. Vinculación de recursos intangibles y orientación empresarial para el rendimiento de las exportaciones: el efecto mediador de las capacidades dinámicas Modelo conceptual

Figura 5. Factores que inciden en la creación de born global en Colombia - Modelo

Estructural

Figura 6. Factores que inciden en la creación de born global en Colombia - Modelo

Estructural

Figura 7. El efecto de las capacidades de marketing de exportación en el rendimiento de la exportación: una investigación de los exportadores chinos - Modelo conceptual.........21 Figura 8. Modelo propuesto basado en el estudio "Innovation, Organizational Capabilities, and the Born Global Firm" (Knight \& Cavusgil, 2004)..... .22

Figura 9. La empresa está a la vanguardia tecnológica de la industria en el mercado. ....38 Figura 10. La empresa inventa mucha de la tecnología incorporada en sus productos....39 Figura 11. En comparación con los competidores locales, a menudo la empresa es de las primeras en introducir innovaciones de productos o nuevos enfoques operativos. 40 Figura 12. Somos reconocidos en nuestro principal mercado de exportación de productos tecnológicamente superiores.

Figura 13. La marca es muy apreciada por su experiencia técnica entre los miembros del canal en el mercado.

Figura 14. En el diseño y fabricación de este producto, emplean a algunos de los especialistas más calificados de la industria.

Figura 15. Su principal producto de exportación satisface una necesidad especializada que es difícil para sus competidores.

Figura 16. En la industria, sus productos representan un enfoque nuevo e innovador para abordar las necesidades básicas del cliente.

Figura 17. En comparación con las ofertas de sus principales competidores, su producto es único con respecto al diseño clientes y la competencia. 
Figura 18. En comparación con las ofertas de sus principales competidores, sus productos son únicos con respecto a la tecnología.

Figura 19. En comparación con las ofertas de sus principales competidores, sus

productos son únicos con respecto al rendimiento.

Figura 20. Enfatizar la calidad del servicio al cliente es importante para la estrategia de la empresa en el mercado.

Figura 21. Enfatizar la calidad del producto es importante para la estrategia de la empresa en el mercado.

Figura 22. Para nosotros, el éxito en el mercado está impulsado por la verdadera satisfacción de las necesidades de nuestros clientes allí.

Figura 23. El rendimiento de los productos realmente cumple con las expectativas de los clientes en el mercado.

Figura 24. El servicio brindado con los productos realmente cumple con las expectativas de los clientes en el mercado.

Figura 25. Los distribuidores cumplen con las expectativas en cuanto a establecimiento de precios locales.

Figura 26. Los distribuidores cumplen con las expectativas en cuanto a venta local........55

Figura 27. Los distribuidores cumplen con las expectativas en cuanto a publicidad local.56

Figura 28. Los distribuidores cumplen con las expectativas en cuanto a servicio.

Figura 29. Los distribuidores cumplen con las expectativas en cuanto a recopilación de información del mercado local...

Figura 30. Los distribuidores cumplen con las expectativas en relación con el gobierno local.

Figura 31. Los distribuidores cumplen con las expectativas en cuanto a cultivar nuevos negocios / expansión.

Figura 32. Los distribuidores cumplen con las expectativas en cuanto a modificación del producto (si existe)

Figura 33. Los distribuidores cumplen con las expectativas en cuanto a organización del envío internacional.

Figura 34. Los distribuidores cumplen con las expectativas en cuanto a organización del envío local.

Figura 35. Los distribuidores cumplen con las expectativas en cuanto a relaciones públicas locales.

Figura 36. Los distribuidores cumplen con las expectativas en cuanto a soporte técnico al cliente / capacitación. .65 
Figura 37. Los distribuidores cumplen con las expectativas en cuanto a traducción de literatura de ventas, instrucciones de uso o etiquetas.

Figura 38. Durante el periodo 2014-2018, la empresa ha estado satisfecha con el rendimiento del producto con respecto a la cuota de mercado.

Figura 39. Durante el periodo 2014-2018, la empresa ha estado satisfecha con el rendimiento del producto con respecto al crecimiento de ventas en el mercado.

Figura 40. Durante el periodo 2014-2018, la empresa ha estado satisfecha con el rendimiento de sus productos con respecto a la rentabilidad antes de impuestos en el mercado.

Figura 41. Durante el periodo 2014-2018, la empresa ha estado satisfecha con el crecimiento de las ventas en su principal mercado de exportación en comparación con sus principales competidores.

Figura 42. Durante el periodo 2014-2018, la empresa ha estado satisfecha con el éxito de sus productos en su principal mercado de exportación.

Figura 43. Durante el periodo 2014-2018, la empresa ha estado satisfecha con el rendimiento total de inversión $(\mathrm{ROI})$ de sus productos en su principal mercado de

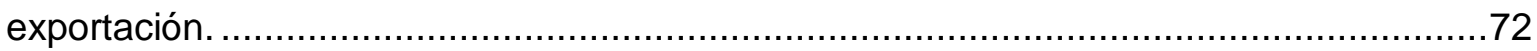

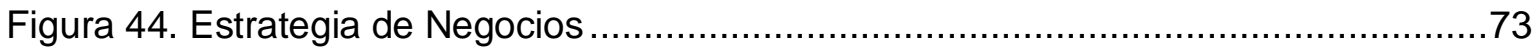

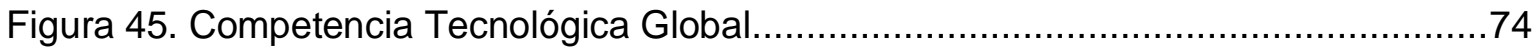

Figura 46. Desarrollo de Productos Únicos .............................................................. 75

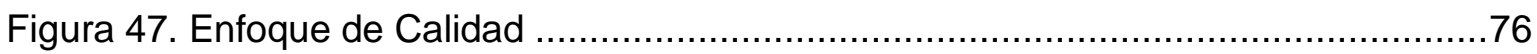

Figura 48. Competencias de los Distribuidores ................................................... 77

Figura 49. Rendimiento de las Exportaciones ........................................................ 78 


\section{Introducción}

En la última década, la industria panadera en el Perú ha pasado por varias etapas para lograr el nivel de crecimiento que mantiene el día de hoy. Entre los años 2013 - 2016, por consecuencia de la menor demanda interna, el sector experimentó una fase de desaceleración y contracción de la producción, lo cual condujo a una caída del 8\% (Sociedad Nacional de Industrias, 2018). Para el cierre del año 2017, la situación empezó a mejorar, teniendo un crecimiento de 3.5\%; y para el primer semestre del año 2018, se registró un crecimiento del $4.1 \%$ con respecto al mismo periodo del año anterior (Instituto de Estudios Económicos y Sociales, 2018). Uno de los factores del crecimiento del sector es la mayor inversión en tecnología, específicamente en máquinas que mejoran la producción en calidad y tiempos.

La oferta nacional de empresas que comercializan maquinarias para la panificación es variada. Estas empresas están en la constante búsqueda de expandir sus ventas actuales, y algunas de ellas ven en la exportación una forma de lograrlo ya que, al tratarse de bienes con una larga vida útil, la frecuencia de venta se reduce.

Si bien los programas de promoción de exportaciones del estado han ayudado a que las empresas puedan dar el paso a la internacionalización aún no se han sentado las bases para que estas exportaciones tengan un crecimiento sostenido a lo largo de los años. Actualmente es solo un número reducido de empresas las que exportan constantemente estos bienes de capital al exterior; y el volumen de estas ventas en términos monetarios aún es mínimo para la mayoría de los casos. (SUNAT, 2018).

Diversos autores han investigado el impacto de los factores que determinan el rendimiento exportador. En la presente investigación nos enfocaremos en determinar la relación de las estrategias de negocios (competencia tecnológica global, desarrollo de productos únicos, enfoque en la calidad y el aprovechamiento de las competencias de los distribuidores extranjeros) y el rendimiento de las exportaciones de empresas peruanas fabricantes de máquinas para la industria panadera. 


\section{Capítulo 1}

\subsection{Problema de Investigación}

\subsubsection{Planteamiento del problema.}

Durante la última década, la industria panadera en el Perú ha pasado por distintas etapas para lograr el nivel de crecimiento que mantiene el día de hoy. Entre los años 2013 - 2016, por consecuencia de la menor demanda interna, el sector experimentó una fase de desaceleración y contracción de la producción, lo que produjo una caída en la misma del 8\% (Sociedad Nacional de Industrias, 2018).

Para el cierre del año 2017, las cosas empezaron a mejorar, llegando a tener un crecimiento de 3.5\%; y para el primer semestre del año 2018, llegar al crecimiento del $4.1 \%$ con respecto al mismo periodo del año anterior (Instituto de Estudios Económicos y Sociales, 2018). Dicho incremento es explicado por la mayor oferta de productos panaderos con más valor nutricional, mayor inversión en máquinas y, por último, gracias a la eliminación del paradigma de que el pan genera un aumento en el peso corporal.

Tomando en consideración la mayor inversión en máquinas para la industria alimentaria como factor de crecimiento en la industria panadera en el Perú, es necesario mencionar que la oferta nacional es muy variada, contando con aproximadamente 152 empresas entre fabricantes e importadoras de este tipo de equipos. Estas empresas están en la constante búsqueda de expandir sus ventas actuales, y algunas de ellas ven en la exportación una forma de lograrlo ya que, al tratarse de bienes con una larga vida útil, la frecuencia de venta se reduce a que un cliente cambie cada máquina cada 10 años aproximadamente. (Dato de la industria). Sin embargo, la oferta exportable en el periodo 20142018, se reduce a solo 34 empresas que en conjunto exportaron un promedio de US\$1,008,849 FOB anuales. Es Nova Industrial Tools SAC la empresa más importante del rubro pues representa el $82.82 \%$ del total de dichas exportaciones (SUNAT, 2014 - 2018).

La oferta exportable de las máquinas de panificación (hornos y otras máquinas) para la industria alimentaria durante los últimos 5 años han tenido como destino 22 países con foco en el continente americano en países como Bolivia, Ecuador, 
Estados Unidos, Chile, Colombia, Panamá, y Venezuela; y del continente europeo teniendo a Italia como su máximo representante.

Del total de las 34 empresas exportadoras tan solo 16 superan las ventas por 10000 dólares anuales en valor FOB, ya que la mayoría concentra sus esfuerzos en la venta local y no se enfoca en la actividad de comercio internacional.

Si miramos más recientemente, durante el 2018 las exportaciones de máquinas de la industria llegaron a 767309 dólares FOB alcanzando un 9\% de crecimiento con respecto al año anterior (SUNAT, 2019), un crecimiento significativo sin tomar en cuenta el pequeño tamaño de la industria. Se debe resaltar que, en el año 2018, fueron solamente 10 empresas que tuvieron operaciones de comercio exterior, resultando NOVA INDUSTRIAL TOOLS SAC como el principal representante nacional con el $86.86 \%$ de las ventas totales internacionales ese año.

Si tomamos en cuenta los años 2014-2018, los países latinoamericanos recibieron el $77 \%$ de nuestras exportaciones en relación con el total, alcanzando en este lapso US\$. 3,870,374 FOB. Bolivia se consolidó como el país que recibió más exportaciones, seguido de Ecuador. Estados Unidos por su lado recibió el $12 \%$ de exportaciones a lo largo de los 5 años, y Europa (Italia, Holanda y España) $11 \%$.

Sin embargo, si analizamos año a año, las exportaciones de máquinas de panificación sufrieron al inicio del 2016 una caída notable, para luego mantenerse estable, pero con un crecimiento discreto.

En la presente investigación nos enfocaremos en determinar la relación de las estrategias de negocios (competencia tecnológica global, desarrollo de productos únicos, enfoque en la calidad y el aprovechamiento de las competencias de los distribuidores extranjeros) y el rendimiento de las exportaciones de empresas peruanas fabricantes de máquinas para la industria panadera. 


\subsubsection{Formulación del problema.}

\section{- General.}

¿Cuál es la relación entre las estrategias de negocio y el rendimiento de las exportaciones de empresas peruanas fabricantes de máquinas para la industria panadera del 2014 al 2018 ?

\section{- Específicos.}

- ¿Cuál es la relación entre competencia tecnológica global y el rendimiento de las exportaciones de empresas peruanas fabricantes de máquinas para la industria panadera del 2014 al $2018 ?$

- ¿Cuál es la relación entre desarrollo de productos únicos y el rendimiento de las exportaciones de empresas peruanas fabricantes de máquinas para la industria panadera del 2014 al $2018 ?$

- ¿Cuál es la relación entre el enfoque en la calidad y el rendimiento de las exportaciones de empresas peruanas fabricantes de máquinas para la industria panadera del 2014 al $2018 ?$

- ¿Cuál es la relación entre el aprovechamiento de las competencias de los distribuidores extranjeros y el rendimiento de las exportaciones de empresas peruana fabricantes de máquinas para la industria panadera del 2014 al 2018?

\subsubsection{Justificación de la investigación.}

La presente investigación tiene como fin principal la identificación de la relación entre las estrategias de negocio y el rendimiento de las exportaciones de estas empresas fabricantes de máquinas de panificación, dado que las empresas peruanas fabricantes de máquinas de panificación buscan expandir sus horizontes mediante la venta en mercados internacionales. Con este análisis se sugerirán recomendaciones que contribuyan a la mejora del desempeño de las empresas del sector.

Para la justificación de nuestra investigación podemos distinguir también tipos de relevancia práctica, teórica y social. 


\section{- Relevancia práctica.}

Según los objetivos expuestos de la investigación, los resultados nos permitirán establecer una relación entre la variable dependiente e independiente, es decir una relación entre las estrategias de negocios y el rendimiento de las exportaciones. Al final de la investigación podremos comprobar esta relación, lo cual ayudará a los empresarios exportadores de maquinarias para la industria de panadería a tener más información con respecto al comercio exterior y así mejorar la toma de decisiones.

Este estudio también servirá como base bibliográfica enfocada en la realidad peruana para una industria que aún se encuentra en nacimiento.

\section{- Relevancia teórica.}

Este tipo de relevancia está relacionada con los modelos y antecedentes empleados referente a las estrategias de negocio y al desempeño de las exportaciones.

Indirectamente también se podrán beneficiar centros de investigación, asociaciones, y estudiantes ya que aportará al desarrollo de futuros estudios que se relacionen con las teorías usadas y que promoverá un mayor entendimiento de las variables.

\section{- Relevancia social.}

Nuestra investigación será relevante para todas aquellas empresas exportadoras y fabricantes de máquinas de panificación, así como también será escalable para otras empresas similares de bienes industriales. Se pretende que más empresas de la misma industria, e industrias relacionadas encuentren en nuestra investigación un instrumento para explotar sus ventas en el exterior a través de la evaluación de sus estrategias de negocio.

Encontramos finalmente un alcance positivo para el desarrollo de la economía nacional, ya que una mejora en el rendimiento de las exportaciones contribuye al crecimiento del producto bruto interno. 


\subsection{Marco Referencial}

\subsubsection{Antecedentes.}

\section{- Estudios.}

- Losada, Navarro, Ruzo y Barreiro (2006) realizaron un estudio titulado "La Performance de Exportación: Revisión Teórica y propuesta de un marco integrador" el cual tuvo como objetivo llegar a un consenso a partir de investigaciones previas sobre cuáles eran los determinantes que afectaban a los resultados obtenidos por las empresas en su actividad exportadora y a partir de esto proponer un marco conceptual que pueda aplicarse a una diversidad de empresas. Se llegó a la conclusión que todas las investigaciones a pesar de la diferencia muestral, diferencias en técnicas estadísticas, tipología de las empresas y otras variables coinciden en que la planificación, el compromiso de los dirigentes, la estrategia de selección de mercados, la estrategia de marketing mix, la orientación al mercado, las relaciones con los representantes comerciales, las características empresariales, ventajas competitivas y el entorno tienen determinación en los resultados que pueda obtener una empresa exportadora.

- Lee y Jang (1990) realizaron un estudio empírico titulado "Impact of Export Market Expansion Strategy on Export Performance" en donde se investigó la relación entre la elección de una estrategia de expansión para el mercado a exportar y el posterior desempeño de las empresas exportadoras. Se compararon múltiples medidas del desempeño de exportaciones en tres grupos de empresas que seguían distintas estrategias de expansión: concentración del mercado de exportación, diversificación concéntrica y estrategia de diversificación. Se usó una muestra de 52 pequeños y medianos fabricantes estadounidenses de tecnología y se mostró diferencias importantes entre 3 grupos estratégicos en cuanto a nivel de exportación y medidas de crecimiento, pero no se encontraron diferencias significativas en rentabilidad de exportaciones. 
- Escandón y Hurtado (2014) hicieron un estudio titulado "Factores que influyen en el desarrollo exportador de las pymes en Colombia" donde se investigaron cuáles son las variables que influencian las exportaciones en pequeñas y medianas empresas colombianas. Los autores realizaron un análisis de las características del emprendedor, de la empresa y del entorno, así como también los recursos de la empresa y su capacidad de innovar. Los resultados de este estudio arrojaron que los factores internos de la empresa tienen un efecto en el desarrollo exportador, pero que éstos no son determinantes de su internacionalización. Además, se concluyó que la innovación es un factor relevante para el desarrollo de las exportaciones.

- Ormeño (2003) realizó una investigación con título "Exportaciones del Perú y el APEC desde una perspectiva de la dotación de factores (19801999)" donde explica el porqué de la disminución de las exportaciones durante los años ochenta. Adicionalmente, comenta sobre la incorporación del APEC en 1998 y cómo esta reforma brinda posibilidades para el intercambio comercial en el ámbito internacional. Los resultados de esta investigación indican que las exportaciones no tradicionales han aumentado significativamente y que factores tales como la población y capital por trabajador influyen en dicho incremento. Adicionalmente el autor explica que hay otras variables importantes como la apertura a nuevos mercados, la innovación o tecnología y el nivel educativo de la población que afectan positivamente al desempeño de las exportaciones peruanas.

- Robles y Jáuregui (2017) realizaron un estudio llamado "International markets entry strategy determinants: An exploratory study in Peru" donde se centran en empresas peruanas con crecientes niveles de exportaciones no tradicionales. El propósito de los autores con su investigación es identificar los factores que determinan la internacionalización de dichas empresas, cuáles son las estrategias implementadas y sus resultados. El estudio hace referencia a factores internos de las empresas que influyen en sus exportaciones, la más importante según Robes \& Jáuregui no es tener una ventaja competitiva en cuanto procesos difíciles de replicar, sino que radica en el Know-How 
de la empresa. Además de ellos, también mencionan otros factores importantes tales como reconocimiento de marca en el extranjero y tecnología e innovación de productos.

- Suwannarat (2016) realizó un estudio titulado "The Study of Export Intermediary Performance Determinants" el cual tuvo como propósito estudiar la influencia directa e indirecta de tres recursos intangibles en los intermediarios del país destino: Conocimiento de la exportación, habilidades de especialización y negociación y confiabilidad en el desempeño del intermediario de exportación a través de la competencia para la reducción de los costos de transacción de los clientes. Este estudio se realizó con una muestra de 400 empresas intermediarias de exportación tailandesas. Los resultados indicaron que las tres habilidades mencionadas afectan de manera positiva y relevante al desempeño del intermediario de exportación como la competencia para reducir los costos de transacción de los clientes.

- Tafesse (2019) realizo una investigación de nombre "Empirical examination of the trade show performance construct and determinants of trade show effectiveness: a developing country case" en donde se investigó el desempeño ferial como un modelo de múltiples dimensiones: análisis del mercado, creación de imagen, inteligencia competitiva y relación con el cliente; todas estas en sus tres etapas: planificación, desarrollo y seguimiento e incorporando variables tácticas en cada una de estas. Para el autor las ferias se han convertido en una importante estrategia de mercadotecnia y ventas. Los resultados de la investigación confirman que tanto las variables tácticas y los recursos que las empresas emplean en las ferias durante cada una de las tres etapas tienen efectos positivos relevantes sobre las dimensiones del desempeño ferial.

- Ortiz (2009) en su investigación titulada "Factores internos de las pymes en Puerto Rico que afectan su entrada a los mercados internacionales" explica que existen diversos factores por los que las pequeñas empresas inician su internacionalización. Específicamente identifica 3 factores que son: las características del empresario, actitudes del empresario hacia la innovación y actitudes del empresario hacia el riesgo de la exportación. 
La investigación propone que las empresas serían más propensas a exportar si hicieran más uso de la tecnología e innovación (internet), pertenecieran a asociaciones y tuvieran mejor actitud hacia el riesgo.

\subsubsection{Marco teórico.}

\section{- Marco Conceptual.}

a. Estrategia de Negocios.

Según Young, Bell y Crick (2000) la estrategia de negocios es una visión holística de la empresa acerca del despliegue de sus recursos y capacidades que le proporciona la base para crear, producir y comercializar productos.

La estrategia de negocios brinda una dirección a la empresa que involucra objetivos de organización, políticas de desarrollo, y planes para llegar a las metas. Porter (2016) identifica tres principios como parte de la estrategia de negocios. En primer lugar, la creación de un posicionamiento de valor en el mercado; en segundo lugar, una promesa de lo que no se debe hacer; y en tercero, la alineación de las actividades para que sigan la estrategia en curso. Según Porter (2016), la estrategia de diferenciación innovadora era las más probable a utilizar en aquellos entornos inciertos y se relaciona al uso de personal técnico y grupos de trabajo. Otra estrategia es la de liderazgo en costos, asociada hacia entornos más estables y a uso de controles.

Para Knight y Cavusgil (2004) las capacidades de las empresas born global poseen capacidades fundamentales de la orientación internacional y orientación de marketing, lo cual genera estrategias organizacionales. Las estrategias de negocios o comerciales más importantes empleadas que surgieron tras investigar a las born global son la competencia tecnológica global, el desarrollo de productos únicos el enfoque en la calidad y el aprovechamiento de las competencias de los distribuidores extranjeros. 
- Competencia tecnológica global: El énfasis en el desarrollo de nuevas tecnologías es una rutina natural para las empresas innovadoras y emprendedoras (Nelson \& Winter, 1982). La innovación es un proceso empresarial crítico para el rendimiento de la empresa en mercados internacionales competitivos (Zahra, Ireland \& Hitt, 2000). Para Knight y Cavusgil (2004) la competencia tecnológica global se refiere a la capacidad tecnológica de la empresa en relación con las demás empresas de la industria. Esto facilita la creación de productos con valor agregado, mejora de productos existentes y una mayor efectividad y eficiencia en los procesos de producción. Esto afecta directamente a los costos y la satisfacción de necesidades especializadas.

Según Knox (2002) para que las empresas puedan crecer sosteniblemente y mantenerse en competencia en los mercados internacionales necesitan utilizar su capacidad de innovación. Por su parte Kam y Singh (2004) afirman que la innovación tecnológica hace que las empresas tengan una mayor tendencia a la exportación de sus productos, y en el caso de las pymes, la adquisición de tecnologías es incluso más relevante en su desarrollo exportador debido a que les permite mejorar su ventaja competitiva en el mercado internacional (Moen, 2002)

- Desarrollo de productos únicos: Para Porter (1980) los beneficios de seguir esta estrategia es la capacidad que tienen las empresas para servir a mercados más especializados con mayor capacidad sin necesidad de competir con otras empresas del sector, lo cual daría lugar a una mejor posición en el mercado y mejores ingresos.

- Enfoque en la calidad: Buzzel y Gale (1987) afirman que el enfoque en la calidad requiere de un sistema de recursos dedicados en crear ofertas de valor superiores hacia los clientes para generar su satisfacción y fidelidad a largo plazo y que la empresa pueda obtener beneficios como un mayor rendimiento.

- Competencias de los distribuidores: Según Bowersox y Cooper (1992) aprovechar las competencias de los distribuidores extranjeros es 
determinante para el éxito en el mercado internacional. Estos son capaces de realizar actividades de marketing, manejo de canales de venta y actividades logísticas que permitan mejorar el desempeño de la empresa, la cual puede concentrarse en sus actividades centrales.

Bello (2003) considera que hay una importancia vital en la creación de una relación con los distribuidores como socios estratégicos ya que de esta manera se pueden crear sinergias en actividades de marketing, y porque existirá una coordinación entre las tareas que ambas partes realicen. El autor considera que el intercambio de información, flexibilidad y solidaridad ayuda a la organización en roles entre el exportador y su distribuidor en el extranjero.

Haddoud, Nowiski, Jones y Newbery (2019) proponen una visión dual de las estrategias de negocios basadas en recurso y redes, o recursos internos y externos.

- Recursos internos: Los recursos internos de una empresa son aquellos que pueden generar impactos dentro de la misma, ya sean positivos o negativos. De acuerdo con Lages, Silva, y Styles (2009), los recursos internos de la empresa se definen como: capital físico, capital humano y capital organizacional. Por su lado, Haddoud, Nowinski, Jones y Newbery (2019) dividen estos recursos internos en cuatro elementos: tecnología, administración, relaciones locales y relaciones internacionales.

- Recursos externos: Al igual que los recursos internos, los recursos externos también generan impactos positivos o negativos para la empresa. Los recursos externos como networks a veces pueden compensar la falta de recursos internos (Chetty \& Holm, 2000; Johanson \& Mattsson, 1988). Esto es particularmente importante en las pequeñas y medianas empresas de los mercados emergentes, que son vulnerables a las limitaciones de recursos y a menudo ponen un mayor énfasis en combinar activos internos y externos. 
Monteiro, Soares y Rua (2019) estudiaron las estrategias de negocio para la exportación mediante dos elementos, las capacidades dinámicas (compuestos por recursos intangibles) y la orientación empresarial.

- Capacidades dinámicas: Según estudio de Monteiro, Soares y Rua (2019), las capacidades dinámicas implican la adaptación y el cambio ya que dichas capacidades son consideradas como transformadoras para convertir recursos en un rendimiento mejorado y crear una ventaja competitiva. Es decir, solo con tener recursos no es suficiente para tener un buen rendimiento, sino también las empresas necesitan de capacidades dinámicas para desarrollar dichos recursos. Permite a la empresa reaccionar a las situaciones cambiantes del mercado.

- Recursos intangibles: Los recursos intangibles de una empresa se dividen en 3: recursos financieros, recursos informativos y recursos relacionales (Monteiro, Soares \& Rua, 2019). Los recursos financieros se refieren a aquellos activos con cierta liquidez, por ejemplo, bonos, acciones, los créditos. En cuanto a recursos informativos, se hace referencia a la información confidencial de la empresa que está grabada en disco duro o en la nube. $Y$ los recursos relacionales se refiere a los contactos que tiene la empresa con terceros: clientes, proveedores, instituciones gubernamentales.

- Orientación empresarial: La orientación empresarial incluye tres dimensiones: Innovación, toma de riesgos y proactividad. Estas dimensiones están asociadas a una tendencia de actuar de manera autónoma y asumir riesgos, así como también a ser agresivos con los competidores y proactivo en cuanto a las oportunidades que el mercado ofrece (Monteiro, Soares \& Rua, 2019).

b. Rendimiento de las exportaciones.

Según Zhang y Zhu (2016), el rendimiento de las exportaciones se define como una forma de medir los logros de los objetivos que tiene una empresa en su comercialización al exterior. Este rendimiento analiza las expectativas sobre el logro de los objetivos empresariales en metas económicas convencionales como rentabilidad y crecimiento en ventas; participación en el mercado; éxito internacional general; entre otros. 
Cavusgil y Zou (1994) dan una definición del rendimiento de las exportaciones como la medida en que los objetivos estratégicos $u$ económicos con respecto a la exportación de un producto a un mercado extranjero se logra a través de la planificación y ejecución de la estrategia de comercialización. La planificación es considerada uno de los pilares de éxito en las exportaciones, especialmente cuando se habla del desarrollo de una estrategia de Marketing internacional (Shoham, 1996). Permite de igual forma el cumplimiento de los objetivos y la búsqueda de mercados atractivos (Evangelista, 1994). Esto se puede traducir en una ventaja competitiva con beneficios en crecimiento (Madsen, 1988), volumen de ventas y rentabilidad (Axinn, Noordewier \& Sinkula, 1996).

De similar forma que Cavusgil y Zou, Tonesakulrungruang (2009) define el rendimiento de las exportaciones como la medida en que se logran los objetivos de una compañía en mercados extranjeros de acuerdo con estrategias específicas y orientaciones. Por lo tanto, la medición del rendimiento se basa en los objetivos de la empresa como aumento en los márgenes de ganancia, aumento de la cuota del mercado, ingreso a nuevos mercados y alcance de un nuevo segmento de clientes.

Hultman, Katsikeas y Robson (2011) mencionan que, si bien la mayor parte de los estudios evalúan el rendimiento utilizando múltiples indicadores, los investigadores generalmente han conceptualizado el rendimiento como unidimensional o global. Solo tres estudios (Katsikeas, Samiee \& Theodosiou, 2006; Lages, Jap \& Griffith, 2008; Schilke, Reimann \& Thomas, 2009) conceptualizan el rendimiento como una variable multidimensional.

\section{c. Empresas exportadoras de máquinas de panificación.}

Las máquinas de panificación son consideradas bienes de capital. Según Eatwell, Milgate y Newman (2001), los bienes de capital son adquiridos con el objetivo de la generación de riqueza y se usan en la producción de otros bienes o servicios en un periodo de tiempo. Los bienes de capital juegan un rol muy importante en la economía actual (Acha et al. 2004) pues, además de permitir generar otros bienes, esta puede servir como barrera de entrada o ventajas competitivas para las empresas. Si una 
empresa no puede comprar las maquinas necesarias para fabricar un producto, no podrá competir en el mercado.

Las máquinas necesarias para la elaboración del pan pueden ser de varios tipos. Las principales y estudiadas en la presente investigación son hornos de panadería (Subpartida nacional: 8417209000) y máquinas de panadería (Subpartida nacional 8438101000) ambas se pueden agrupar bajo el nombre general de Maquinas de Panificación o panadería.

Son aproximadamente 152 empresas las que actualmente se dedican a la comercialización de estas maquinarias de panificación a nivel nacional (entre fabricantes e importadoras que revenden), dentro de su mayoría pequeñas y medianas empresas. Sin embargo, en el periodo 2014-2018 la oferta exportable se redujo solo a 34 empresas que en conjunto exportaron en promedio una totalidad de US\$ 1 millón FOB anuales.

Tabla 1.

Principales 20 empresas exportadoras de máquinas de panificación.

\begin{tabular}{|r|l|r|}
\hline № & \multicolumn{1}{|c|}{ Top 20 exportadores (2014-2018) } & US \$ FOB \\
\hline 1 & NOVA-INDUSTRIAL TOOLS S.A.C. & $4,177,550$ \\
2 & CRUZ HUACARPUMA YOLANDA & 244,970 \\
3 & MACHINES'S WORLD E.I.R.L. & 112,904 \\
4 & ARTEBIANCA S.A.C. & 96,117 \\
5 & VULCANO TECNOLOGIA APLICADA EI RL & 70,517 \\
6 & AFV SERVICIOS SOCIEDAD ANONIMA CERRADA & 61,647 \\
7 & FABRICACION DE MAQUINARIA INDUSTRIAL DEL EMPAQUETADO S.A.C. & 45,017 \\
8 & PMAN DEL PERU SAC EN LIQUIDACION & 31,967 \\
9 & CNC ESPECIALISTAS S.A.C. & 30,000 \\
10 & H. RUIZ HNOS. E.I.R.L. & 25,294 \\
11 & SINIT SOLUCIONES INDUSTRIALES INTEGRALES E.I.R.L & 21,188 \\
12 & INVERSIONES PERU PANAMA SAC & 19,386 \\
13 & GRUPO LEVAPAN S.A. & 17,442 \\
14 & COCINAS SUPERIOR S.A.C. & 17,120 \\
15 & PEĐA BEDOYA RONALD EMILIO & 16,000 \\
16 & MAIGAS COMERCIAL PERU S.A.C. & 15,642 \\
17 & ENVIROTEST S.A.C & 7,061 \\
18 & FAMAIC S.A.C. & 6,200 \\
19 & MIKIS E.I.R.L. & 5,050 \\
20 & MACRONEGOCIOS MARY'S E.I.R.L. & 4,800 \\
\hline
\end{tabular}

Elaboración Propia

Fuente: SUNAT (2014 - 2018) 
La oferta exportable de equipos (hornos y otras máquinas) para la industria alimentaria durante los últimos 5 años han tenido como destino 22 países con foco en el continente americano en países como Bolivia, Ecuador, Estados Unidos, Chile, Colombia, Panamá, y Venezuela; y del continente europeo teniendo a Italia como su máximo representante.

Tabla 2.

Principales 10 países importadores.

\begin{tabular}{|c|l|c|r|}
\hline № & Paises & $\begin{array}{c}\% \text { Part } \\
(2014-\mathbf{2 0 1 8})\end{array}$ & $\begin{array}{c}\text { US \$ FOB } \\
(\mathbf{2 0 1 4}-\mathbf{2 0 1 8})\end{array}$ \\
\hline 1 & BOLIVIA & $35.21 \%$ & $1,776,007$ \\
2 & ECUADOR & $16.39 \%$ & 826,980 \\
3 & UNITED STATES & $11.53 \%$ & 581,736 \\
4 & ITALY & $10.29 \%$ & 519,290 \\
5 & CHILE & $7.20 \%$ & 363,057 \\
6 & COLOMBIA & $6.88 \%$ & 347,228 \\
7 & PANAMA & $4.84 \%$ & 243,906 \\
8 & VENEZUELA & $2.98 \%$ & 150,246 \\
9 & CUBA & $0.77 \%$ & 39,000 \\
10 & MEXICO & $0.62 \%$ & 31,304 \\
11 & OTROS (12) & $\mathbf{3 . 2 8 \%}$ & 165,493 \\
\hline
\end{tabular}

Elaboración Propia

Fuente: SUNAT (2014 - 2018)

Si analizamos más recientemente, solo en el 2018 las exportaciones de máquinas de la industria alcanzaron 767309 dólares FOB lo que significó un $9 \%$ de crecimiento con respecto al año anterior (SUNAT, 2019), un crecimiento significativo sin tomar en cuenta el pequeño tamaño de la industria. 


\section{- Modelos previos.}

- Knight y Cavusgil (2004) investigaron empresas born global como adaptadores tempranos de internacionalización. Su estudio se centra en el rol crítico de una cultura innovadora, así como también conocimiento y habilidades de las empresas para lograr tener éxito en el mercado internacional.

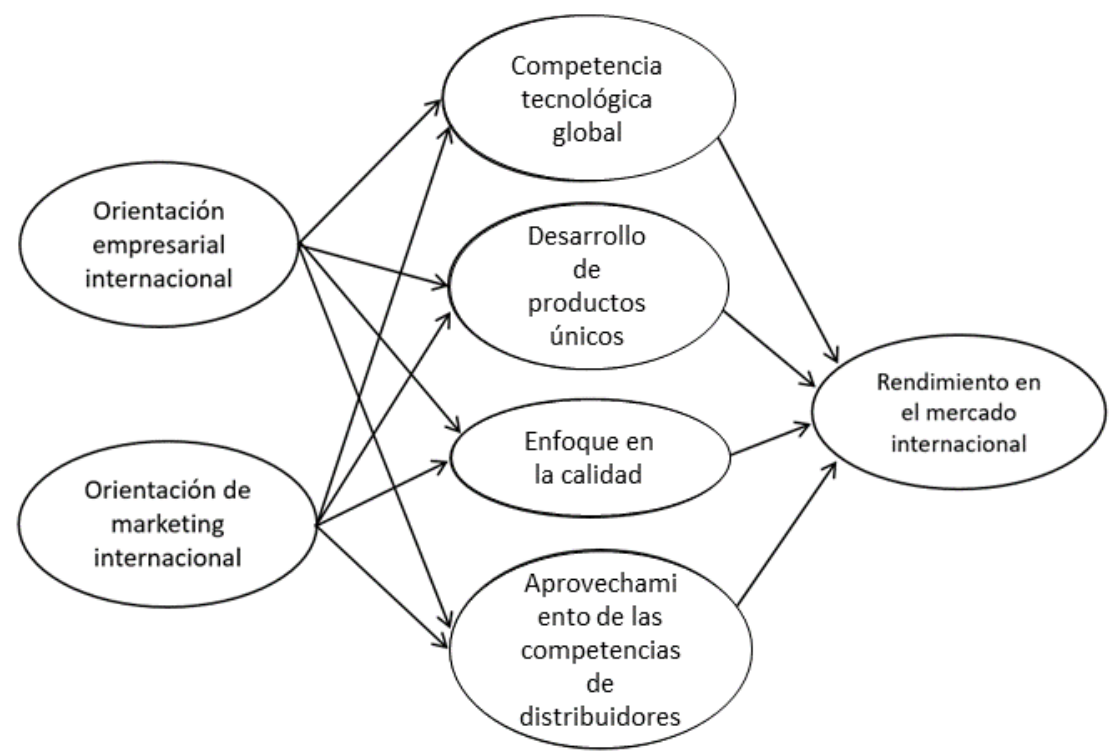

Figura 1. Innovación, capacidades organizacionales y empresas Born Global - Modelo Conceptual

- Lages, Silva y Styles (2009) en "Relationship capabilities, quality, and innovation as determinants of export performance" emplean una perspectiva basada en recursos para entender como un conjunto de capacidades (aprendizaje organizacional, relación y capacidades de calidad) influyen en la estrategia de producto (calidad e innovación del producto) y exportación (desempeño de la relación y desempeño económico). Finalmente encuentran un fuerte vínculo entre capacidadestrategia de desempeño concluyendo que los gerentes deberían invertir en capacidades de gestión para mejorar la innovación y calidad de producto, esto dará lugar a una mejora del rendimiento de las exportaciones. 


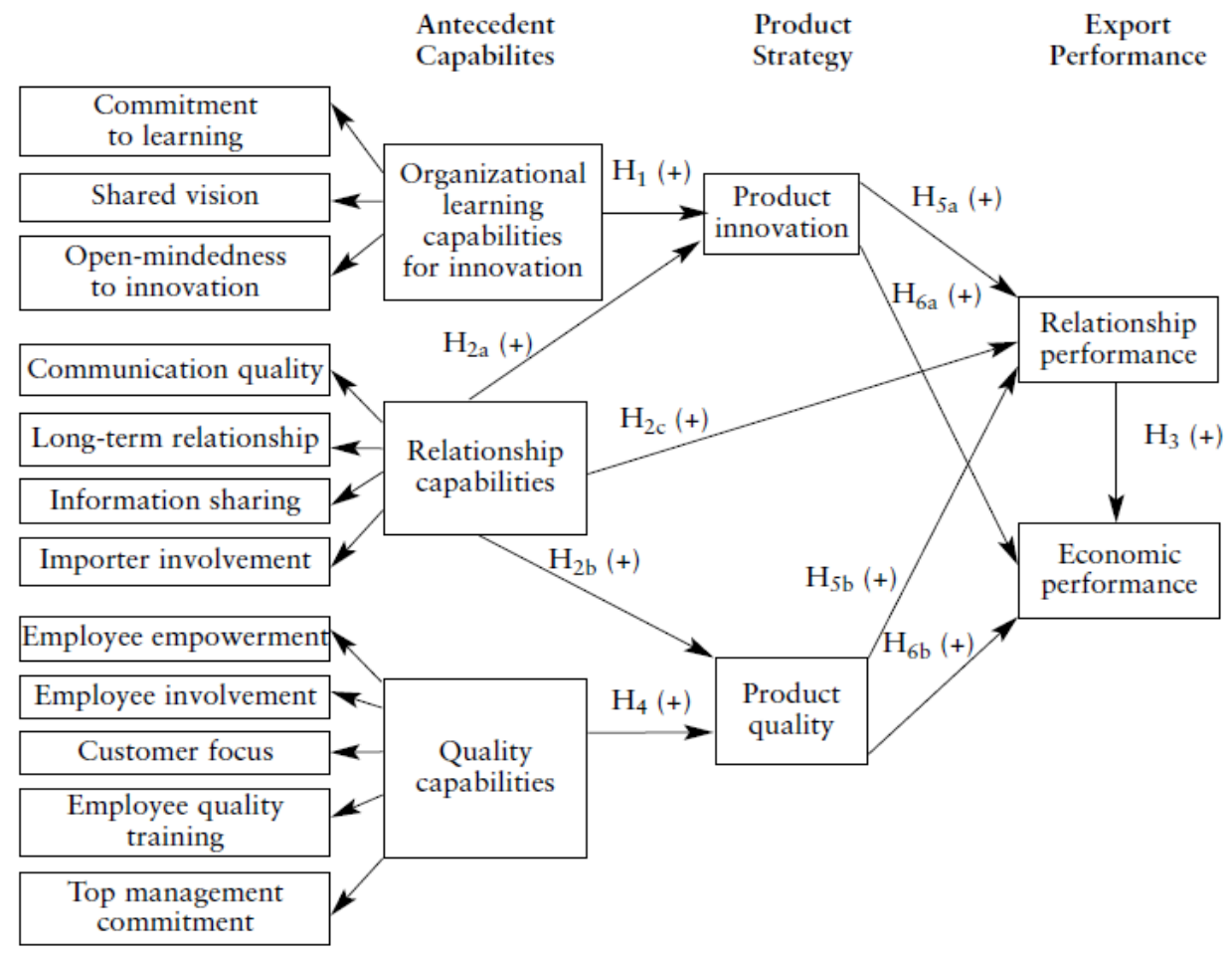

Figura 2. Capacidades de relación, calidad e innovación como determinantes del desempeño de las exportaciones - Modelo Conceptual.

- Haddoud, Nowinski, Jones y Newbery (2019) en "Internal and external determinants of export performance: Insights from Algeria" investigaron a las Pymes que evolucionan en un contexto de país en desarrollo, en este caso Argelia. Basándose en una visión dual basada en recurso y redes, este estudio investiga la importancia en recursos y en redes. Este estudio investiga simultáneamente la importancia de los recursos internos y externos para el desempeño de las PYMES que exportan. Se encuentra que hay una superioridad de los discursos discretos para aumentar el rendimiento y regularidad de la exportación. 


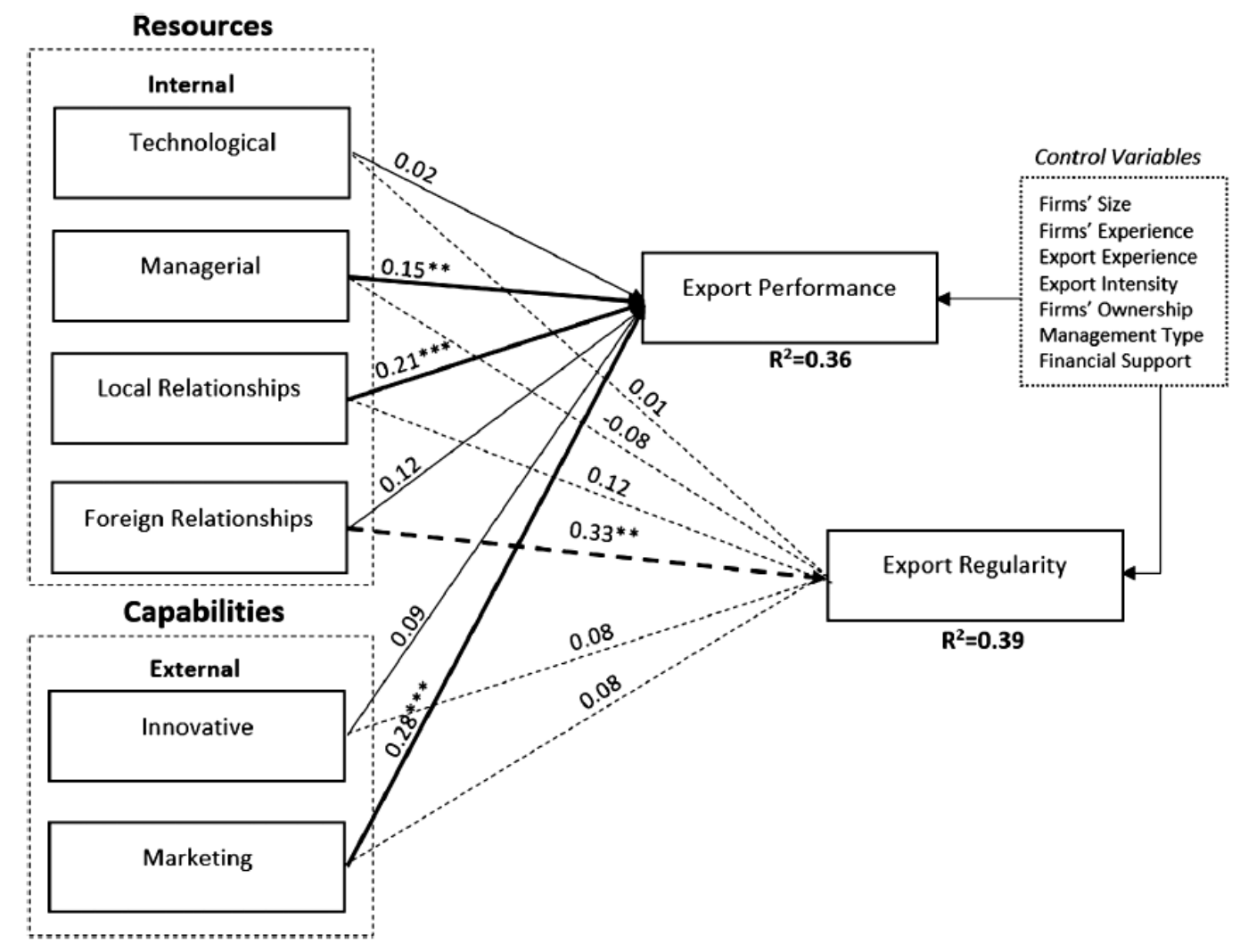

Figura 3. Determinantes internos y externos del desempeño de las exportaciones - Modelo conceptual

- Monteiro, Soares y Rua (2019) realizaron una investigación titulada "Linking intangible resources and entrepreneurial orientation to export performance: The mediating effect of dynamic capabilities" en donde se investiga el efecto de los recursos intangibles y la orientación empresarial en el desempeño de las exportaciones, examinando el efecto mediador de las capacidades dinámicas. Se investigaron 265 empresas exportadoras portuguesas encontrándose que las capacidades dinámicas y la orientación empresarial tienen un impacto directo en el 
rendimiento de las exportaciones; mientras que, los recursos financieros, informativos y relacionales tienen un impacto indirecto.

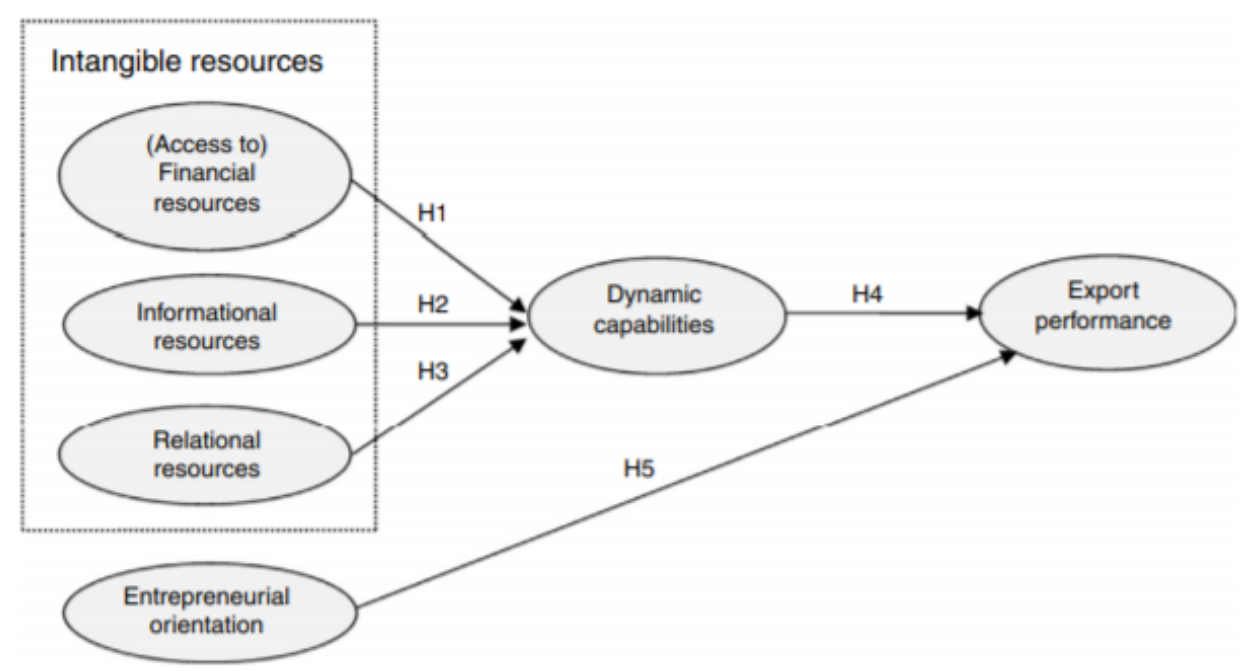

Figura 4. Vinculación de recursos intangibles y orientación empresarial para el rendimiento de las exportaciones: el efecto mediador de las capacidades dinámicas - Modelo conceptual

- Escandón y Hurtado (2009) proponen un modelo de factores que inciden en la creación de born global en Colombia y que muy probablemente les aseguren tener éxito en el mercado. El estudio confirma que los factores directamente relacionados con las Born global son los factores internos de la empresa, las condiciones del mercado y las características del fundador.

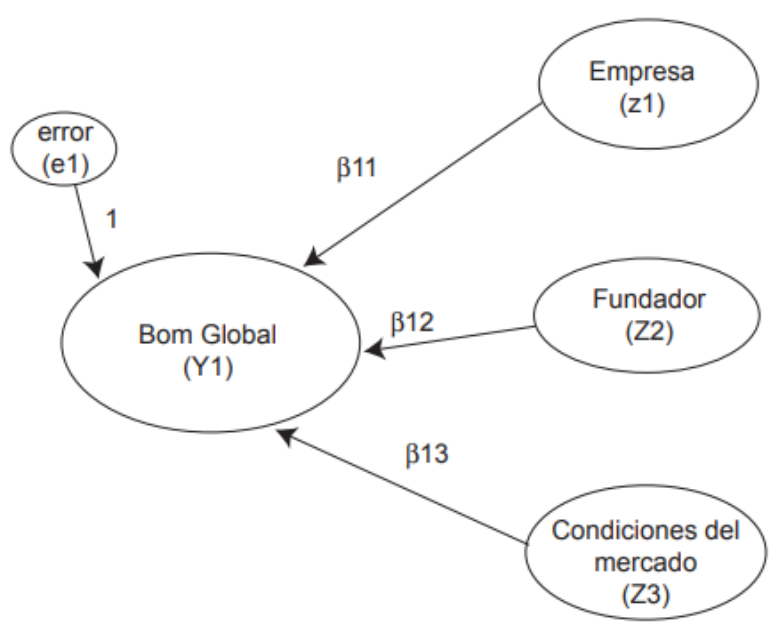


Figura 5. Factores que inciden en la creación de born global en Colombia - Modelo Estructural
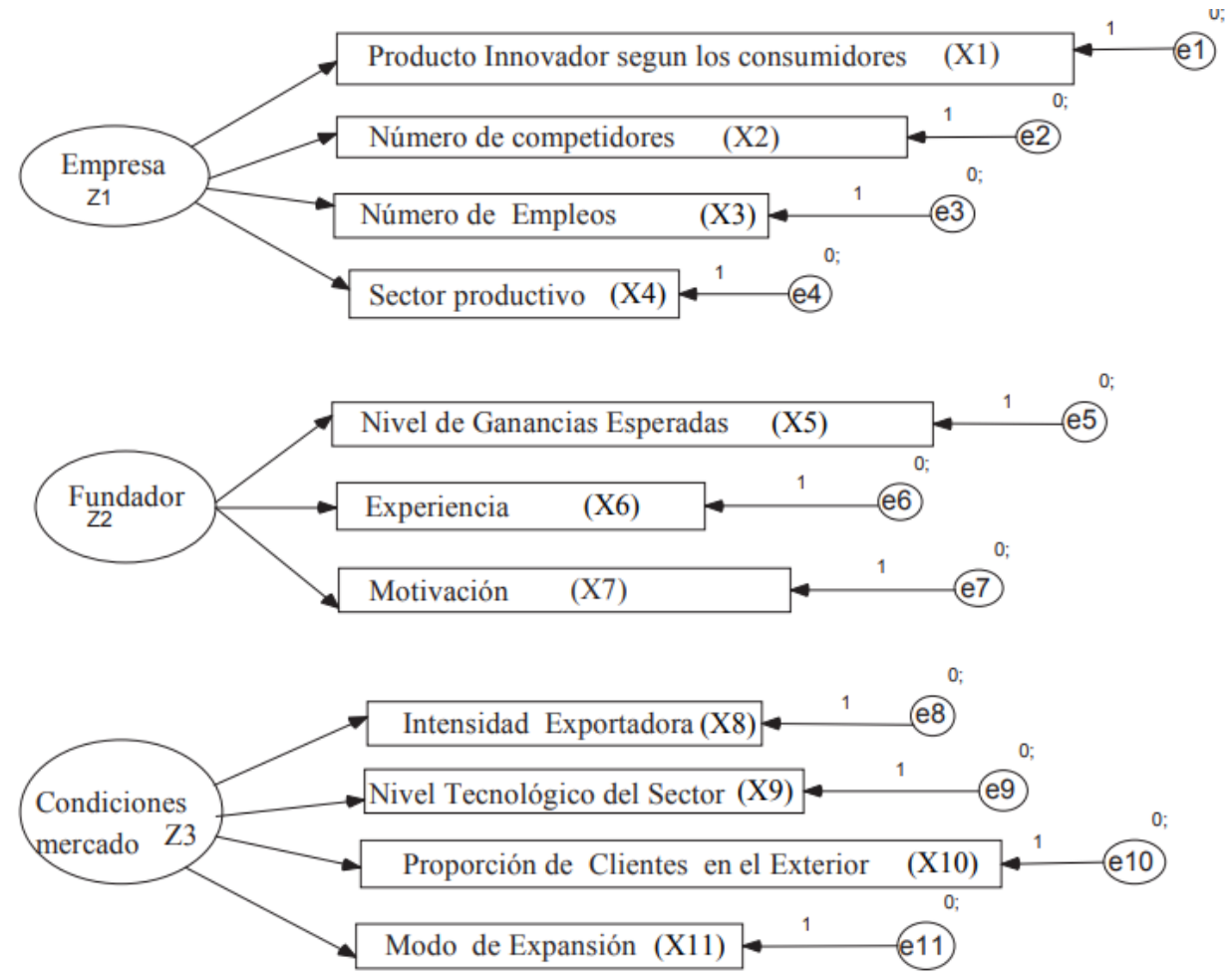

Figura 6. Factores que inciden en la creación de born global en Colombia - Modelo Estructural

- Zou, Fang y Zhao (2003) realizaron una investigación titulada "The effect of export marketing capabilities on export performance: an investigation of chinese exporters" en donde se estudió el efecto de las capacidades de marketing de exportación en el rendimiento de la exportación. Sobre la base de una encuesta a empresas exportadores chinas y basándose en una visión basada en recursos, los autores desarrollan un modelo que vincula la capacidad de desarrollo de productos, capacidad de distribución, capacidad de comunicación y de fijación de precios de un exportador con sus ventajas diferenciales (bajo costo, marca) y su rendimiento en las exportaciones. 


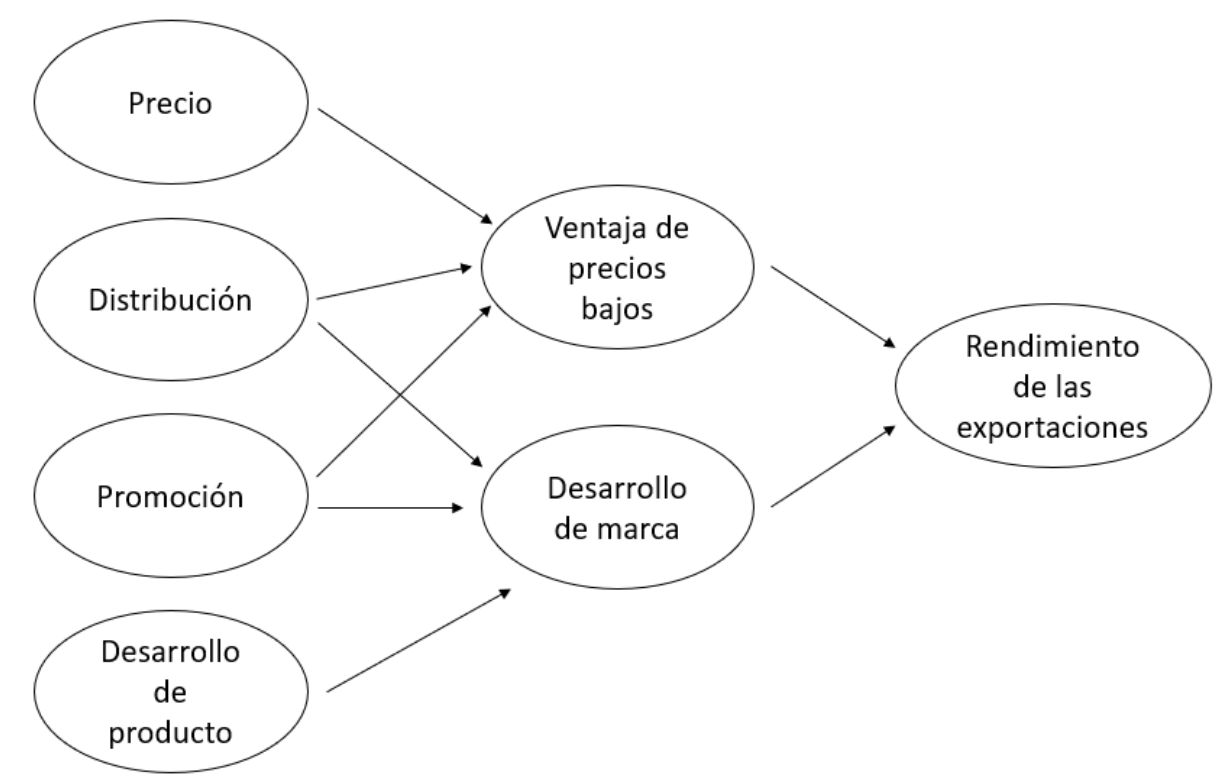

Figura 7. El efecto de las capacidades de marketing de exportación en el rendimiento de la exportación: una investigación de los exportadores chinos - Modelo conceptual

\section{- Modelo propuesto.}

- Nuestro modelo propuesto está basado en el modelo desarrollado por Knight y Cavusgil (2004) con algunas adaptaciones. El modelo que propone esta investigación consta de una variable independiente de 4 dimensiones (X1: competencia de tecnología global, X2: desarrollo de productos únicos, X3: enfoque en la calidad y X4: aprovechamiento de las competencias de distribuidores) y una dependiente (Y: Rendimiento de las exportaciones). 


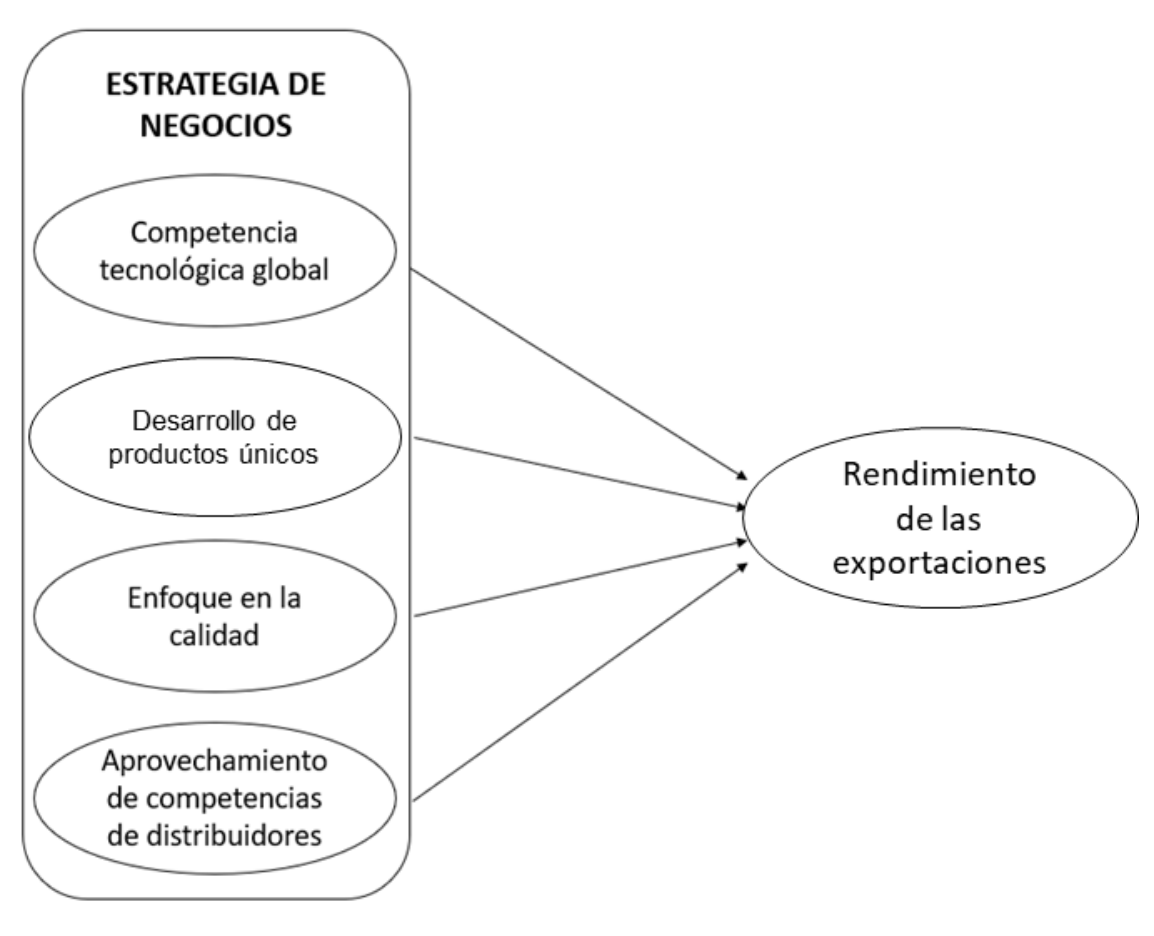

Figura 8. Modelo propuesto basado en el estudio "Innovation, Organizational Capabilities, and the Born Global Firm" (Knight \& Cavusgil, 2004)

\section{- Máquinas de Panificación.}

Andrés Ugaz (2007) en su libro "Panes del Perú: el encuentro del maíz y el trigo", nos da un recorrido desde el antiguo Perú hasta la actualidad, contándonos la historia del pan y la evolución de las máquinas necesarias para su fabricación.

De acuerdo con el autor, uno de los alimentos que ha estado ligado a todas las clases sociales de nuestro país es el pan. La historia del pan en el Perú y el mundo nos ayudará a entender la necesidad de la producción de este insumo utilizando máquinas especializadas que ayudan a la eficiencia en su preparación sin dejar de lado lo artesanal.

En el Perú, la producción de panes es de vital importancia, pues han sido parte de la canasta básica familiar desde su inicio. De acuerdo con las costumbres de los locales, y además de su procedencia regional, existen diferentes variedades en cuanto a tamaño, sabor y forma. 
Hoy en día, la panadería se ha convertido en una actividad más moderna gracias a la tecnología. Con la creación de máquinas industriales, poco a poco se ha ido reemplazando el uso de herramientas rústicas, lo que genera mayor volumen de producción a menor costo, y por ende más ingresos para el productor.

La historia del pan comienza en la época prehistórica. Finalizando la Edad de Piedra surgieron un ciclo de lluvias invernales y la elevación de los mares a consecuencia de una glaciación y un posterior calentamiento muy brusco. Esta situación dio como resultado la aparición de gramíneas en las tierras entre el mar Caspio y mar Negro. Dichas gramíneas sobrevivieron a la naturaleza sin ningún cuidado. Tenían barbas largas que facilitaba su transporte con el viento para volver a ser plantadas en el suelo.

El autor también nos habla sobre los primeros trigos silvestres: la escanda y el almidonero, los cuales empezaron a formar parte de la dieta de los cazadores, implicando así un cambio en su estilo de vida. Esta transición de cazadores a sedentarios va de la mano con el desarrollo de la agricultura de aquellos tiempos. Ellos domesticaron su alimentación y comenzaron a usar técnicas que los convirtieron en hombres más organizados.

Miles de años después, como hombres más civilizados, empezaron a hacer uso de herramientas y técnicas mejoradas; Ya habían descubierto el fuego y lo utilizaban para la cocina. La cocina permitió al hombre pasar del medio animal al medio social. De esa forma, los cereales fueron expandiéndose por todo el mundo, llegando hasta nuestro país por la costa, para luego asentarse en la sierra. Vale precisar que la escanda y el almidonero mencionados anteriormente, son los ancestros del trigo que llegó al Perú.

De acuerdo con el autor e investigaciones del año 2007, el origen del trigo se encuentra en las regiones entre Asia menor y Afganistán, y su evolución desde las gramíneas fue en la zona de Mesopotamia, entre los ríos Tigris y Éufrates. Actualmente, la mayor producción de trigo se da en Israel e Irán.

El trigo ocupó un lugar ponderante durante toda la historia. La sociedad que lo producía tenía cierto control sobre las demás. Las transacciones comerciales de aquel tiempo se daban a través del trueque usaban el trigo como medida ya que era la base de la alimentación. Si alguna civilización 
quería conquistar otra, lo que hacían era atacar sus cultivos o almacenes de cereal, ya que de esa forma dejaban sin comida al pueblo y al ejército, dejando claro la supremacía de la civilización conquistadora.

De acuerdo con el historiador Herodoto, el pan fue inventado en Egipto, según el historiador, es muy probable que haya sido accidental.

Posteriormente, se vieron los primeros avances en cuanto a la elaboración del pan. Los griegos fueron los panaderos y posteriormente pasteleros. La cultura griega aportó la exquisitez al pan, y en aquella época ya existían 72 tipos de panes, entre ellos el pan de trigo. Dicho aporte fue llevado al imperio romano. Luego llegaron a Roma unos panaderos griegos quienes trabajaban todo el proceso de elaboración del pan, desde moler los granos hasta hornear la masa. El ser panadero iba de generación en generación y era exclusivamente para el género masculino, es así como el pan pasó a ser la base de la alimentación, difundiendo la panificación por el todo el mundo. Con la caída del imperio romano, el pan de trigo pasó a ser solo parte de la dieta de los más poderosos. Sin embargo, la influencia griega en la gastronomía estuvo presente en el tránsito de la Edad Antigua a la Edad Media. De ahí se puede entender la gran gastronomía de países como Italia, España o Francia.

En Perú, en la época prehispánica, según el cronista Inca Garcilaso de la Vega en su obra "Comentarios reales de los Incas" (1609). En aquellas épocas, el pan se consumía en las diferentes comidas del día, lo que generó mayor demanda y por ende incrementaron las panaderías.

Durante la época Inca, las vírgenes del sol producían el "zancu", que únicamente se consumía en el mes de septiembre en referencia a la fiesta del Inti Raymi.

El 1492, con la llegada de los españoles a América, fueron descubriendo las diferentes variantes del pan, por ejemplo, en México conocieron las tortillas de maíz, en Venezuela eran las arepas, en Centroamérica el pan de yuca y en el Perú el famoso "Tanta". 
A inicios de los años 1500, los españoles adoptaron el maíz como equivalente del trigo que ellos consumían en Europa. Las mujeres españolas utilizaban la harina de maíz para la preparación de bizcochos.

Una señal clara de la transición de la panadería se puede observar en el diseño del "kero cusqueño", vaso ritual de madera en donde se pueden apreciar las distintas etapas del proceso de elaboración del pan, donde los indígenas realizan el amasado y posteriormente trasladan la masa fermentada a una tabla para que las mujeres modelaran el pan y dirigieran la cocción. Además, se puede ver un horno artesanal, en el que se introducen los panes con paletas de madera.

De aquella época de transición de la panadería, se puede resumir que la ciudad del Cusco ya manejaba un sistema organizado para la producción del pan, que constaba básicamente con la mano de obra de los indígenas, mientras que las mujeres se encargaban de la modelación y formación del pan, además de dirigir todo el proceso de preparación (junto con los dueños de la panadería). Estas mujeres aprendieron a usar los hornos de piedra gracias a sus patronas españolas.

Durante todo lo que continuó del siglo XVI, las mujeres indígenas, quienes pertenecían a las clases más bajas de la época, cumplieron una labor muy importante, pues estaban a cargo de la producción y horneado de los panes que serían finalmente consumidos diariamente por la población y abastecían también a los navíos y ejército peruano. Con el paso del tiempo, el trigo fue incorporándose a la dieta diaria de los habitantes de la colonia. Tuvo que pasar un tiempo para que los peruanos aceptaran el trigo traído por los españoles y emplearlos en la elaboración del pan. La transición del maíz al trigo no fue fácil, pero el maíz nunca pudo reemplazar el sabor del pan de trigo en el gusto de los europeos. Sin embargo, no fue hasta 1539 que se obtuvo la cantidad necesaria de harina de trigo (hecha en el primer molino de Lima) para la producción del pan. Para finales del siglo XVI, todo el virreinato cosechaba el trigo, que poco a poco fue desplazando al maíz, sin embargo, la única localidad donde aún se consumía pan de maíz era el Cusco. Con el paso del tiempo, se instalaron molinos y hornos en los campos de cultivo y el pan de trigo se comenzó a preparar para la alimentación diaria de la población, entre españoles e indios. 
Durante los siguientes años, las cosechas de trigo aumentaron mucho, lo que llegó a convertir al Perú en el granero de la zona. Esta situación duró poco, pues por causa de una epidemia de un parásito de varios cereales en 1687, la producción de trigo disminuyó tanto que fue necesaria la importación de este producto desde Chile. Desde ese momento, la capacidad productiva triguera del Perú no pudo dar abasto a las nuevas costumbres de los pobladores.

En el siglo XVII, se logró conformar el gremio de panaderos. Durante esos años, las panaderías eran conocidas como centros de industria, pero también como cárceles, dónde trabajaban presos por delitos no graves, esclavos y rebeldes (Mejía, 1993).

La industria panificadora pasó por cuatro etapas: La primera fue durante la colonia, donde estaban al mando de los españoles. Luego siguió la independencia, donde hubo un ascenso social entre los panaderos. Después, en 1872 se crea la SIE (Sociedad de Inmigración Europea), donde muchos extranjeros se dedicaban a la panadería. Finalmente, entre 1920 y 1930 la herencia panadera se vuelve un ejercicio laboral que continúa de generación en generación.

Los hornos de piedra y/o adobe son los que sustentan la panadería tradicional artesanal. Estos fueron heredados de la época colonial y su principal motor de funcionamiento es la leña de eucalipto y otras maderas locales. Estos hornos y el tipo de horneado logran que el pan obtenga un sabor característico artesanal, y se ha mantenido así durante varias generaciones en las distintas regiones del Perú.

Actualmente, además de Chile, el Perú importa desde Estados Unidos, Canadá y México un estimado de un millón y medio de toneladas de trigo, de los cuales solo $6 \%$ se destina a la producción de pan. El resto se consume en forma de grano.

Manuel Mazzi fue el fundador de "Estrella del Perú", sociedad de panaderos en 1887 y luego en 1912 de la Sociedad de Industriales en Panaderías. El gremio de panaderos de esa época estaba muy bien organizado. Obreros y empresarios compartían sus conocimientos y así fueron forjando una relación 
íntima. Hubo un periodo terrible para la industria panificadora por la competencia informal y el crack de 1929, el cual resistieron.

El problema en el entorno nacional es ocasionado por 3 razones principales: la informalidad de las panaderías, falta de competitividad con precios justos y el bajo consumo de pan per cápita al año. Por esa razón, en 2004, se formó para enfrentar esa situación "la cadena productiva del pan", de la que son miembros la Asociación de Peruana de Empresarios de Panadería y Pastelería (ASPAN), quienes representan a los panaderos frente al estado; la Sociedad Nacional de Industrias (SNI), que impulsa la producción de harina nacional y promueve el mayor consumo de pan; la Universidad Agraria (UNALM), que realiza investigaciones para la creación de nuevas variedades de trigo nacional; Cáritas del Perú, quienes fomentan el desarrollo integral de los más necesitados a través de programas; el Ministerio de Agricultura, el SENATI y el Comité de Fabricantes de Levadura.

En el año 2013 se publicó un artículo en el diario Gestión haciendo referencia al pan artesanal.

Poco se habla de la panadería y sus innovadores y diversos ingredientes. Sin embargo, los panaderos peruanos, hace ya varios años, hacen sus productos con insumos de la mejor calidad: harina de centeno, granos andinos, sal de maras. Lo que buscan es que la propuesta de panadería artesanal nacional se fortalezca y siga creciendo. Otro ingrediente que fue puesto en relieve a mediados de octubre de 2013 en una noticia es el talento de los maestros panaderos.

En tal sentido, la gerente general de Escuela Nova Alina San Román explica que, dentro de la formación de cada uno de sus estudiantes, la panadería artesanal ocupa un rol esencial, pues ellos preparan más de 100 tipos de panes y pasteles.

De acuerdo con Becerra (2015) en su artículo "El pan nuestro" publicado por el diario El Peruano, el pan es un alimento básico para la canasta familiar de nuestra sociedad. Los hábitos de consumo de este han variado con el tiempo, es así como hoy en día el clásico pan francés solo se refiere al $50 \%$ de los ingresos. El tener esta diversificación hace necesario que haya capacitación constante a los panaderos en cuanto a técnicas y nuevas tecnologías. 
Según la investigación realizada por Becerra, son aproximadamente 200,000 puestos de trabajo que se generan gracias a la industria panadera. Esta cifra envuelve a toda la cadena de producción y vuelve necesaria la adquisición de maquinaria especializada para realizar dichas labores de forma eficiente.

Actualmente hay varias empresas que brindan soluciones para la industria de panificación, sin embargo, la que más resalta es NOVA INDUSTRIAL TOOLS SAC, quien ocupa mayor porcentaje del mercado nacional y se está posicionando también a nivel internacional en los distintos países de América y Europa.

Los tipos de máquinas de panificación estudiadas en la presente investigación son específicamente hornos de panadería (8417209000) y máquinas de panadería (8438101000) ambas se pueden agrupar bajo el nombre general de Maquinas de Panificación o panadería.

Según la base de datos de SICEXX, los principales países compradores para ambos tipos son mundialmente Rusia, China, Estados Unidos, Francia, y entre los exportadores tenemos principalmente a China, Alemania, Países Bajos, Japón y Estados Unidos.

Los hornos de panadería pueden variar según diferentes características, las más importantes están referidas al material de la cubierta en donde el acero inoxidable es el estándar en calidad. Otras están referidas al optimo consumo de energía, almacenamiento, cantidad de producción (calculada en tiempo de horneada y número de panes por horneada), y combustible (gas, petróleo o eléctrico).

Por su lado, las máquinas de panadería pueden ser clasificadas en amasadoras, batidoras, divisoras, rebanadoras, laminadoras y boleadoras. Las variaciones o especificaciones por cada una se dan de acuerdo con los accesorios, velocidad, tipo y tamaño del motor y capacidad de contenido. 


\subsection{Objetivos e hipótesis}

\subsubsection{Objetivos.}

\section{General.}

Analizar la relación entre las estrategias de negocio y el rendimiento de las exportaciones de empresas peruanas fabricantes de máquinas para la industria panadera del 2014 al 2018

\section{Específicos.}

- Determinar la relación entre competencia tecnológica global y el rendimiento de las exportaciones de empresas peruanas fabricantes de máquinas para la industria panadera del 2014 al 2018

- Determinar la relación entre el desarrollo de productos únicos y el rendimiento de las exportaciones de empresas peruanas fabricantes de máquinas para la industria panadera del 2014 al 2018

- Determinar la relación entre el enfoque en la calidad y el rendimiento de las exportaciones de empresas peruanas fabricantes de máquinas para la industria panadera del 2014 al 2018

- Determinar la relación entre el aprovechamiento de las competencias de los distribuidores extranjeros y el rendimiento de las exportaciones de empresas peruanas fabricantes de máquinas para la industria panadera del 2014 al 2018

\subsubsection{Hipótesis.}

\section{General.}

Existe relación entre las estrategias de negocio y el rendimiento de las exportaciones de empresas peruanas fabricantes de máquinas para la industria panadera del 2014 al 2018 


\section{Específicos.}

- Existe relación entre la competencia tecnológica global y el rendimiento de las exportaciones de empresas peruanas fabricantes de máquinas para la industria panadera del 2014 al 2018

- Existe relación entre el desarrollo de productos únicos y el rendimiento de las exportaciones de empresas peruanas fabricantes de máquinas para la industria panadera del 2014 al 2018

- Existe relación entre el enfoque en la calidad y el rendimiento de las exportaciones de empresas peruanas fabricantes de máquinas para la industria panadera del 2014 al 2018

- Existe relación entre el aprovechamiento de las competencias de los distribuidores extranjeros y el rendimiento de las exportaciones de empresas peruanas fabricantes de máquinas para la industria panadera del 2014 al 2018 


\section{Capítulo 2}

\subsection{Método}

El método que se utiliza en la presente investigación es el descriptivo - explicativo, pues un estudio explicativo tiene como interés estudiar porque dos variables están relacionadas entre sí (Hernández, Fernández y Baptista, 2014). Además, se busca definir la influencia de las estrategias de negocio sobre el rendimiento de las exportaciones de las empresas fabricantes de máquinas de panadería.

\subsection{Tipo de investigación}

El tipo de investigación tiene un enfoque cuantitativo correlacional y tiene el objetivo de conocer las condiciones en que dos o más variables se relacionan. En este caso el cómo las estrategias de negocio se relacionan al rendimiento de las empresas fabricantes de máquinas para la industria panadera.

\subsection{Diseño de investigación}

Nuestra investigación es "no experimental", ya que no introduce variable experimental alguna ni la manipula o cambia arbitrariamente; es además correlacional-causal pues se busca identificar la relación entre dos variables con el objetivo de conocer el comportamiento de otras variables que estén relacionadas.

Se le puede clasificar también como una investigación de corte transversal, pues según los autores Hernández, Fernández y Baptista (2014) ésta recolectará datos en un solo momento o tiempo único.

\subsection{Variables}

\subsubsection{Variable Independiente: Estrategias de Negocios.}

(X1) Competencia tecnológica global

Según los autores Knight y Cavusgil (2004), la competencia tecnológica global es una tendencia clave que han reducido sustancialmente los costos de transacción de la expansión del mercado extranjero. La difusión generalizada del correo electrónico, Internet y tecnologías relacionadas ha hecho que la internacionalización sea una opción más viable y rentable. 
(X2) Desarrollo de productos únicos

Se refiere a aquellas empresas que exportan, complementando sus actividades comerciales con una innovación sostenida en procesos, tecnología, gestión y producto. Según Knight y Cavusgil (2004) en Relación entre Innovación y exportaciones de las empresas, existe una relación positiva entre las estrategias de innovación y exportación que solo se cumple al analizar a aquellas empresas que exportan e innovan, más no viceversa

(X3) Enfoque en la calidad

El enfoque en la calidad es un componente clave. Como una estrategia de mercadeo importante, es probable que las empresas con una fuerte orientación de mercadeo internacional también promuevan un enfoque en la calidad. El brindar ofertas valiosas y de calidad mejorada es uno de los enfoques estrechamente asociados con fuertes capacidades de marketing. Los productos de calidad son más fáciles de vender para los distribuidores extranjeros, y los distribuidores extranjeros también pueden mejorar la calidad del producto al proporcionar un servicio postventa superior, distribución intensiva, etc.

(X4) Aprovechamiento de las competencias de los distribuidores extranjeros

El aprovechamiento de las competencias de los distribuidores extranjeros es una estrategia de negocios muy importante que ayuda a la reducción de riesgos y costos fijos; y a la vez que los resultados favorables se maximicen. Para los autores Daniels, Radebaugh y Sullivan (2013), los exportadores pueden recurrir a una variedad de métodos para acceder al país destino, una forma común es el uso de intermediarios. Los representantes comerciales o agentes de ventas y distribuidores tienen la función de facilitar el comercio de bienes mediante la estimulación de las ventas, investigación de mercados y apoyo en la distribución. En la industria de exportación de máquinas para panificación no ha sido la excepción, ya que los mismos han jugado un rol importante en la internacionalización de las empresas. 


\subsubsection{Variable Dependiente: Rendimiento de las exportaciones.}

Según Zhang y Zhu (2016), el rendimiento de las exportaciones se define como una forma de medir los logros de los objetivos que tiene una empresa en su comercialización al exterior. Este rendimiento analiza las expectativas sobre el logro de los objetivos empresariales como metas económicas convencionales, tales como: la rentabilidad y el crecimiento de las ventas o la participación en el mercado y el éxito internacional general, entre otros.

\subsubsection{Operacionalización de las variables.}

Tabla 3.

Operacionalización de las variables.

\begin{tabular}{|c|c|c|c|}
\hline Variables & Definición Conceptual & Dimensiones & Indicadores \\
\hline \multirow{4}{*}{$\begin{array}{l}\text { Independiente: } \\
\text { Estrategia de } \\
\text { negocios }\end{array}$} & \multirow{4}{*}{$\begin{array}{l}\text { Visión holística de la } \\
\text { empresa acerca del } \\
\text { despliegue de sus } \\
\text { recursos y } \\
\text { capacidades que le } \\
\text { proporciona la base } \\
\text { para crear, producir y } \\
\text { comercializar } \\
\text { productos (Young et } \\
\text { al., 2000) }\end{array}$} & $\begin{array}{l}\text { X1: Competencia } \\
\text { tecnológica global }\end{array}$ & $\begin{array}{l}\text { - Capacidad tecnológica de la empresa en } \\
\text { relación con las empresas de la industria } \\
\text { - Creación de productos superiores y mejora } \\
\text { de los productos existentes } \\
\text { - Efectividad y eficiencia en los procesos de } \\
\text { producción } \\
\text { - Énfasis en el desarrollo de nuevas } \\
\text { tecnologías } \\
\text { Adaptación de productos para mercados } \\
\text { extranjeros. }\end{array}$ \\
\hline & & $\begin{array}{l}\text { X2: Desarrollo de } \\
\text { productos únicos }\end{array}$ & $\begin{array}{l}\text { - Satisfacción de una necesidad especializada } \\
\text { - Características innovadoras del producto en } \\
\text { diseño o funcionalidad } \\
\text { - Conocimiento en los procesos o know how } \\
\text { patentado }\end{array}$ \\
\hline & & $\begin{array}{l}\text { X3: Enfoque en la } \\
\text { calidad }\end{array}$ & $\begin{array}{l}\text { - Desarrollo de productos / servicios que } \\
\text { cumplan o superen las expectativas del } \\
\text { cliente } \\
\text { - Calidad en el producto y servicio al cliente }\end{array}$ \\
\hline & & $\begin{array}{l}\text { X4: Competencias } \\
\text { de los distribuidores }\end{array}$ & $\begin{array}{l}\text { - Competencias específicas de los } \\
\text { distribuidores para las actividades } \\
\text { comerciales en el extranjero } \\
\text { - Conocimiento del mercado destino }\end{array}$ \\
\hline
\end{tabular}




\begin{tabular}{|c|c|c|}
\hline $\begin{array}{l}\text { Dependiente: } \\
\text { Rendimiento de } \\
\text { las } \\
\text { exportaciones }\end{array}$ & $\begin{array}{l}\text { Medición de los logros } \\
\text { de los objetivos que } \\
\text { tiene una empresa en } \\
\text { su comercialización al } \\
\text { exterior como metas } \\
\text { económicas, } \\
\text { participación de } \\
\text { mercado, etc. (Zhang } \\
\text { \& Zhu, 2016) }\end{array}$ & $\begin{array}{l}\text { - Cuota de mercado, crecimiento año a año, } \\
\text { utilidades, ROI }\end{array}$ \\
\hline
\end{tabular}

\subsection{Población}

La población de estudio de esta investigación está conformada por 11 empresas peruanas fabricantes de máquinas para la industria panadera con exportaciones mayores a los US\$10,000 FOB en los años 2014 - 2018, que actualmente existan y que no se traten de empresas unipersonales. Estas empresas son:

- Nova-Industrial Tools S.A.C.

- Machines's World E.I.R.L.

- Artebianca S.A.C.

- Vulcano Tecnología Aplicada E.I.R.L

- Fabricación De Maquinaria Industrial Del Empaquetado S.A.C.

- CNC Especialistas S.A.C.

- H. Ruiz Hnos. E.I.R.L.

- SINIT Soluciones Industriales Integrales E.I.R.L.

- Grupo Levapan S.A.

- Inversiones Peru Panamá S.A.C

- Cocinas Superior S.A.C.

\subsection{Censo}

Dado que la población de estudio no excede las 50 unidades muestrales, la recolección de información para esta investigación se realizó tomando como referencia las 11 empresas peruanas fabricantes con exportaciones mayores a US\$ 10000 FOB en máquinas de panificación en el periodo 2014 - 2018, que actualmente existan y que no se traten de empresas unipersonales. 


\subsubsection{Instrumentos de investigación.}

El instrumento de investigación utilizado fue un cuestionario, validado por Knight y Cavusgil (2004) y adaptado a la realidad peruana. Esta encuesta se aplicó al encargado del área de exportaciones, o del área comercial con roles de exportación de cada empresa. Fueron en total 11 empresas encuestadas, estas debían cumplir con los requisitos de haber tenido exportaciones mayores a US\$10 000 durante el periodo 2014 - 2018, que actualmente existan y que no sean empresas unipersonales. La encuesta está conformada por 35 ítems que ayudaron a definir la influencia de la variable independiente sobre la variable dependiente: rendimiento de las exportaciones de empresas peruanas fabricantes de máquinas para la industria panadera. El cuestionario está formulado según la escala de Likert del 1 al 5, donde 1 es totalmente en desacuerdo, 2 en desacuerdo, 3 ni de acuerdo ni en desacuerdo, 4 de acuerdo y 5 totalmente de acuerdo. De esa forma se podrá medir el grado de conformidad de los representantes de cada empresa frente a los enunciados.

El instrumento utilizado fue validado por juicio de expertos. Los expertos considerados para la validación del cuestionario fueron: (Ver anexo 8)

- Jimmy Sánchez Gómez (MBA en Administración, Magister en Educación. Catedrático en USIL)

- Enrique Alonso Castro Guzmán (Magister en Ciencias Empresariales. Coordinador académico de la carrera de Administración y Emprendimiento en USIL)

- Carlos Eduardo Ossio Sal y Rosas (MBA en Administración y Finanzas, Doctor en Administración de negocios. Catedrático en la Escuela de Postgrado USIL)

La confiabilidad fue medida a través del coeficiente de Alfa de Cronbach. Este coeficiente analiza la consistencia interna de los datos de cada ítem que compone una variable. El coeficiente de Alfa de Cronbach puede ir de $1 \mathrm{a}+1$; cuanto más cerca esté al valor de +1 mayor confiabilidad de los ítems evaluados. 
El coeficiente Alfa de Cronbach para la variable Estrategia de negocios fue 0,860; de manera que los ítems que componen esta variable poseen confiabilidad. (Ver anexo 6)

El coeficiente Alfa de Cronbach para la variable Rendimiento de las exportaciones fue 0,902; de manera que los ítems que componen esta variable poseen confiabilidad. (Ver anexo 7)

La validez fue cuantificada mediante el coeficiente de la $V$ de Aiken, con lo cual se evaluó los puntajes que los 3 expertos en el tema de investigación pusieron al instrumento. En definitiva, el resultado de la $V$ de Aiken fue 0,95 (Ver anexo 9), lo cual, al estar por encima del valor de 0,8 , indica que el instrumento empleado posee validez para medir lo que se propone.

\subsubsection{Procedimientos de recolección de datos.}

De acuerdo con Hernández, Fernández y Baptista "la recolección de datos implica elaborar un plan detallado de procedimientos que nos conduzcan a reunir datos, conceptos o variables con un propósito específico" (2014, p.198). Por lo tanto, se procedió a aplicar el instrumento de medición, el cual manifiesta las variables de la investigación y cumple con los requisitos de objetividad, validez y confiabilidad.

El procedimiento de recolección de datos se realizó a través de la aplicación del cuestionario a los representantes de las empresas peruanas exportadoras de hornos y máquinas para la industria panadera. Para ello, se buscó información de contacto de las personas encargadas del área de comercio exterior de cada una de las empresas listadas. Con esa información, se procedió a llamar o escribir por correo electrónico solicitando su apoyo y aplicando la encuesta. 


\section{Capítulo 3}

Urrutia y Gomez (2005) nos indican que hay distintos niveles de error para los tipos de investigación. Para nuestro caso, utilizamos el censo para la recolección de datos, por lo que lo más común es considerar un nivel de error del $5 \%$, por ende, el nivel de confianza sería del 95\%.

\subsection{Análisis de los resultados}

Se aplicó el cuestionario a los representantes de las 11 empresas dedicadas a la exportación de máquinas para la industria de la panificación. En este capítulo se presentarán y analizarán los resultados de la aplicación del cuestionario, para lo cual se utilizó el software SPSS. 


\section{- X1: Competencia tecnológica global}

Tabla 4.

A1. La empresa está a la vanguardia tecnológica de la industria en el mercado.

\begin{tabular}{llcccc}
\hline & & & Porcentaje & Porcentaje \\
válido & $\begin{array}{c}\text { Pocuencia } \\
\text { acumulado }\end{array}$ \\
\hline Válido & En desacuerdo & 1 & 9,1 & 9,1 & 9,1 \\
& Ni de acuerdo ni en & 7 & 63,6 & 63,6 & 72,7 \\
& desacuerdo & & & & \\
De acuerdo & 3 & 27,3 & 27,3 & 100,0 \\
& Total & 11 & 100,0 & 100,0 & \\
\hline
\end{tabular}

Elaboración propia

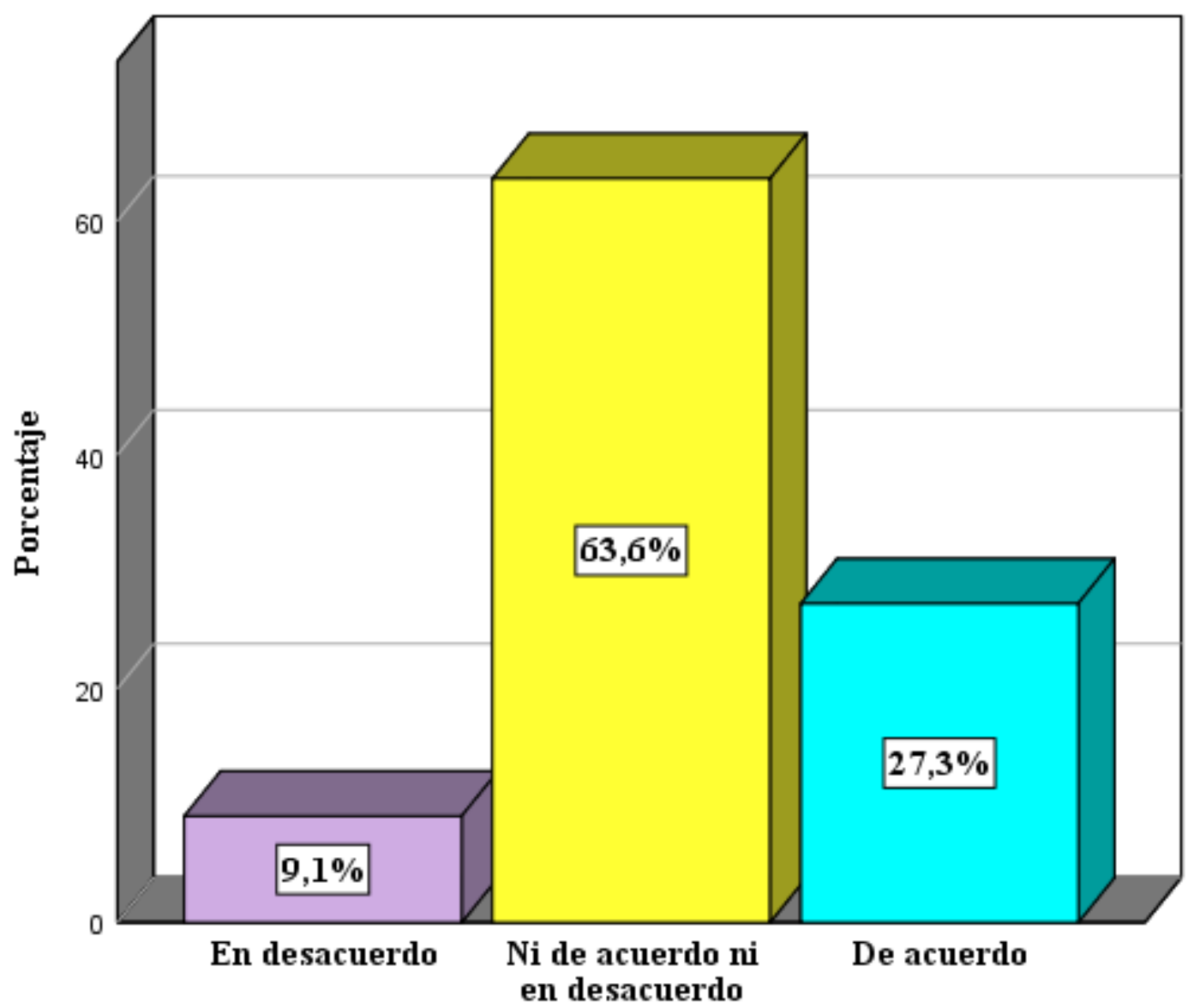

Figura 9. La empresa está a la vanguardia tecnológica de la industria en el mercado.

Elaboración propia

Interpretación: En la afirmación 1 se aprecia que en su mayoría el 63,6\% de los representantes no está de acuerdo ni en desacuerdo en que la empresa está a la vanguardia tecnológica en la industria en el mercado. Un $27,3 \%$ se muestra de acuerdo, mientras que el $9,1 \%$ restante se muestra en desacuerdo. 
Tabla 5.

A2. La empresa inventa mucha de la tecnología incorporada en sus productos.

\begin{tabular}{llcccc}
\hline & & & Porcentaje & Porcentaje \\
válido & $\begin{array}{c}\text { Focuencia } \\
\text { acumulado }\end{array}$ \\
\hline Válido & En desacuentaje & 6 & 54,5 & 54,5 & 54,5 \\
& Ni de acuerdo ni en & 5 & 45,5 & 45,5 & 100,0 \\
& desacuerdo & & & & \\
& Total & 11 & 100,0 & 100,0 & \\
\hline
\end{tabular}

Elaboración propia

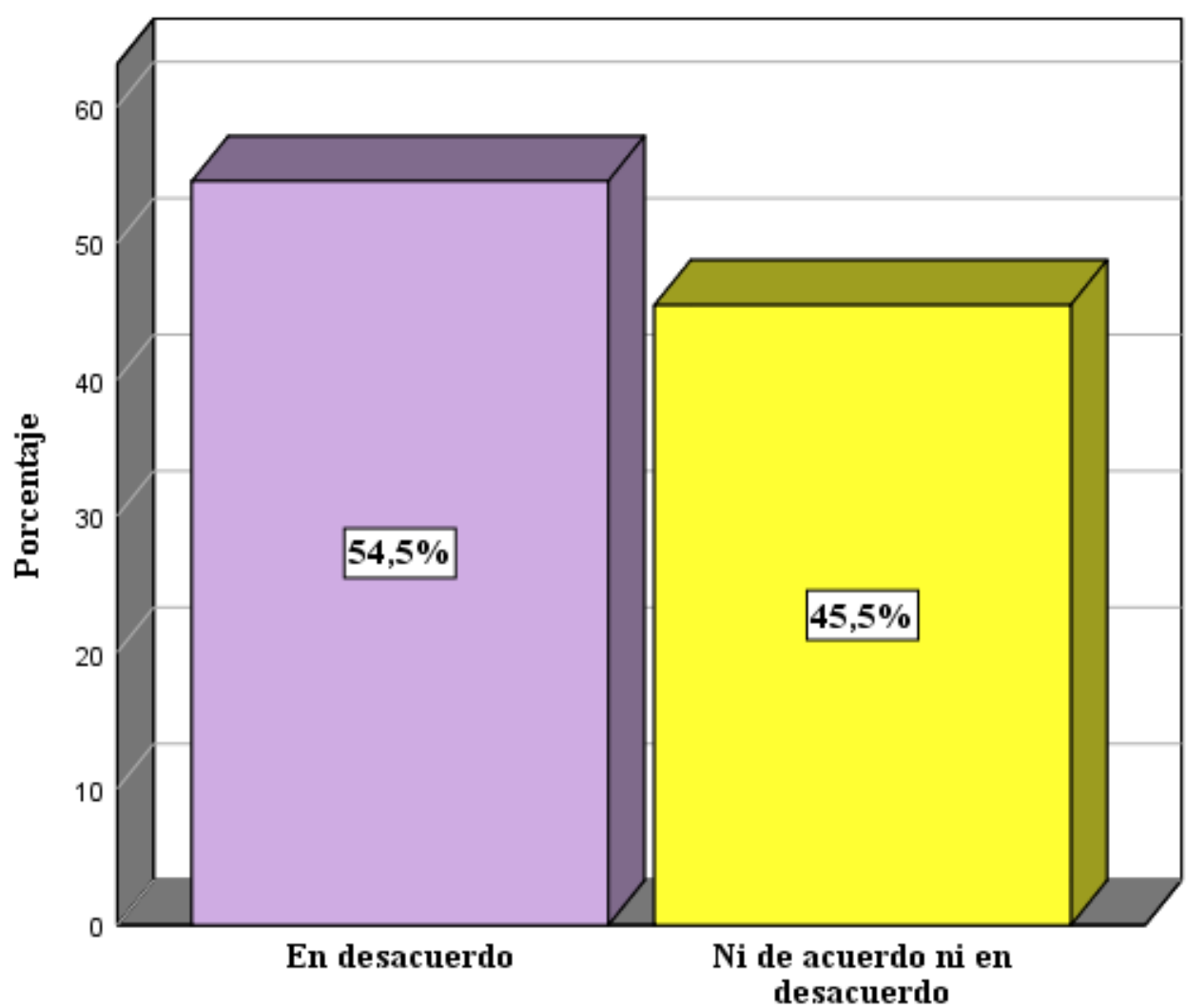

Figura 10. La empresa inventa mucha de la tecnología incorporada en sus productos. Elaboración propia

Interpretación: En la afirmación 2 se aprecia que principalmente el 54,5\% de los representantes está en desacuerdo en que la empresa crea mucha de la tecnología que pone en sus productos. Mientras que el $45,5 \%$ se muestra ni de acuerdo ni en desacuerdo. 
Tabla 6.

A3. En comparación con los competidores locales, a menudo la empresa es de las primeras en introducir innovaciones de productos o nuevos enfoques operativos.

\begin{tabular}{|c|c|c|c|c|c|}
\hline & & Frecuencia & Porcentaje & $\begin{array}{c}\text { Porcentaje } \\
\text { válido } \\
\end{array}$ & $\begin{array}{l}\text { Porcentaje } \\
\text { acumulado } \\
\end{array}$ \\
\hline \multirow[t]{5}{*}{ Válido } & En desacuerdo & 1 & 9,1 & 9,1 & 9,1 \\
\hline & $\begin{array}{l}\text { Ni de acuerdo ni en } \\
\text { desacuerdo }\end{array}$ & 8 & 72,7 & 72,7 & 81,8 \\
\hline & De acuerdo & 1 & 9,1 & 9,1 & 90,9 \\
\hline & Totalmente de acuerdo & 1 & 9,1 & 9,1 & 100,0 \\
\hline & Total & 11 & 100,0 & 100,0 & \\
\hline
\end{tabular}

Elaboración propia

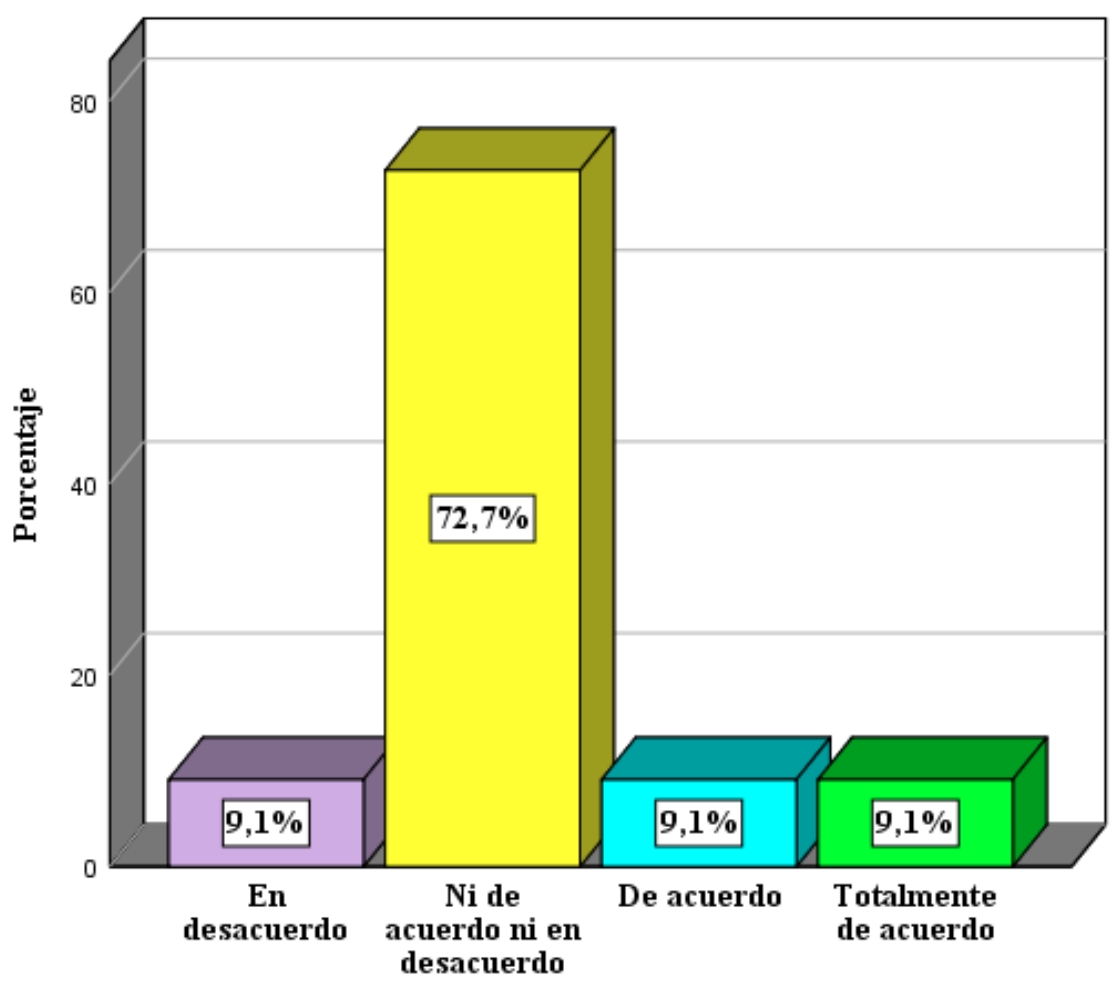

Figura 11. En comparación con los competidores locales, a menudo la empresa es de las primeras en introducir innovaciones de productos o nuevos enfoques operativos.

Elaboración propia

Interpretación: En la afirmación 3 se observa que predominantemente el 72,7\% de los representantes no está de acuerdo ni en desacuerdo en que, en comparación con los competidores locales, a menudo la empresa es de las primeras en introducir innovaciones de productos o nuevos enfoques operativos. Por otro lado, el 9,1\% se muestra en desacuerdo, el otro $9,1 \%$ en desacuerdo y el $9,1 \%$ restante totalmente de acuerdo. 
Tabla 7.

A4. Somos reconocidos en nuestro principal mercado de exportación de productos tecnológicamente superiores.

\begin{tabular}{llcccc}
\hline & & & $\begin{array}{c}\text { Porcentaje } \\
\text { válido }\end{array}$ & $\begin{array}{c}\text { Porcentaje } \\
\text { acumulado }\end{array}$ \\
\hline Válido & En desacuerdo & 2 & 18,2 & 18,2 & 18,2 \\
& Ni de acuerdo ni en & 7 & 63,6 & 63,6 & 81,8 \\
& desacuerdo & & & & \\
De acuerdo & 2 & 18,2 & 18,2 & 100,0 \\
Total & 11 & 100,0 & 100,0 & \\
\hline
\end{tabular}

Elaboración propia

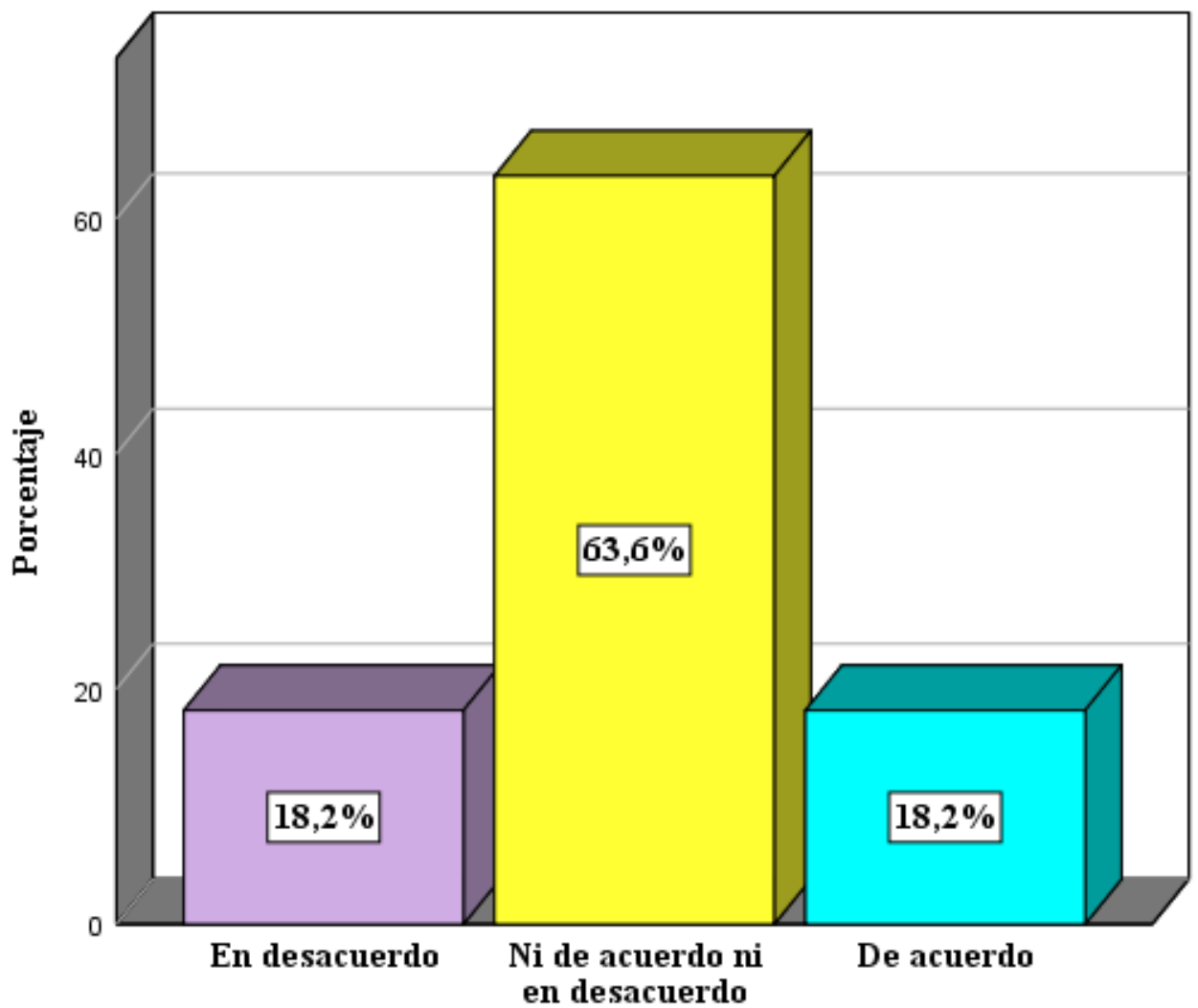

Figura 12. Somos reconocidos en nuestro principal mercado de exportación de productos tecnológicamente superiores.

\section{Elaboración propia}

Interpretación: En la afirmación 4 se aprecia que en su mayoría el $63,6 \%$ de los representantes no está de acuerdo ni en desacuerdo en que son reconocidos en su principal mercado de exportación de productos tecnológicamente superiores. Un 18,2\% se muestra de acuerdo, y el otro 18,2\% restante se muestra en desacuerdo. 
Tabla 8.

A5. La marca es muy apreciada por su experiencia técnica entre los miembros del canal en el mercado.

\begin{tabular}{llcccc}
\hline & Frecuencia & Porcentaje & $\begin{array}{c}\text { Porcentaje } \\
\text { válido }\end{array}$ & $\begin{array}{c}\text { Porcentaje } \\
\text { acumulado }\end{array}$ \\
\hline Válido & En desacuerdo & 2 & 18,2 & 18,2 & 18,2 \\
& Ni de acuerdo ni en & 4 & 36,4 & 36,4 & 54,5 \\
desacuerdo & & & & \\
De acuerdo & 5 & 45,5 & 45,5 & 100,0 \\
Total & 11 & 100,0 & 100,0 & \\
\hline
\end{tabular}

Elaboración propia

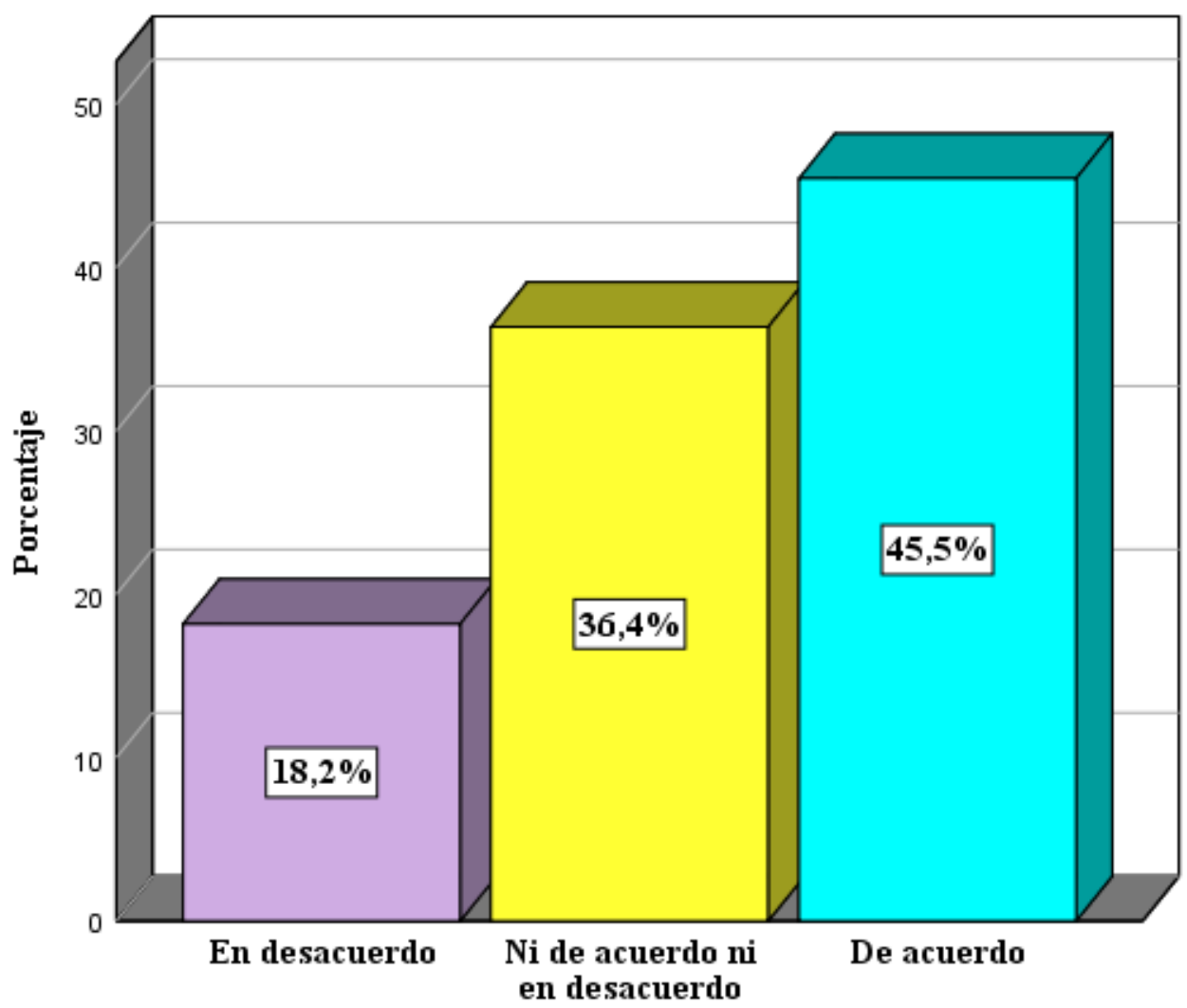

Figura 13. La marca es muy apreciada por su experiencia técnica entre los miembros del canal en el mercado

Elaboración propia

Interpretación: En la afirmación 5 se observa que principalmente el $45,5 \%$ de los representantes está de acuerdo en que su marca es muy apreciada por su experiencia técnica entre los miembros de su canal en el mercado. Un 35,4\% se muestra ni de acuerdo ni en desacuerdo; mientras que el 18,2\% se muestra en desacuerdo. 
Tabla 9.

A6. En el diseño y fabricación de este producto, emplean a algunos de los especialistas más calificados de la industria.

\begin{tabular}{|c|c|c|c|c|c|}
\hline & & Frecuencia & Porcentaje & $\begin{array}{c}\text { Porcentaje } \\
\text { válido }\end{array}$ & $\begin{array}{l}\text { Porcentaje } \\
\text { acumulado }\end{array}$ \\
\hline \multirow[t]{4}{*}{ Válido } & En desacuerdo & 3 & 27,3 & 27,3 & 27,3 \\
\hline & $\begin{array}{l}\text { Ni de acuerdo ni en } \\
\text { desacuerdo }\end{array}$ & 6 & 54,5 & 54,5 & 81,8 \\
\hline & De acuerdo & 2 & 18,2 & 18,2 & 100,0 \\
\hline & Total & 11 & 100,0 & 100,0 & \\
\hline
\end{tabular}

Elaboración propia

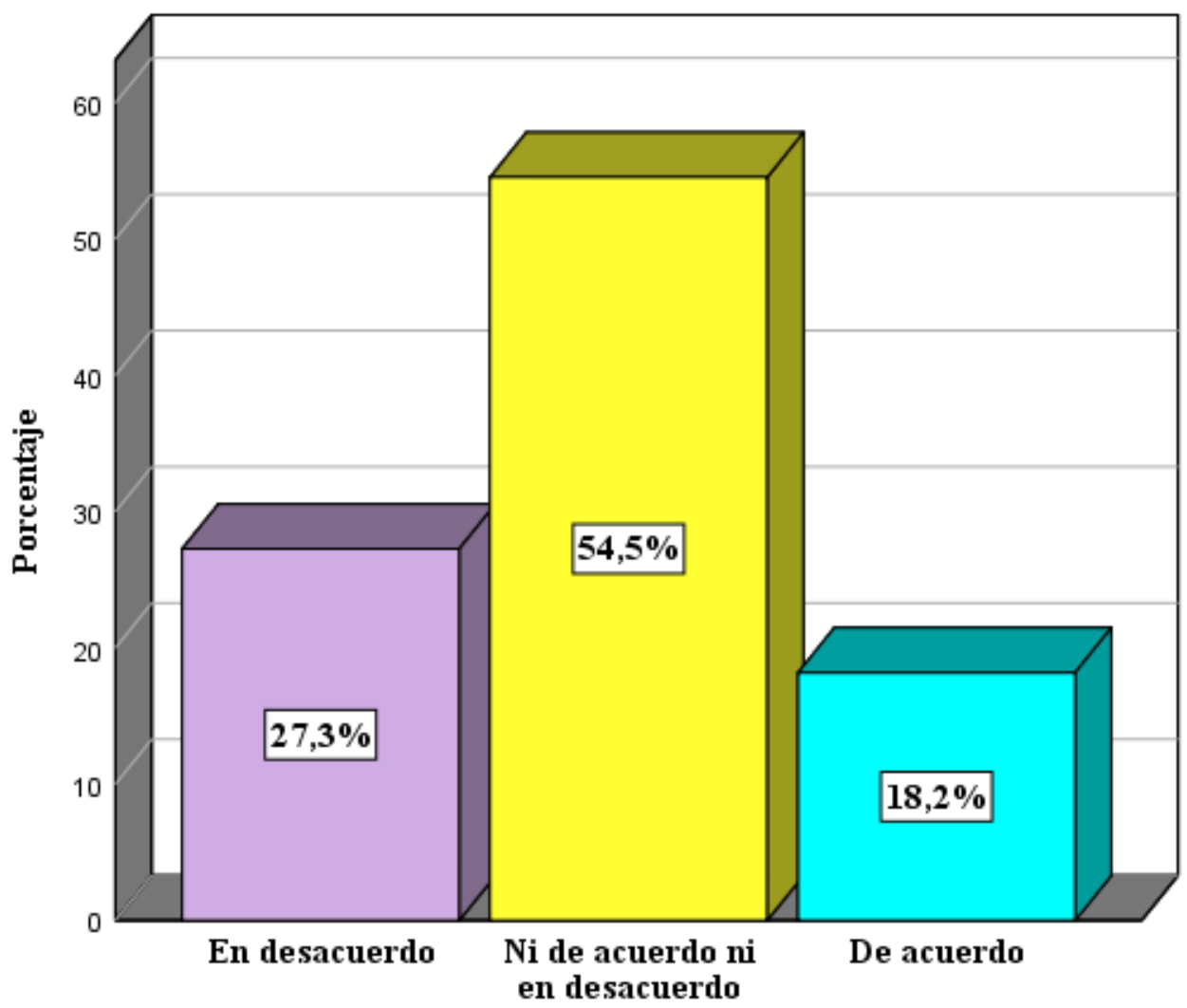

Figura 14. En el diseño y fabricación de este producto, emplean a algunos de los especialistas más calificados de la industria.

Elaboración propia

Interpretación: En la afirmación 6 se observa que mayoritariamente el 54,5\% de los representantes no está ni de acuerdo ni en desacuerdo en que, en el diseño y fabricación de este producto, emplean a algunos de los especialistas más capacitados de la industria. Un $27,3 \%$ se muestra en desacuerdo, mientras que el $18,2 \%$ se muestra de acuerdo. 
- X2: Desarrollo de productos únicos

Tabla 10.

A7. Su principal producto de exportación satisface una necesidad especializada que es difícil para sus competidores.

\begin{tabular}{llcccc}
\hline & & & $\begin{array}{c}\text { Porcentaje } \\
\text { válido }\end{array}$ & $\begin{array}{c}\text { Porcentaje } \\
\text { acumulado }\end{array}$ \\
\hline Válido & En desacuerdo & 3 & 27,3 & 27,3 & 27,3 \\
& Ni de acuerdo ni en & 7 & 63,6 & 63,6 & 90,9 \\
& desacuerdo & & & & 100,0 \\
De acuerdo & 1 & 9,1 & 9,1 & \\
Total & 11 & 100,0 & 100,0 & \\
\hline
\end{tabular}

Elaboración propia

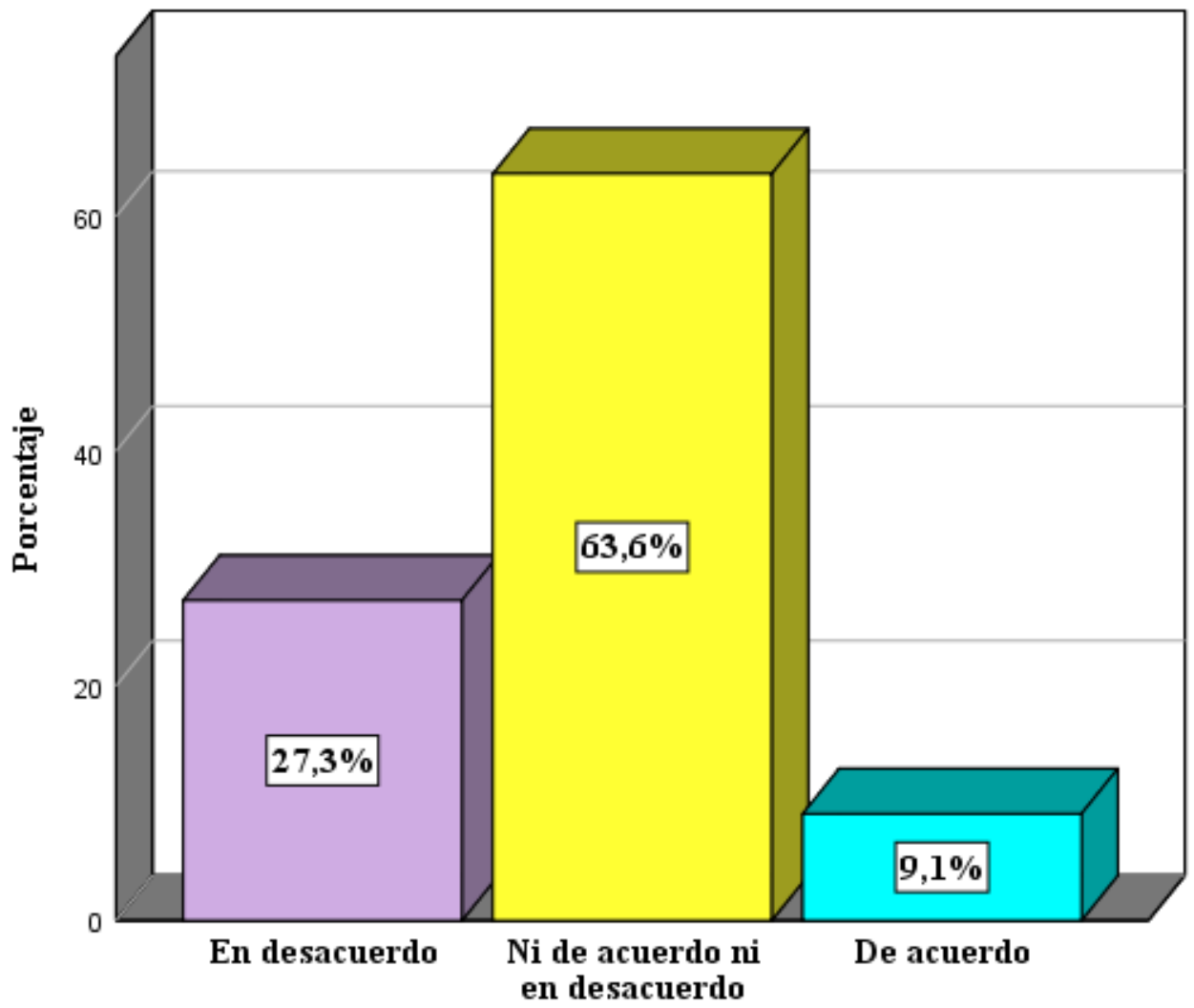

Figura 15. Su principal producto de exportación satisface una necesidad especializada que es difícil para sus competidores.

\section{Elaboración propia}

Interpretación: En la afirmación 7 se aprecia que en su mayoría el $63,6 \%$ de los representantes no está de acuerdo ni en desacuerdo en que su principal producto de exportación satisface una necesidad especializada que es difícil para sus competidores. Un $27,3 \%$ se muestra en desacuerdo, mientras que solo el $9,1 \%$ se muestra de acuerdo. 
Tabla 11.

A8. En la industria, sus productos representan un enfoque nuevo e innovador para abordar las necesidades básicas del cliente.

\begin{tabular}{|c|c|c|c|c|c|}
\hline & & Frecuencia & Porcentaje & $\begin{array}{c}\text { Porcentaje } \\
\text { válido } \\
\end{array}$ & $\begin{array}{l}\text { Porcentaje } \\
\text { acumulado } \\
\end{array}$ \\
\hline \multirow[t]{3}{*}{ Válido } & En desacuerdo & 3 & 27,3 & 27,3 & 27,3 \\
\hline & $\begin{array}{l}\text { Ni de acuerdo ni en } \\
\text { desacuerdo }\end{array}$ & 8 & 72,7 & 72,7 & 100,0 \\
\hline & Total & 11 & 100,0 & 100,0 & \\
\hline
\end{tabular}

Elaboración propia

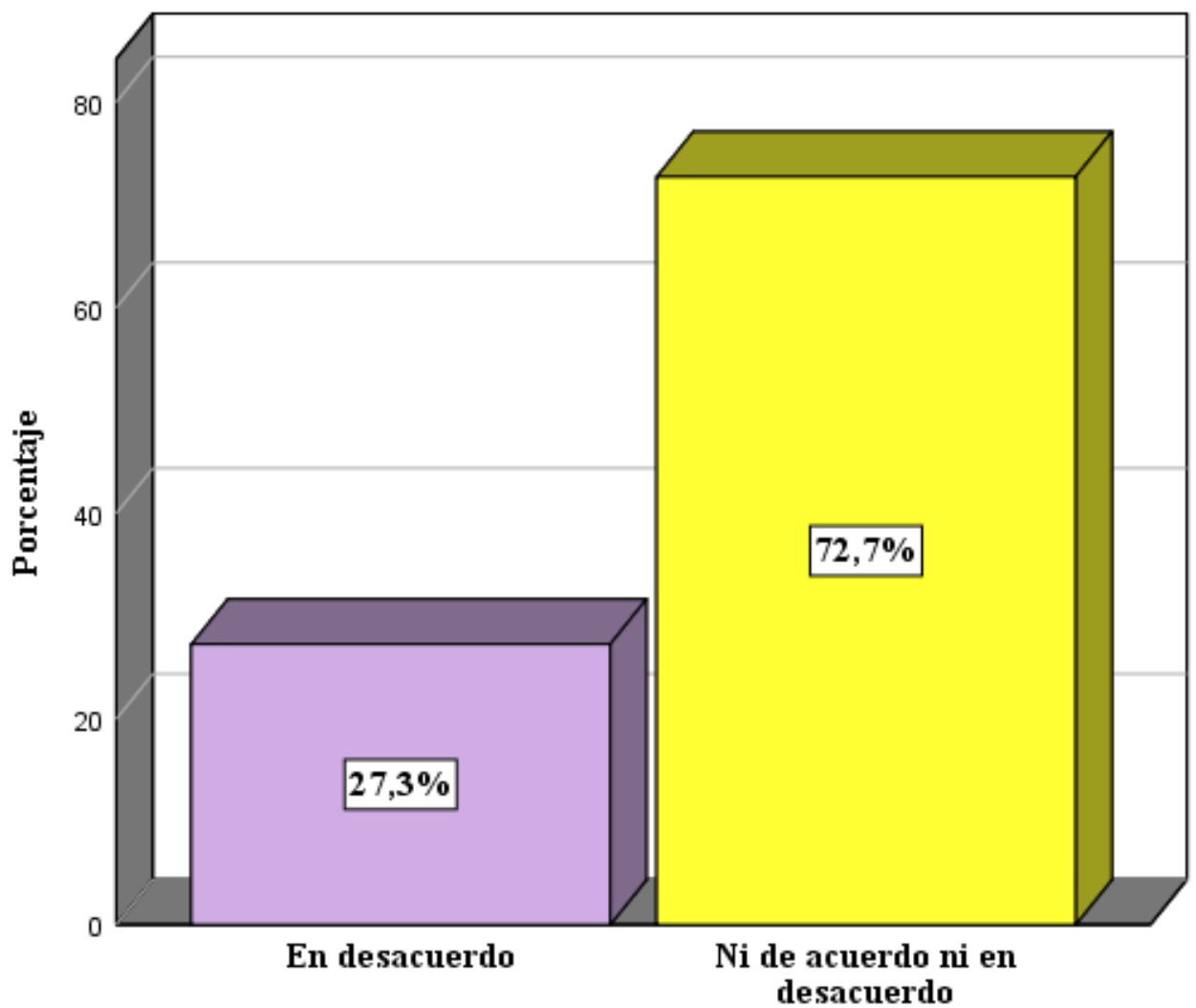

Figura 16. En la industria, sus productos representan un enfoque nuevo e innovador para abordar las necesidades básicas del cliente.

Elaboración propia

Interpretación: En la afirmación 8 se aprecia que predominantemente el $72,7 \%$ de los representantes no está ni de acuerdo ni en desacuerdo en que en la industria sus productos representan un enfoque novedoso e innovador para abordar las necesidades básicas del cliente. Mientras que el restante $27,3 \%$ se muestra en desacuerdo. 
Tabla 12.

A9. En comparación con las ofertas de sus principales competidores, su producto es único con respecto al diseño clientes y la competencia.

\begin{tabular}{|c|c|c|c|c|c|}
\hline & & Frecuencia & Porcentaje & $\begin{array}{c}\text { Porcentaje } \\
\text { válido }\end{array}$ & $\begin{array}{l}\text { Porcentaje } \\
\text { acumulado }\end{array}$ \\
\hline \multirow[t]{3}{*}{ Válido } & En desacuerdo & 5 & 45,5 & 45,5 & 45,5 \\
\hline & $\begin{array}{l}\text { Ni de acuerdo ni en } \\
\text { desacuerdo }\end{array}$ & 6 & 54,5 & 54,5 & 100,0 \\
\hline & Total & 11 & 100,0 & 100,0 & \\
\hline
\end{tabular}

Elaboración propia

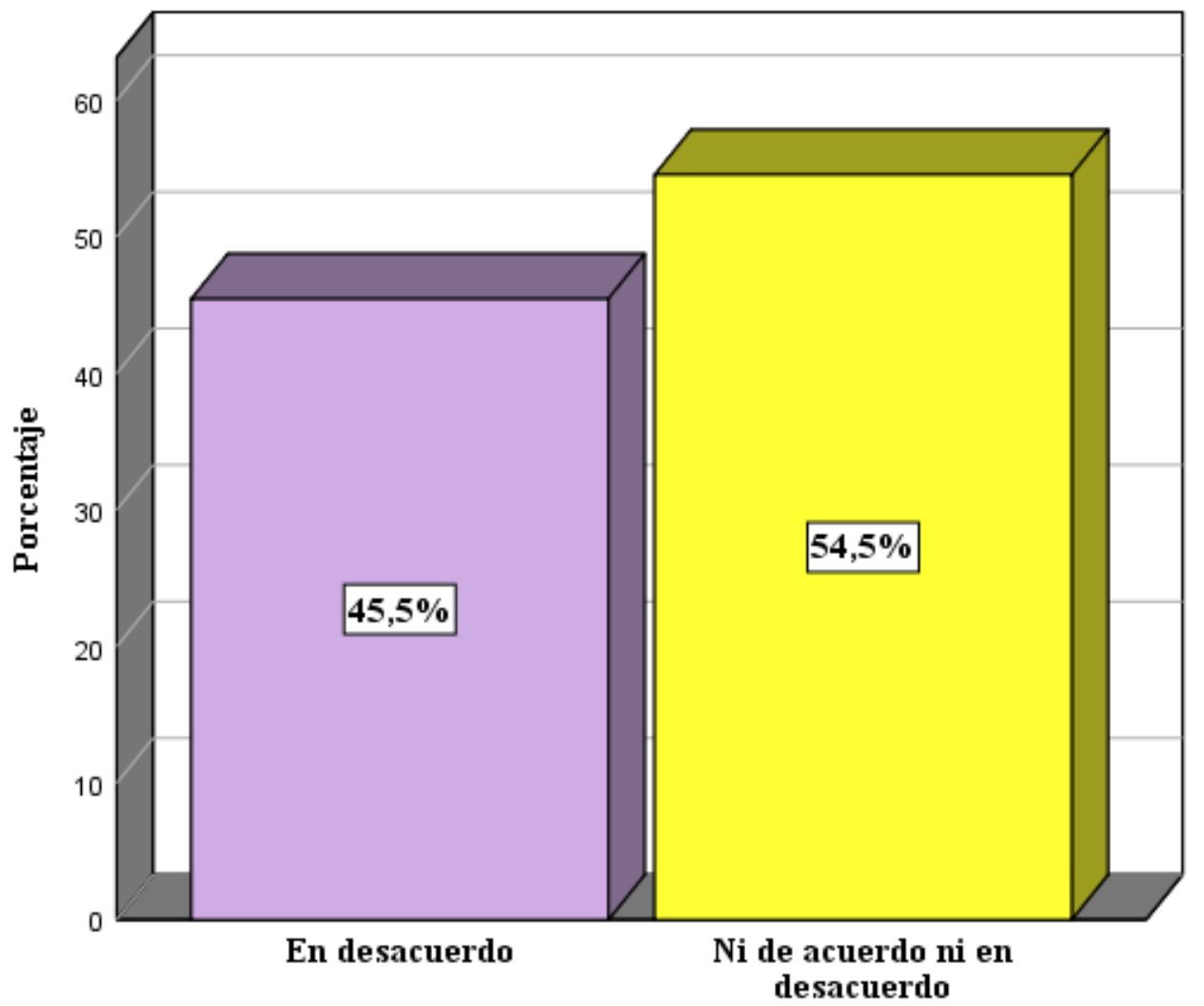

Figura 17. En comparación con las ofertas de sus principales competidores, su producto es único con respecto al diseño clientes y la competencia.

Elaboración propia

Interpretación: En la afirmación 9 se aprecia que principalmente el 54,5\% de los representantes no está ni de acuerdo ni en desacuerdo en que, en comparación con las ofertas de sus principales competidores, su producto es único con respecto al diseño clientes y la competencia. Mientras que el $45,5 \%$ se muestra en desacuerdo. 
Tabla 13.

A10. En comparación con las ofertas de sus principales competidores, sus productos son únicos con respecto a la tecnología.

\begin{tabular}{llcccc}
\hline & Frecuencia & Porcentaje & $\begin{array}{c}\text { Porcentaje } \\
\text { válido }\end{array}$ & $\begin{array}{c}\text { Porcentaje } \\
\text { acumulado }\end{array}$ \\
\hline Válido & En desacuerdo & 7 & 63,6 & 63,6 & 63,6 \\
& Ni de acuerdo ni en & 3 & 27,3 & 27,3 & 90,9 \\
& desacuerdo & & & & \\
De acuerdo & 1 & 9,1 & 9,1 & 100,0 \\
Total & 11 & 100,0 & 100,0 & \\
\hline
\end{tabular}

Elaboración propia

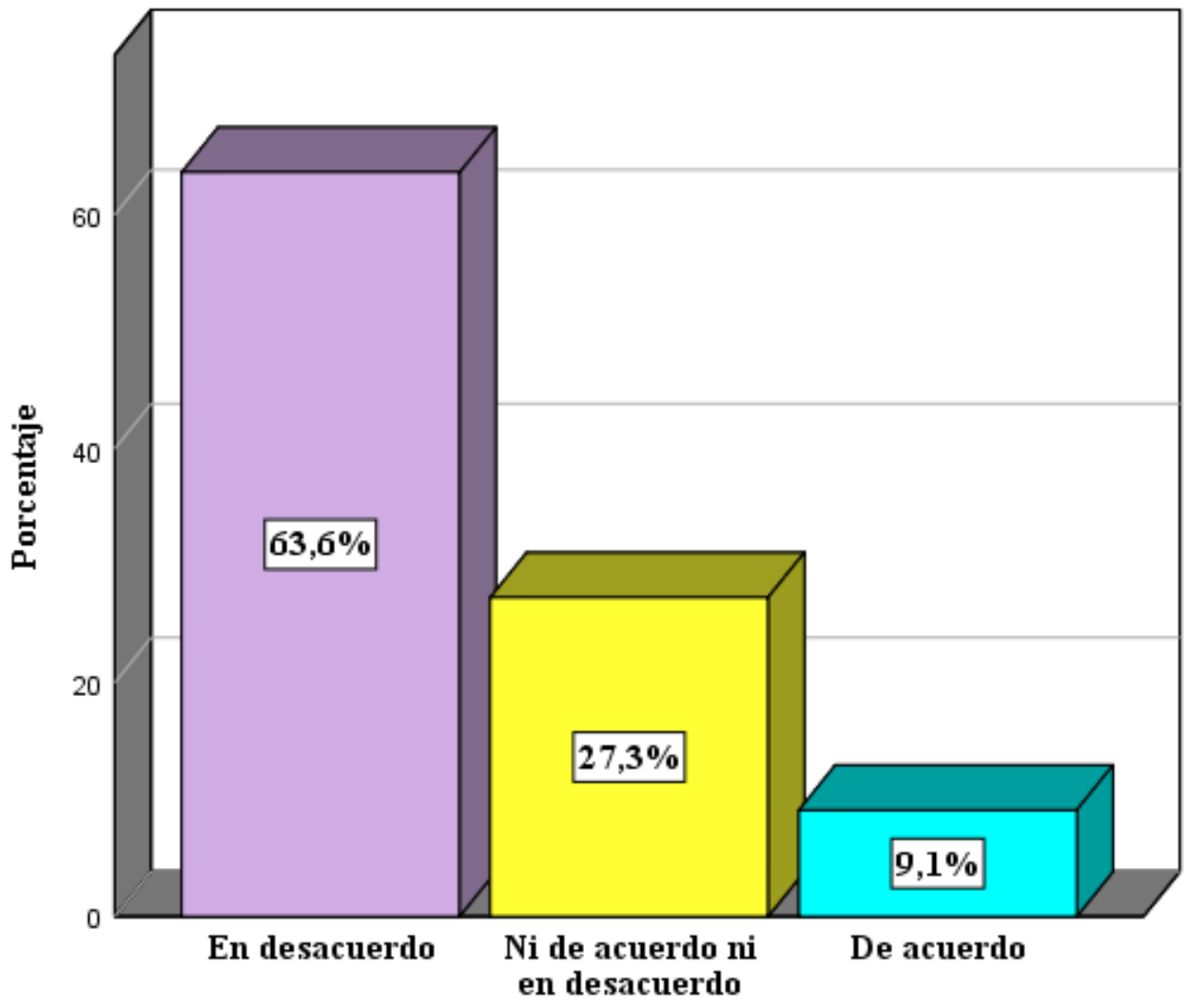

Figura 18. En comparación con las ofertas de sus principales competidores, sus productos son únicos con respecto a la tecnología.

Elaboración propia

Interpretación: En la afirmación 10 se aprecia que principalmente el 63,6\% de los representantes está en desacuerdo en que, en comparación con las ofertas de sus principales competidores, sus productos son únicos con respecto a la tecnología. Un $27,3 \%$ se muestra ni de acuerdo ni en desacuerdo, y solo el 9,1\% se muestra de acuerdo. 
Tabla 14.

A11. En comparación con las ofertas de sus principales competidores, sus productos son únicos con respecto al rendimiento.

\begin{tabular}{llcccc}
\hline & Frecuencia & Porcentaje & $\begin{array}{c}\text { Porcentaje } \\
\text { válido }\end{array}$ & $\begin{array}{c}\text { Porcentaje } \\
\text { acumulado }\end{array}$ \\
\hline Válido & En desacuerdo & 2 & 18,2 & 18,2 & 18,2 \\
& Ni de acuerdo ni en & 6 & 54,5 & 54,5 & 72,7 \\
& desacuerdo & & & & 100,0 \\
& De acuerdo & 3 & 27,3 & 27,3 & \\
Total & 11 & 100,0 & 100,0 & \\
\hline
\end{tabular}

Elaboración propia

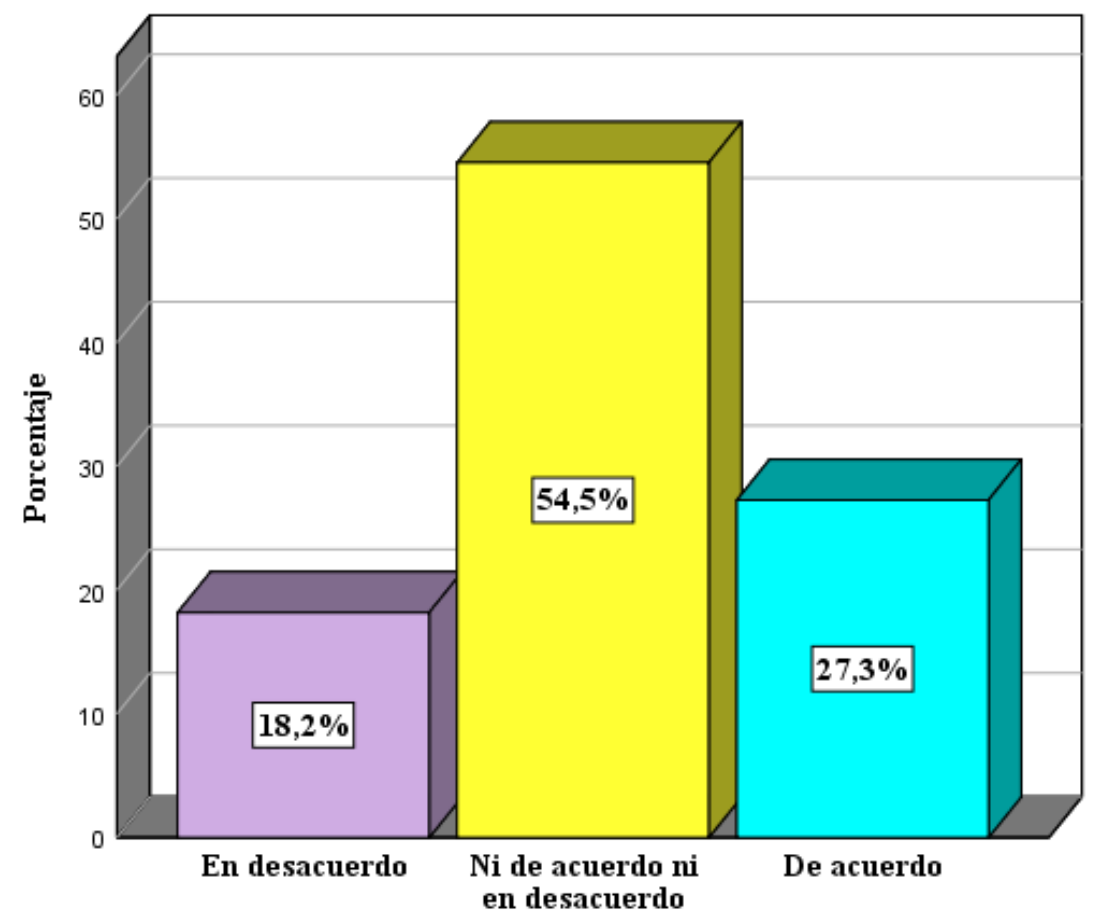

Figura 19. En comparación con las ofertas de sus principales competidores, sus productos son únicos con respecto al rendimiento.

Elaboración propia

Interpretación: En la afirmación 11 se aprecia que en su mayoría el 54,5\% de los representantes no está de acuerdo ni en desacuerdo en que, en comparación con las ofertas de sus principales competidores, sus productos son únicos con respecto al rendimiento. Un $27,3 \%$ se muestra de acuerdo, mientras que el $18,2 \%$ restante se muestra en desacuerdo. 
- X3: Enfoque de calidad

Tabla 15.

A12. Enfatizar la calidad del servicio al cliente es importante para la estrategia de la empresa en el mercado.

\begin{tabular}{llcccc}
\hline & Frecuencia & Porcentaje & $\begin{array}{c}\text { Porcentaje } \\
\text { válido }\end{array}$ & $\begin{array}{c}\text { Porcentaje } \\
\text { acumulado }\end{array}$ \\
\hline Válido & En desacuerdo & 1 & 9,1 & 9,1 & 9,1 \\
& Ni de acuerdo ni en & 2 & 18,2 & 18,2 & 27,3 \\
& desacuerdo & & & & \\
De acuerdo & 8 & 72,7 & 72,7 & 100,0 \\
& Total & 11 & 100,0 & 100,0 & \\
\hline
\end{tabular}

Elaboración propia

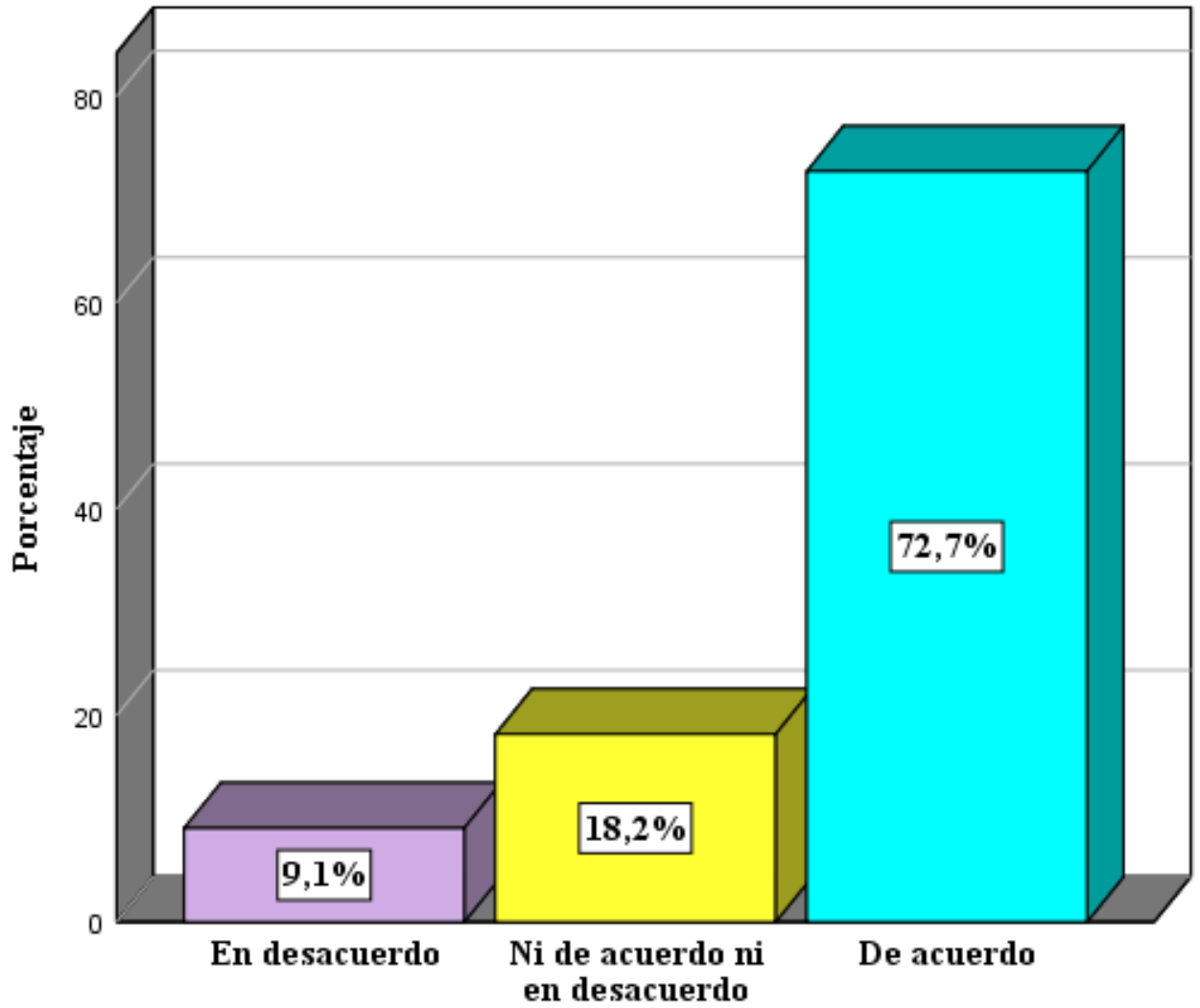

Figura 20. Enfatizar la calidad del servicio al cliente es importante para la estrategia de la empresa en el mercado.

Elaboración propia

Interpretación: En la afirmación 12 se observa que predominantemente el 72,7\% de los representantes está de acuerdo en que enfatizar la calidad del servicio al cliente es importante para realizar una buena estrategia de la en el mercado. Un 18,2\% se muestra ni de acuerdo ni en desacuerdo; mientras que el 9,1\% se muestra en desacuerdo. 
Tabla 16.

A13. Enfatizar la calidad del producto es importante para la estrategia de la empresa en el mercado.

\begin{tabular}{llcccc}
\hline & & & $\begin{array}{c}\text { Porcentaje } \\
\text { válido }\end{array}$ & $\begin{array}{c}\text { Porcentaje } \\
\text { acumulado }\end{array}$ \\
\hline Válido & En desacuerdo & 1 & 9,1 & 9,1 & 9,1 \\
& Ni de acuerdo ni en & 7 & 63,6 & 63,6 & 72,7 \\
desacuerdo & & & & \\
De acuerdo & 2 & 18,2 & 18,2 & 90,9 \\
Totalmente de acuerdo & 1 & 9,1 & 9,1 & 100,0 \\
Total & 11 & 100,0 & 100,0 & \\
\hline
\end{tabular}

Elaboración propia

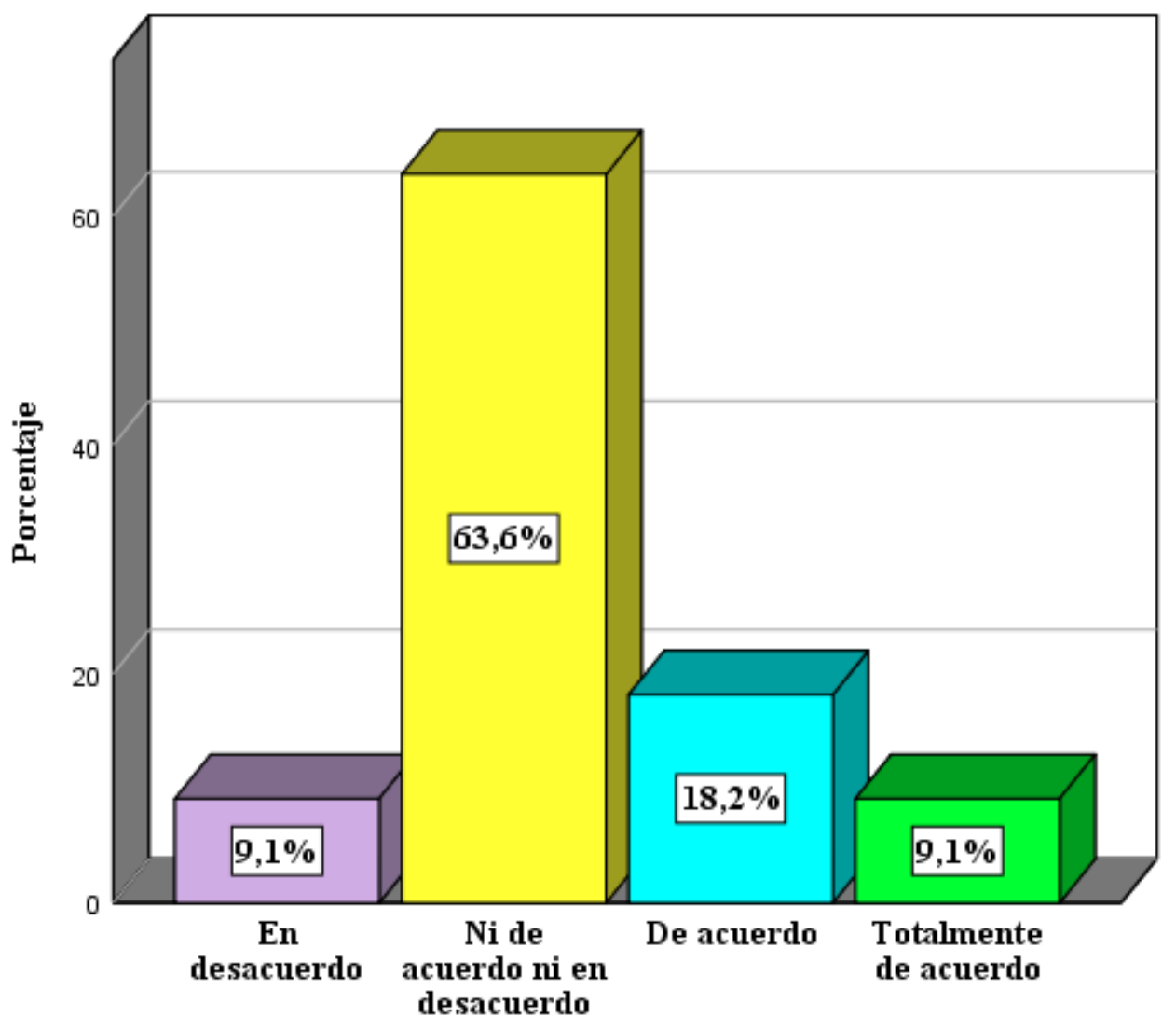

Figura 21. Enfatizar la calidad del producto es importante para la estrategia de la empresa en el mercado.

\section{Elaboración propia}

Interpretación: En la afirmación 13 se observa que, en su gran mayoría, el 63,6\% de los representantes no está de acuerdo ni en desacuerdo en que enfatizar la calidad del producto es importante para la estrategia de la empresa en el mercado. Un $18,2 \%$ se muestra de acuerdo, el $9,1 \%$ se muestra en desacuerdo, y el otro $9,1 \%$ se muestra totalmente de acuerdo. 
Tabla 17.

A14. Para nosotros, el éxito en el mercado está impulsado por la verdadera satisfacción de las necesidades de nuestros clientes allí.

\begin{tabular}{llcccc}
\hline & Frecuencia & Porcentaje & $\begin{array}{c}\text { Porcentaje } \\
\text { válido }\end{array}$ & $\begin{array}{c}\text { Porcentaje } \\
\text { acumulado }\end{array}$ \\
\hline Válido & Ni de acuerdo ni en & 5 & 45,5 & 45,5 & 45,5 \\
& & & & \\
& desacuerdo & 6 & 54,5 & 54,5 & 100,0 \\
& De acuerdo & 11 & 100,0 & 100,0 & \\
\hline
\end{tabular}

Elaboración propia

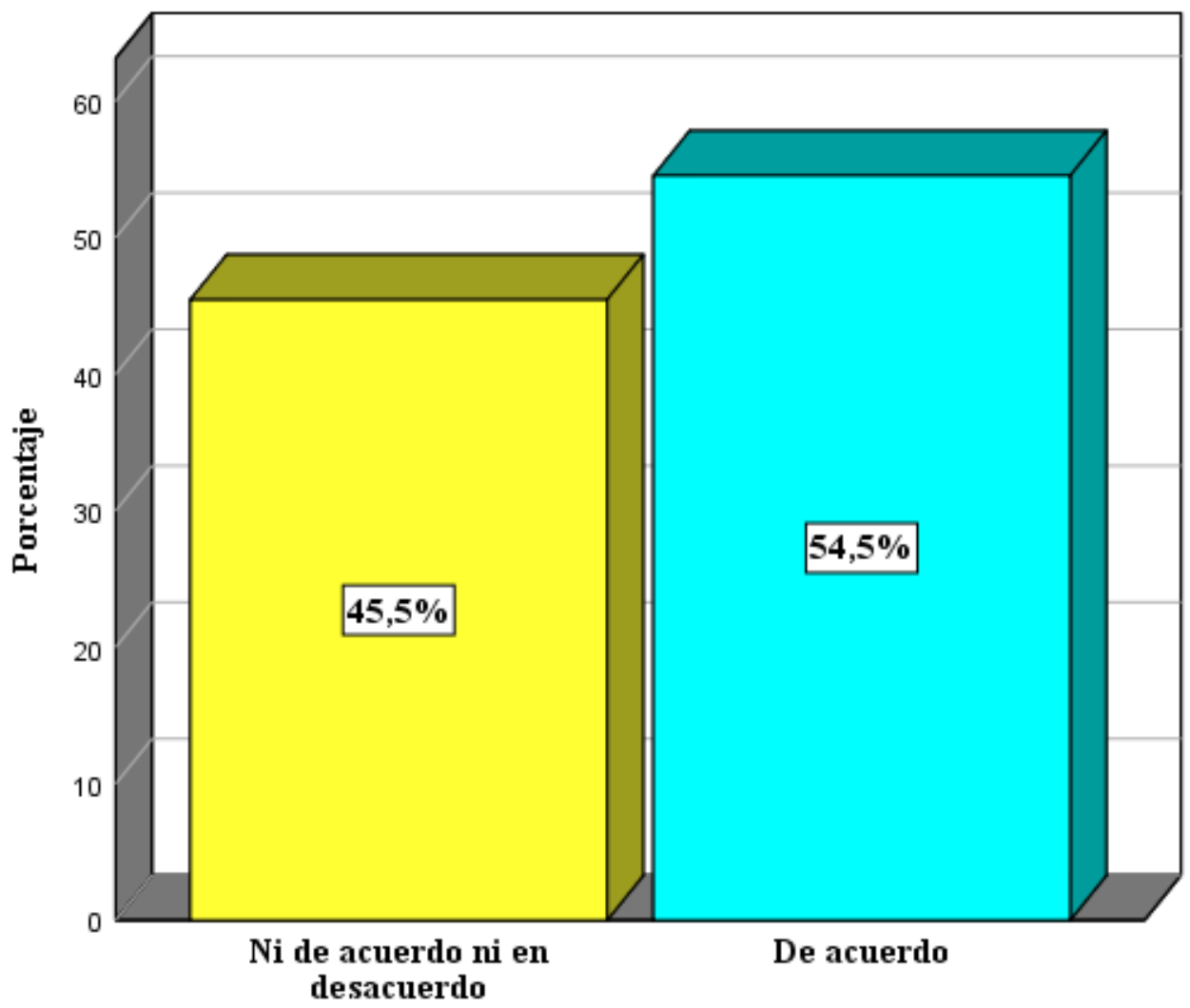

Figura 22. Para nosotros, el éxito en el mercado está impulsado por la verdadera satisfacción de las necesidades de nuestros clientes allí.

Elaboración propia

Interpretación: En la afirmación 14 se observa que principalmente el $54,5 \%$ de los representantes está de acuerdo en que, para ellos, el éxito en el mercado está impulsado por la verdadera satisfacción de las necesidades de sus clientes. Mientras que el $45,5 \%$ se muestra ni de acuerdo ni en desacuerdo. 
Tabla 18.

A15. El rendimiento de los productos realmente cumple con las expectativas de los clientes en el mercado.

\begin{tabular}{|c|c|c|c|c|c|}
\hline & & Frecuencia & Porcentaje & $\begin{array}{c}\text { Porcentaje } \\
\text { válido }\end{array}$ & $\begin{array}{l}\text { Porcentaje } \\
\text { acumulado }\end{array}$ \\
\hline \multirow[t]{5}{*}{ Válido } & En desacuerdo & 1 & 9,1 & 9,1 & 9,1 \\
\hline & $\begin{array}{l}\text { Ni de acuerdo ni en } \\
\text { desacuerdo }\end{array}$ & 7 & 63,6 & 63,6 & 72,7 \\
\hline & De acuerdo & 2 & 18,2 & 18,2 & 90,9 \\
\hline & Totalmente de acuerdo & 1 & 9,1 & 9,1 & 100,0 \\
\hline & Total & 11 & 100,0 & 100,0 & \\
\hline
\end{tabular}

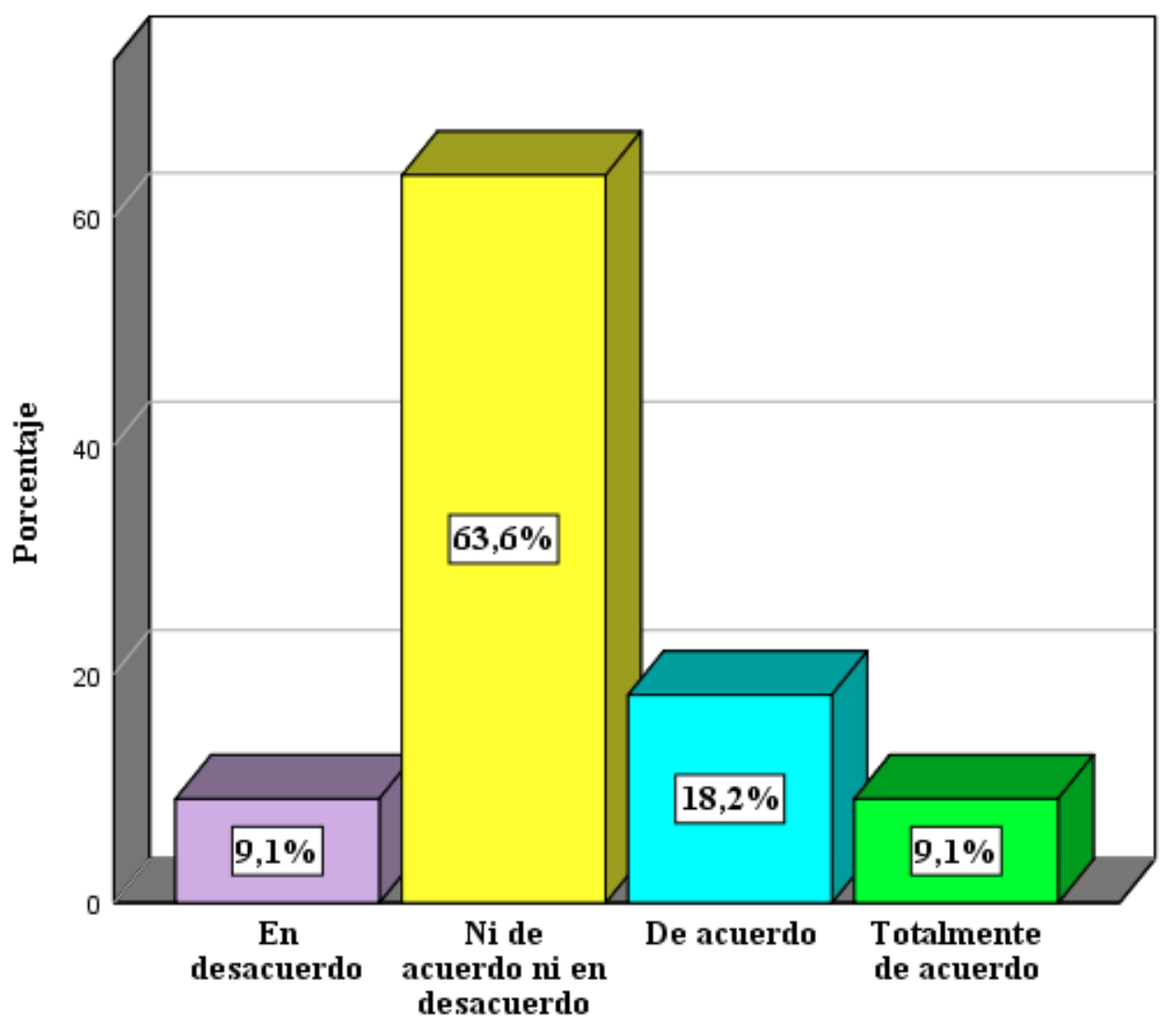

Figura 23. El rendimiento de los productos realmente cumple con las expectativas de los clientes en el mercado.

\section{Elaboración propia}

Interpretación: En la afirmación 15 se observa que, en su gran mayoría, el 63,6\% de los representantes no está de acuerdo ni en desacuerdo en que el rendimiento de los productos realmente cumple con las expectativas de los clientes en el mercado. Un 18,2\% se muestra de acuerdo, el 9,1\% se muestra totalmente de acuerdo, mientras que el otro $9,1 \%$ se muestra en desacuerdo. 
Tabla 19.

A16. El servicio brindado con los productos realmente cumple con las expectativas de los clientes en el mercado.

\begin{tabular}{llcccc}
\hline & Frecuencia & Porcentaje & $\begin{array}{c}\text { Porcentaje } \\
\text { válido }\end{array}$ & $\begin{array}{c}\text { Porcentaje } \\
\text { acumulado }\end{array}$ \\
\hline Válido & En desacuerdo & 2 & 18,2 & 18,2 & 18,2 \\
& $\begin{array}{l}\text { Ni de acuerdo ni en } \\
\text { desacuerdo }\end{array}$ & 8 & 72,7 & 72,7 & 90,9 \\
& De acuerdo & 1 & & & 100,0 \\
Total & 11 & 100,0 & 100,0 & \\
\hline
\end{tabular}

Elaboración propia

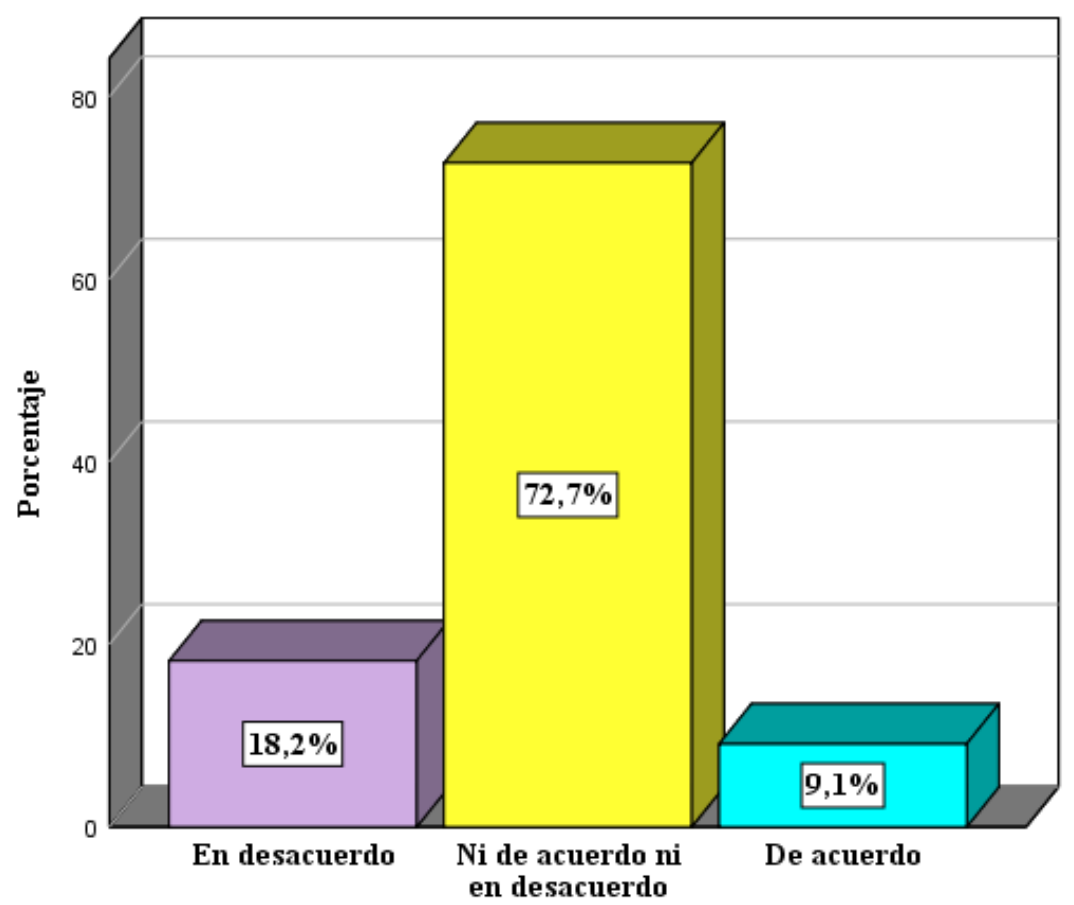

Figura 24. El servicio brindado con los productos realmente cumple con las expectativas de los clientes en el mercado.

Elaboración propia

Interpretación: En la afirmación 16 se aprecia que en su gran mayoría el 72,7\% de los representantes no está de acuerdo ni en desacuerdo en que el servicio brindado con los productos realmente cumple con las expectativas de sus clientes en el mercado. Un 18,2\% se muestra en desacuerdo, mientras que solo el 9,1\% se muestra de acuerdo. 
- X4: Aprovechamiento de las competencias de los distribuidores extranjeros

Tabla 20.

A17. Los distribuidores cumplen con las expectativas en cuanto a establecimiento de precios locales.

\begin{tabular}{|c|c|c|c|c|c|}
\hline & & Frecuencia & Porcentaje & $\begin{array}{c}\text { Porcentaje } \\
\text { válido }\end{array}$ & $\begin{array}{l}\text { Porcentaje } \\
\text { acumulado } \\
\end{array}$ \\
\hline \multirow[t]{4}{*}{ Válido } & En desacuerdo & 1 & 9,1 & 9,1 & 9,1 \\
\hline & $\begin{array}{l}\text { Ni de acuerdo ni en } \\
\text { desacuerdo }\end{array}$ & 7 & 63,6 & 63,6 & 72,7 \\
\hline & De acuerdo & 3 & 27,3 & 27,3 & 100,0 \\
\hline & Total & 11 & 100,0 & 100,0 & \\
\hline
\end{tabular}

Elaboración propia

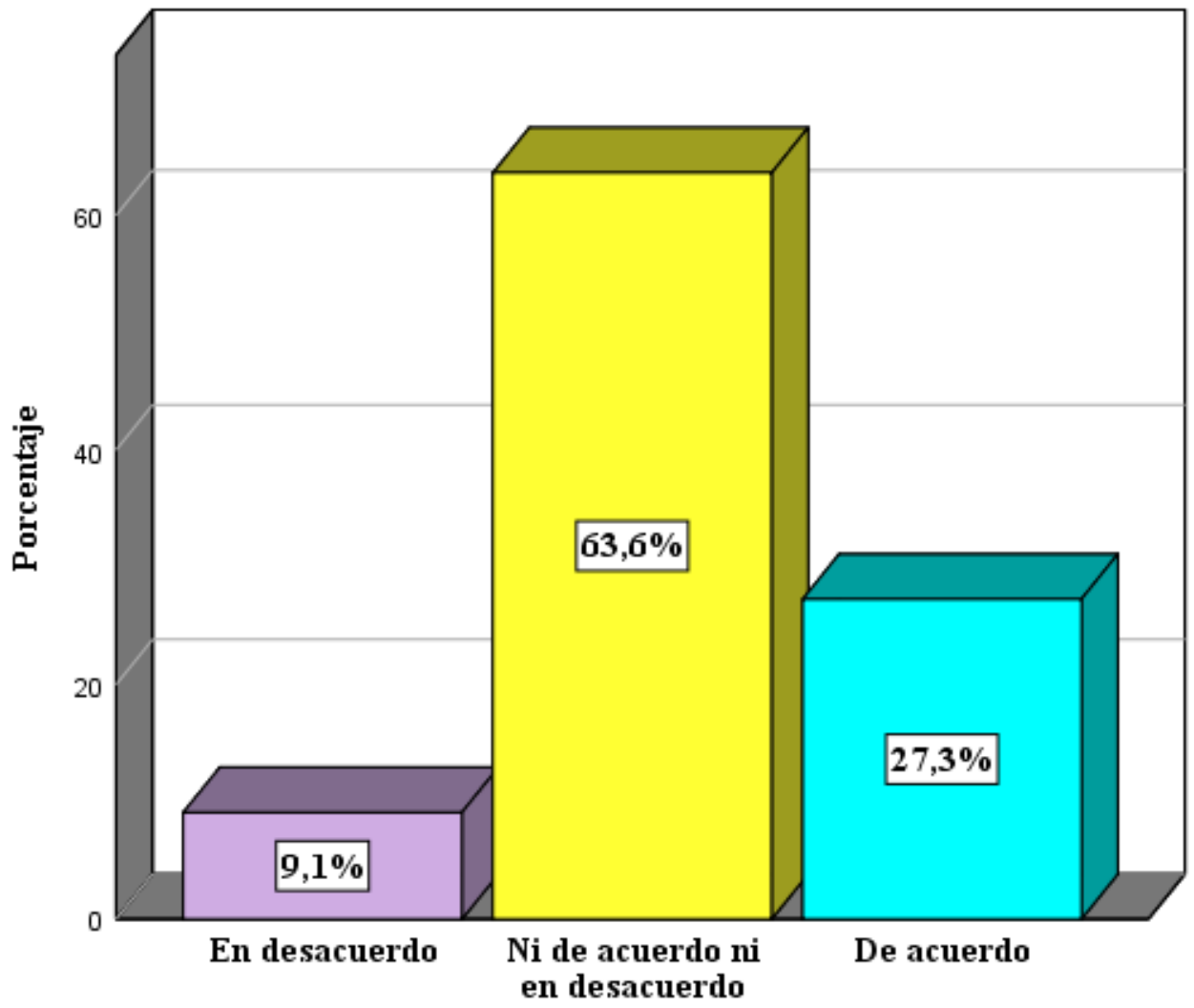

Figura 25. Los distribuidores cumplen con las expectativas en cuanto a establecimiento de precios locales.

Elaboración propia

Interpretación: En la afirmación 17 se aprecia que en su mayoría el 63,6\% de los representantes no está de acuerdo ni en desacuerdo en que, los distribuidores cumplen con las expectativas en cuanto a establecimiento de precios locales. Un $27,3 \%$ se muestra de acuerdo, mientras que solo el 9,1\% se muestra en desacuerdo. 
Tabla 21.

A18. Los distribuidores cumplen con las expectativas en cuanto a venta local.

\begin{tabular}{llcccc}
\hline & & & Porcentaje & Porcentaje \\
& & Frecuencia & Porcentaje & $\begin{array}{c}\text { válido } \\
\text { acumulado }\end{array}$ \\
\hline Válido & En desacuerdo & 3 & 27,3 & 27,3 & 27,3 \\
& Ni de acuerdo ni en & 8 & 72,7 & 72,7 & 100,0 \\
& desacuerdo & & & & \\
& Total & 11 & 100,0 & 100,0 & \\
\hline
\end{tabular}

Elaboración propia

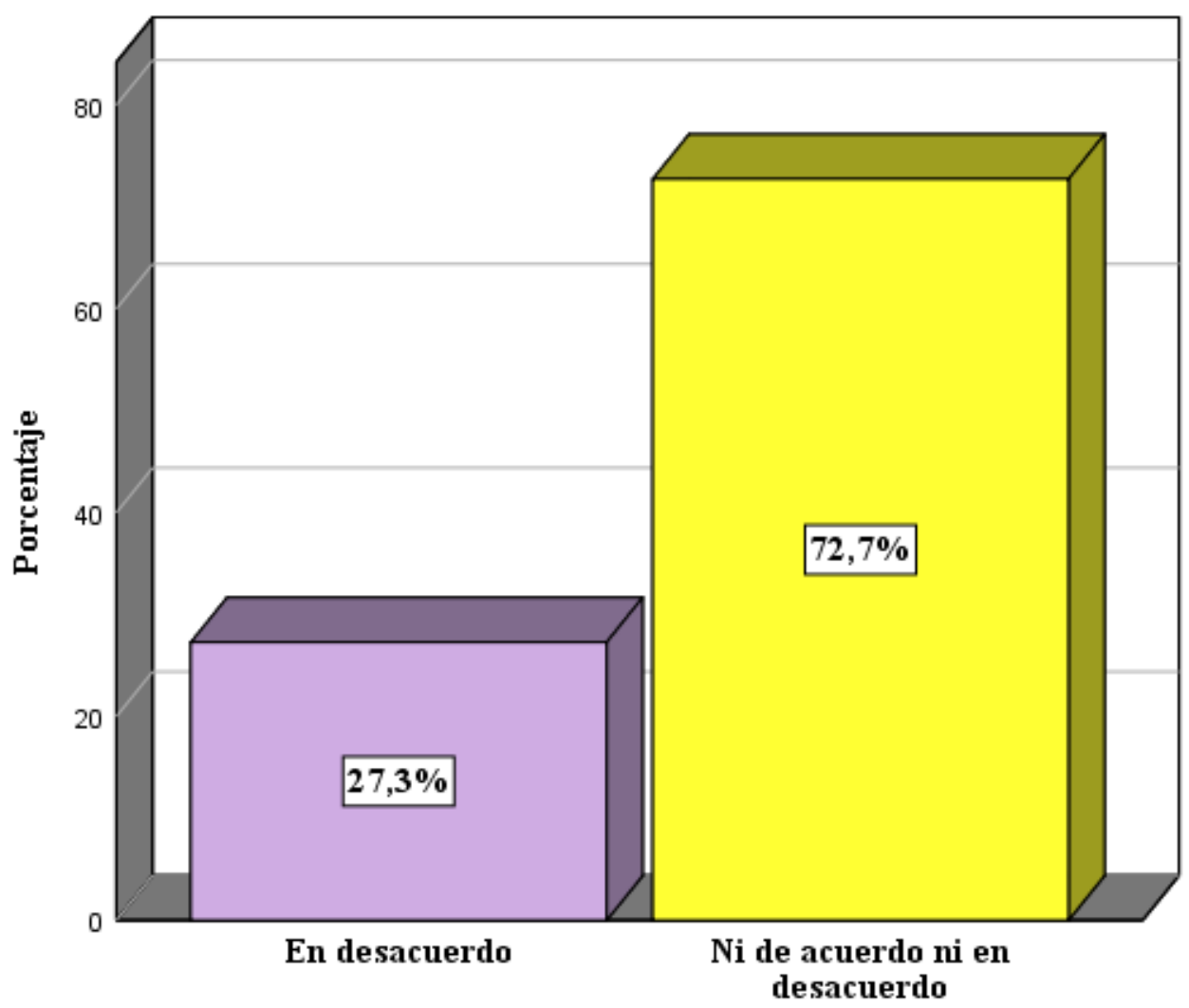

Figura 26. Los distribuidores cumplen con las expectativas en cuanto a venta local.

Elaboración propia

Interpretación: En la afirmación 18 se aprecia que predominantemente el 72,7\% de los representantes no está ni de acuerdo ni en desacuerdo en que los distribuidores cumplen con las expectativas en cuanto a venta local. Mientras que el restante $27,3 \%$ se muestra en desacuerdo. 
Tabla 22.

A19. Los distribuidores cumplen con las expectativas en cuanto a publicidad local.

\begin{tabular}{|c|c|c|c|c|c|}
\hline & & Frecuencia & Porcentaje & $\begin{array}{c}\text { Porcentaje } \\
\text { válido }\end{array}$ & $\begin{array}{l}\text { Porcentaje } \\
\text { acumulado } \\
\end{array}$ \\
\hline \multirow[t]{4}{*}{ Válido } & $\begin{array}{l}\text { Totalmente en } \\
\text { desacuerdo }\end{array}$ & 2 & 18,2 & 18,2 & 18,2 \\
\hline & En desacuerdo & 5 & 45,5 & 45,5 & 63,6 \\
\hline & $\begin{array}{l}\text { Ni de acuerdo ni en } \\
\text { desacuerdo }\end{array}$ & 4 & 36,4 & 36,4 & 100,0 \\
\hline & Total & 11 & 100,0 & 100,0 & \\
\hline
\end{tabular}

Elaboración propia

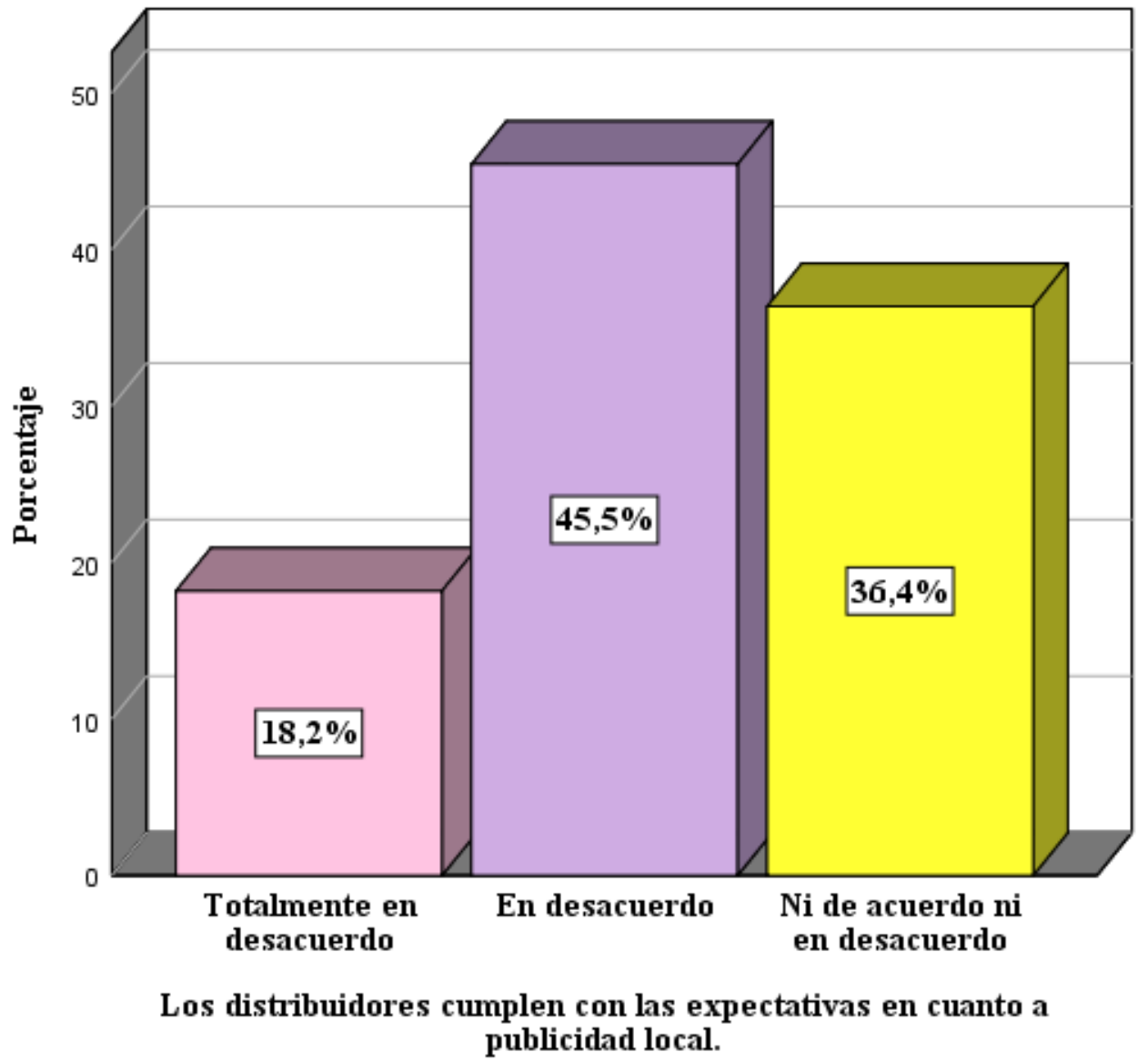

Figura 27. Los distribuidores cumplen con las expectativas en cuanto a publicidad local.

Elaboración propia

Interpretación: En la afirmación 19 se aprecia que principalmente el 45,5\% de los representantes está en desacuerdo en que los distribuidores cumplen con las expectativas en cuanto a publicidad local. Un $36,4 \%$ se muestra ni de acuerdo ni en desacuerdo; y el restante $18,2 \%$ se muestra totalmente en desacuerdo. 
Tabla 23.

A20. Los distribuidores cumplen con las expectativas en cuanto a servicio.

\begin{tabular}{llcccc}
\hline & Frecuencia & Porcentaje & $\begin{array}{c}\text { Porcentaje } \\
\text { válido }\end{array}$ & $\begin{array}{c}\text { Porcentaje } \\
\text { acumulado }\end{array}$ \\
\hline Válido & En desacuerdo & 4 & 36,4 & 36,4 & 36,4 \\
& $\begin{array}{l}\text { Ni de acuerdo ni en } \\
\text { desacuerdo }\end{array}$ & 6 & 54,5 & 54,5 & 90,9 \\
& De acuerdo & 1 & & & 100,0 \\
Total & 11 & 100,0 & 100,0 & \\
\hline
\end{tabular}

Elaboración propia

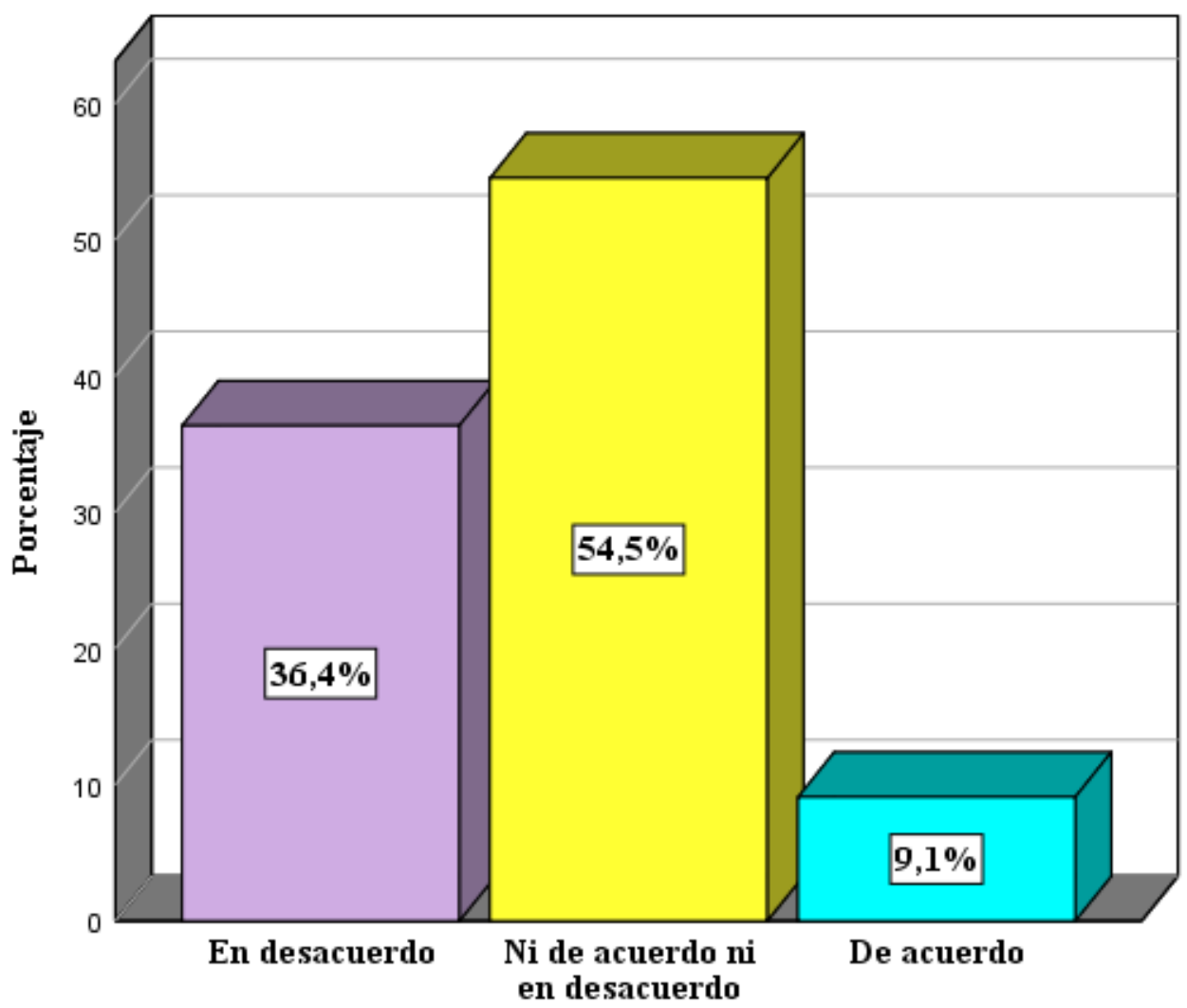

Figura 28. Los distribuidores cumplen con las expectativas en cuanto a servicio.

Elaboración propia

Interpretación: En la afirmación 20 se aprecia que en su mayoría el 54,5\% de los representantes no está de acuerdo ni en desacuerdo en que los distribuidores cumplen con las expectativas en cuanto a servicio brindado. Un $36,4 \%$ se muestra en desacuerdo, mientras que solo el $9,1 \%$ se muestra de acuerdo. 
Tabla 24.

A21. Los distribuidores cumplen con las expectativas en cuanto a recopilación de información del mercado local.

\begin{tabular}{llcccc}
\hline & & & $\begin{array}{c}\text { Porcentaje } \\
\text { válido }\end{array}$ & $\begin{array}{c}\text { Porcentaje } \\
\text { acumulado }\end{array}$ \\
\hline Válido & En desacuerdo & 3 & 27,3 & 27,3 & 27,3 \\
& Ni de acuerdo ni en & 6 & 54,5 & 54,5 & 81,8 \\
& desacuerdo & & & & \\
De acuerdo & 2 & 18,2 & 18,2 & 100,0 \\
Total & 11 & 100,0 & 100,0 & \\
\hline
\end{tabular}

Elaboración propia

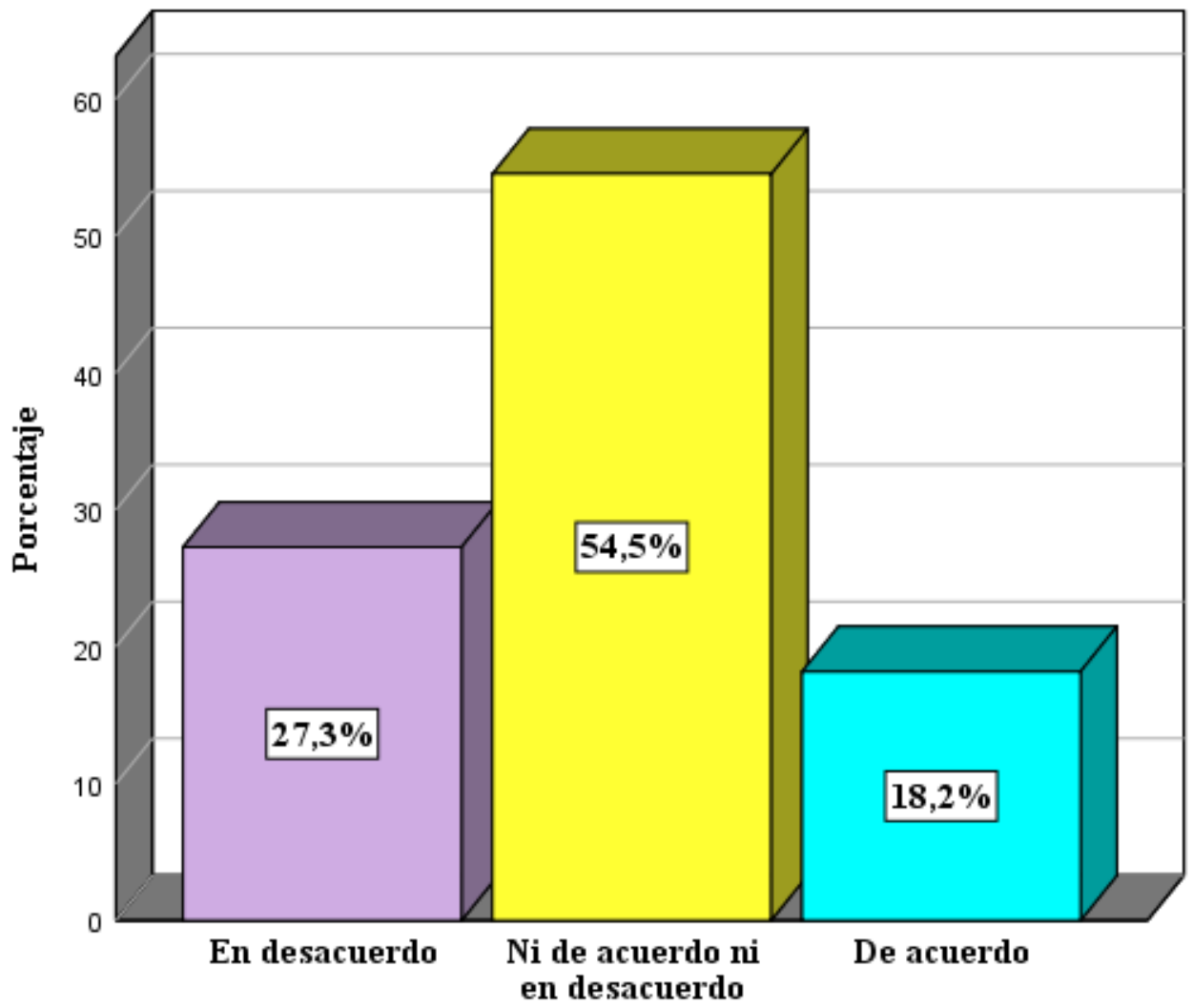

Figura 29. Los distribuidores cumplen con las expectativas en cuanto a recopilación de información del mercado local.

Elaboración propia

Interpretación: En la afirmación 21 se aprecia que en su gran mayoría el 54,5\% de los representantes no está de acuerdo ni en desacuerdo en que los distribuidores cumplen con las expectativas en cuanto a recopilación de información del mercado local. Un 27,3\% se muestra en desacuerdo, mientras que solo el restante $18,2 \%$ se muestra de acuerdo. 
Tabla 25.

A22. Los distribuidores cumplen con las expectativas en relación con el gobierno local.

\begin{tabular}{llcccc}
\hline & & & $\begin{array}{c}\text { Porcentaje } \\
\text { válido }\end{array}$ & $\begin{array}{c}\text { Porcentaje } \\
\text { acumulado }\end{array}$ \\
\hline Válido & En desacuerdo & 2 & 18,2 & 18,2 & 18,2 \\
& Ni de acuerdo ni en & 7 & 63,6 & 63,6 & 81,8 \\
desacuerdo & & & & \\
De acuerdo & 1 & 9,1 & 9,1 & 90,9 \\
Totalmente de acuerdo & 1 & 9,1 & 9,1 & 100,0 \\
Total & 11 & 100,0 & 100,0 & \\
\hline
\end{tabular}

Elaboración propia

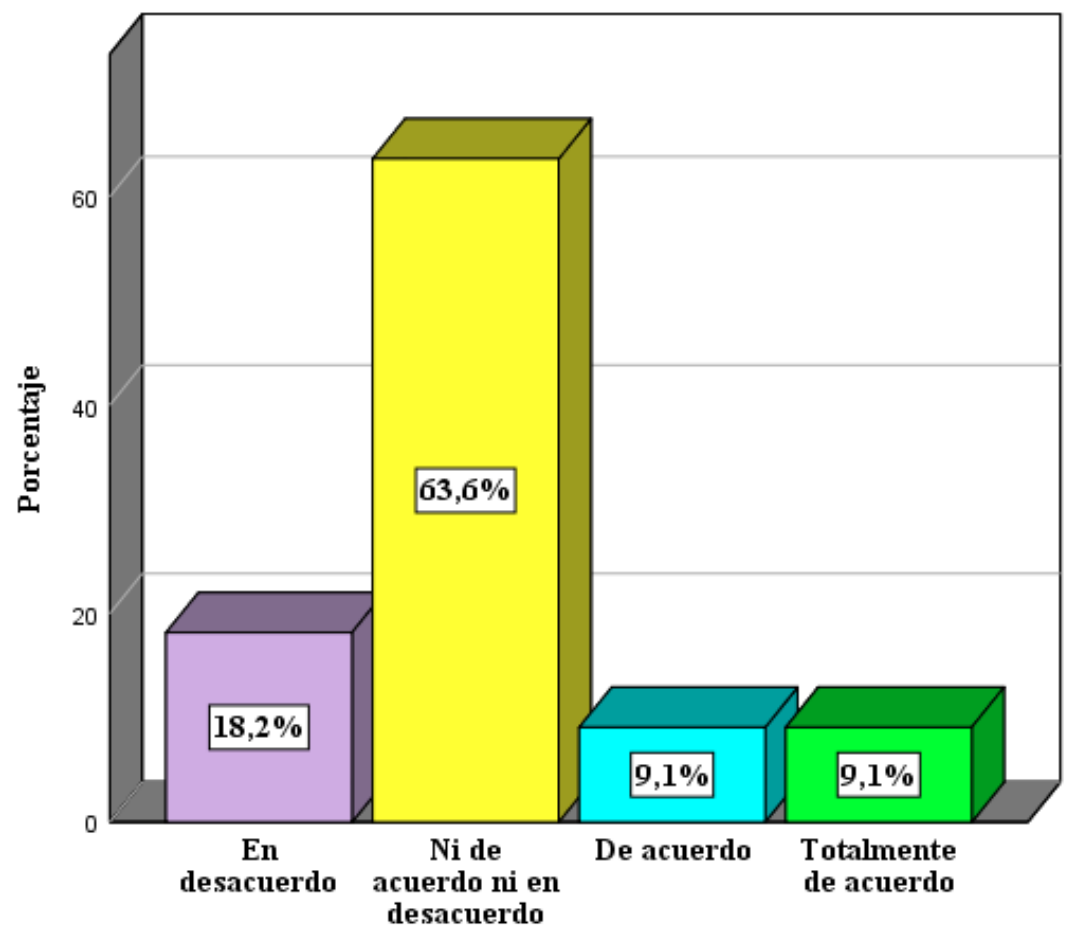

Figura 30. Los distribuidores cumplen con las expectativas en relación con el gobierno local.

\section{Elaboración propia}

Interpretación: En la afirmación 22 se observa que en predominantemente el 63,6\% de los representantes no está de acuerdo ni en desacuerdo en que los distribuidores cumplen con las expectativas en relación con el gobierno local. Un $18,2 \%$ se muestra en desacuerdo, mientras que el restante $9,1 \%$ se muestra de acuerdo y el otro $9,1 \%$ se muestra totalmente de acuerdo. 
Tabla 26.

A23. Los distribuidores cumplen con las expectativas en cuanto a cultivar nuevos negocios lexpansión.

\begin{tabular}{|c|c|c|c|c|c|}
\hline & & Frecuencia & Porcentaje & $\begin{array}{c}\text { Porcentaje } \\
\text { válido }\end{array}$ & $\begin{array}{l}\text { Porcentaje } \\
\text { acumulado }\end{array}$ \\
\hline \multirow[t]{5}{*}{ Válido } & $\begin{array}{l}\text { Totalmente en } \\
\text { desacuerdo }\end{array}$ & 1 & 9,1 & 9,1 & 9,1 \\
\hline & En desacuerdo & 5 & 45,5 & 45,5 & 54,5 \\
\hline & $\begin{array}{l}\text { Ni de acuerdo ni en } \\
\text { desacuerdo }\end{array}$ & 4 & 36,4 & 36,4 & 90,9 \\
\hline & De acuerdo & 1 & 9,1 & 9,1 & 100,0 \\
\hline & Total & 11 & 100,0 & 100,0 & \\
\hline
\end{tabular}

Elaboración propia

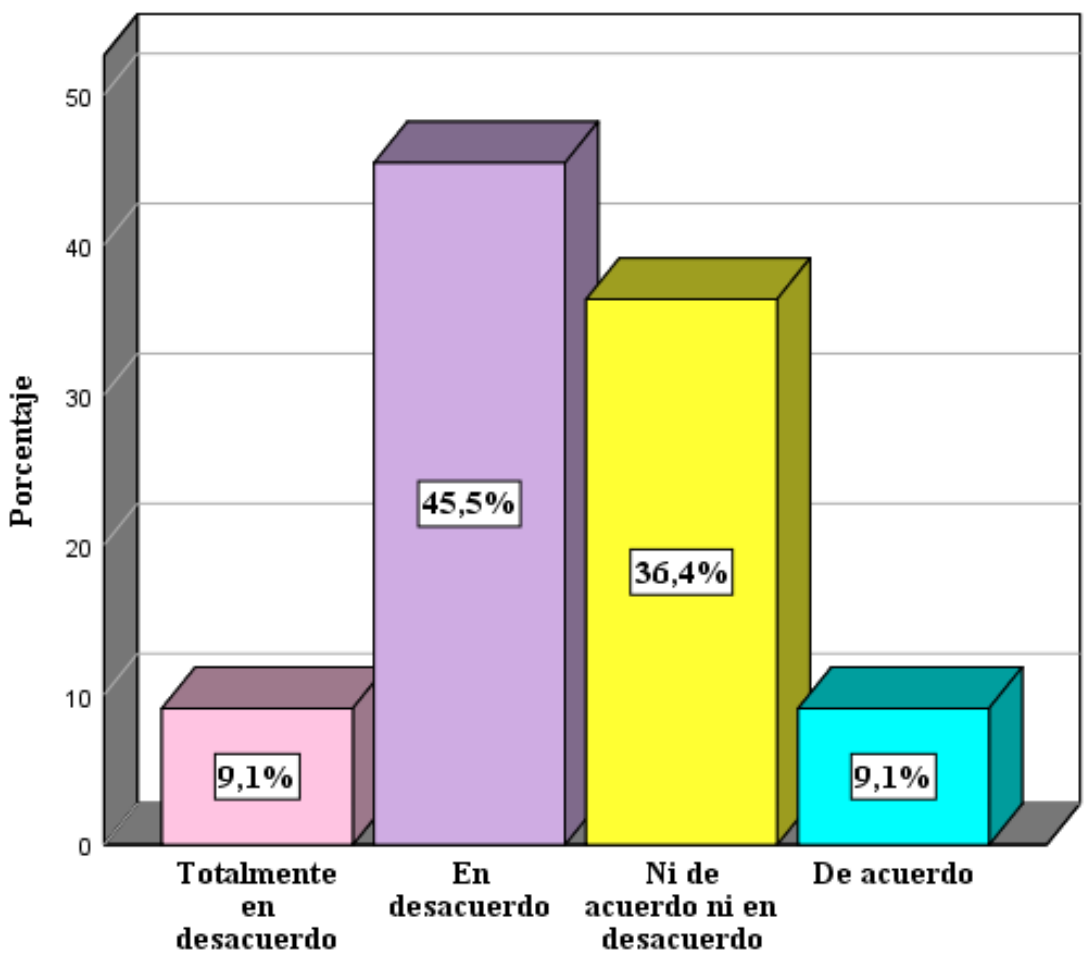

Figura 31. Los distribuidores cumplen con las expectativas en cuanto a cultivar nuevos negocios / expansión.

Elaboración propia

Interpretación: En la afirmación 23 se aprecia que principalmente el 45,5\% de los representantes está en desacuerdo en que los distribuidores cumplen con las expectativas en cuanto a cultivar nuevos negocios/expansión. Un 36,4\% se muestra ni de acuerdo ni en desacuerdo; el $9,1 \%$ se muestra de acuerdo, y el otro $9,1 \%$ se muestra totalmente en desacuerdo. 
Tabla 27.

A24. Los distribuidores cumplen con las expectativas en cuanto a modificación del producto (si existe).

\begin{tabular}{llcccc} 
& & & $\begin{array}{c}\text { Porcentaje } \\
\text { válido }\end{array}$ & $\begin{array}{c}\text { Porcentaje } \\
\text { acumulado }\end{array}$ \\
\hline Válido & En desacuerdo & 2 & 18,2 & 18,2 & 18,2 \\
& Ni de acuerdo ni en & 6 & 54,5 & 54,5 & 72,7 \\
desacuerdo & & & & \\
De acuerdo & 2 & 18,2 & 18,2 & 90,9 \\
Totalmente de acuerdo & 1 & 9,1 & 9,1 & 100,0 \\
Total & 11 & 100,0 & 100,0 & \\
\hline Elaboración propia & & & &
\end{tabular}

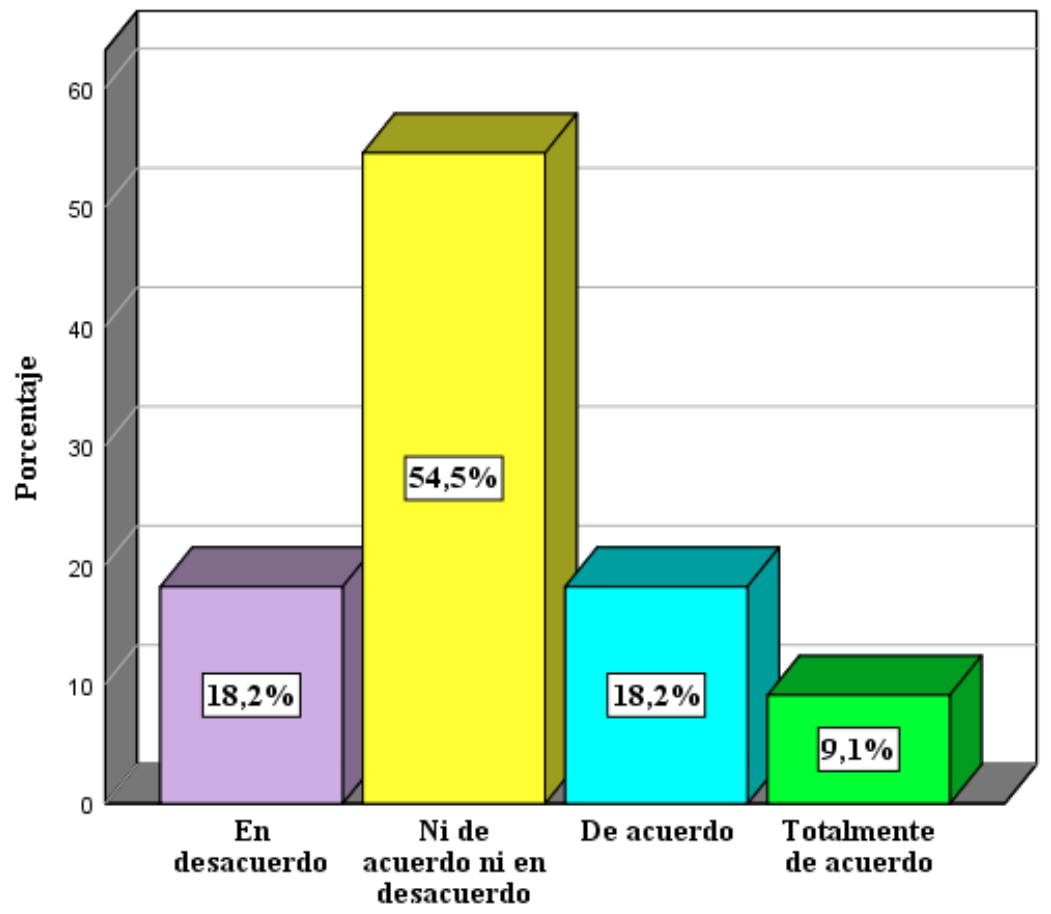

Figura 32. Los distribuidores cumplen con las expectativas en cuanto a modificación del producto (si existe).

\section{Elaboración propia}

Interpretación: En la afirmación 24 se observa que en predominantemente el 54,5\% de los representantes no está de acuerdo ni en desacuerdo en que los distribuidores cumplen con las expectativas en cuanto a modificación del producto si existe. Un 18,2\% se muestra en desacuerdo, el otro 18,2\% se muestra de acuerdo, y únicamente el 9,1\% se muestra totalmente de acuerdo. 
Tabla 28.

A25. Los distribuidores cumplen con las expectativas en cuanto a organización del envío internacional.

\begin{tabular}{llcccc}
\hline & & & $\begin{array}{c}\text { Porcentaje } \\
\text { válido }\end{array}$ & $\begin{array}{c}\text { Porcentaje } \\
\text { acumulado }\end{array}$ \\
\hline Válido & En desacuerdo & 2 & 18,2 & 18,2 & 18,2 \\
& Ni de acuerdo ni en & 5 & 45,5 & 45,5 & 63,6 \\
& desacuerdo & & & & \\
De acuerdo & 4 & 36,4 & 36,4 & 100,0 \\
Total & 11 & 100,0 & 100,0 & \\
\hline
\end{tabular}

Elaboración propia

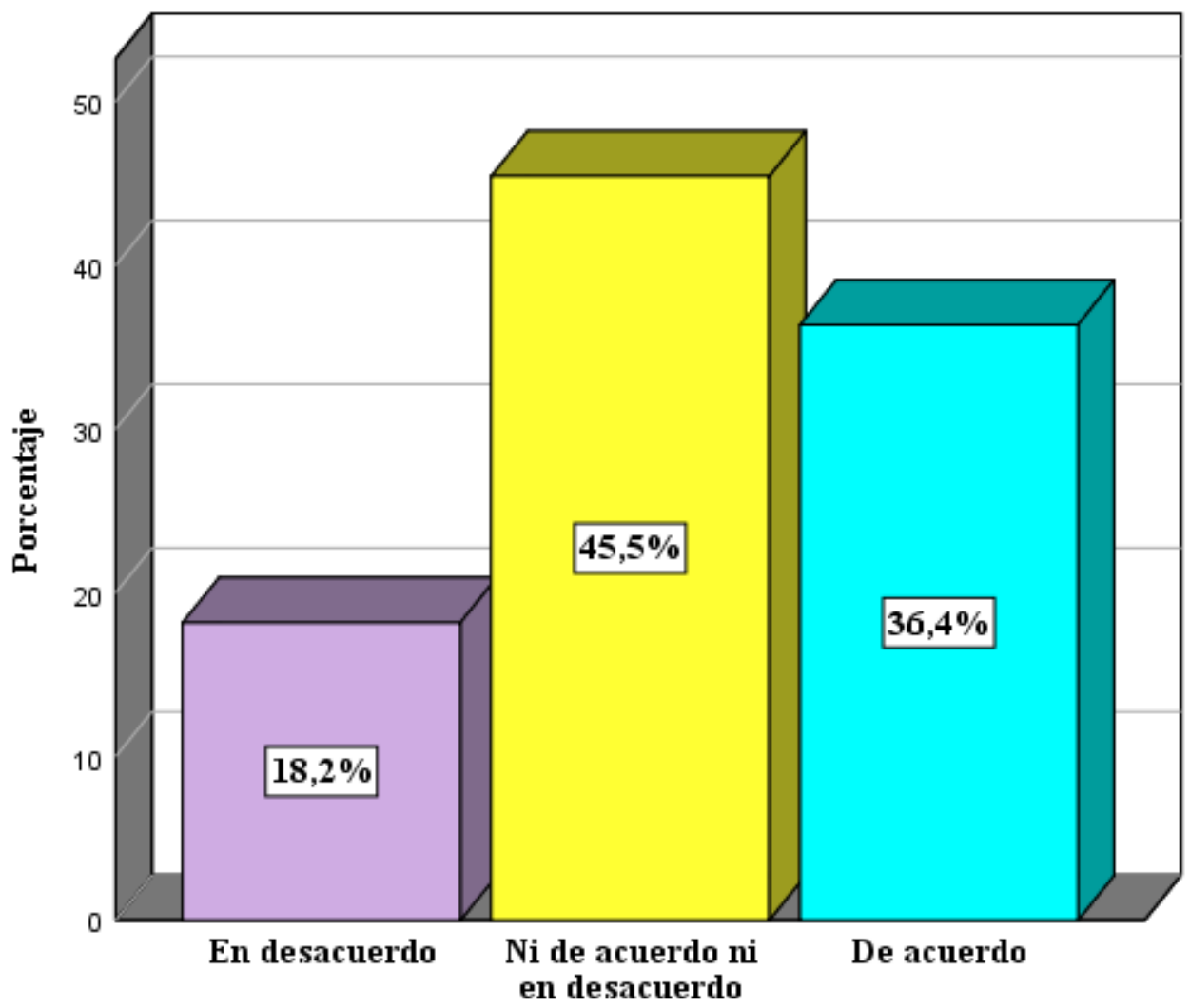

Figura 33. Los distribuidores cumplen con las expectativas en cuanto a organización del envío internacional.

Elaboración propia

Interpretación: En la afirmación 25 se aprecia que en su mayoría el 45,5\% de los representantes no está de acuerdo ni en desacuerdo en que los distribuidores cumplen con las expectativas en cuanto a la organización del envío internacional. Un 36,4\% se muestra de acuerdo, mientras que solo el $18,2 \%$ se muestra en desacuerdo. 
Tabla 29.

A26. Los distribuidores cumplen con las expectativas en cuanto a organización del envío local.

\begin{tabular}{llcccc}
\hline & & & $\begin{array}{c}\text { Porcentaje } \\
\text { válido }\end{array}$ & $\begin{array}{c}\text { Porcentaje } \\
\text { acumulado }\end{array}$ \\
\hline Válido & En desacuerdo & 2 & 18,2 & 18,2 & 18,2 \\
& Ni de acuerdo ni en & 3 & 27,3 & 27,3 & 45,5 \\
& desacuerdo & & & & \\
De acuerdo & 6 & 54,5 & 54,5 & 100,0 \\
Total & 11 & 100,0 & 100,0 & \\
\hline
\end{tabular}

Elaboración propia

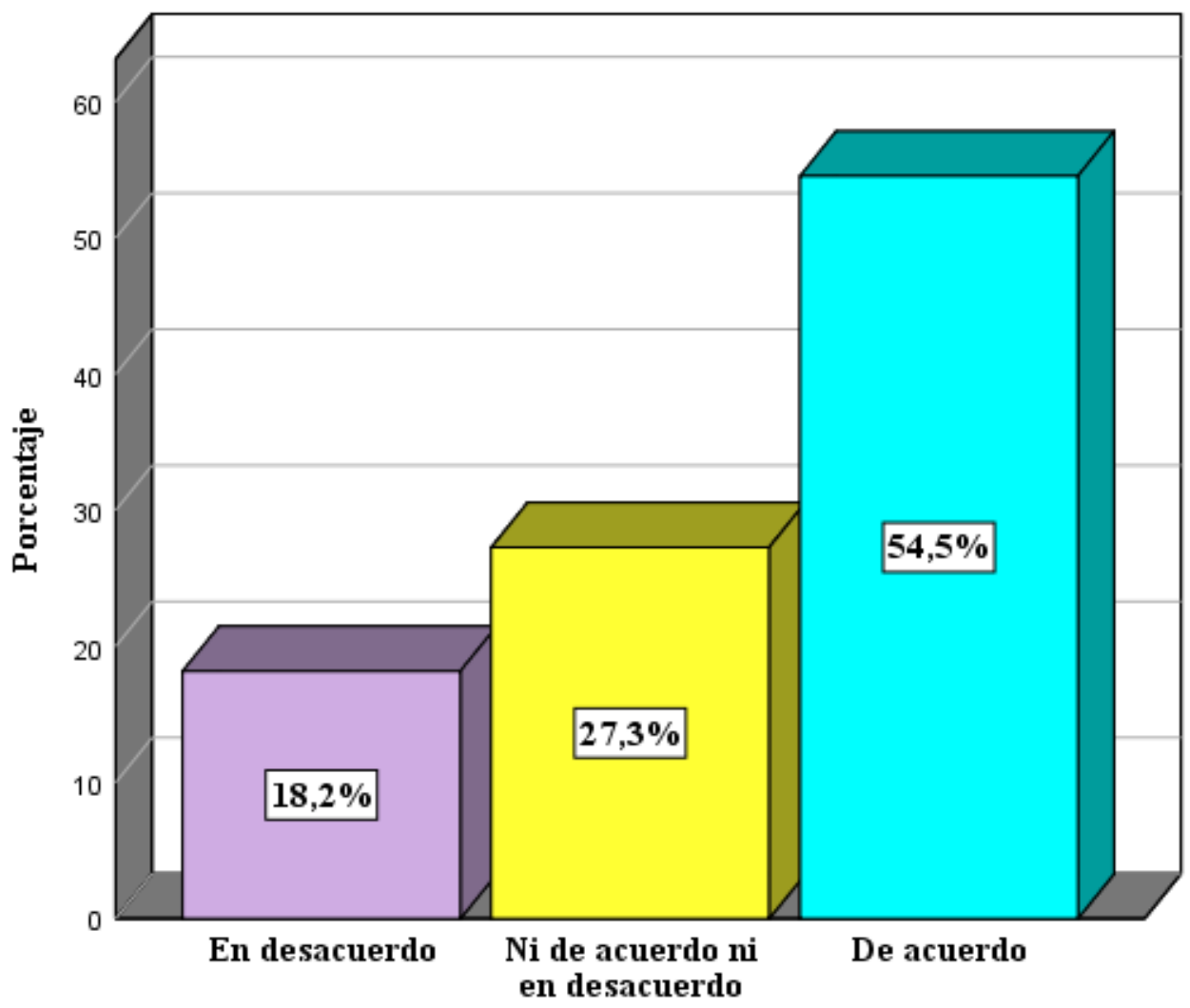

Figura 34. Los distribuidores cumplen con las expectativas en cuanto a organización del envío local.

Elaboración propia

Interpretación: En la afirmación 26 se observa que en su mayoría el 54,5\% de los representantes está de acuerdo en que los distribuidores cumplen con las expectativas en cuanto a organización del envío local. Un $27,3 \%$ se muestra ni de acuerdo ni en desacuerdo; mientras que el $18,2 \%$ se muestra en desacuerdo. 
Tabla 30.

A27. Los distribuidores cumplen con las expectativas en cuanto a relaciones públicas locales.

\begin{tabular}{|c|c|c|c|c|c|}
\hline & & Frecuencia & Porcentaje & $\begin{array}{c}\text { Porcentaje } \\
\text { válido } \\
\end{array}$ & $\begin{array}{l}\text { Porcentaje } \\
\text { acumulado } \\
\end{array}$ \\
\hline \multirow[t]{5}{*}{ Válido } & $\begin{array}{l}\text { Totalmente en } \\
\text { desacuerdo }\end{array}$ & 2 & 18,2 & 18,2 & 18,2 \\
\hline & En desacuerdo & 3 & 27,3 & 27,3 & 45,5 \\
\hline & $\begin{array}{l}\text { Ni de acuerdo ni en } \\
\text { desacuerdo }\end{array}$ & 3 & 27,3 & 27,3 & 72,7 \\
\hline & De acuerdo & 3 & 27,3 & 27,3 & 100,0 \\
\hline & Total & 11 & 100,0 & 100,0 & \\
\hline
\end{tabular}

Elaboración propia

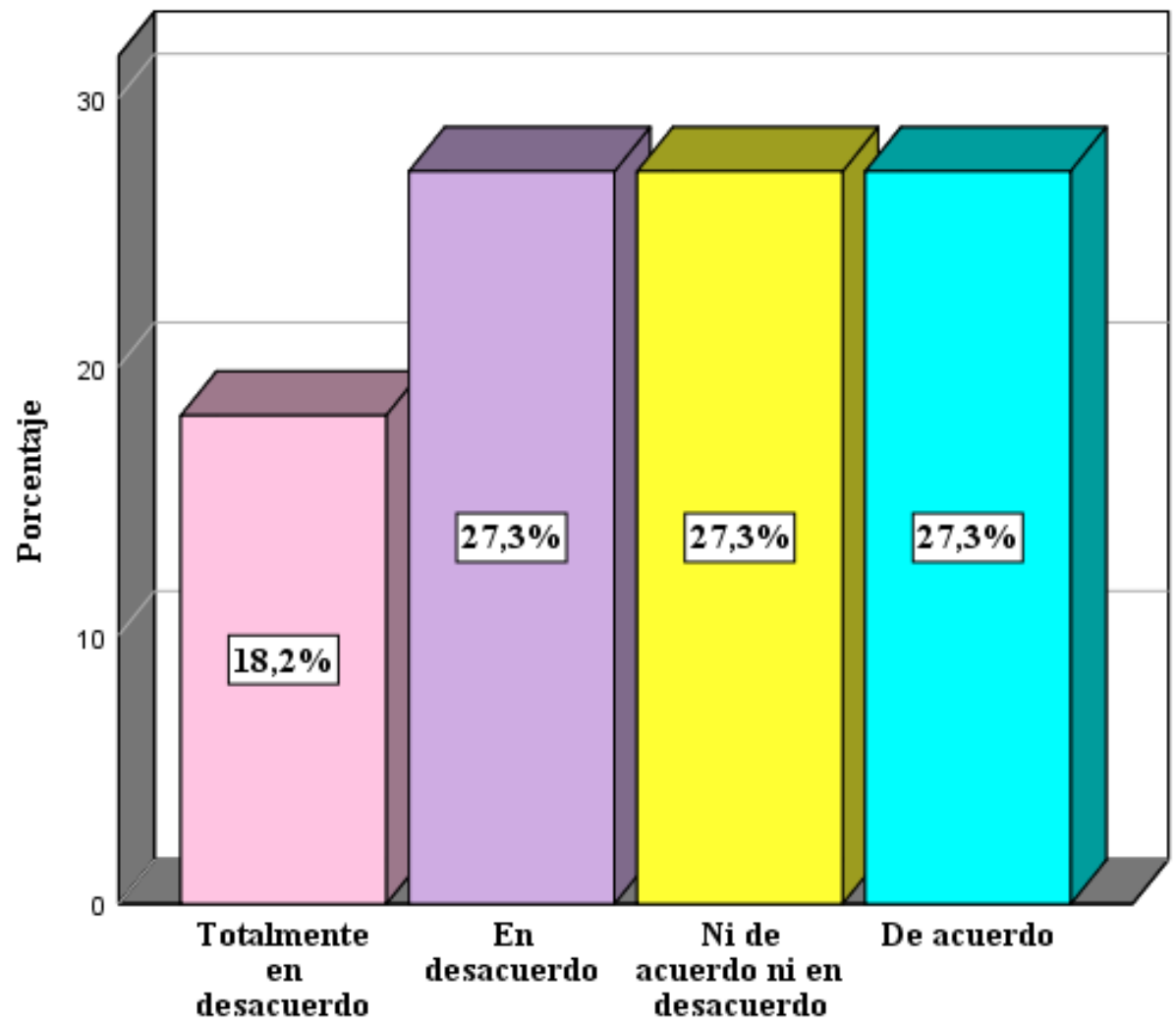

Figura 35. Los distribuidores cumplen con las expectativas en cuanto a relaciones públicas locales.

Elaboración propia

Interpretación: En la afirmación 27 se aprecia que el 27,3\% de los representantes está de acuerdo en que los distribuidores cumplen con las expectativas en cuanto a relaciones públicas. El otro $27,3 \%$ se muestra ni de acuerdo ni en desacuerdo; mientras que el otro $27,3 \%$ se muestra en desacuerdo y el restante $18,2 \%$ se muestra totalmente en desacuerdo. 
Tabla 31.

A28. Los distribuidores cumplen con las expectativas en cuanto a soporte técnico al cliente / capacitación.

\begin{tabular}{llcccc}
\hline & & & $\begin{array}{c}\text { Porcentaje } \\
\text { válido }\end{array}$ & $\begin{array}{c}\text { Porcentaje } \\
\text { acumulado }\end{array}$ \\
\hline Válido & En desacuerdo & 2 & 18,2 & 18,2 & 18,2 \\
& Ni de acuerdo ni en & 6 & 54,5 & 54,5 & 72,7 \\
& desacuerdo & & & & \\
De acuerdo & 3 & 27,3 & 27,3 & 100,0 \\
Total & 11 & 100,0 & 100,0 & \\
\hline
\end{tabular}

Elaboración propia

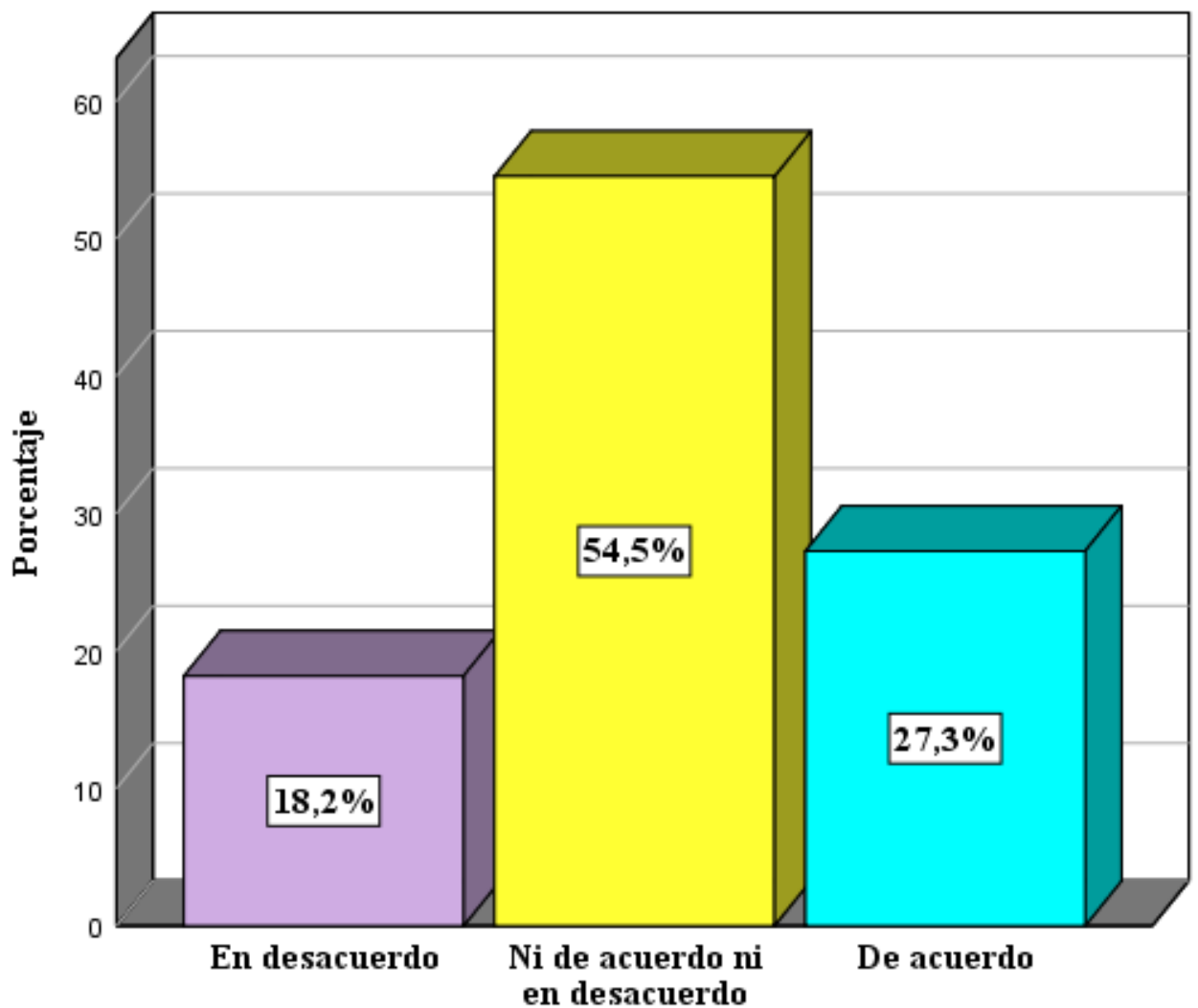

Figura 36. Los distribuidores cumplen con las expectativas en cuanto a soporte técnico al cliente / capacitación.

Elaboración propia

Interpretación: En la afirmación 28 se observa que en su mayoría el 54,5\% de los representantes no está de acuerdo ni en desacuerdo en que los distribuidores cumplen con las expectativas en cuanto a soporte técnico al cliente y capacitación. Un 27,3\% se muestra de acuerdo, mientras que solo el $18,2 \%$ se muestra en desacuerdo. 
Tabla 32.

A29. Los distribuidores cumplen con las expectativas en cuanto a traducción de literatura de ventas, instrucciones de uso o etiquetas.

\begin{tabular}{llcccc}
\hline & Frecuencia & Porcentaje & $\begin{array}{c}\text { Porcentaje } \\
\text { válido }\end{array}$ & $\begin{array}{c}\text { Porcentaje } \\
\text { acumulado }\end{array}$ \\
\hline Válido & En desacuerdo & 1 & 9,1 & 9,1 & 9,1 \\
& Ni de acuerdo ni en & 5 & 45,5 & 45,5 & 54,5 \\
& desacuerdo & & & & \\
De acuerdo & 5 & 45,5 & 45,5 & 100,0 \\
& Total & 11 & 100,0 & 100,0 & \\
\hline
\end{tabular}

Elaboración propia

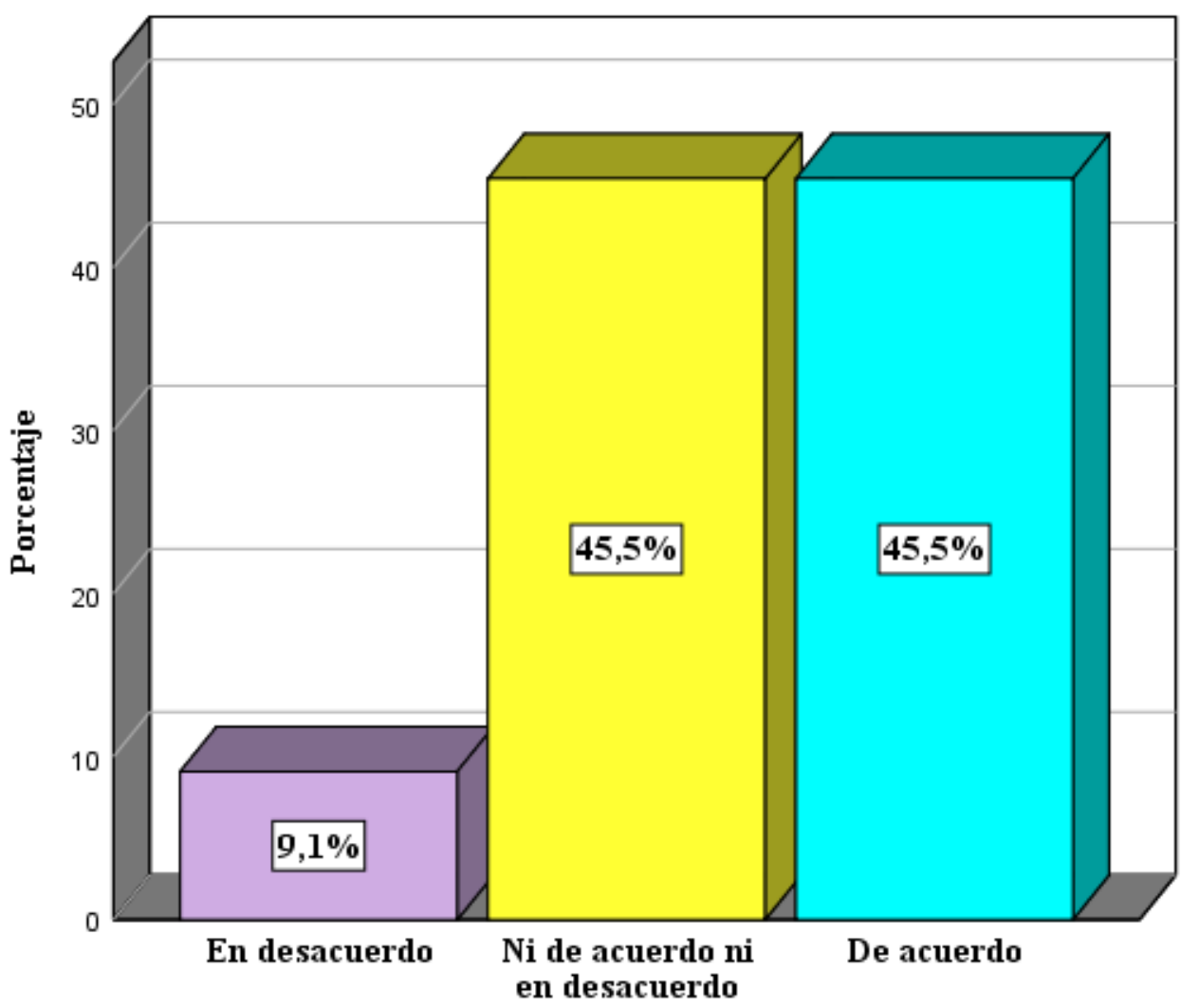

Figura 37. Los distribuidores cumplen con las expectativas en cuanto a traducción de literatura de ventas, instrucciones de uso o etiquetas.

Elaboración propia

Interpretación: En la afirmación 29 se aprecia que el 45,5\% de los representantes está de acuerdo en que los distribuidores cumplen con las expectativas en cuanto a traducción de literatura de ventas, instrucciones de uso o etiquetas. Por su parte, el otro $45,5 \%$ se muestra ni de acuerdo ni en desacuerdo acuerdo, y el restante $9,1 \%$ se muestra en desacuerdo. 


\section{- Y: Rendimiento en los mercados internacionales}

Tabla 33.

A30. Durante el periodo 2014-2018, la empresa ha estado satisfecha con el rendimiento del producto con respecto a la cuota de mercado.

\begin{tabular}{llcccc}
\hline & & & $\begin{array}{c}\text { Porcentaje } \\
\text { válido }\end{array}$ & $\begin{array}{c}\text { Porcentaje } \\
\text { acumulado }\end{array}$ \\
\hline Válido & En desacuerdo & 4 & 36,4 & 36,4 & 36,4 \\
& $\begin{array}{l}\text { Ni de acuerdo ni en } \\
\text { desacuerdo }\end{array}$ & 6 & 54,5 & 54,5 & 90,9 \\
& De acuerdo & 1 & & & \\
Total & 11 & 100,0 & 100,0 & \\
\hline
\end{tabular}

Elaboración propia

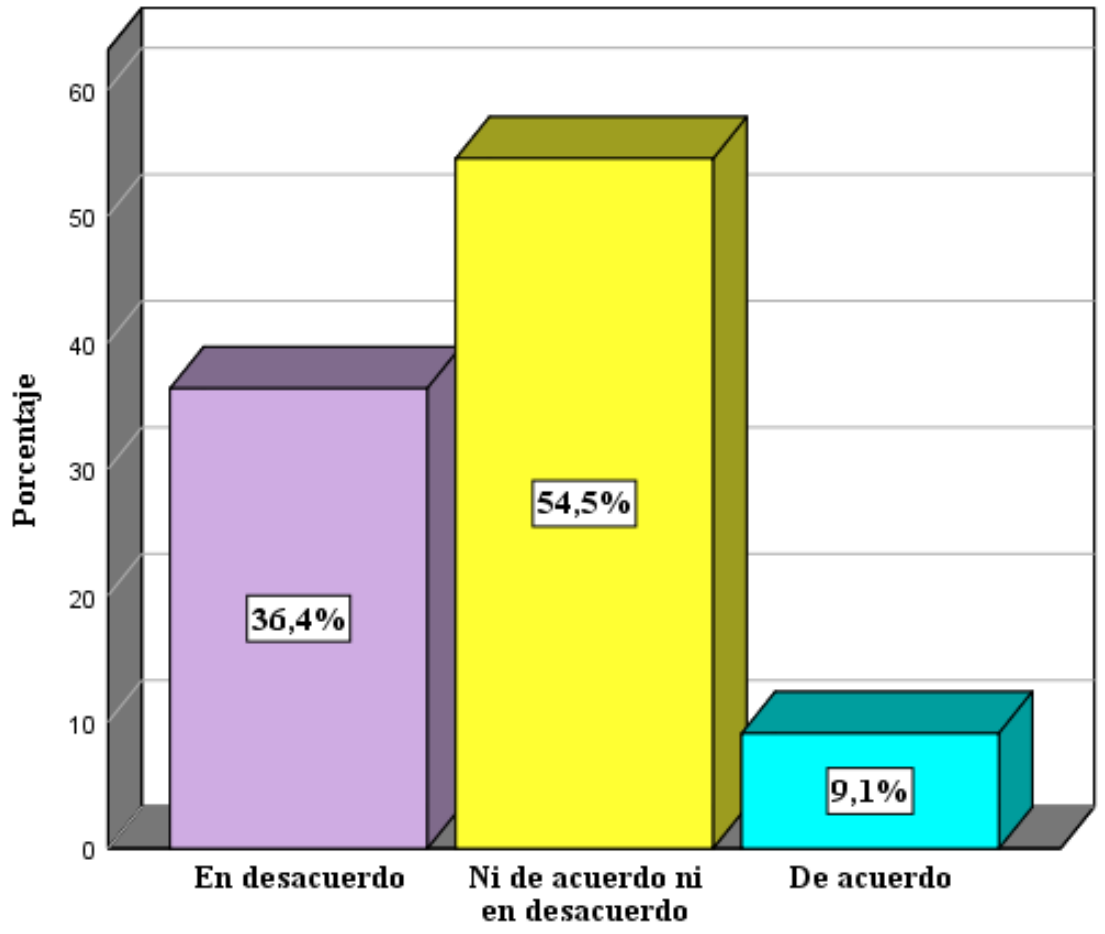

Figura 38. Durante el periodo 2014-2018, la empresa ha estado satisfecha con el rendimiento del producto con respecto a la cuota de mercado.

Elaboración propia

Interpretación: En la afirmación 30 se aprecia que en su mayoría el 54,5\% de los representantes no está de acuerdo ni en desacuerdo en que, durante el periodo 2014-2018, su empresa ha estado satisfecha con el rendimiento del producto con respecto a la cuota de mercado. Un $36,4 \%$ se muestra en desacuerdo, mientras que solo el $9,1 \%$ se muestra de acuerdo. 
Tabla 34.

A31. Durante el periodo 2014-2018, la empresa ha estado satisfecha con el rendimiento del producto con respecto al crecimiento de ventas en el mercado.

\begin{tabular}{llcccc}
\hline & & & $\begin{array}{c}\text { Porcentaje } \\
\text { válido }\end{array}$ & $\begin{array}{c}\text { Porcentaje } \\
\text { acumulado }\end{array}$ \\
\hline Válido & En desacuerdo & 2 & 18,2 & 18,2 & 18,2 \\
& Ni de acuerdo ni en & 7 & 63,6 & 63,6 & 81,8 \\
& desacuerdo & & & & 100,0 \\
De acuerdo & 2 & 18,2 & 18,2 & \\
Total & 11 & 100,0 & 100,0 & \\
\hline
\end{tabular}

Elaboración propia

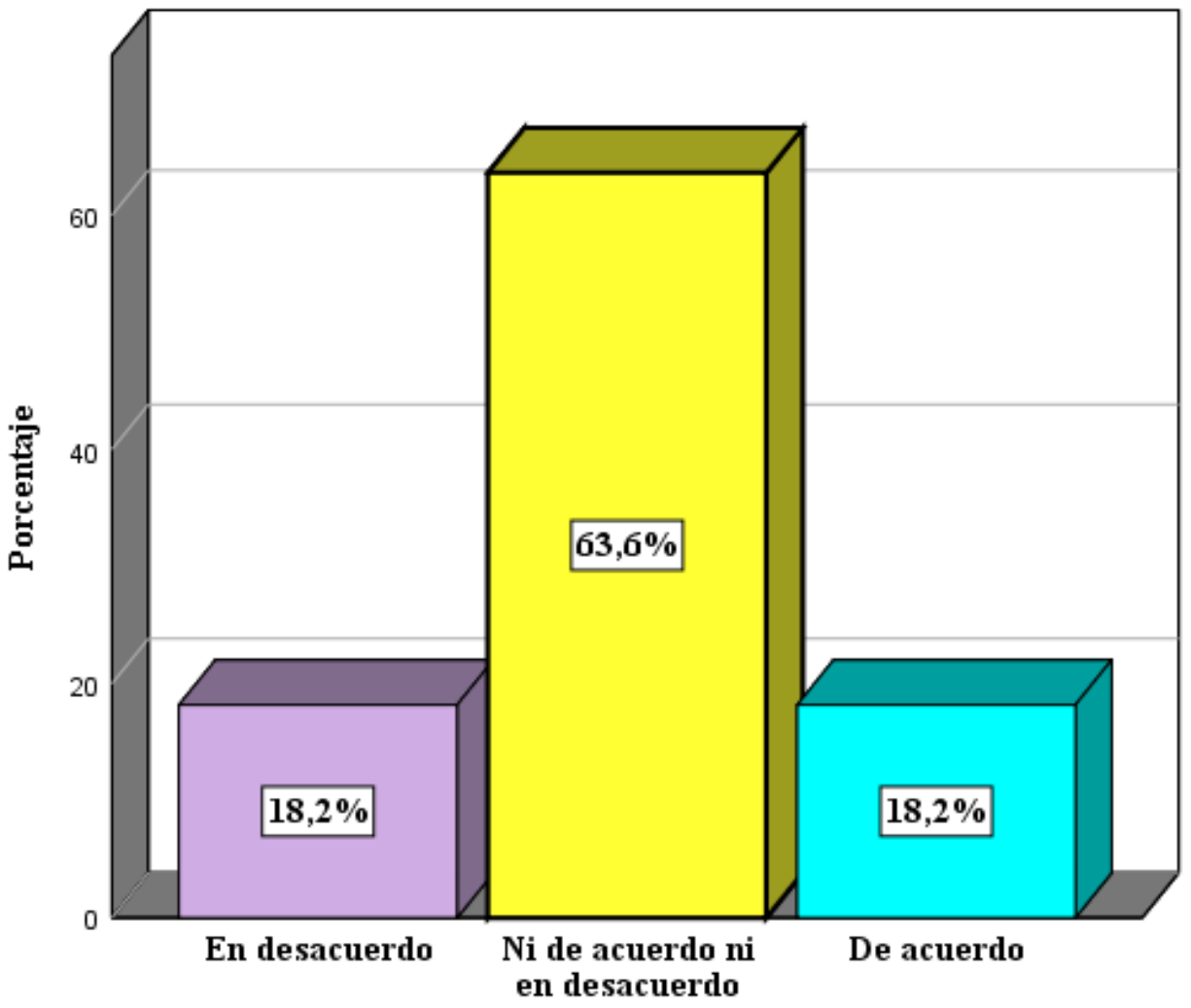

Figura 39. Durante el periodo 2014-2018, la empresa ha estado satisfecha con el rendimiento del producto con respecto al crecimiento de ventas en el mercado.

Elaboración propia

Interpretación: En la afirmación 31 se aprecia que en su gran mayoría el 63,6\% de los representantes no está de acuerdo ni en desacuerdo en que, durante el periodo 2014-2018, su empresa ha estado satisfecha con el rendimiento del producto con respecto al crecimiento de ventas en el mercado. Un $18,2 \%$ se muestra en desacuerdo, mientras que el otro $18,2 \%$ se muestra de acuerdo. 
Tabla 35.

A32. Durante el periodo 2014-2018, la empresa ha estado satisfecha con el rendimiento de sus productos con respecto a la rentabilidad antes de impuestos en el mercado.

\begin{tabular}{|c|c|c|c|c|c|}
\hline & & Frecuencia & Porcentaje & $\begin{array}{c}\text { Porcentaje } \\
\text { válido }\end{array}$ & $\begin{array}{l}\text { Porcentaje } \\
\text { acumulado } \\
\end{array}$ \\
\hline \multirow[t]{4}{*}{ Válido } & En desacuerdo & 1 & 9,1 & 9,1 & 9,1 \\
\hline & $\begin{array}{l}\text { Ni de acuerdo ni en } \\
\text { desacuerdo }\end{array}$ & 6 & 54,5 & 54,5 & 63,6 \\
\hline & De acuerdo & 4 & 36,4 & 36,4 & 100,0 \\
\hline & Total & 11 & 100,0 & 100,0 & \\
\hline
\end{tabular}

Elaboración propia

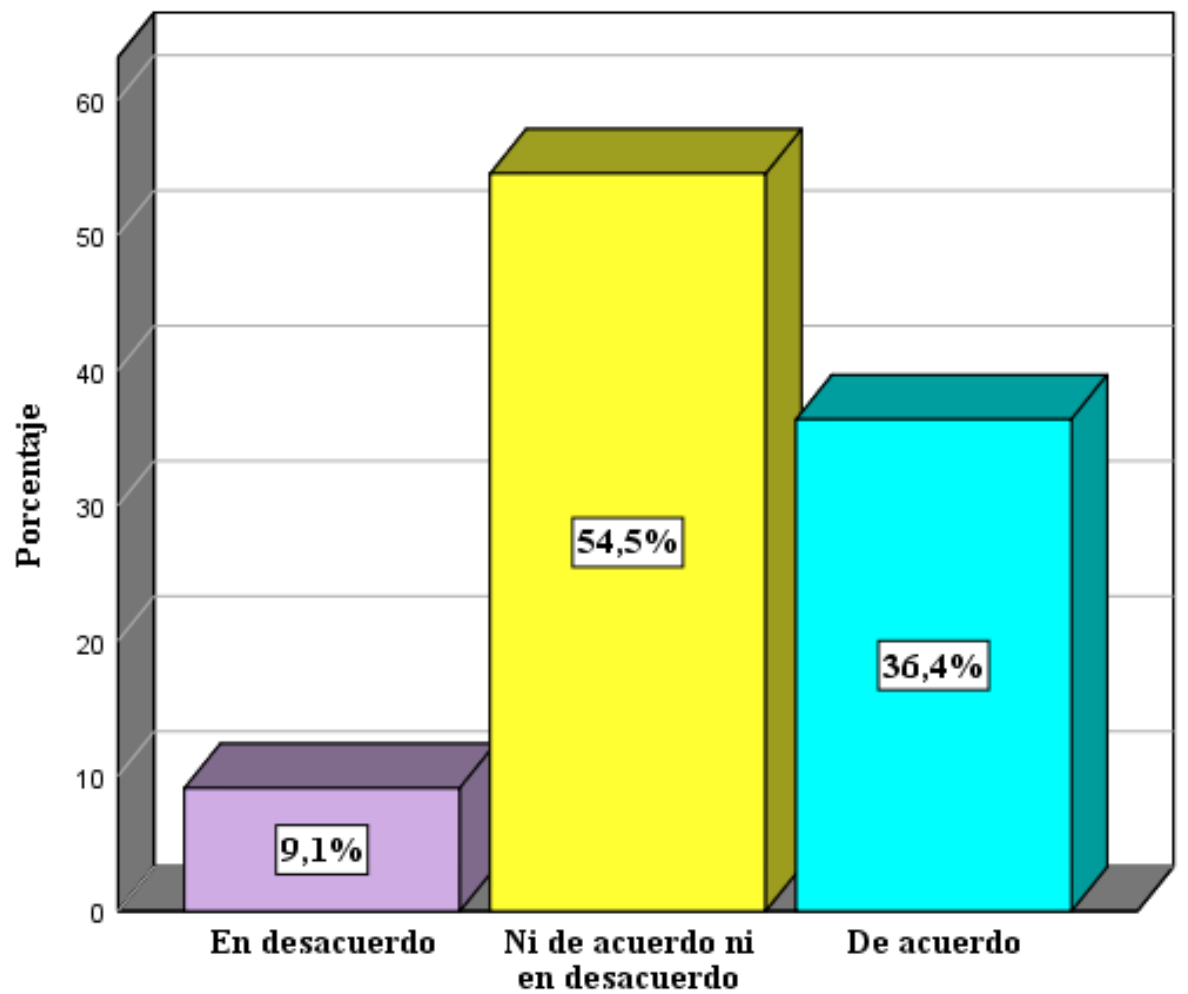

Figura 40. Durante el periodo 2014-2018, la empresa ha estado satisfecha con el rendimiento de sus productos con respecto a la rentabilidad antes de impuestos en el mercado.

\section{Elaboración propia}

Interpretación: En la afirmación 32 se aprecia que en su mayoría el 54,5\% de los representantes no está de acuerdo ni en desacuerdo en que, durante el periodo 2014-2018, su empresa ha estado satisfecha con el rendimiento de sus productos con respecto a la rentabilidad antes de impuestos en el mercado. Un 36,4\% se muestra de acuerdo, mientras que solo el $9,1 \%$ se muestra en desacuerdo. 
Tabla 36.

A33. Durante el periodo 2014-2018, la empresa ha estado satisfecha con el crecimiento de las ventas en su principal mercado de exportación en comparación con sus principales competidores.

\begin{tabular}{llcccc}
\hline & & & $\begin{array}{c}\text { Porcentaje } \\
\text { válido }\end{array}$ & $\begin{array}{c}\text { Porcentaje } \\
\text { acumulado }\end{array}$ \\
\hline Válido & En desacuerdo & 6 & 54,5 & 54,5 & 54,5 \\
& Ni de acuerdo ni en & 5 & 45,5 & 45,5 & 100,0 \\
& $\begin{array}{l}\text { desacuerdo } \\
\text { Total }\end{array}$ & 11 & 100,0 & 100,0 & \\
\hline
\end{tabular}

Elaboración propia

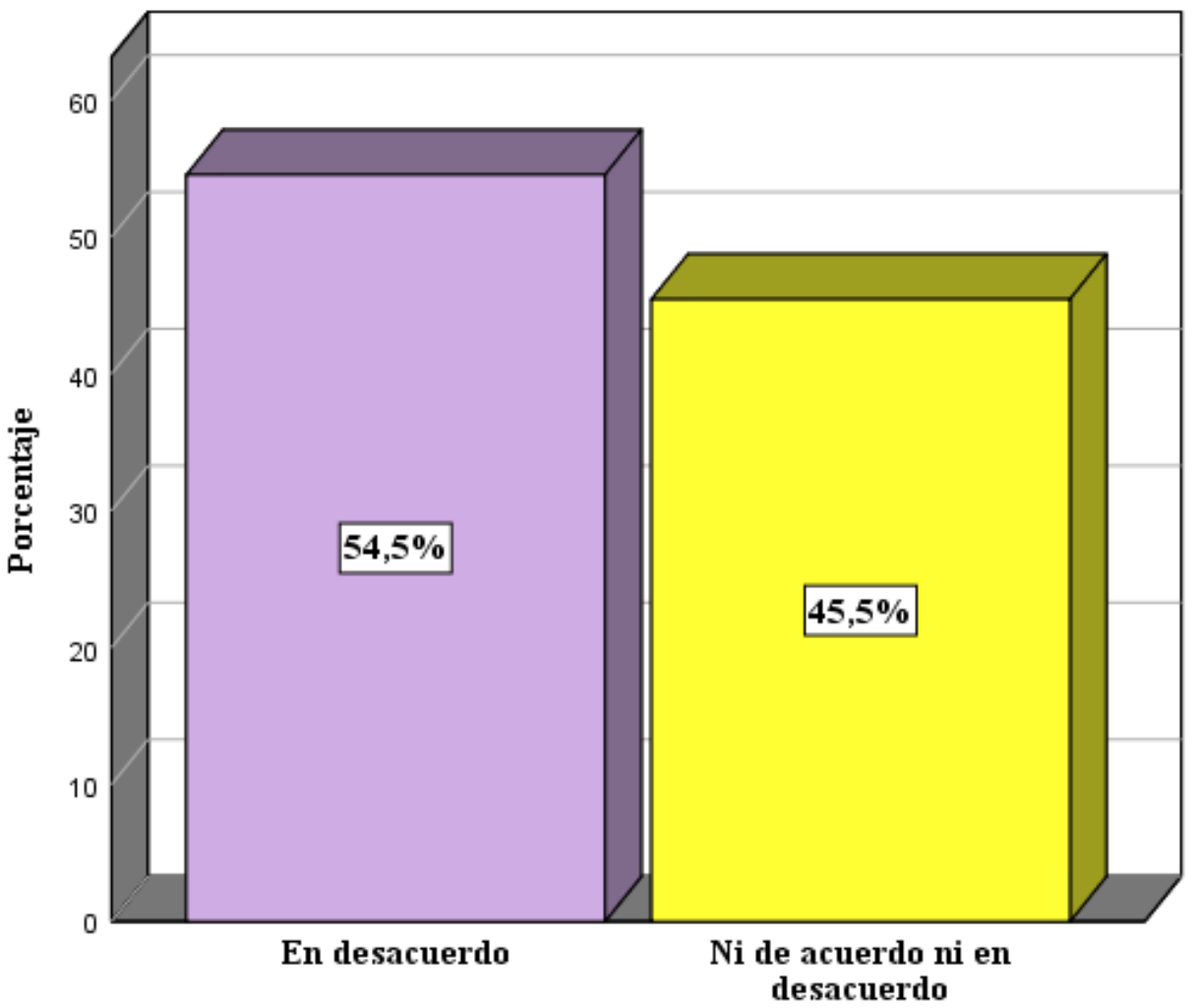

Figura 41. Durante el periodo 2014-2018, la empresa ha estado satisfecha con el crecimiento de las ventas en su principal mercado de exportación en comparación con sus principales competidores.

Elaboración propia

Interpretación: En la afirmación 33 se observa que principalmente el 54,4\% de los representantes está en desacuerdo en que durante el periodo 2014-2018, su empresa ha estado satisfecha con el crecimiento de las ventas en su principal mercado de exportaciones en comparación con sus principales competidores. Por su parte, el restante $45,5 \%$ se muestra ni de acuerdo ni en desacuerdo. 
Tabla 37.

A34. Durante el periodo 2014-2018, la empresa ha estado satisfecha con el éxito de sus productos en su principal mercado de exportación.

\begin{tabular}{|c|c|c|c|c|c|}
\hline & & Frecuencia & Porcentaje & $\begin{array}{c}\text { Porcentaje } \\
\text { válido }\end{array}$ & $\begin{array}{l}\text { Porcentaje } \\
\text { acumulado }\end{array}$ \\
\hline \multirow[t]{4}{*}{ Válido } & En desacuerdo & 3 & 27,3 & 27,3 & 27,3 \\
\hline & $\begin{array}{l}\text { Ni de acuerdo ni en } \\
\text { desacuerdo }\end{array}$ & 6 & 54,5 & 54,5 & 81,8 \\
\hline & De acuerdo & 2 & 18,2 & 18,2 & 100,0 \\
\hline & Total & 11 & 100,0 & 100,0 & \\
\hline
\end{tabular}

Elaboración propia

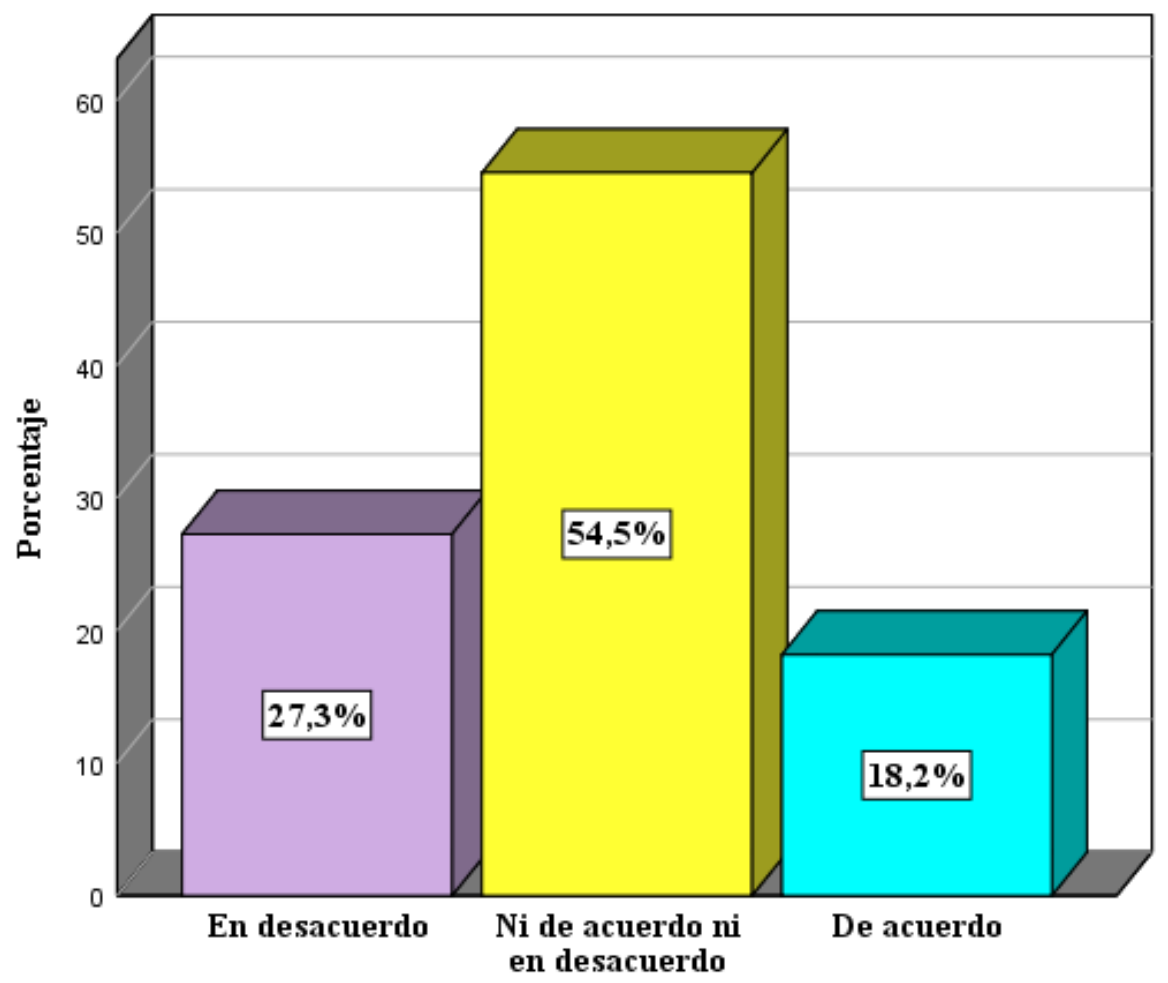

Figura 42. Durante el periodo 2014-2018, la empresa ha estado satisfecha con el éxito de sus productos en su principal mercado de exportación.

Elaboración Propia

Interpretación: En la afirmación 34 se observa que en su mayoría el 54,5\% de los representantes no está de acuerdo ni en desacuerdo en que, durante el periodo 2014-2018, su empresa ha estado satisfecha con el éxito de sus productos en su principal mercado de exportación. Un $27,3 \%$ se muestra en desacuerdo, mientras que el restante $18,2 \%$ se muestra de acuerdo. 
Tabla 38.

A35. Durante el periodo 2014-2018, la empresa ha estado satisfecha con el rendimiento total de inversión (ROI) de sus productos en su principal mercado de exportación.

\begin{tabular}{|c|c|c|c|c|c|}
\hline & & Frecuencia & Porcentaje & $\begin{array}{c}\text { Porcentaje } \\
\text { válido }\end{array}$ & $\begin{array}{l}\text { Porcentaje } \\
\text { acumulado } \\
\end{array}$ \\
\hline \multirow[t]{4}{*}{ Válido } & En desacuerdo & 2 & 18,2 & 18,2 & 18,2 \\
\hline & $\begin{array}{l}\text { Ni de acuerdo ni en } \\
\text { desacuerdo }\end{array}$ & 8 & 72,7 & 72,7 & 90,9 \\
\hline & De acuerdo & 1 & 9,1 & 9,1 & 100,0 \\
\hline & Total & 11 & 100,0 & 100,0 & \\
\hline
\end{tabular}

Elaboración propia

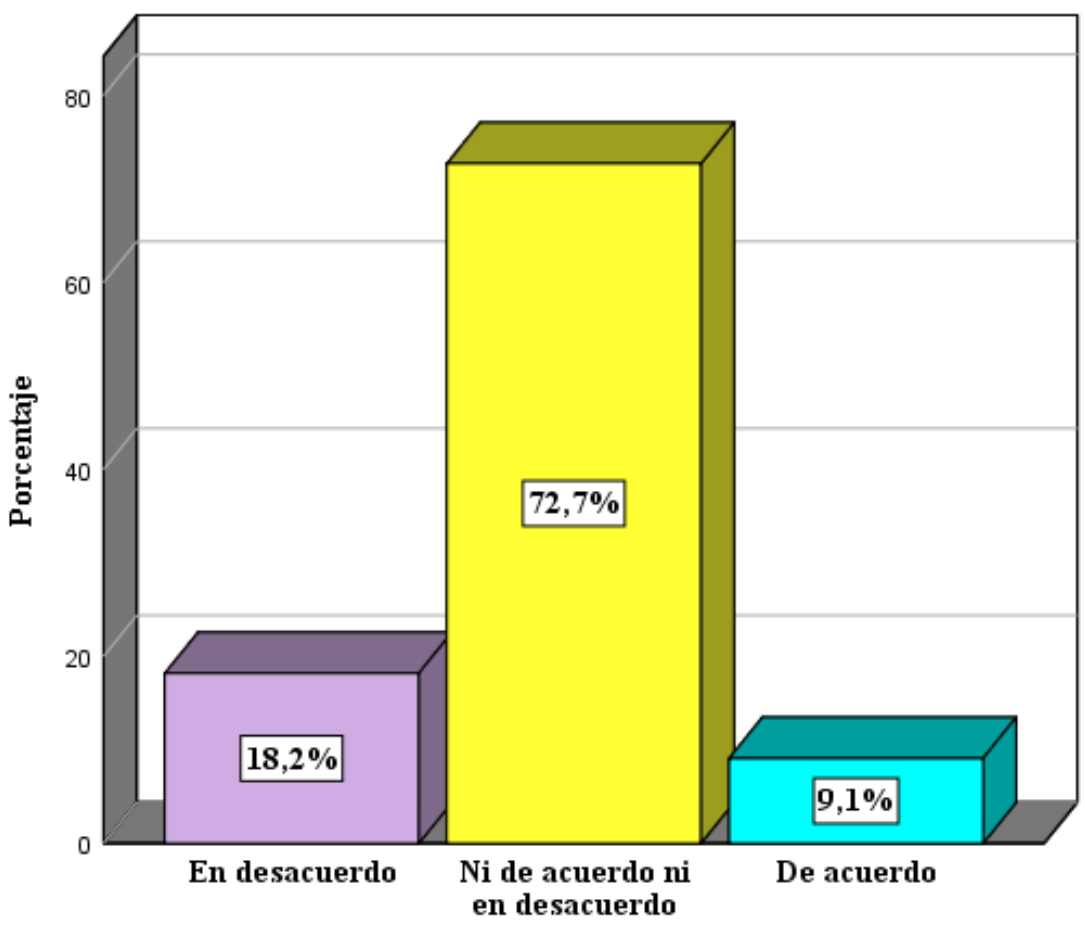

Figura 43. Durante el periodo 2014-2018, la empresa ha estado satisfecha con el rendimiento total de inversión $(\mathrm{ROI})$ de sus productos en su principal mercado de exportación.

\section{Elaboración propia}

Interpretación: En la afirmación 35 se observa que predominantemente el 72,7\% de los representantes no está de acuerdo ni en desacuerdo en que, durante el periodo 2014-2018, su empresa ha estado satisfecha con el rendimiento total de inversión (ROI) de sus productos en su principal mercado de exportación. Un 18,2\% se muestra en desacuerdo, mientras que el restante $9,1 \%$ se muestra de acuerdo. 


\subsubsection{Análisis de Estrategia de Negocios.}

Tabla 39.

$X$. Estrategia de Negocios.

\begin{tabular}{llcccc}
\hline & & & Porcentaje & Porcentaje \\
válido & Frecuencia & Porcentaje & $\begin{array}{c}\text { Pacumulado } \\
\text { ando }\end{array}$ \\
\cline { 2 - 5 } & En desacuerdo & 1 & 9,1 & 9,1 & 9,1 \\
& Ni de acuerdo ni en & 9 & 81,8 & 81,8 & 90,9 \\
& desacuerdo & & & & \\
& De acuerdo & 1 & 9,1 & 9,1 & 100,0 \\
& Total & 11 & 100,0 & 100,0 & \\
\hline
\end{tabular}

Elaboración propia

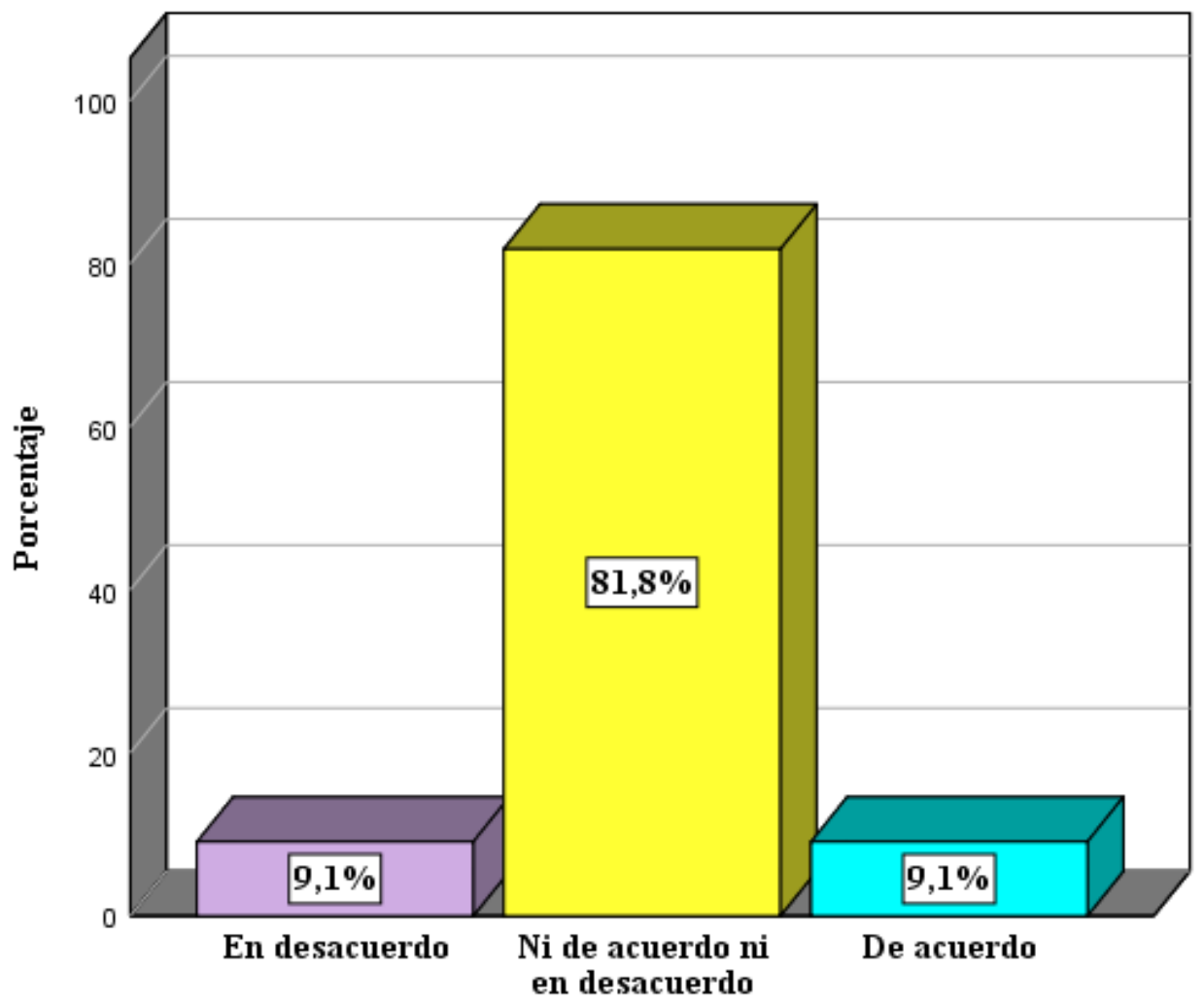

Figura 44. Estrategia de Negocios

Elaboración propia

Interpretación: En la tabla y en el gráfico se aprecia que predominantemente el $81,8 \%$ de los representantes no está de acuerdo ni en desacuerdo en que, del 2014 al 2018, se ha dado adecuadas estrategias de negocios en las empresas peruanas fabricantes de máquinas para la industria panadera. Por otro lado, el 9,1\% se muestra de acuerdo, mientras que el otro $9,1 \%$ se muestra en desacuerdo. 


\subsubsection{Análisis de Competencia Tecnológica Global.}

Tabla 40.

X1. Competencia Tecnológica Global.

\begin{tabular}{llcccc}
\hline & & & Porcentaje & Porcentaje \\
& & Frecuencia & Porcentaje & $\begin{array}{c}\text { válido } \\
\text { acumulado }\end{array}$ \\
\hline Válido & $\begin{array}{l}\text { Ni de acuerdo ni en } \\
\text { desacuerdo }\end{array}$ & 9 & 81,8 & 81,8 & 81,8 \\
& & & & \\
& De acuerdo & 2 & 18,2 & 18,2 & 100,0 \\
& Total & 11 & 100,0 & 100,0 & \\
\hline
\end{tabular}

Elaboración propia

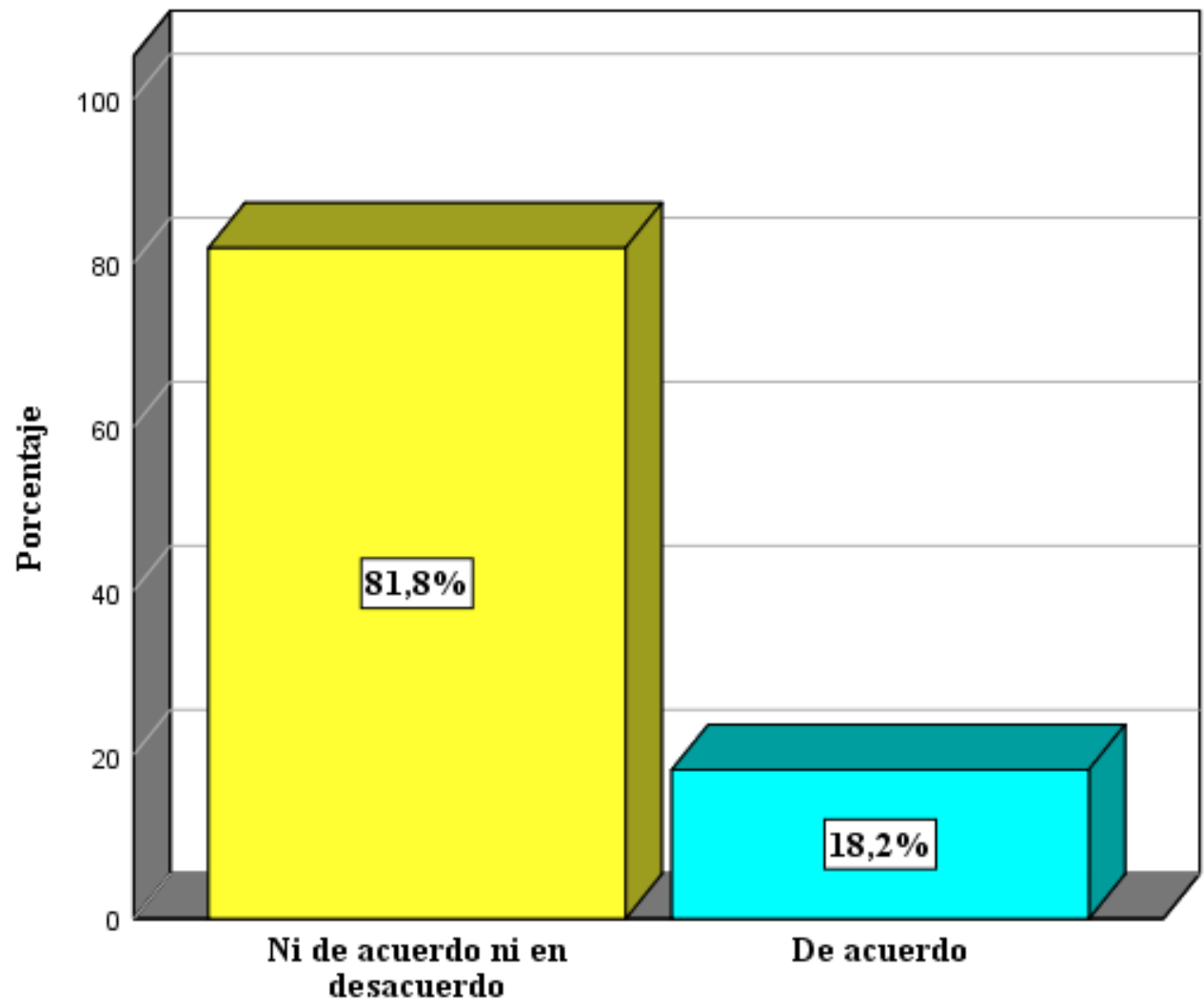

Figura 45. Competencia Tecnológica Global

Elaboración propia

Interpretación: En la tabla y en el gráfico se aprecia que en su gran mayoría el 81,8\% de los representantes no está de acuerdo ni en desacuerdo en que, del 2014 al 2018, se ha dado una adecuada competencia tecnológica global en las empresas peruanas fabricantes de máquinas para la industria panadera. Mientras que el 18,2\% se muestra de acuerdo 


\subsubsection{Análisis de Desarrollo de Productos Únicos.}

Tabla 41.

X2. Desarrollo de Productos Únicos.

\begin{tabular}{|c|c|c|c|c|c|}
\hline & & Frecuencia & Porcentaje & $\begin{array}{c}\text { Porcentaje } \\
\text { válido }\end{array}$ & $\begin{array}{l}\text { Porcentaje } \\
\text { acumulado }\end{array}$ \\
\hline \multirow[t]{3}{*}{ Válido } & En desacuerdo & 2 & 18,2 & 18,2 & 18,2 \\
\hline & $\begin{array}{l}\text { Ni de acuerdo ni en } \\
\text { desacuerdo }\end{array}$ & 9 & 81,8 & 81,8 & 100,0 \\
\hline & Total & 11 & 100,0 & 100,0 & \\
\hline
\end{tabular}

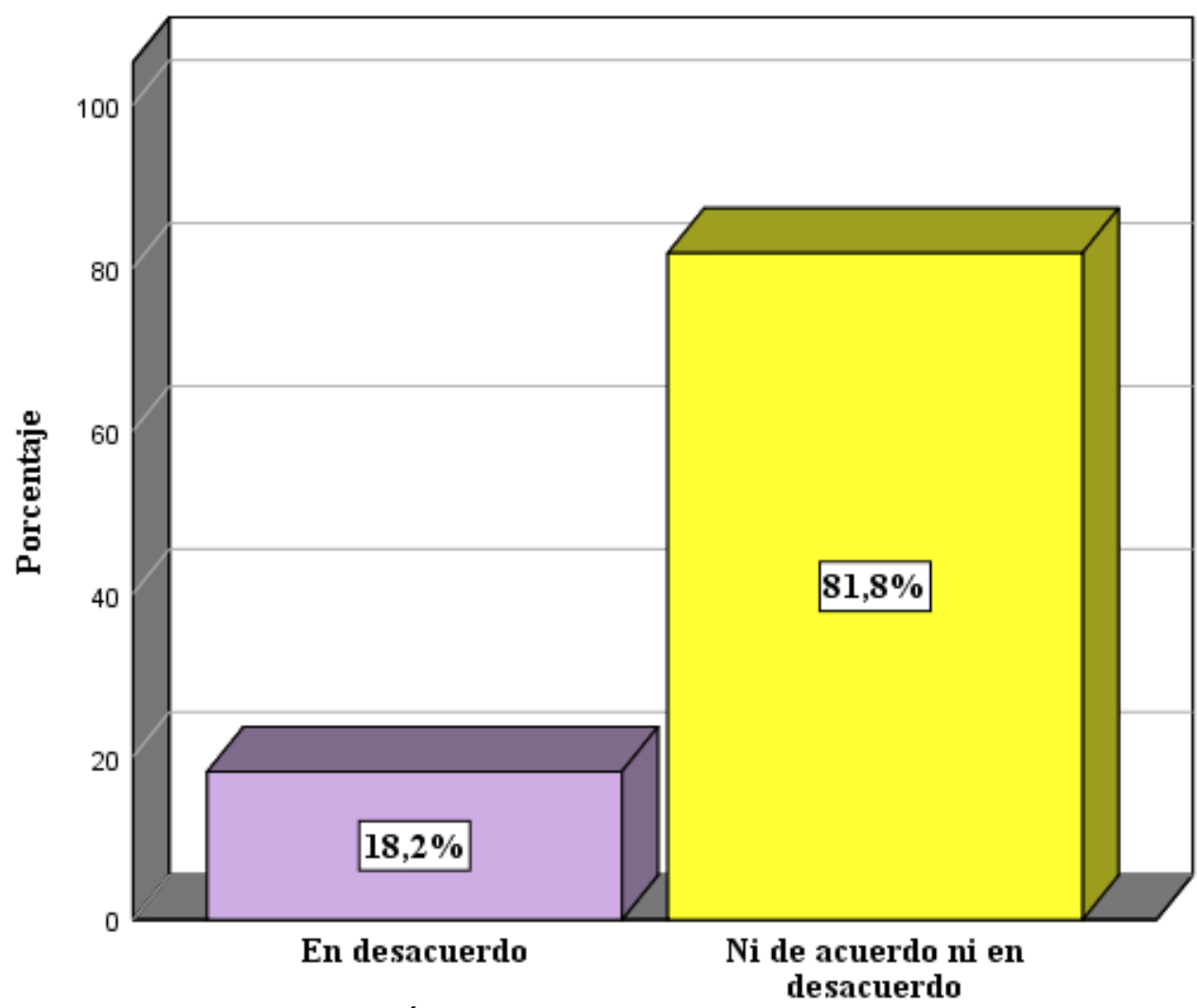

Figura 46. Desarrollo de Productos Únicos

Elaboración propia

Interpretación: En la tabla y en el gráfico se observa que en su gran mayoría el 81,8\% de los representantes no está de acuerdo ni en desacuerdo en que, del 2014 al 2018, se ha dado un adecuado desarrollo de productos únicos en las empresas peruanas fabricantes de máquinas para la industria panadera. Mientras que el 18,2\% se muestra en desacuerdo. 


\subsubsection{Análisis de Enfoque de Calidad.}

Tabla 42.

X3. Enfoque de Calidad.

\begin{tabular}{|c|c|c|c|c|c|}
\hline & & Frecuencia & Porcentaje & $\begin{array}{c}\text { Porcentaje } \\
\text { válido }\end{array}$ & $\begin{array}{l}\text { Porcentaje } \\
\text { acumulado }\end{array}$ \\
\hline \multirow[t]{4}{*}{ Válido } & En desacuerdo & 1 & 9,1 & 9,1 & 9,1 \\
\hline & $\begin{array}{l}\text { Ni de acuerdo ni en } \\
\text { desacuerdo }\end{array}$ & 7 & 63,6 & 63,6 & 72,7 \\
\hline & De acuerdo & 3 & 27,3 & 27,3 & 100,0 \\
\hline & Total & 11 & 100,0 & 100,0 & \\
\hline
\end{tabular}

Elaboración propia

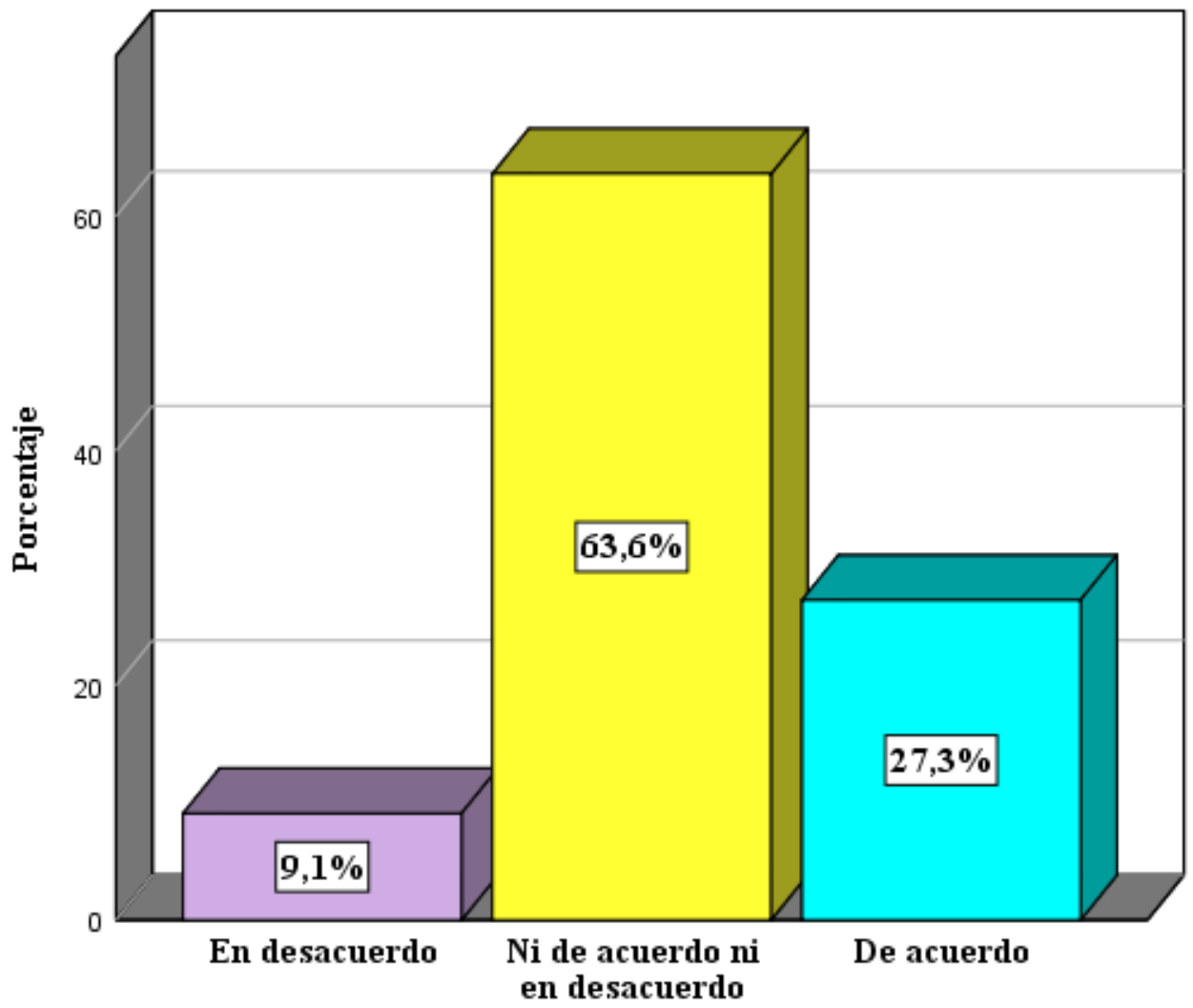

Figura 47. Enfoque de Calidad

Elaboración propia

Interpretación: En la tabla y en el gráfico se aprecia que en su mayoría el $81,8 \%$ de los representantes no está de acuerdo ni en desacuerdo en que, del 2014 al 2018, se ha dado un adecuado enfoque de calidad en las empresas peruanas fabricantes de máquinas para la industria panadera. Por otro lado, el $27,3 \%$ se muestra de acuerdo, mientras que el restante $9,1 \%$ se muestra en desacuerdo. 


\subsubsection{Análisis de Competencias de los Distribuidores.}

Tabla 43.

X4. Competencias de los Distribuidores.

\begin{tabular}{llcccc}
\hline & Frecuencia & Porcentaje & $\begin{array}{c}\text { Porcentaje } \\
\text { válido }\end{array}$ & $\begin{array}{c}\text { Porcentaje } \\
\text { acumulado }\end{array}$ \\
\hline Válido & En desacuerdo & 1 & 9,1 & 9,1 & 9,1 \\
& Ni de acuerdo ni en & 9 & 81,8 & 81,8 & 90,9 \\
& desacuerdo & & & & \\
De acuerdo & 1 & 9,1 & 9,1 & 100,0 \\
Total & 11 & 100,0 & 100,0 & \\
\hline
\end{tabular}

Elaboración propia

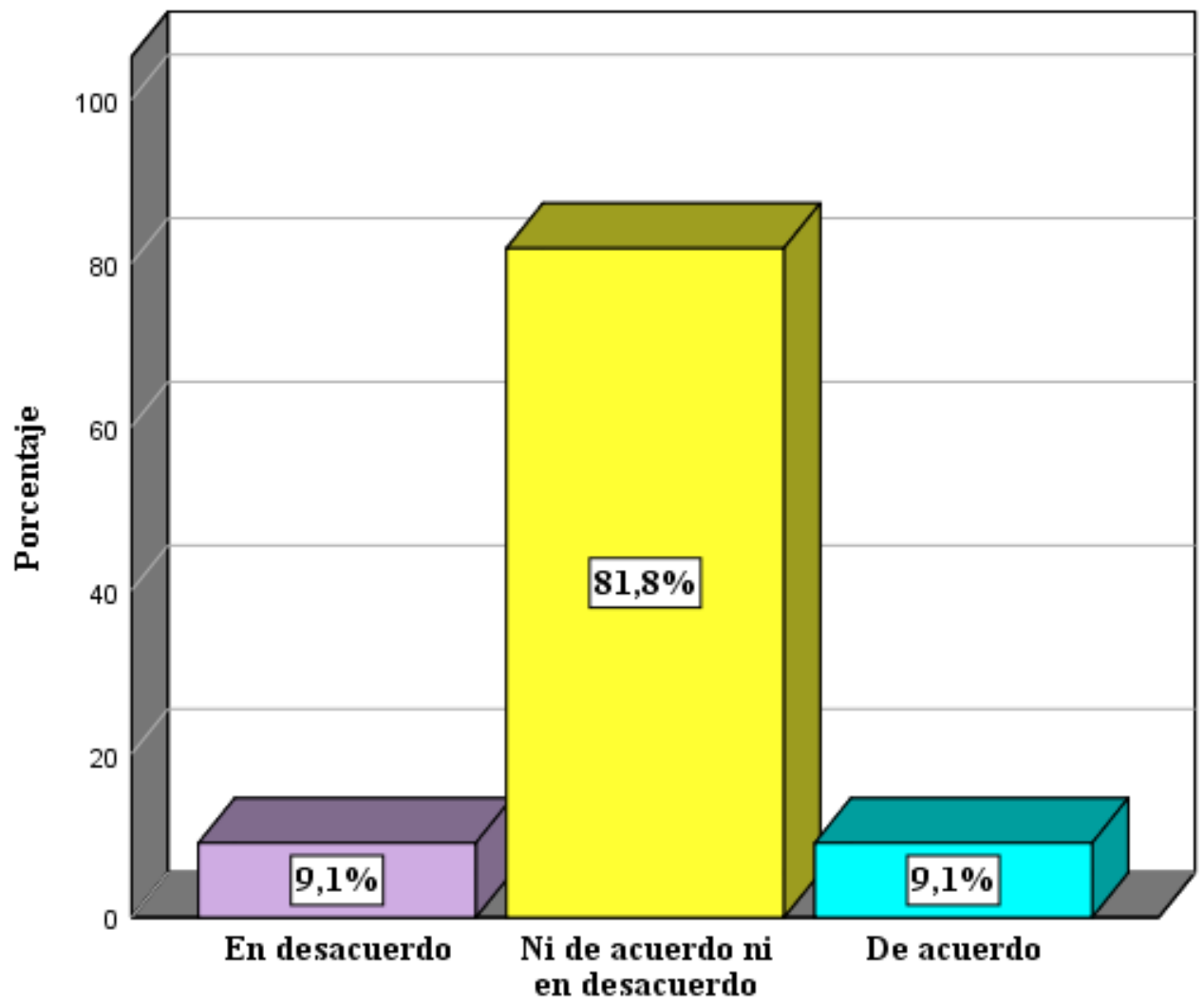

Figura 48. Competencias de los Distribuidores

Elaboración propia

Interpretación: En la tabla y en el gráfico se observa que en su gran mayoría el 81,8\% de los representantes no está de acuerdo ni en desacuerdo en que, del 2014 al 2018, se ha dado adecuadas competencias de los distribuidores para las empresas peruanas fabricantes de máquinas para la industria panadera. Por otro lado, el 9,1\% se muestra de acuerdo, mientras que el otro $9,1 \%$ se muestra en desacuerdo. 


\subsubsection{Análisis de Rendimiento de las Exportaciones.}

Tabla 44.

Y. Rendimiento de las Exportaciones.

\begin{tabular}{|c|c|c|c|c|c|}
\hline & & Frecuencia & Porcentaje & $\begin{array}{c}\text { Porcentaje } \\
\text { válido }\end{array}$ & $\begin{array}{l}\text { Porcentaje } \\
\text { acumulado }\end{array}$ \\
\hline \multirow[t]{4}{*}{ Válido } & En desacuerdo & 2 & 18,2 & 18,2 & 18,2 \\
\hline & $\begin{array}{l}\text { Ni de acuerdo ni en } \\
\text { desacuerdo }\end{array}$ & 7 & 63,6 & 63,6 & 81,8 \\
\hline & De acuerdo & 2 & 18,2 & 18,2 & 100,0 \\
\hline & Total & 11 & 100,0 & 100,0 & \\
\hline
\end{tabular}

Elaboración propia

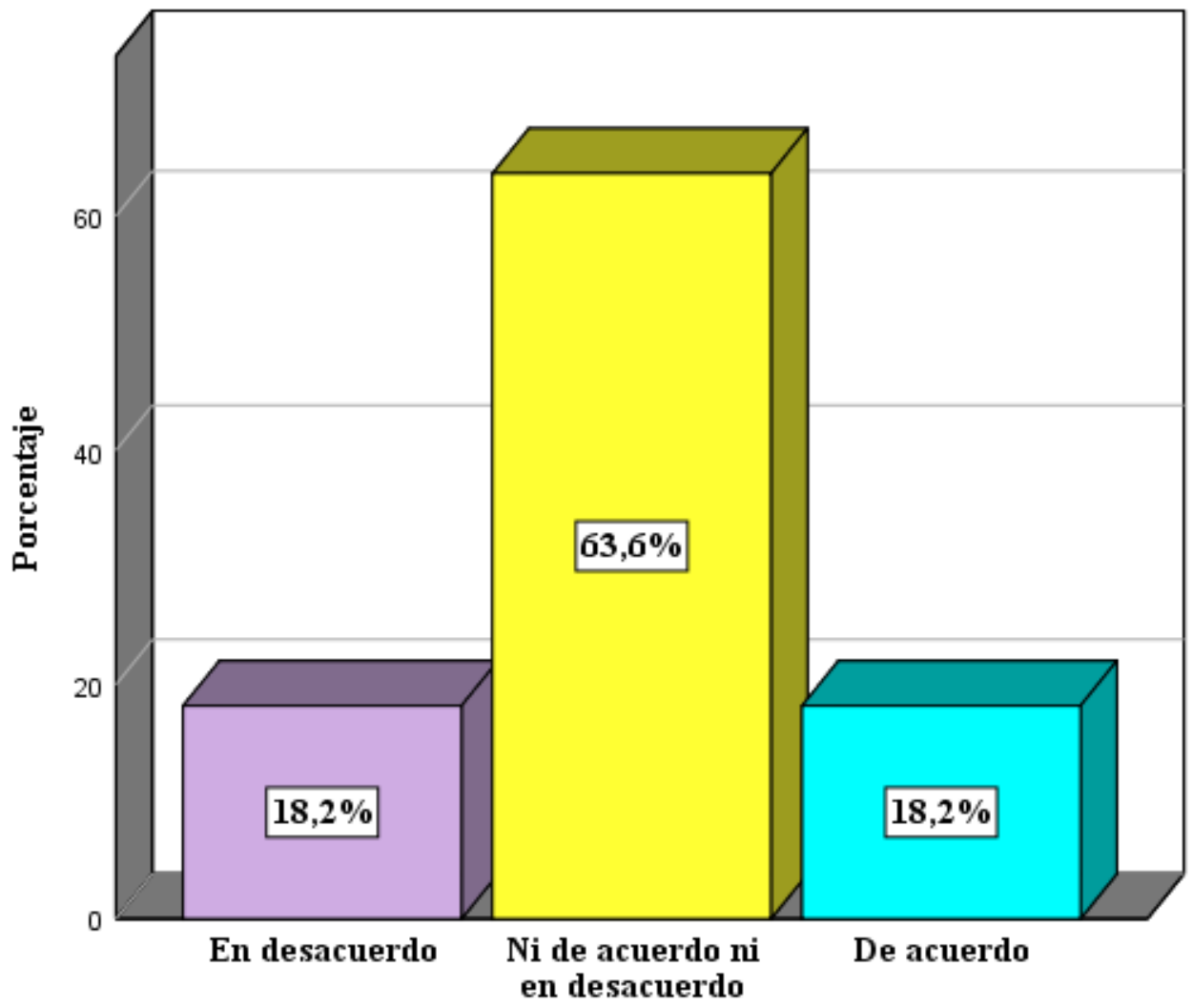

Figura 49. Rendimiento de las Exportaciones

Elaboración propia

Interpretación: En la tabla y en el gráfico se aprecia que en su mayoría el 63,6\% de los representantes no está de acuerdo ni en desacuerdo en que, del 2014 al 2018, se ha dado un satisfactorio rendimiento de las exportaciones de las empresas peruanas fabricantes de máquinas para la industria panadera. Por otro lado, el 18,2\% se muestra de acuerdo, mientras que el otro $18,2 \%$ se muestra en desacuerdo. 


\subsection{Pruebas de hipótesis}

Con el propósito de analizar si existe relación según las hipótesis propuestas se realizó en primer lugar la prueba de normalidad de Shapiro-Wilk, para analizar si los datos evaluados tienen distribución normal. Si tienen distribución normal entonces se utiliza la prueba Pearson. De no tener distribución normal se utiliza la prueba de Spearman. Para la interpretación de la intensidad de la correlación se utilizó los siguientes criterios.

Tabla 45.

Criterios para interpretar la correlación.

\begin{tabular}{cl}
\hline Valor & \multicolumn{1}{c}{ Significado } \\
\hline-1 & Correlación negativa perfecta \\
$-0,9$ a $-0,99$ & Correlación negativa muy alta \\
$-0,7$ a $-0,89$ & Correlación negativa alta \\
$-0,4$ a $-0,69$ & Correlación negativa moderada \\
$-0,2$ a $-0,39$ & Correlación negativa baja \\
$-0,01$ a $-0,19$ & Correlación negativa muy baja \\
0 & Correlación nula \\
0,01 a 0,19 & Correlación positiva muy baja \\
0,2 a 0,39 & Correlación positiva baja \\
0,4 a 0,69 & Correlación positiva moderada \\
0,7 a 0,89 & Correlación positiva alta \\
0,9 a 0,99 & Correlación positiva muy alta \\
1 & Correlación positiva perfecta \\
\hline
\end{tabular}

Elaboración propia. Basado en: "The Spearman rank correlation coefficient between intuitionistic fuzzy sets” por Szmidt, E., y Kacprzyk, J., 2010. 


\subsubsection{Pruebas de normalidad.}

\section{Hipótesis de normalidad}

H1: No existe normalidad en los datos evaluados

H0: Existe normalidad en los datos evaluados

\section{Nivel de significancia}

Para esta investigación se consideró el 0,05 (5\% de error).

\section{Regla para decidir}

Si Sig. $<0,05$ se rechaza la $\mathrm{HO}$

Si Sig. > 0,05 no se rechaza la $\mathrm{HO}$

Tabla 46.

Pruebas de normalidad de Shapiro-Wilk

\begin{tabular}{lccc}
\hline & \multicolumn{3}{c}{ Shapiro-Wilk } \\
\cline { 2 - 4 } & Estadístico & gl & Sig. \\
\hline Estrategia de negocios & 0,934 & 11 & 0,456 \\
Competencia Tecnológica Global & 0,864 & 11 & 0,065 \\
Desarrollo de Productos Únicos & 0,929 & 11 & 0,403 \\
Enfoque de Calidad & 0,871 & 11 & 0,081 \\
Competencias de los distribuidores & 0,919 & 11 & 0,312 \\
Rendimiento de las exportaciones & 0,968 & 11 & 0,863 \\
\hline
\end{tabular}

Con un nivel de significancia de 0,05 existe distribución normal en todas las distribuciones analizadas pues cada una de ellas tiene un resultado de significancia mayor a 0,05. De manera que se utilizó la prueba de Pearson para realizar cada prueba de hipótesis. 


\subsubsection{Pruebas de hipótesis general.}

Existe relación entre las estrategias de negocio y el rendimiento de las exportaciones de empresas peruanas fabricantes de máquinas para la industria panadera del 2014 al 2018.

\section{Hipótesis}

$\mathrm{HO}$ : No existe relación entre las estrategias de negocio y el rendimiento de las exportaciones de empresas peruanas fabricantes de máquinas para la industria panadera del 2014 al 2018.

$\mathrm{H} 1$ : Existe relación entre las estrategias de negocio y el rendimiento de las exportaciones de empresas peruanas fabricantes de máquinas para la industria panadera del 2014 al 2018.

\section{Nivel de significancia}

Para esta investigación se consideró el 0,05.

\section{Estadístico de prueba}

Tabla 47.

Correlación de Pearson entre estrategias de negocio y el rendimiento de las exportaciones

\begin{tabular}{|c|c|c|c|}
\hline & & $\begin{array}{c}\text { Estrategia de } \\
\text { negocios }\end{array}$ & $\begin{array}{c}\text { Rendimiento } \\
\text { de las } \\
\text { exportaciones }\end{array}$ \\
\hline \multirow[t]{3}{*}{ Estrategia de negocios } & Correlación de Pearson & 1 & $0,970^{\star *}$ \\
\hline & Sig. (bilateral) & & 0,000 \\
\hline & $\mathrm{N}$ & 11 & 11 \\
\hline \multirow{3}{*}{$\begin{array}{l}\text { Rendimiento de las } \\
\text { exportaciones }\end{array}$} & Correlación de Pearson & $0,970^{\star *}$ & 1 \\
\hline & Sig. (bilateral) & 0,000 & \\
\hline & $\mathrm{N}$ & 11 & 11 \\
\hline
\end{tabular}

**. La correlación es significativa en el nivel 0,01 (bilateral).

\section{Decisión}

La significancia dio un resultado de 0,000 , lo cual indica que se rechaza la hipótesis nula y por tanto existe relación entre las estrategias de negocio y el rendimiento de las exportaciones de empresas peruanas fabricantes de máquinas para la industria panadera del 2014 al 2018. Por su parte, el coeficiente de correlación fue 0,970; de manera que la relación hallada tiene 
intensidad positiva muy alta. Este resultado es respaldado por Knight, G \& Cavusgil, T. (2004), puesto que su investigación sobre la internacionalización de empresas se centra en el rol de las estrategias de negocios para el mejor rendimiento de una empresa en el mercado internacional.

\subsubsection{Pruebas de hipótesis específica 1.}

Existe relación entre la competencia tecnológica global y el rendimiento de las exportaciones de empresas peruanas fabricantes de máquinas para la industria panadera del 2014 al 2018.

\section{Hipótesis}

H0: No existe relación entre la competencia tecnológica global y el rendimiento de las exportaciones de empresas peruanas fabricantes de máquinas para la industria panadera del 2014 al 2018.

H1: Existe relación entre la competencia tecnológica global y el rendimiento de las exportaciones de empresas peruanas fabricantes de máquinas para la industria panadera del 2014 al 2018.

\section{Nivel de significancia}

Para esta investigación se consideró el 0,05.

\section{Estadístico de prueba}

Tabla 48.

Correlación de Pearson entre la competencia tecnológica global y el rendimiento de las exportaciones

\begin{tabular}{llcc}
\hline & & $\begin{array}{c}\text { Competencia } \\
\text { Tecnológica } \\
\text { Global }\end{array}$ & $\begin{array}{c}\text { Rendimiento } \\
\text { de las } \\
\text { exportaciones }\end{array}$ \\
\hline $\begin{array}{l}\text { Competencia Tecnológica } \\
\text { Global }\end{array}$ & Correlación de Pearson & 1 & $0,781^{* *}$ \\
& Sig. (bilateral) & 11 & 0,005 \\
& $\mathrm{~N}$ & $0,781^{* *}$ & 11 \\
\hline $\begin{array}{l}\text { Rendimiento de las } \\
\text { exportaciones }\end{array}$ & Correlación de Pearson & & 1 \\
& Sig. (bilateral) & 0,005 & 11 \\
\hline
\end{tabular}

${ }^{* *}$. La correlación es significativa en el nivel 0,01 (bilateral). 


\section{Decisión}

La significancia dio un resultado de 0,005 , lo cual indica que se rechaza la hipótesis nula y por tanto existe relación entre la competencia tecnológica global y el rendimiento de las exportaciones de empresas peruanas fabricantes de máquinas para la industria panadera del 2014 al 2018. Por su parte, el coeficiente de correlación fue 0,781 ; de manera que la relación hallada tiene intensidad positiva alta.

Como lo afirman Escandón \& Hurtado (2009) en su investigación "Factores que inciden en la creación de born global en Colombia", la baja tecnología implementada en productos y procesos refleja una debilidad al momento de la supervivencia en un mercado internacional.

\subsubsection{Pruebas de hipótesis específica 2.}

Existe relación entre el desarrollo de productos únicos y el rendimiento de las exportaciones de empresas peruanas fabricantes de máquinas para la industria panadera del 2014 al 2018.

\section{Hipótesis}

HO: No existe relación entre el desarrollo de productos únicos y el rendimiento de las exportaciones de empresas peruanas fabricantes de máquinas para la industria panadera del 2014 al 2018.

H1: Existe relación entre el desarrollo de productos únicos y el rendimiento de las exportaciones de empresas peruanas fabricantes de máquinas para la industria panadera del 2014 al 2018.

\section{Nivel de significancia}

Para esta investigación se consideró el 0,05. 


\section{Estadístico de prueba}

Tabla 49.

Correlación de Pearson entre el desarrollo de productos únicos y el rendimiento de las exportaciones

\begin{tabular}{llcc}
\hline & Cesarrollo de & $\begin{array}{c}\text { Rendimiento } \\
\text { Productos } \\
\text { Únicos }\end{array}$ & $\begin{array}{c}\text { de las } \\
\text { exportaciones }\end{array}$ \\
\hline $\begin{array}{l}\text { Desarrollo de Productos } \\
\text { Únicos }\end{array}$ & Correlación de Pearson & 1 & $0,623^{*}$ \\
& Sig. (bilateral) & 11 & 0,041 \\
& $\mathrm{~N}$ & $0,623^{*}$ & 11 \\
\hline Rendimiento de las & Correlación de Pearson & 0,041 & 1 \\
exportaciones & Sig. (bilateral) & 11 & 11 \\
\hline
\end{tabular}

*. La correlación es significativa en el nivel 0,05 (bilateral).

\section{Decisión}

La significancia fue 0,041 ; de manera que se rechaza la hipótesis nula y por tanto existe relación entre el desarrollo de productos únicos y el rendimiento de las exportaciones de empresas peruanas fabricantes de máquinas para la industria panadera del 2014 al 2018. Por otro lado, el coeficiente de correlación fue 0,623; por cual la relación hallada tiene intensidad positiva moderada.

La investigación de Knight, G \& Cavusgil, T. (2004) también concuerda con la hipótesis de la relación positiva entre la innovación y el rendimiento de las exportaciones. Así lo afirman indicando que las empresas con una fuerte cultura de innovación tienden a tener mayor éxito en su internalización, en comparación a empresas que carecen de cultura de innovación.

\subsubsection{Pruebas de hipótesis específica 3.}

Existe relación entre el enfoque en la calidad y el rendimiento de las exportaciones de empresas peruanas fabricantes de máquinas para la industria panadera del 2014 al 2018

\section{Hipótesis}


H0: No existe relación entre el enfoque en la calidad y el rendimiento de las exportaciones de empresas peruanas fabricantes de máquinas para la industria panadera del 2014 al 2018.

H1: Existe relación entre el enfoque en la calidad y el rendimiento de las exportaciones de empresas peruanas fabricantes de máquinas para la industria panadera del 2014 al 2018.

\section{Nivel de significancia}

Para esta investigación se consideró el 0,05.

\section{Estadístico de prueba}

Tabla 50.

Correlación de Pearson entre el enfoque de calidad y el rendimiento de las exportaciones

\begin{tabular}{|c|c|c|c|}
\hline & & $\begin{array}{c}\text { Enfoque de } \\
\text { Calidad }\end{array}$ & $\begin{array}{l}\text { Rendimiento de } \\
\text { las } \\
\text { exportaciones }\end{array}$ \\
\hline \multirow[t]{3}{*}{ Enfoque de Calidad } & Correlación de Pearson & 1 & $0,749^{\star *}$ \\
\hline & Sig. (bilateral) & & 0,008 \\
\hline & $\mathrm{N}$ & 11 & 11 \\
\hline \multirow{3}{*}{$\begin{array}{l}\text { Rendimiento de las } \\
\text { exportaciones }\end{array}$} & Correlación de Pearson & $0,749^{* *}$ & 1 \\
\hline & Sig. (bilateral) & 0,008 & \\
\hline & $\mathrm{N}$ & 11 & 11 \\
\hline
\end{tabular}

**. La correlación es significativa en el nivel 0,01 (bilateral).

\section{Decisión}

La significancia dio un valor de 0,008; de manera que se rechaza la hipótesis nula y por tanto existe relación entre el enfoque de calidad y el rendimiento de las exportaciones de empresas peruanas fabricantes de máquinas para la industria panadera del 2014 al 2018. Por otro lado, el coeficiente de correlación fue 0,749 ; por cual la relación hallada tiene intensidad positiva alta.

Como lo resalta la investigación "Relationship capabilities, quality, and innovation as determinants of export performance" de Lages, Silva y Styles (2009), existe un vínculo grande entre la calidad de los productos y su desempeño en las relaciones comerciales. 


\subsubsection{Pruebas de hipótesis específica 4.}

Existe relación entre el aprovechamiento de las competencias de los distribuidores extranjeros y el rendimiento de las exportaciones de empresas peruanas fabricantes de máquinas para la industria panadera del 2014 al 2018.

\section{Hipótesis}

H0: No existe relación entre el aprovechamiento de las competencias de los distribuidores extranjeros y el rendimiento de las exportaciones de empresas peruanas fabricantes de máquinas para la industria panadera del 2014 al 2018.

H1: Existe relación entre el aprovechamiento de las competencias de los distribuidores extranjeros y el rendimiento de las exportaciones de empresas peruanas fabricantes de máquinas para la industria panadera del 2014 al 2018.

\section{Nivel de significancia}

Para esta investigación se consideró el 0,05.

\section{Estadístico de prueba}

Tabla 51.

Correlación de Pearson entre las competencias de los distribuidores y el rendimiento de las exportaciones

\begin{tabular}{llcc}
\hline & & $\begin{array}{c}\text { Competencias } \\
\text { de los } \\
\text { distribuidores }\end{array}$ & $\begin{array}{c}\text { Rendimiento de } \\
\text { las } \\
\text { exportaciones }\end{array}$ \\
\hline $\begin{array}{l}\text { Competencias de los } \\
\text { distribuidores }\end{array}$ & Correlación de Pearson & 1 & $0,849^{* *}$ \\
& Sig. (bilateral) & 11 & 0,001 \\
& $\mathrm{~N}$ & $0,849^{* *}$ & 11 \\
\hline Rendimiento de las & Correlación de Pearson & 0,001 & 11 \\
exportaciones & Sig. (bilateral) & 11 & 11 \\
& $\mathrm{~N}$ & & \\
\hline
\end{tabular}

${ }^{* *}$. La correlación es significativa en el nivel 0,01 (bilateral).

\section{Decisión}

La significancia fue 0,001 ; de manera que se rechaza la hipótesis nula y por tanto existe relación entre las competencias de los distribuidores y el rendimiento de las 
exportaciones de empresas peruanas fabricantes de máquinas para la industria panadera del 2014 al 2018. Por otro lado, el coeficiente de correlación fue 0,849; por cual la relación hallada tiene intensidad positiva alta.

Zou, Fang y Zhao (2003) respaldan este resultado, ellos en su investigación plantean una hipótesis similar, la cual dice que la adecuada distribución internacional de productos influye positivamente en el desempeño de las ventas.

\subsection{Conclusiones}

Luego de analizar los resultados sobre la relación entre las estrategias de negocio y el rendimiento de las exportaciones de empresas peruanas fabricantes de máquinas para la industria panadera, concluimos lo siguiente:

i. Esta investigación está dirigida a los representantes de comercio exterior o empresarios de empresas peruanas fabricantes de máquinas de panadería, donde se buscó determinar si existía una relación entre las estrategias de negocio y el rendimiento de las exportaciones. Los resultados de este estudio contribuyen a ampliar la limitada información existente sobre estrategias de negocios para que los resultados de venta internacional tengan un crecimiento sostenido en la industria. Se logró determinar una relación alta entre las estrategias de negocios y el rendimiento de las exportaciones probándose así la hipótesis planteada.

ii. Los resultados obtenidos determinaron que existe una relación entre la competencia tecnológica global y el rendimiento de las exportaciones de empresas peruanas fabricantes de máquinas de panadería. Se encontró que el manejo de tecnología de última generación favorece notablemente a un mayor beneficio a la empresa. La hipótesis planteada fue probada y la relación es de intensidad positiva alta.

iii. Según los resultados obtenidos, se determinó que el desarrollo de productos únicos está relacionado al rendimiento de las exportaciones de empresas peruanas fabricantes de máquinas de panadería. La innovación ayuda a las empresas a especializarse y satisfacer necesidades que nadie más atiende mediante un producto único. A un mayor desarrollo de productos únicos, mejor 
será el rendimiento de las exportaciones. La hipótesis planteada fue probada y la relación tiene intensidad positiva alta.

iv. Según los resultados obtenidos, se determinó que el enfoque de calidad está relacionado con el rendimiento de las exportaciones de empresas peruanas fabricantes de máquinas de panadería. Se halló un coeficiente de correlación de 0,783; por cual la relación hallada tiene intensidad positiva alta. Dicho resultado resalta la importancia de fabricar productos con un nivel alto de calidad como una ventaja competitiva.

v. Según los resultados obtenidos, el estudio logró identificar que existe relación entre el aprovechamiento de las competencias de los distribuidores extranjeros y el rendimiento de las exportaciones de empresas fabricantes de máquinas de panadería. El coeficiente de correlación fue 0,707 ; por lo cual la relación hallada tiene intensidad positiva alta; es decir que la hipótesis planteada fue probada. Cabe resaltar que una de las primeras acciones que debe tomar una empresa, especialmente una del sector de bienes industriales, que busca expandir sus ventas al exterior es buscar una alianza con distribuidor o representante comercial que pueda apoyarlos en el país destino.

\subsection{Recomendaciones}

Las recomendaciones de este estudio podrán ser utilizadas por empresas fabricantes de máquinas de panadería, así como por programas de promoción de exportaciones y futuros investigadores del rubro de la panificación.

En esta investigación se determinan cuatro estrategias de negocios que potenciarán las exportaciones y su desempeño en el mercado internacional, es por esta razón que se recomienda a las empresas establecer dichas estrategias.

i. Para la hipótesis específica 1, sobre la competencia tecnológica global, se recomienda que las empresas tengan un estándar en cuanto a tecnología de los productos que fabrican, y de la misma manera, que amolden sus procesos antiguos a la nueva tecnología. Otra acción importante es brindar capacitaciones continuas al personal técnico, en este caso a los ingenieros de producto.

ii. Para la hipótesis específica 2, acerca del desarrollo de productos únicos, se recomienda que las empresas identifiquen las nuevas necesidades del 
consumidor mediante investigación de mercado cualitativa y cuantitativa que les permitan especializarse e incluir implementaciones diferenciadoras en sus productos.

iii. Para la hipótesis específica 3, acerca del enfoque de calidad, se recomienda a las empresas que establezcan un flujo de medición de calidad en el desarrollo de cada uno de sus productos. El flujo deberá pasar por varias etapas para minimizar y eliminar errores, hasta finalmente llegar al ingeniero especialista de turno quien dará el visto bueno. Todo este proceso debe ser supervisado.

iv. Para la hipótesis específica 4, acerca del aprovechamiento de las competencias de los distribuidores extranjeros, se recomienda a las empresas en primer lugar establecer un estándar con requisitos mínimos y una matriz de selección de elección de distribuidores internacionales. Por ejemplo, evaluar si serán exclusivos o si manejarán otras marcas que puedan ser competencia directa, su desempeño de ventas, imagen, conocimiento de mercado, solidez financiera, términos de pago, entre otros criterios importantes. Si ya se trabaja con un distribuidor en específico, las empresas deben evaluar los resultados monetarios en una cadencia determinada (en forma trimestral, semestral o anual). 


\section{Referencias bibliográficas}

Aaby, N. \& Slater, S. (1989). Management influences on export performance: a review of the empirical literature 1978-88. International marketing review, 6(4), 7-26.

Andrade, M. (2013). Application of an approach to the innovation management in micro and small enterprises. Independent journal of management and production, Vol. 5, № 3, p. 23. Septiembre 2019, De Ebsco Base de datos.

Angles, E. (2016). La evaluación del desempeño ferial de los expositores en ferias internacionales en el Perú: El caso de los expositores en las ferias internacionales Perú moda y la Perú Gift del año 2010. Universidad Nacional Mayor de San Marcos. Lima

Anónimo. (2018). Industria panadera creció 4.1\% en el primer semestre del 2018. Sociedad Nacional de Industrias. Extraído de http://www.sni.org.pe/industria-panaderacrecio-4-1-primer-semestre-del-2018/

Axinn, C., Noordewier, T., \& Sinkula, J. M. (1996). Export strategies and export performance: an empirical investigation of a products / markets typology. Advances in international marketing, 8(2), 7-58.

Becerra, C. (7 de setiembre del 2015). El pan nuestro. Diario el peruano.

Bello, D., Chelariu, C. \& Zhang, L. (2003). "The antecedents and performance consequences of relationalism in export distribution channels", Journal of Business Research.

Bello, D., \& Gilliland, D. (1997). The effect of output controls, process controls, and flexibility on export channel performance. Journal of Marketing.

Belzusarri D., León J., Yesang, S., \& Cachay, A. (2018). Plan de negocio para una panadería especializada en panes enriquecidos con granos andinos del Perú. Lima.

Bigliardi, B. (2013). The effect of innovation on financial performance: A research study involving SMEs. Innovation, 15(2), 245-255. 
Bigliardi, B., \& Dormio, A. (2009). An empirical investigation of innovation determinants in food machinery enterprises. European Journal of Innovation Management.

Bowersox, D. \& Cooper, M. (1992). Strategic marketing channel management. New York: McGraw-Hill.

Buzzell, R. \& Gale, B. (1987). The PIMS principles: Linking strategy to performance. New York: Free Press.

Cavusgil, S. \& Zou, S. (1994). Marketing strategy-performance relationship: an investigation of the empirical link in export market ventures. The Journal of Marketing, 1-21.

Cadogan, J., Cui, C., \& Yeung, L. (2003). Export market-oriented behavior and export performance. The moderating roles of competitive intensity and technological turbulence.

Chetty, S., \& Holm, D. B. (2000). Internationalization of small to medium-sized manufacturing firms: a network approach. International business review, 9(1), 7793.

Daniels, J., Radebaugh, L., \& Sullivan, D. (2013). Negocios internacionales, ambientes y operaciones (14 ed.). México D. F: Pearson.

De la Fuente, M. \& Echarri, A. (1999). Modelos de contratos internacionales (3 ed.). Madrid: FC editorial.

De Luz, M. (1993). "Relationship between export strategy variables and export performance for brazil-based manufacturers", Journal of Global Marketing, vol. 7, n 1, pp. 87 107.

Eatwell, J., Milgate, M. \& Newman, P. (2001). The New Palgrave: The world of economics. Londres: Norton.

Escandón, D. \& Hurtado, A. (2014). Factores que influyen en el desarrollo exportador de las pymes en Colombia. Elsevier. Estudios Gerenciales, 30(131), 172-183. 
Escandon, D., Rialp, J., Fuerst, S., Rodriguez, A., \& Castro, G. (2019). Born global: the influence of international orientation on export performance. Heliyon, 5(11), e02688.

Evangelista, F. (1994). Export performance and its determinants: some empirical evidence from Australian manufacturing firms. Advances in international marketing, 6(1), 207229.

Garza, J. (2015). La importancia de las relaciones con los proveedores. Recuperado de: https://www.linkedin.com/pulse/la-importancia-de-las-relaciones-con-losproveedores-juan-garza/

Gómez, D \& Cristóbal G. (2004). Los contratos en el marketing internacional. Madrid: ESIC editorial.

Haddoud, M. Y., Nowinski, W., Jones, P., \& Newbery, R. (2019). Internal and external determinants of export performance: Insights from Algeria. Thunderbird International Business Review, 61(1), 43-60.

Hernández, R., Fernández, C., \& Baptista, P. (2006). Metodología de la investigación (4 ed.). México D. F: Mc Graw Hill editorial.

Hernández, R., Fernández, C., \& Baptista, P. (2014). Metodología de la investigación. Ciudad de México.

Johanson, J., \& Mattsson, L. (1987). Interorganizational relations in industrial systems: a network approach compared with the transaction-cost approach. International Studies of Management \& Organization, 17(1), 34-48.

Kam, W., \& Singh, A. (2004). The pattern of innovation in the knowledge intensive business services sector of Singapore. Singapore management review, 26(1), 21-44.

Keswell, D. (2010). The effectiveness of trade show marketing capabilities on the financial performance of South African companies. South Africa: University of Pretoria.

Knight, G., \& Cavusgil, S. (2004). Innovation, organizational capabilities, and the bornglobal firm. Journal of international business studies, 35(2), 124-141. 
Knox, S. (2002). The boardroom agenda: developing the innovative organization. Corporate Governance: The international journal of business in society.

Kotler, P \& Keller, K. (2012). Dirección de Marketing (14 ed). México D. F: Pearson.

Lages, L. F., Silva, G., \& Styles, C. (2009). Relationship capabilities, quality, and innovation as determinants of export performance. Journal of international Marketing, 17(4), 47-70.

Lake, L. (2000). The competitiveness of Canada's food processing industry: A resourcebased approach. Ontario: The University of Guelph.

Lee, C. \& Yang, Y. (1990). Impact of Export Market Expansion Strategy on Export Performance", International Marketing Review.

Leonard-Barton, D. (1992) 'Core capabilities and core rigidities: a paradox in managing new product development', Strategic. Management Journal 13: 111-126.

Leonidou, L., Katsikeas, C., \& Hadjimarcou, J. (2002): "Executive Insights: Building successful export business relationships: a behavioral perspective"

Li, C. (2014). Exploring the Relations between Service Quality and Consumer Behaviors A case study of $85^{\circ} \mathrm{C}$ Bakery Café from Taiwán. The International Journal of Organizational Innovation, Vol. 6 № 3, p. 12. Septiembre 2019, De Ebsco Base de datos.

Liberopoulos, G. \& Tsarouhas, P. (2002). Systems Analysis Speeds Up Chipita's FoodProcessing Line. University of Thessaly, Vol. 32, № 3, p. 16. septiembre 2019, De Ebsco Base de datos.

Litovchenko, I. (2008). The study of the baking ovens by computer simulation. Acta Universitatis Cibiniensis Series E: Food Technology, Vol. 17 № 2, p. 13. Septiembre 2019, De Ebsco Base de datos. 
Losada, F., Navarro, A., Ruzo, E. \& Barreiro, J. (2006). La Performance De Exportación: Revisión Teórica Y Propuesta De Un Marco Integrador. Investigaciones Europeas de Dirección y Economía de la Empresa.

Lugones, G. (2001). Teorías del comercio internacional. Argentina: ATUEL.

Ma, X. (2006). Beyond transaction cost determinants: An integrated framework for export intermediary selection in emerging economies. Advances in International Marketing, 16,23

Madsen, T. (1998). Executive insights: managerial judgment of export performance. Journal of International Marketing, 6(3), 82-93.

Martínez, D. (2015). Estudio de mejora integral en la empresa de pastelería Claudia Cupcakes. Lima.

Martins, I. (2014). El efecto del comportamiento exportador sobre el compromiso del propietario-gerente con la innovación en Colombia: Interpretaciones bajo el enfoque del aprendizaje. Cuadernos de Administración de Pontificia Universidad Javeriana, Vol. 17 № 49, pp. 135-153. Septiembre 2019, De Ebsco Base de datos.

Moen, O. (2002). The born globals: A new generation of small European exporters. International Marketing Review, 19 (2) (2002), pp. 156-175

Monteiro, A., Soares, A., \& Rua, O. (2019). Linking intangible resources and entrepreneurial orientation to export performance: the mediating effect of dynamic capabilities. Journal of Innovation \& Knowledge, 4(3), 179-187.

Morris A., Narendra, A. \& Vipul, A. (2006). Ganar en el mercado postventa. Harvard Deusto business review, 68-79.

Navaneethakrishnan, P. (2008). Numerical and experimental investigation of temperature distribution inside a heating oven. Journal of Food Processing and Preservation, Vol. 34, pp. 275-288. Septiembre 2019, De Ebsco Base de datos. 
Navarro, A., Rey, R. \& Barrera, R. (2017). Compromiso, recursos, Emprendimiento exportador y resultados empresariales.

Nelson, R., \& Winter, S. (1982). An evolutionary theory of economic change. Cambridge, Mass: Belknap Press of Harvard University Press.

Nettleton, D. (2003). Análisis de datos comerciales. Madrid: Diaz de Santos.

Ormeño, A. (2003). Exportaciones del Perú y el APEC desde una perspectiva de la dotación de factores (1980-1999). Lima: Universidad del Pacifico.

Obregón, R. (2012). Modelos de contratos internacionales. Lima: PROMPERU.

Porter, M. (1982). Estrategia competitiva, técnica para el análisis de los sectores industriales y de la competencia. Mexico: Compañía editorial continental.

Porter, M., Coria, P., Pastor, R., Orozco, M., \& Pecina, H. (2016). Ventaja competitiva: Creación y sostenimiento de un desempeño superior. México, D.F: Grupo Editorial Patria.

Rialp, A., Rialp, J., Urbano, D., \& Vaillant, Y. (2005). The born-global phenomenon: A comparative case study research. Journal of International Entrepreneurship, 3(2), 133-171.

Robles, F. \& Jáuregui, J. (2017). International markets entry strategy determinants: An exploratory study in Peru. Cuadernos de Administración (Universidad del Valle), 33(59), 2-19.

Shoham, A. (1996). Marketing-Mix standardization: Determinants of export performance. Journal of Global Marketing, vol. 10, nํ2, pp. 53-73.

Sousa, C. (2004). Export performance measurement: an evaluation of the empirical research in the literature. Academy of Marketing Science Review.

Suwannarat, P. (2016). The study of export intermediary performance determinants. Multinational Business Review. 
Superintendencia Nacional de Aduanas y de Administración Tributaria (2019). Base de datos de Operatividad Aduanera.

Szmidt, E., \& Kacprzyk, J. (2010). The Spearman rank correlation coefficient between intuitionistic fuzzy sets. 5th IEEE international conference intelligent systems (pp. 276-280). IEEE.

Tafesse, W. (2009). Empirical examination of the trade show performance construct and determinants of trade show effectiveness: a developing country case, Bodo Graduate School of Business, Suecia.

Theingi, \& Purchase, S. (2011). How exporters' and intermediaries' resources influence export performance. Australasian Marketing Journal, 19(2), 100-107.

Tonesakulrungruang, L. (2009). Globalization Entrepreneurial Orientation and Marketing Strategy in Thai Small and Medium-Sized Enterprises. Ramkhamhaeng UniversityInternational Journal, 3(1), 103-112.

Ugaz, A. (2007). Panes del Perú: el encuentro del maíz y el trigo. Lima: Editorial de la Universidad San Martín de Porres.

Urrutia, P., \& Gomez, N. (2006). Errores en investigaciones del mercado electoral: Una aplicación de marketing político. Horizontes Empresariales, 5(1), 53-61.

Young, S., Bell, J. \& Crick, D. (2000) The Resource-based Perspective and Small Firm Internationalization: An Exploratory Approach. St Martin's Press: New York.

Zahra, S., Ireland, R., \& Hitt, M. (2000). International expansion by new venture firms: International diversity, mode of market entry, technological learning, and performance. Academy of Management journal, 43(5), 925-950.

Zhang, J. \& Zhu, M. (2016). Market orientation, product innovation and export performance: evidence from Chinese manufacturers. Journal of Strategic Marketing 
Zou, S., Fang, E., \& Zhao, S. (2003). The effect of export marketing capabilities on export performance: an investigation of Chinese exporters. Journal of International marketing, 11(4), 32-55. 
Anexos

\section{Anexo 1: Matriz de consistencia}

\section{Tabla 52.}

Matriz de Consistencia.

\begin{tabular}{|c|c|c|c|c|}
\hline PROBLEMA & OBJETIVO & HIPÓTESIS & VARIABLES & \multirow{2}{*}{$\begin{array}{l}\text { METODOLOGÍA DE LA } \\
\text { INVESTIGACIÓN }\end{array}$} \\
\hline Problema General & Objetivo General & Hipótesis General & Variable Independiente & \\
\hline $\begin{array}{l}\text { ¿Cuál es la relación entre las } \\
\text { estrategias de negocio y el } \\
\text { rendimiento de las } \\
\text { exportaciones de empresas } \\
\text { peruanas fabricantes de } \\
\text { máquinas para la industria } \\
\text { panadera del } 2014 \text { al } 2018 ?\end{array}$ & $\begin{array}{l}\text { Analizar la relación entre las } \\
\text { estrategias de negocio y el } \\
\text { rendimiento de las } \\
\text { exportaciones de empresas } \\
\text { peruanas fabricantes de } \\
\text { máquinas para la industria } \\
\text { panadera del } 2014 \text { al } 2018\end{array}$ & $\begin{array}{l}\text { Existe relación entre las } \\
\text { estrategias de negocio y el } \\
\text { rendimiento de las } \\
\text { exportaciones de empresas } \\
\text { peruanas fabricantes de } \\
\text { máquinas para la industria } \\
\text { panadera del } 2014 \text { al } 2018\end{array}$ & $\begin{array}{l}\text { X: Estrategias de } \\
\text { Negocios: } \\
\text { X1: Competencia } \\
\text { tecnológica global } \\
\text { X2: Desarrollo de } \\
\text { productos únicos } \\
\text { X3: Enfoque en la calidad } \\
\text { X4: Aprovechamiento de } \\
\text { las competencias de los } \\
\text { distribuidores }\end{array}$ & $\begin{array}{l}\text { - Método: Enfoque } \\
\text { cuantitativo. } \\
\text { - Tipo: Explicativa. } \\
\text { - Diseño: Correlacional, no } \\
\text { experimental, transversal } \\
\text { - Población: } \\
11 \text { empresas peruanas } \\
\text { fabricantes exportadoras } \\
\text { de maquinarias para la } \\
\text { industria panadera. } \\
\text { - Censo: } \\
\text { Las } 11 \text { empresas } \\
\text { contenidas en la población } \\
\\
\text { - Instrumento de } \\
\text { investigación: } \\
\text { Encuesta, contiene } \\
\text { enunciados cerrados } \\
\text { formulados en una } \\
\text { escala de Likert de } 5 \\
\text { niveles }\end{array}$ \\
\hline
\end{tabular}




\begin{tabular}{|c|c|c|c|}
\hline Problemas Específicos & Objetivos Específicos & Hipótesis Especificas & Variable Dependiente \\
\hline $\begin{array}{l}\text { ¿Cuál es la relación entre } \\
\text { competencia tecnológica } \\
\text { global y el rendimiento de } \\
\text { las exportaciones de } \\
\text { empresas peruanas } \\
\text { fabricantes de máquinas } \\
\text { para la industria panadera } \\
\text { del } 2014 \text { al } 2018 ?\end{array}$ & $\begin{array}{l}\text { Determinar la relación entre } \\
\text { competencia tecnológica } \\
\text { global y el rendimiento de } \\
\text { las exportaciones de } \\
\text { empresas peruanas } \\
\text { fabricantes de máquinas } \\
\text { para la industria panadera } \\
\text { del } 2014 \text { al } 2018\end{array}$ & $\begin{array}{l}\text { - Existe relación entre la } \\
\text { competencia tecnológica } \\
\text { global y el rendimiento de } \\
\text { las exportaciones de } \\
\text { empresas peruanas } \\
\text { fabricantes de máquinas } \\
\text { para la industria panadera } \\
\text { del } 2014 \text { al } 2018\end{array}$ & \multirow[t]{2}{*}{$\begin{array}{l}\text { Y1: Rendimiento de las } \\
\text { exportaciones }\end{array}$} \\
\hline $\begin{array}{l}\text { - ¿Cuál es la relación entre } \\
\text { desarrollo de productos } \\
\text { únicos y el rendimiento de } \\
\text { las exportaciones de } \\
\text { empresas peruanas } \\
\text { fabricantes de máquinas } \\
\text { para la industria panadera } \\
\text { del } 2014 \text { al } 2018 ?\end{array}$ & 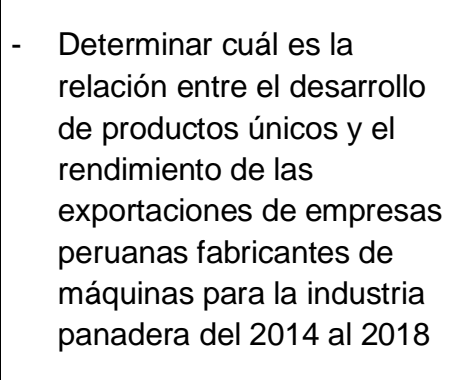 & $\begin{array}{l}\text { Existe relación entre el } \\
\text { desarrollo de productos } \\
\text { únicos y el rendimiento } \\
\text { de las exportaciones de } \\
\text { empresas peruanas } \\
\text { fabricantes de máquinas } \\
\text { para la industria } \\
\text { panadera del } 2014 \text { al } \\
2018\end{array}$ & \\
\hline $\begin{array}{l}\text { - ¿Cuál es la relación entre } \\
\text { el enfoque en la calidad y } \\
\text { el rendimiento de las } \\
\text { exportaciones de } \\
\text { empresas peruanas } \\
\text { fabricantes de máquinas } \\
\text { para la industria panadera } \\
\text { del } 2014 \text { al } 2018 ?\end{array}$ & $\begin{array}{l}\text { Determinar la relación entre } \\
\text { el enfoque en la calidad y el } \\
\text { rendimiento de las } \\
\text { exportaciones de empresas } \\
\text { peruanas fabricantes de } \\
\text { máquinas para la industria } \\
\text { panadera del } 2014 \text { al } 2018\end{array}$ & $\begin{array}{l}\text { - Existe relación entre el } \\
\text { enfoque en la calidad y el } \\
\text { rendimiento de las } \\
\text { exportaciones de } \\
\text { empresas peruanas } \\
\text { fabricantes de máquinas } \\
\text { para la industria panadera } \\
\text { del } 2014 \text { al } 2018\end{array}$ & \\
\hline
\end{tabular}




\begin{tabular}{|l} 
- ¿Cuál es la relación entre \\
el aprovechamiento de las \\
competencias de los \\
distribuidores extranjeros y \\
el rendimiento de las \\
exportaciones de \\
empresas peruana \\
fabricantes de máquinas \\
para la industria panadera \\
del 2014 al $2018 ?$
\end{tabular}

Determinar la relación entre el aprovechamiento de las competencias de los

distribuidores extranjeros y el rendimiento de las

exportaciones de empresas

peruanas fabricantes de

máquinas para la industria

panadera del 2014 al 2018
Existe relación entre el aprovechamiento de las competencias de los distribuidores extranjeros $y$ el rendimiento de las exportaciones de empresas peruanas

fabricantes de máquinas para la industria panadera del 2014 al 2018 


\section{Anexo 2: Encuesta}

Buenos días, somos Jeannette Salazar y Andrea Zuzunaga, egresadas de la Universidad San Ignacio de Loyola. Actualmente, nos encontramos realizando nuestro proyecto de Tesis titulada "Relación entre las estrategias de negocio y el rendimiento de las exportaciones de empresas peruanas fabricantes de máquinas para la industria panadera del 2014 al 2018". Por tal motivo, nos gustaría que formen parte de la investigación y participen del cuestionario.

Hay 5 opciones a escoger, lea con detenimiento y elija la opción que mejor describa su punto de vista al respecto. Cada proposición tiene una sola respuesta. No hay respuestas buenas ni malas.

Descripción de las opciones: 1 = Totalmente en desacuerdo, 2 =En desacuerdo; 3 = Ni de acuerdo ni en desacuerdo; 4 = De acuerdo; $5=$ Totalmente de acuerdo

\begin{tabular}{|c|c|c|c|c|c|c|}
\hline \multirow{2}{*}{\multicolumn{2}{|c|}{ Enunciados }} & \multicolumn{5}{|c|}{ Calificación } \\
\hline & & 1 & 2 & 3 & 4 & 5 \\
\hline \multicolumn{7}{|c|}{ Competencia tecnológica global } \\
\hline P1 & $\begin{array}{l}\text { La empresa está a la vanguardia tecnológica } \\
\text { de la industria en el mercado. }\end{array}$ & & & & & \\
\hline $\mathrm{P} 2$ & $\begin{array}{l}\text { La empresa inventa mucha de la tecnología } \\
\text { incorporada en sus productos. }\end{array}$ & & & & & \\
\hline P3 & $\begin{array}{l}\text { En comparación con los competidores locales, } \\
\text { a menudo la empresa es de las primeras en } \\
\text { introducir innovaciones de productos o nuevos } \\
\text { enfoques operativos. }\end{array}$ & & & & & \\
\hline
\end{tabular}




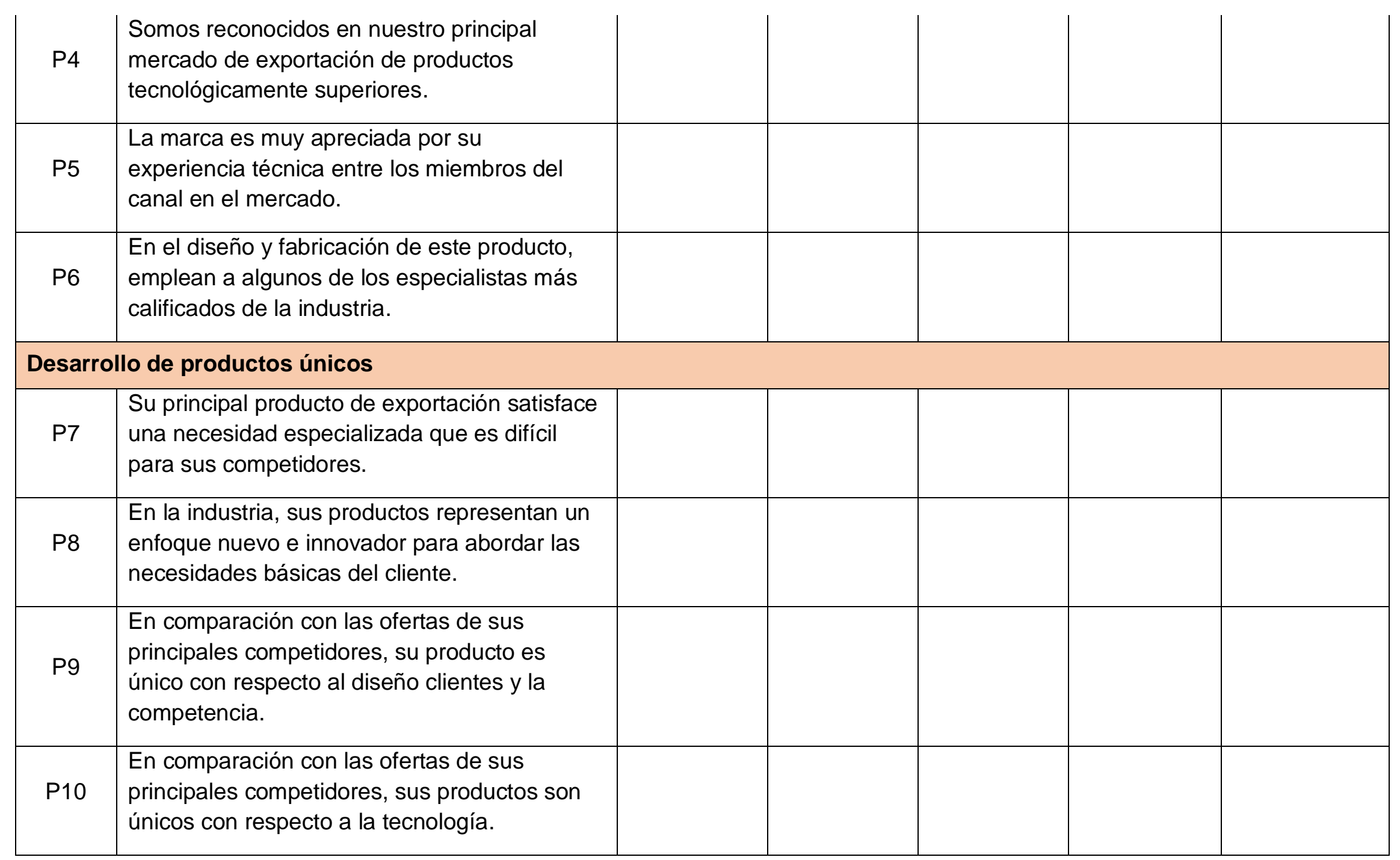




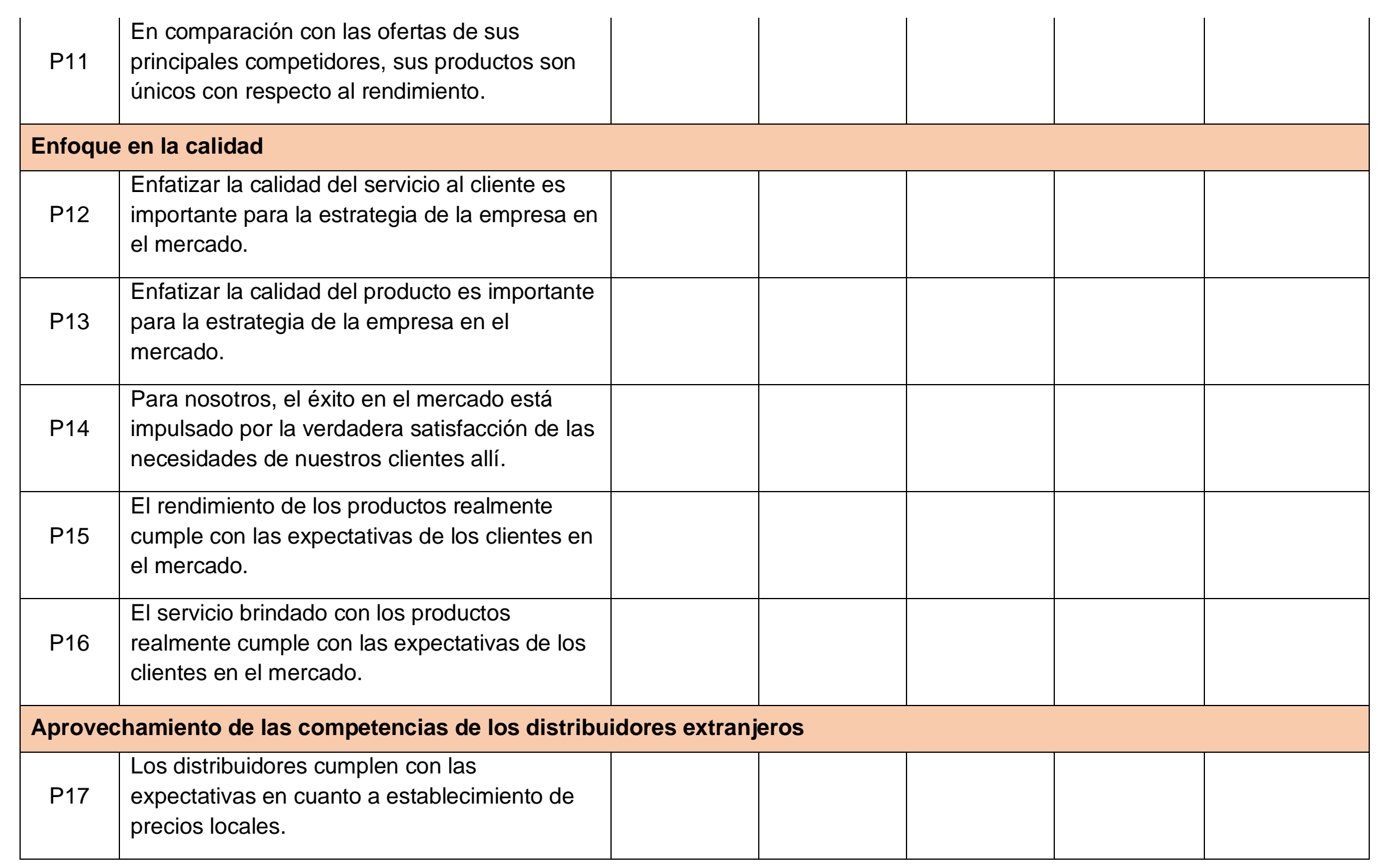




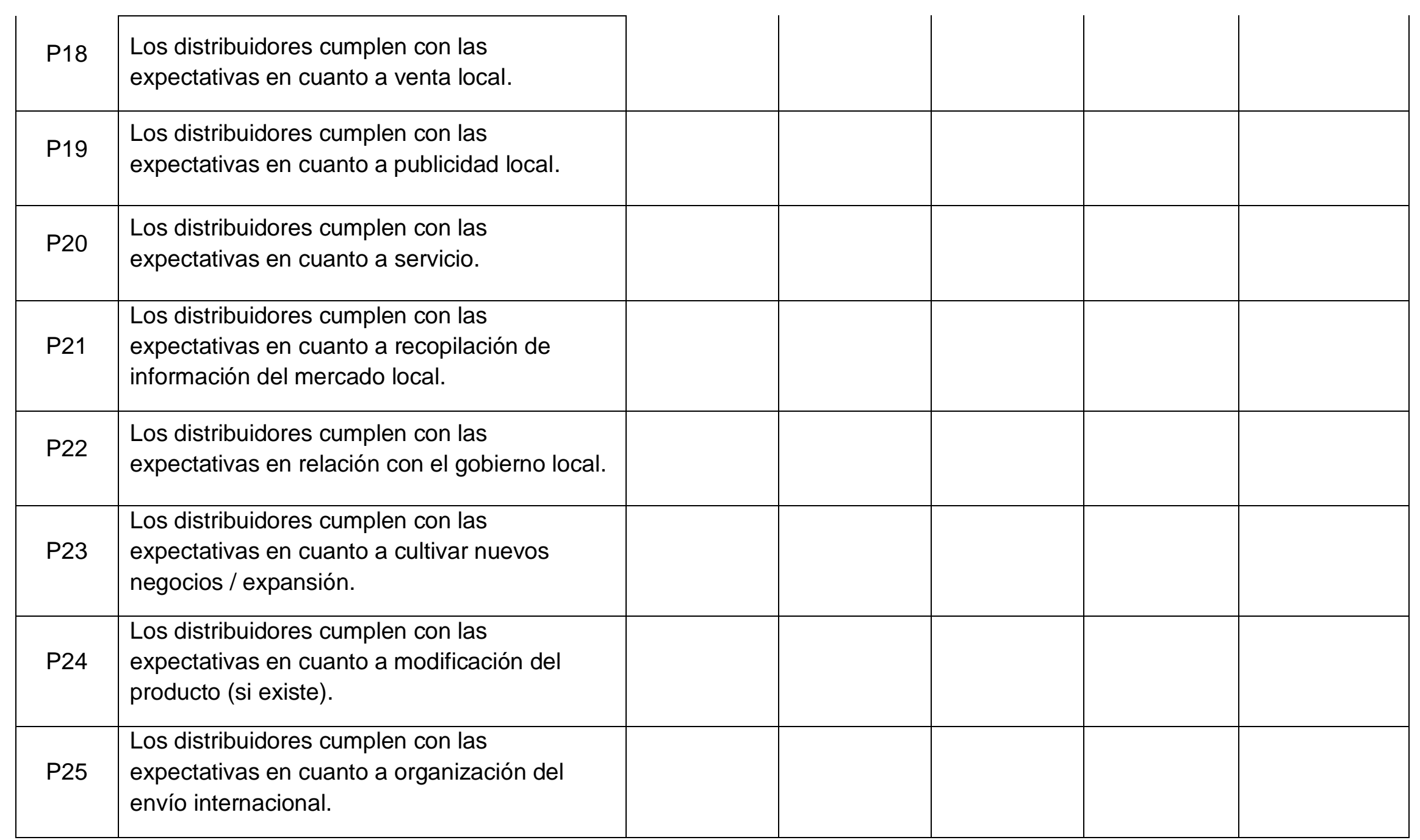




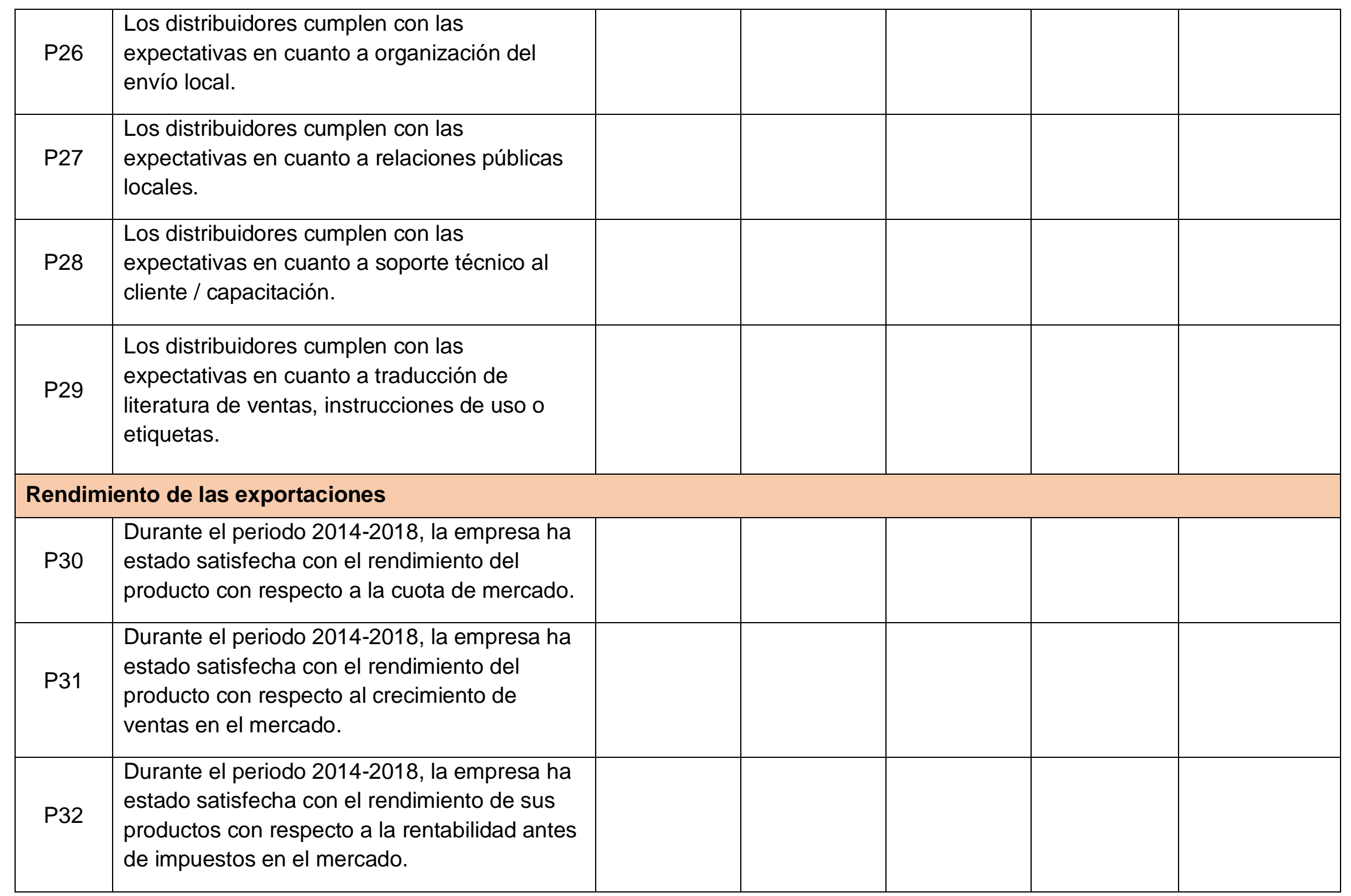




\begin{tabular}{|c|l|l|l|l|} 
P33 & $\begin{array}{l}\text { Durante el periodo 2014-2018, la empresa ha } \\
\text { estado satisfecha con el crecimiento de las } \\
\text { ventas en su principal mercado de exportación } \\
\text { en comparación con sus principales } \\
\text { competidores. }\end{array}$ & & & \\
\hline P34 & $\begin{array}{l}\text { Durante el periodo 2014-2018, la empresa ha } \\
\text { estado satisfecha con el éxito de sus } \\
\text { productos en su principal mercado de } \\
\text { exportación. }\end{array}$ & & & \\
\hline P35 & $\begin{array}{l}\text { Durante el periodo 2014-2018, la empresa ha } \\
\text { estado satisfecha con el rendimiento total de } \\
\text { inversión (ROI) de sus productos en su } \\
\text { principal mercado de exportación. }\end{array}$ & & & \\
\hline
\end{tabular}


Anexo 3: Principales Exportadores por Subpartida Nacional (2014 - 2018)

Tabla 53.

Exportaciones FOB hornos (PA: 8417209000) 2014-2018.

\begin{tabular}{|lrc|}
\hline \multicolumn{1}{c}{ EXPORTADOR } & FOB US\$ & \multicolumn{1}{c|}{$\%$} \\
NOVA-INDUSTRIAL TOOLS S.A.C. & $1,827,742$ & $94.78 \%$ \\
H. RUIZ HNOS. E.I.R.L. & 24,594 & $1.28 \%$ \\
INVERSIONES PERU PANAMA SAC & 19,386 & $1.01 \%$ \\
COCINAS SUPERIOR S.A.C. & 17,120 & $0.89 \%$ \\
ARTEBIANCA S.A.C. & 16,899 & $0.88 \%$ \\
PEĐA BEDOYA RONALD EMILIO & 6,000 & $0.31 \%$ \\
MIKIS E.I.R.L. & 5,050 & $0.26 \%$ \\
MACRONEGOCIOS MARY'S E.I.R.L. & 4,100 & $0.21 \%$ \\
VACCARI TORRES VICTOR MANUEL & 3,050 & $0.16 \%$ \\
ALL BUSINESS IMPORT ALMANZA S.A.C & 2,200 & $0.11 \%$ \\
ALPAIS METALS SAC & 1,276 & $0.07 \%$ \\
EL DIAMANTE SOC.COMERCIAL & 785 & $0.04 \%$ \\
VELASQUEZ CHAVEZ MIGUEL ANGEL & 250 & $0.01 \%$ \\
IMPORT. EXPORT. PRODEX E.I.R.L. & 40 & $0.00 \%$ \\
TOTAL & $\mathbf{1 , 9 2 8 , 4 9 2}$ & $\mathbf{1 0 0 \%}$ \\
\hline
\end{tabular}

Elaboración Propia

Fuente: SUNAT (2014 - 2018) 
Tabla 54.

Exportaciones FOB maquinas en general (PA: 8438101000) 2014- 2018.

\begin{tabular}{|lrc|}
\hline \multicolumn{1}{|c}{ EXPORTADOR } & FOB US $\$$ & $\%$ \\
NOVA-INDUSTRIAL TOOLS S.A.C. & $2,349,808$ & $75.42 \%$ \\
CRUZ HUACARPUMA YOLANDA & 244,970 & $7.86 \%$ \\
MACHINES'S WORLD E.I.R.L. & 112,904 & $3.62 \%$ \\
ARTEBIANCA S.A.C. & 79,218 & $2.54 \%$ \\
VULCANO TECNOLOGIA APLICADA EI RL & 70,517 & $2.26 \%$ \\
AFV SERVICIOS SOCIEDAD ANONIMA CERRADA & 61,647 & $1.98 \%$ \\
FABRICACION DE MAQUINARIA INDUSTRIAL DEL EMPAQUETADO & 45,017 & $1.44 \%$ \\
PMAN DEL PERU SAC EN LIQUIDACION & 31,967 & $1.03 \%$ \\
CNC ESPECIALISTAS S.A.C. & 30,000 & $0.96 \%$ \\
SINIT SOLUCIONES INDUSTRIALES INTEGRALES E.I.R.L & 21,188 & $0.68 \%$ \\
GRUPO LEVAPAN S.A. & 17,442 & $0.56 \%$ \\
MAIGAS COMERCIAL PERU S.A.C. & 15,642 & $0.50 \%$ \\
PEĐA BEDOYA RONALD EMILIO & 10,000 & $0.32 \%$ \\
ENVIROTEST S.A.C & 7,061 & $0.23 \%$ \\
FAMAIC S.A.C. & 6,200 & $0.20 \%$ \\
FALCON SANCHEZ ALBERTO & 3,000 & $0.10 \%$ \\
MALPARTIDA CAMPOS CIRILO & 1,817 & $0.06 \%$ \\
NEGOCIACIONES DEL CARIBE E.I.R.L. & 1,810 & $0.06 \%$ \\
PANASONIC PERUANA S.A. & 1,176 & $0.04 \%$ \\
T \& H CAPLINA E.I.R.L. & 750 & $0.02 \%$ \\
ALL BUSINESS IMPORT ALMANZA S.A.C & 737 & $0.02 \%$ \\
NEGOCIOS INTERNACIONALES LUNA E.I.R.L. & 708 & $0.02 \%$ \\
EXPOARTE TEXTIL S.A.C. & 700 & $0.02 \%$ \\
H. RUIZ HNOS. E.I.R.L. & 700 & $0.02 \%$ \\
MACRONEGOCIOS MARY'S E.I.R.L. & 700 & $0.02 \%$ \\
QUISPE HUATARONGO LEONCIO & 70 & $0.00 \%$ \\
VACCARI TORRES VICTOR MANUEL & 6 & $0.00 \%$ \\
TOTAL & $\mathbf{3 , 1 1 5 , 7 5 5}$ & $\mathbf{1 0 0 \%}$ \\
\hline
\end{tabular}

Elaboración Propia

Fuente: SUNAT (2014 - 2018) 
Tabla 55.

Exportaciones FOB máquinas (ambas partidas) 2014 -2018.

\begin{tabular}{|c|c|c|}
\hline EXPORTADOR & FOB US\$ & $\%$ \\
\hline NOVA-INDUSTRIAL TOOLS S.A.C. & $4,177,550$ & $82.82 \%$ \\
\hline CRUZ HUACARPUMA YOLANDA & 244,970 & $4.86 \%$ \\
\hline MACHINES'S WORLD E.I.R.L. & 112,904 & $2.24 \%$ \\
\hline ARTEBIANCA S.A.C. & 96,117 & $1.91 \%$ \\
\hline VULCANO TECNOLOGIA APLICADA EI RL & 70,517 & $1.40 \%$ \\
\hline AFV SERVICIOS SOCIEDAD ANONIMA CERRADA & 61,647 & $1.22 \%$ \\
\hline FABRICACION DE MAQUINARIA INDUSTRIAL DEL EMPAQUETAD & 45,017 & $0.89 \%$ \\
\hline PMAN DEL PERU SAC EN LIQUIDACION & 31,967 & $0.63 \%$ \\
\hline CNC ESPECIALISTAS S.A.C. & 30,000 & $0.59 \%$ \\
\hline H. RUIZ HNOS. E.I.R.L. & 25,294 & $0.50 \%$ \\
\hline SINIT SOLUCIONES INDUSTRIALES INTEGRALES E.I.R.L & 21,188 & $0.42 \%$ \\
\hline INVERSIONES PERU PANAMA SAC & 19,386 & $0.38 \%$ \\
\hline GRUPO LEVAPAN S.A. & 17,442 & $0.35 \%$ \\
\hline COCINAS SUPERIOR S.A.C. & 17,120 & $0.34 \%$ \\
\hline PEĐA BEDOYA RONALD EMILIO & 16,000 & $0.32 \%$ \\
\hline MAIGAS COMERCIAL PERU S.A.C. & 15,642 & $0.31 \%$ \\
\hline ENVIROTEST S.A.C & 7,061 & $0.14 \%$ \\
\hline FAMAIC S.A.C. & 6,200 & $0.12 \%$ \\
\hline MIKIS E.I.R.L. & 5,050 & $0.10 \%$ \\
\hline MACRONEGOCIOS MARY'S E.I.R.L. & 4,800 & $0.10 \%$ \\
\hline VACCARI TORRES VICTOR MANUEL & 3,056 & $0.06 \%$ \\
\hline FALCON SANCHEZ ALBERTO & 3,000 & $0.06 \%$ \\
\hline ALL BUSINESS IMPORT ALMANZA S.A.C & 2,937 & $0.06 \%$ \\
\hline MALPARTIDA CAMPOS CIRILO & 1,817 & $0.04 \%$ \\
\hline NEGOCIACIONES DEL CARIBE E.I.R.L. & 1,810 & $0.04 \%$ \\
\hline ALPAIS METALS SAC & 1,276 & $0.03 \%$ \\
\hline PANASONIC PERUANA S.A. & 1,176 & $0.02 \%$ \\
\hline EL DIAMANTE SOC.COMERCIAL DE RESP.LTDA. & 785 & $0.02 \%$ \\
\hline T \& H CAPLINA E.I.R.L. & 750 & $0.01 \%$ \\
\hline NEGOCIOS INTERNACIONALES LUNA E.I.R.L. & 708 & $0.01 \%$ \\
\hline EXPOARTE TEXTIL S.A.C. & 700 & $0.01 \%$ \\
\hline VELASQUEZ CHAVEZ MIGUEL ANGEL & 250 & $0.00 \%$ \\
\hline QUISPE HUATARONGO LEONCIO & 70 & $0.00 \%$ \\
\hline IMPORT. EXPORT. PRODEX E.I.R.L. & 40 & $0.00 \%$ \\
\hline TOTAL & $5,044,247$ & $100 \%$ \\
\hline
\end{tabular}

Fuente: SUNAT

Elaboración propia 
Anexo 4. Análisis factorial exploratorio de la variable Estrategia de Negocios

Tabla 56.

Matriz de correlaciones ${ }^{a}$ para la variable Estrategia de negocios.

a. Esta matriz no es cierta positiva.

En la tabla se muestra que en lugar de la prueba de KMO y Bartlet la indicación de que "Esta matriz no es cierta positiva". Lo cual se explica al tener una escasa cantidad de encuestados en comparación con la cantidad de los ítems empleados. Ello indica que no se podría realizar el análisis factorial exploratorio. 
Tabla 57.

Varianza total explicada para la variable estrategia de negocios.

\begin{tabular}{|c|c|c|c|c|c|c|c|c|c|}
\hline \multirow[b]{2}{*}{$\begin{array}{l}\text { Compo } \\
\text { nente }\end{array}$} & \multicolumn{3}{|c|}{ Autovalores iniciales } & \multicolumn{3}{|c|}{$\begin{array}{c}\text { Sumas de cargas al cuadrado } \\
\text { de la extracción }\end{array}$} & \multicolumn{3}{|c|}{$\begin{array}{c}\text { Sumas de cargas al cuadrado } \\
\text { de la rotación }\end{array}$} \\
\hline & Total & $\begin{array}{c}\% \text { de } \\
\text { varianza }\end{array}$ & $\begin{array}{c}\% \\
\text { acumulado } \\
\end{array}$ & Total & $\begin{array}{c}\% \text { de } \\
\text { varianza }\end{array}$ & $\begin{array}{c}\% \\
\text { acumulado } \\
\end{array}$ & Total & $\begin{array}{c}\% \text { de } \\
\text { varianza }\end{array}$ & $\begin{array}{c}\% \\
\text { acumulado } \\
\end{array}$ \\
\hline 1 & 7,710 & 26,587 & 26,587 & 7,710 & 26,587 & 26,587 & 5,729 & 19,755 & 19,755 \\
\hline 2 & 4,631 & 15,970 & 42,557 & 4,631 & 15,970 & 42,557 & 3,055 & 10,534 & 30,289 \\
\hline 3 & 3,603 & 12,423 & 54,980 & 3,603 & 12,423 & 54,980 & 3,012 & 10,386 & 40,675 \\
\hline 4 & 2,982 & 10,284 & 65,264 & 2,982 & 10,284 & 65,264 & 3,003 & 10,356 & 51,031 \\
\hline 5 & 2,543 & 8,767 & 74,031 & 2,543 & 8,767 & 74,031 & 2,928 & 10,098 & 61,128 \\
\hline 6 & 1,985 & 6,844 & 80,875 & 1,985 & 6,844 & 80,875 & 2,875 & 9,913 & 71,042 \\
\hline 7 & 1,950 & 6,725 & 87,599 & 1,950 & 6,725 & 87,599 & 2,792 & 9,629 & 80,671 \\
\hline 8 & 1,476 & 5,091 & 92,690 & 1,476 & 5,091 & 92,690 & 2,673 & 9,218 & 89,889 \\
\hline 9 & 1,252 & 4,318 & 97,008 & 1,252 & 4,318 & 97,008 & 2,065 & 7,119 & 97,008 \\
\hline 10 & 0,868 & 2,992 & 100,000 & & & & & & \\
\hline 11 & $8,546 \mathrm{E}-16$ & 2,947E-15 & 100,000 & & & & & & \\
\hline 12 & $6,801 \mathrm{E}-16$ & $2,345 \mathrm{E}-15$ & 100,000 & & & & & & \\
\hline 13 & $5,466 \mathrm{E}-16$ & $1,885 \mathrm{E}-15$ & 100,000 & & & & & & \\
\hline 14 & $5,316 \mathrm{E}-16$ & $1,833 \mathrm{E}-15$ & 100,000 & & & & & & \\
\hline 15 & $3,431 \mathrm{E}-16$ & $1,183 \mathrm{E}-15$ & 100,000 & & & & & & \\
\hline 16 & $2,518 \mathrm{E}-16$ & $8,684 \mathrm{E}-16$ & 100,000 & & & & & & \\
\hline 17 & $1,900 \mathrm{E}-16$ & $6,550 \mathrm{E}-16$ & 100,000 & & & & & & \\
\hline 18 & $1,805 \mathrm{E}-16$ & $6,225 \mathrm{E}-16$ & 100,000 & & & & & & \\
\hline 19 & $1,341 \mathrm{E}-16$ & $4,623 \mathrm{E}-16$ & 100,000 & & & & & & \\
\hline 20 & $1,568 \mathrm{E}-17$ & $5,406 \mathrm{E}-17$ & 100,000 & & & & & & \\
\hline 21 & $-8,570 \mathrm{E}-17$ & $-2,955 E-16$ & 100,000 & & & & & & \\
\hline 22 & $-1,461 \mathrm{E}-16$ & $-5,037 E-16$ & 100,000 & & & & & & \\
\hline 23 & $-2,077 E-16$ & $-7,162 \mathrm{E}-16$ & 100,000 & & & & & & \\
\hline 24 & $-3,384 E-16$ & $-1,167 \mathrm{E}-15$ & 100,000 & & & & & & \\
\hline 25 & $-4,032 E-16$ & $-1,390 \mathrm{E}-15$ & 100,000 & & & & & & \\
\hline 26 & $-4,767 E-16$ & $-1,644 \mathrm{E}-15$ & 100,000 & & & & & & \\
\hline 27 & $-7,819 E-16$ & $-2,696 \mathrm{E}-15$ & 100,000 & & & & & & \\
\hline 28 & $-1,092 E-15$ & $-3,765 E-15$ & 100,000 & & & & & & \\
\hline 29 & $-1,554 E-15$ & $-5,359 E-15$ & 100,000 & & & & & & \\
\hline
\end{tabular}

Método de extracción: análisis de componentes principales.

En la tabla se muestra el posible porcentaje de varianza total que explicaría el modelo de análisis factorial propuesto, lo cual sería 97,008\%. 
Tabla 58.

Matriz de componente rotado ${ }^{a}$ para la variable Estrategia de negocios.

\begin{tabular}{|c|c|c|c|c|c|c|c|c|c|}
\hline & \multicolumn{9}{|c|}{ Componente } \\
\hline & 1 & 2 & 3 & 4 & 5 & 6 & 7 & 8 & 9 \\
\hline ítem13 & 0,971 & & & & & & & & \\
\hline ítem24 & 0,956 & & & & & & & & \\
\hline ítem3 & 0,912 & & & & & & & & \\
\hline ítem22 & 0,729 & & & & & & & & \\
\hline ítem5 & 0,703 & & & & & & & & \\
\hline ítem28 & & $-0,893$ & & & & & & & \\
\hline ítem2 & & 0,886 & & & & & & & \\
\hline ítem19 & & 0,705 & & & & & & & \\
\hline ítem27 & & 0,539 & & & & & & & \\
\hline ítem7 & & & $-0,869$ & & & & & & \\
\hline ítem26 & & & 0,744 & & & & & & \\
\hline ítem21 & & & 0,706 & & & & & & \\
\hline ítem17 & & & & 0,890 & & & & & \\
\hline ítem9 & & & & 0,679 & & & & & \\
\hline ítem23 & & & & 0,649 & & & & & \\
\hline ítem20 & & & & & 0,892 & & & & \\
\hline ítem16 & & & & & 0,708 & & & & \\
\hline ítem25 & & & & & 0,631 & & & & \\
\hline ítem11 & & & & & & 0,844 & & & \\
\hline ítem4 & & & & & & 0,619 & & & \\
\hline ítem12 & & & & & & 0,585 & & & \\
\hline ítem15 & & & & & & 0,555 & & & \\
\hline ítem29 & & & & & & & 0,913 & & \\
\hline ítem14 & & & & & & & 0,775 & & \\
\hline ítem18 & & & & & & & & 0,950 & \\
\hline ítem1 & & & & & & & & $-0,595$ & \\
\hline ítem8 & & & & & & & & 0,590 & \\
\hline ítem6 & & & & & & & & 0,540 & \\
\hline ítem10 & & & & & & & & & 0,931 \\
\hline
\end{tabular}

Método de extracción: análisis de componentes principales.

Método de rotación: Varimax con normalización Kaiser.

a. La rotación ha convergido en 18 iteraciones. 
En la tabla se muestra que el modelo factorial exploratorio para la variable Estrategia de negocio se compondría de 9 factores. Se observan, por otro lado, los autovalores con los cuales cada ítem se correlaciona de mayor manera con cada factor.

\section{Anexo 5. Análisis factorial exploratorio de la variable Rendimiento de las exportaciones}

Tabla 59.

Prueba de KMO y Bartlett para la variable Rendimiento de las exportaciones.

\begin{tabular}{lrr}
\hline Medida Kaiser-Meyer-Olkin de adecuación de muestreo & 0,745 \\
Prueba de esfericidad de Bartlett & Aprox. Chi-cuadrado & 34,332 \\
& gl & 15 \\
& Sig. & 0,003 \\
\hline
\end{tabular}

En la tabla se muestra la prueba de KMO y Bartlett. En primer lugar, la prueba de esfericidad de Bartlett indica si resulta adecuado la utilización del análisis factorial. Al ser la significancia inferior al nivel de significancia de 0,05, entonces indica que sí resulta adecuado la utilización del análisis factorial. Por otro lado, el coeficiente de KMO indica el valor de 0,745 , lo cual, al estar cerca del valor de 1 , expresa que el análisis factorial exploratorio resulta medianamente adecuado.

Tabla 60.

Varianza total explicada para la variable Rendimiento de las exportaciones.

\begin{tabular}{lccc|ccc}
\hline & \multicolumn{3}{c|}{ Autovalores iniciales } & \multicolumn{3}{c}{$\begin{array}{c}\text { Sumas de cargas al cuadrado de la } \\
\text { extracción }\end{array}$} \\
\cline { 2 - 7 } Component & \multicolumn{3}{c}{$\%$ de } & $\begin{array}{c}\% \\
\text { e de }\end{array}$ & $\%$ \\
\hline 1 & Total & varianza & acumulado & Total & varianza & acumulado \\
\hline 2 & 4,069 & 67,824 & 67,824 & 4,069 & 67,824 & 67,824 \\
3 & 0,839 & 13,976 & 81,800 & & & \\
4 & 0,539 & 8,979 & 90,779 & & & \\
5 & 0,309 & 5,148 & 95,927 & & & \\
6 & 0,140 & 2,325 & 98,252 & & & \\
\hline
\end{tabular}

Método de extracción: análisis de componentes principales. 
En la tabla se muestra el porcentaje de varianza total que explica el modelo de análisis factorial propuesto, lo cual es $67,824 \%$.

Tabla 61.

Matriz de componente rotado para la variable Rendimiento de las exportaciones

a. Sólo se ha extraído un componente. La solución no se puede rotar.

Como se puede observar la tabla indica que solamente habría un solo factor resultante para hacer el análisis factorial exploratorio. Por lo cual no aparece resultado.

\section{Anexo 6: Alfa de Cronbach Estrategia de negocios}

Tabla 62.

Alfa de cronbach para la variable Estrategia de negocios

Alfa de Cronbach

$\mathrm{N}$ de elementos

$$
0,860
$$

29

\section{Anexo 7: Alfa de Cronbach Rendimiento de las exportaciones}

Tabla 63.

Alfa de cronbach para la variable Rendimiento de las exportaciones

Alfa de Cronbach

$\mathrm{N}$ de elementos

0,902

6 
Anexo 8: Instrumento para validez de contenido - Juicio de Expertos

INSTRUMENTO PARA VALIDEZ DE CONTENIDO

\section{JUICIO DE EXPERTOS}

El presente instrumento tiene como finalidad validar el formulario de la relación entre las Estrategias de Negocio (competencia de tecnología global, desarrollo de productos únicos, enfoque en la calidad y aprovechamiento de competencias de distribuidores) y el Rendimiento Exportador. El mismo que será aplicado a empresas que forman parte del estudio "RELACIÓN ENTRE LAS ESTRATEGIAS DE NEGOCIO Y EL RENDIMIENTO DE LAS EXPORTACIONES DE EMPRESAS PERUANAS FABRICANTES DE MAQUINAS PARA LA INDUSTRIA PANADERA DEL 2014 AL 2018" que corresponde a un diseño de investigación cuantitativo correlacional no experimental transversal.

\section{Instrucciones}

La evaluación requiere de la lectura detallada y completa de cada uno de los ítems propuestos a fin de cotejarlos de manera cualitativa con los criterios propuestos relativos a: Claridad de la redacción, Congruencia con el contenido, Contexto correcto del ítem y Dominio del Constructo. Para ellos deberá asignar una valoración si el ítem presenta o no los criterios propuestos, y en caso necesario se ofrece un espacio para las observaciones en caso hubiese.

Fecha actual: 02/03/2020

Nombres y apellidos del evaluador: Jimmy Sánchez Gómez

Puesto de trabajo: Asesor y docente USIL / Gerente de Marketing en Delcore Institución donde se elabora: Universidad San Ignacio de Loyola.

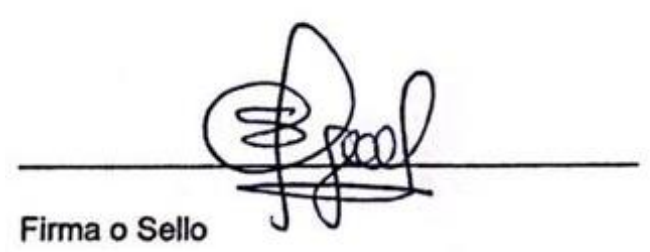


INVENTARIO DEL CUESTIONARIO, INSTRUMENTO PARA FINES ESPECÍFICOS DE LA VALIDACIÓN DE CONTENIDOS (JUICIO DE EXPERTOS)

Calificación: Inaceptable (1) Poco aceptable (2) Regular (3) Aceptable (4) Muy aceptable (5)

\begin{tabular}{|c|c|c|c|c|c|c|}
\hline & \multirow[b]{2}{*}{ Enunciados } & \multicolumn{5}{|c|}{ Calificación } \\
\hline & & Claridad $^{1}$ & Congruencia $^{2}$ & Contexto $^{3}$ & $\begin{array}{l}\text { Dominio del } \\
\text { constructo }^{4}\end{array}$ & Sugerencias \\
\hline \multicolumn{7}{|c|}{ Competencia tecnológica global } \\
\hline $\mathrm{P} 1$ & $\begin{array}{l}\text { La empresa está a la } \\
\text { vanguardia tecnológica } \\
\text { de la industria en el } \\
\text { mercado. }\end{array}$ & 5 & 5 & 5 & 5 & \\
\hline $\mathrm{P} 2$ & $\begin{array}{l}\text { La empresa inventa } \\
\text { mucha de la tecnología } \\
\text { incorporada en sus } \\
\text { productos. }\end{array}$ & 5 & 5 & 5 & 5 & \\
\hline P3 & $\begin{array}{l}\text { En comparación con los } \\
\text { competidores locales, a } \\
\text { menudo la empresa es } \\
\text { de las primeras en } \\
\text { introducir innovaciones } \\
\text { de productos o nuevos } \\
\text { enfoques operativos. }\end{array}$ & 5 & 5 & 5 & 5 & \\
\hline
\end{tabular}

\footnotetext{
${ }^{1}$ El ítem no tiene dificultad para entenderse

${ }^{2}$ El ítem tiene relación con el constructo

${ }^{3}$ En el ítem todas las palabras son usuales para nuestro contexto

${ }^{4}$ El ítem evalúa el componente o dimensión específica del constructo (bloques)
} 


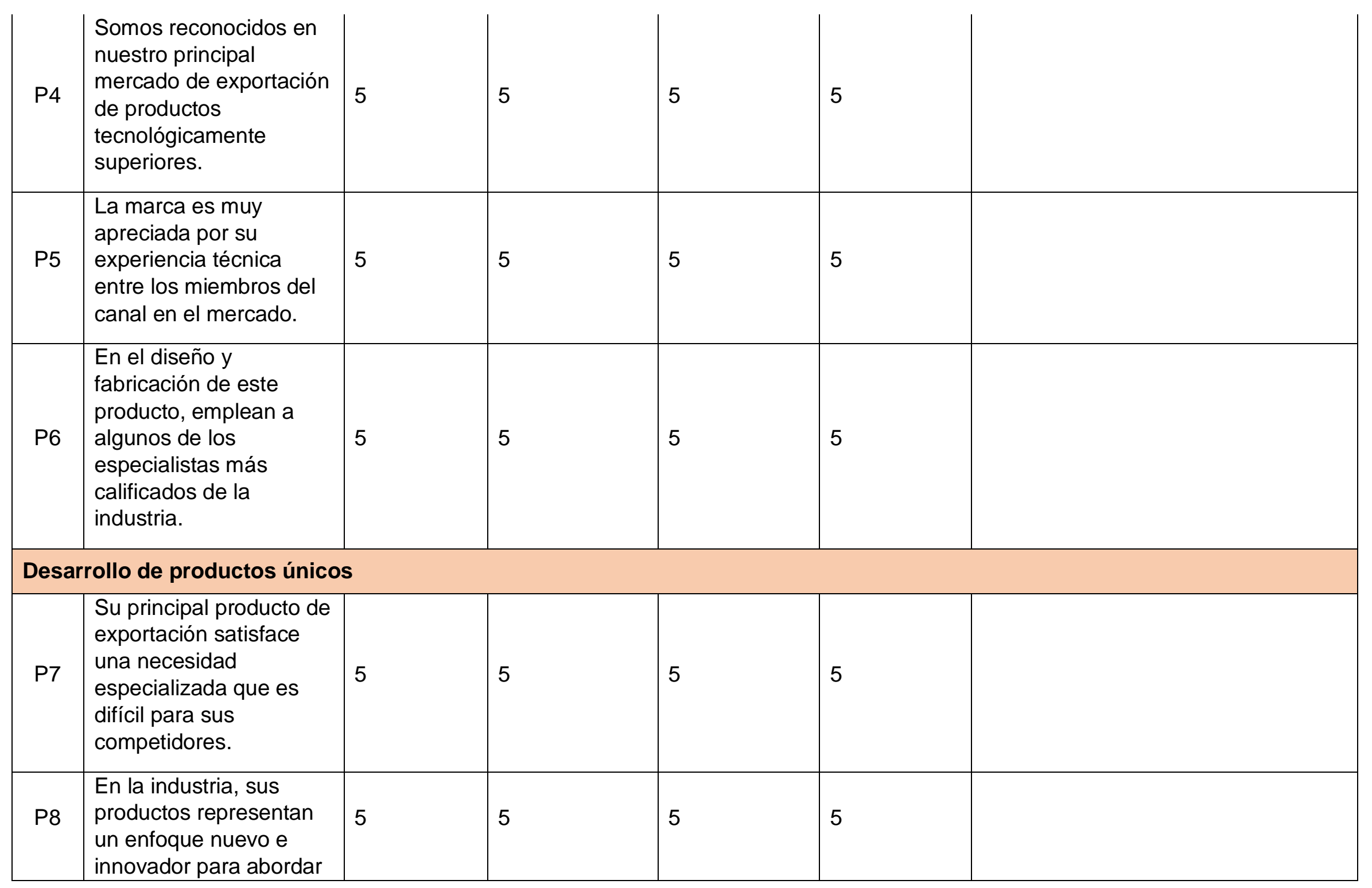




\begin{tabular}{|c|c|c|c|c|c|c|}
\hline & $\begin{array}{l}\text { las necesidades básicas } \\
\text { del cliente. }\end{array}$ & & & & & \\
\hline P9 & $\begin{array}{l}\text { En comparación con las } \\
\text { ofertas de sus } \\
\text { principales } \\
\text { competidores, su } \\
\text { producto es único con } \\
\text { respecto al diseño } \\
\text { clientes y la } \\
\text { competencia. }\end{array}$ & 5 & 5 & 5 & 5 & \\
\hline P10 & $\begin{array}{l}\text { En comparación con las } \\
\text { ofertas de sus } \\
\text { principales } \\
\text { competidores, sus } \\
\text { productos son únicos } \\
\text { con respecto a la } \\
\text { tecnología. }\end{array}$ & 5 & 5 & 5 & 5 & \\
\hline P11 & $\begin{array}{l}\text { En comparación con las } \\
\text { ofertas de sus } \\
\text { principales } \\
\text { competidores, sus } \\
\text { productos son únicos } \\
\text { con respecto al } \\
\text { rendimiento. }\end{array}$ & 5 & 5 & 5 & 5 & \\
\hline \multicolumn{7}{|c|}{ Enfoque en la calidad } \\
\hline P12 & $\begin{array}{l}\text { Enfatizar la calidad del } \\
\text { servicio al cliente es } \\
\text { importante para la }\end{array}$ & 5 & 5 & 5 & 5 & \\
\hline
\end{tabular}




\begin{tabular}{|c|c|c|c|c|c|c|}
\hline & $\begin{array}{l}\text { estrategia de la } \\
\text { empresa en el mercado. }\end{array}$ & & & & & \\
\hline $\mathrm{P} 13$ & $\begin{array}{l}\text { Enfatizar la calidad del } \\
\text { producto es importante } \\
\text { para la estrategia de la } \\
\text { empresa en el mercado. }\end{array}$ & 5 & 5 & 5 & 5 & \\
\hline P14 & $\begin{array}{l}\text { Para nosotros, el éxito } \\
\text { en el mercado está } \\
\text { impulsado por la } \\
\text { verdadera satisfacción } \\
\text { de las necesidades de } \\
\text { nuestros clientes allí. }\end{array}$ & 5 & 5 & 5 & 5 & \\
\hline P15 & $\begin{array}{l}\text { El rendimiento de los } \\
\text { productos realmente } \\
\text { cumple con las } \\
\text { expectativas de los } \\
\text { clientes en el mercado. }\end{array}$ & 5 & 5 & 5 & 5 & \\
\hline P16 & $\begin{array}{l}\text { El servicio brindado con } \\
\text { los productos realmente } \\
\text { cumple con las } \\
\text { expectativas de los } \\
\text { clientes en el mercado. }\end{array}$ & 5 & 5 & 5 & 5 & \\
\hline \multicolumn{7}{|c|}{ Aprovechamiento de las competencias de los distribuidores extranjeros } \\
\hline P17 & $\begin{array}{l}\text { Los distribuidores } \\
\text { cumplen con las } \\
\text { expectativas en cuanto } \\
\text { a establecimiento de } \\
\text { precios locales. }\end{array}$ & 5 & 5 & 5 & 5 & \\
\hline
\end{tabular}




\begin{tabular}{|l|l|l|l|l|l|l|}
\hline P18 & $\begin{array}{l}\text { Los distribuidores } \\
\text { cumplen con las } \\
\text { expectativas en cuanto } \\
\text { a venta local. }\end{array}$ & 5 & 5 & 5 & 5 & \\
\hline P19 & $\begin{array}{l}\text { Los distribuidores } \\
\text { cumplen con las } \\
\text { expectativas en cuanto } \\
\text { a publicidad local. }\end{array}$ & 5 & 5 & 5 & 5 & \\
\hline P20 & $\begin{array}{l}\text { Los distribuidores } \\
\text { cumplen con las } \\
\text { expectativas en cuanto } \\
\text { a servicio. }\end{array}$ & 5 & 5 & 5 & 5 & \\
\hline P21 & $\begin{array}{l}\text { Los distribuidores } \\
\text { cumplen con las } \\
\text { expectativas en cuanto } \\
\text { a recopilación de } \\
\text { información del } \\
\text { mercado local. }\end{array}$ & 5 & 5 & 5 & 5 & \\
\hline P22 & $\begin{array}{l}\text { Los distribuidores } \\
\text { cumplen con las } \\
\text { expectativas en relación } \\
\text { con el gobierno local. }\end{array}$ & 5 & 5 & 5 & 5 & \\
\hline P23 & $\begin{array}{l}\text { Los distribuidores } \\
\text { cumplen con las } \\
\text { expectativas en cuanto } \\
\text { a cultivar nuevos } \\
\text { negocios / expansión. }\end{array}$ & 5 & 5 & 5 & 5 & \\
\hline
\end{tabular}




\begin{tabular}{|c|c|c|c|c|c|}
\hline P24 & $\begin{array}{l}\text { Los distribuidores } \\
\text { cumplen con las } \\
\text { expectativas en cuanto } \\
\text { a modificación del } \\
\text { producto (si existe). }\end{array}$ & 5 & 5 & 5 & 5 \\
\hline P25 & $\begin{array}{l}\text { Los distribuidores } \\
\text { cumplen con las } \\
\text { expectativas en cuanto } \\
\text { a organización del envío } \\
\text { internacional. }\end{array}$ & 5 & 5 & 5 & 5 \\
\hline P26 & $\begin{array}{l}\text { Los distribuidores } \\
\text { cumplen con las } \\
\text { expectativas en cuanto } \\
\text { a organización del envío } \\
\text { local. }\end{array}$ & 5 & 5 & 5 & 5 \\
\hline P27 & $\begin{array}{l}\text { Los distribuidores } \\
\text { cumplen con las } \\
\text { expectativas en cuanto } \\
\text { a relaciones públicas } \\
\text { locales. }\end{array}$ & 5 & 5 & 5 & 5 \\
\hline P28 & $\begin{array}{l}\text { Los distribuidores } \\
\text { cumplen con las } \\
\text { expectativas en cuanto } \\
\text { a soporte técnico al } \\
\text { cliente / capacitación. }\end{array}$ & 5 & 5 & 5 & 5 \\
\hline
\end{tabular}




\begin{tabular}{|l|l|l|l|l|l|l|}
\hline P29 & $\begin{array}{l}\text { Los distribuidores } \\
\text { cumplen con las } \\
\text { expectativas en cuanto } \\
\text { a traducción de } \\
\text { literatura de ventas, } \\
\text { instrucciones de uso o } \\
\text { etiquetas. }\end{array}$ & 5 & 5 & 5 & 5 & \\
\hline Rendimiento de las exportaciones & $\begin{array}{l}\text { Durante el periodo } \\
\text { 2014-2018, la empresa } \\
\text { ha estado satisfecha } \\
\text { con el rendimiento del } \\
\text { producto con respecto a } \\
\text { la cuota de mercado. }\end{array}$ & 5 & 5 & 5 & 5 & \\
\hline P31 & $\begin{array}{l}\text { Durante el periodo } \\
\text { 2014-2018, la empresa } \\
\text { ha estado satisfecha } \\
\text { con el rendimiento del } \\
\text { producto con respecto } \\
\text { al crecimiento de ventas } \\
\text { en el mercado. }\end{array}$ & 5 & 5 & 5 & 5 & \\
\hline P32 & $\begin{array}{l}\text { Durante el periodo } \\
\text { 2014-2018, la empresa } \\
\text { ha estado satisfecha } \\
\text { con el rendimiento de } \\
\text { sus productos con } \\
\text { respecto a la } \\
\text { rentabilidad antes de }\end{array}$ & 5 & 5 & 5 & 5 & \\
\hline
\end{tabular}




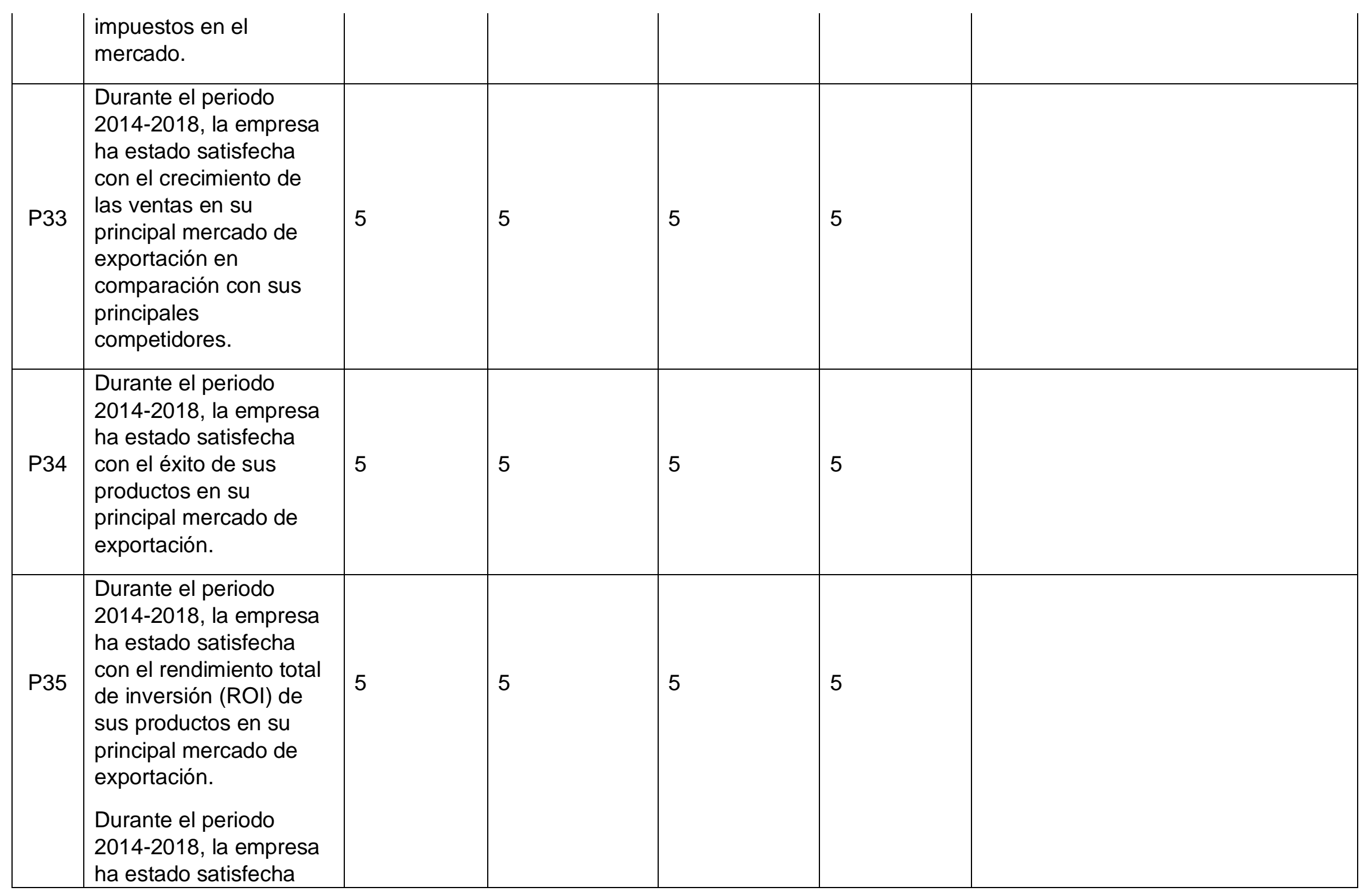




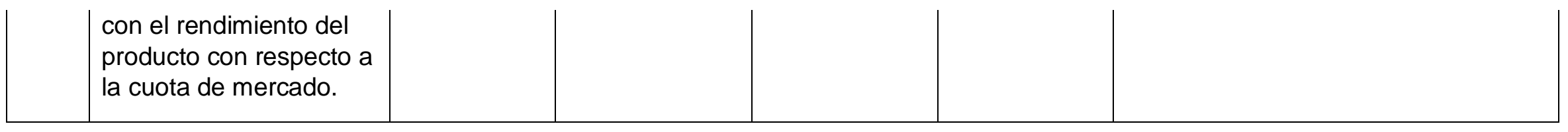

124 


\section{INSTRUMENTO PARA VALIDEZ DE CONTENIDO JUICIO DE EXPERTOS}

El presente instrumento tiene como finalidad validar el formulario de la relación entre las Estrategias de Negocio (competencia de tecnología global, desarrollo de productos únicos, enfoque en la calidad y aprovechamiento de competencias de distribuidores) y el Rendimiento Exportador. El mismo que será aplicado a empresas que forman parte del estudio "RELACIÓN ENTRE LAS ESTRATEGIAS DE NEGOCIO Y EL RENDIMIENTO DE LAS EXPORTACIONES DE EMPRESAS PERUANAS FABRICANTES DE MAQUINAS PARA LA INDUSTRIA PANADERA DEL 2014 AL 2018" que corresponde a un diseño de investigación cuantitativo correlacional no experimental transversal.

\section{Instrucciones}

La evaluación requiere de la lectura detallada y completa de cada uno de los ítems propuestos a fin de cotejarlos de manera cualitativa con los criterios propuestos relativos a: Claridad de la redacción, Congruencia con el contenido, Contexto correcto del ítem y Dominio del Constructo. Para ellos deberá asignar una valoración si el ítem presenta o no los criterios propuestos, y en caso necesario se ofrece un espacio para las observaciones en caso hubiese.

Fecha actual: 28/02/2020

Nombres y apellidos del evaluador: Enrique Alonso Castro Guzmán

Puesto de trabajo: Coordinador académico Administración y Emprendimiento Institución donde se elabora: Universidad San Ignacio de Loyola.

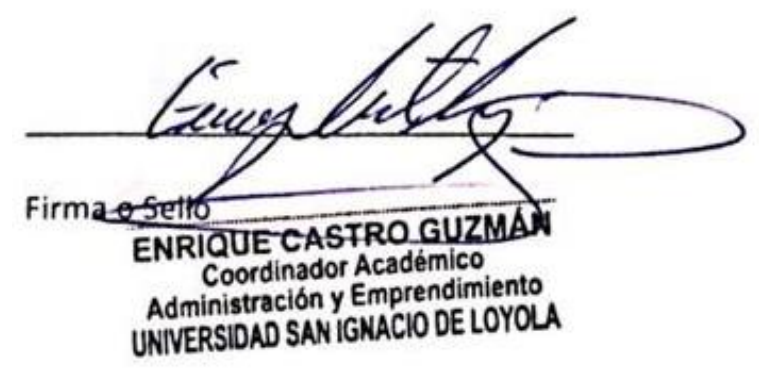


INVENTARIO DEL CUESTIONARIO, INSTRUMENTO PARA FINES ESPECÍFICOS DE LA VALIDACIÓN DE CONTENIDOS (JUICIO DE EXPERTOS)

Calificación: Inaceptable (1) Poco aceptable (2) Regular (3) Aceptable (4) Muy aceptable (5)

\begin{tabular}{|c|c|c|c|c|c|c|}
\hline \multirow{2}{*}{\multicolumn{2}{|c|}{ Enunciados }} & \multicolumn{5}{|c|}{ Calificación } \\
\hline & & Claridad $^{5}$ & Congruencia $^{6}$ & Contexto ${ }^{7}$ & $\begin{array}{l}\text { Dominio del } \\
\text { constructo }^{8}\end{array}$ & Sugerencias \\
\hline \multicolumn{7}{|c|}{ Competencia tecnológica global } \\
\hline P1 & $\begin{array}{l}\text { La empresa está a la } \\
\text { vanguardia tecnológica } \\
\text { de la industria en el } \\
\text { mercado. }\end{array}$ & 4 & 4 & 4 & 4 & \\
\hline P3 & $\begin{array}{l}\text { En comparación con los } \\
\text { competidores locales, a } \\
\text { menudo la empresa es } \\
\text { de las primeras en } \\
\text { introducir innovaciones } \\
\text { de productos o nuevos } \\
\text { enfoques operativos. }\end{array}$ & 5 & 5 & 5 & 5 & \\
\hline
\end{tabular}

${ }^{5}$ El ítem no tiene dificultad para entenderse

${ }^{6}$ El ítem tiene relación con el constructo

${ }^{7}$ En el ítem todas las palabras son usuales para nuestro contexto

${ }^{8}$ El ítem evalúa el componente o dimensión específica del constructo (bloques) 


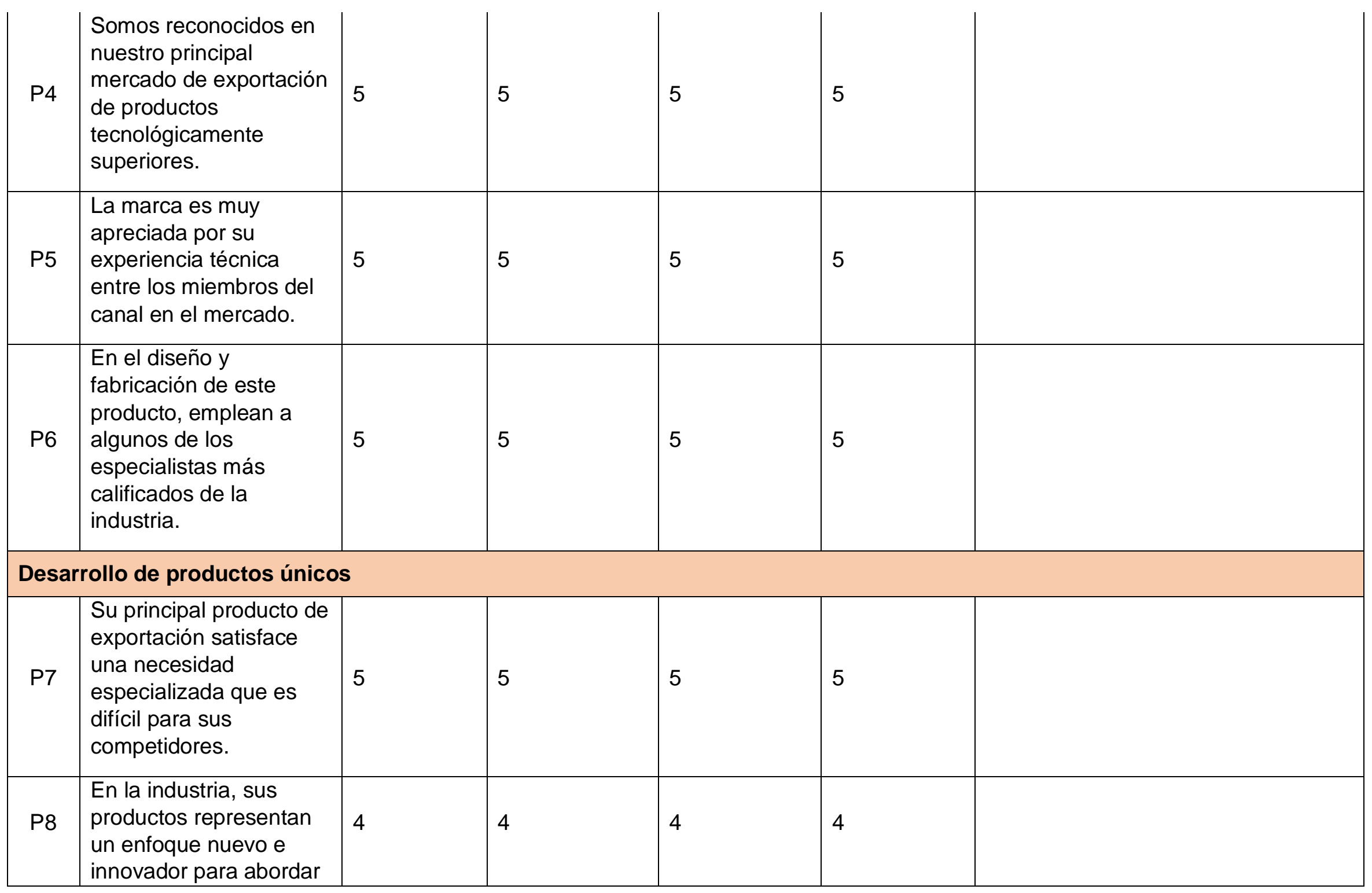




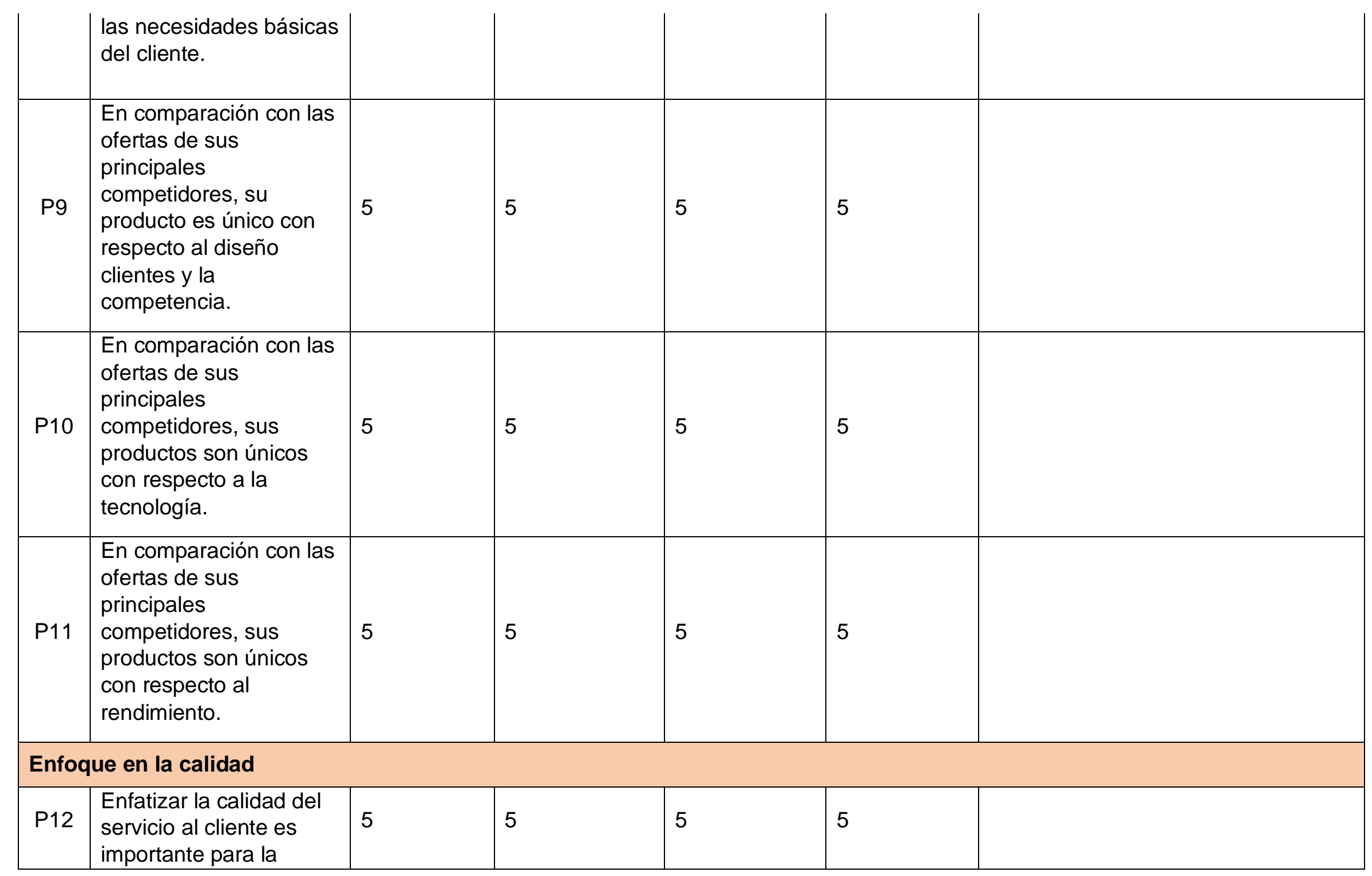




\begin{tabular}{|c|c|c|c|c|c|c|}
\hline & $\begin{array}{l}\text { estrategia de la } \\
\text { empresa en el mercado. }\end{array}$ & & & & & \\
\hline $\mathrm{P} 13$ & $\begin{array}{l}\text { Enfatizar la calidad del } \\
\text { producto es importante } \\
\text { para la estrategia de la } \\
\text { empresa en el mercado. }\end{array}$ & 5 & 5 & 5 & 5 & \\
\hline P14 & $\begin{array}{l}\text { Para nosotros, el éxito } \\
\text { en el mercado está } \\
\text { impulsado por la } \\
\text { verdadera satisfacción } \\
\text { de las necesidades de } \\
\text { nuestros clientes allí. }\end{array}$ & 4 & 4 & 4 & 4 & \\
\hline P15 & $\begin{array}{l}\text { El rendimiento de los } \\
\text { productos realmente } \\
\text { cumple con las } \\
\text { expectativas de los } \\
\text { clientes en el mercado. }\end{array}$ & 4 & 4 & 4 & 4 & $\begin{array}{l}\text { Asegurarse si los encuestados han } \\
\text { hecho estudios de nivel de } \\
\text { satisfacción a sus clientes. }\end{array}$ \\
\hline P16 & $\begin{array}{l}\text { El servicio brindado con } \\
\text { los productos realmente } \\
\text { cumple con las } \\
\text { expectativas de los } \\
\text { clientes en el mercado. }\end{array}$ & 4 & 4 & 4 & 4 & $\begin{array}{l}\text { Asegurarse si los encuestados han } \\
\text { hecho estudios de nivel de } \\
\text { satisfacción a sus clientes. }\end{array}$ \\
\hline \multicolumn{7}{|c|}{ Aprovechamiento de las competencias de los distribuidores extranjeros } \\
\hline P17 & $\begin{array}{l}\text { Los distribuidores } \\
\text { cumplen con las } \\
\text { expectativas en cuanto } \\
\text { a establecimiento de } \\
\text { precios locales. }\end{array}$ & 5 & 5 & 5 & 5 & \\
\hline
\end{tabular}




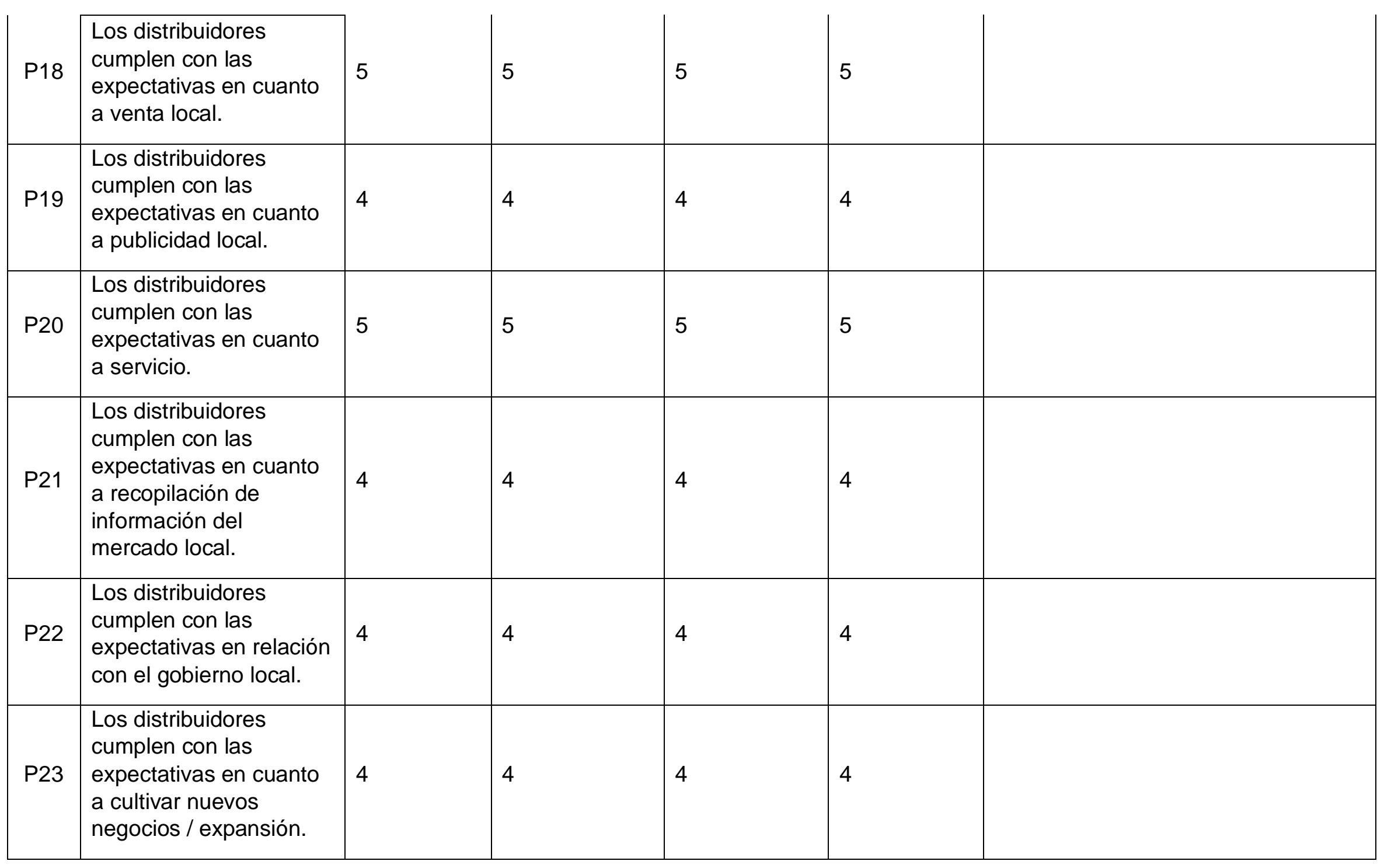




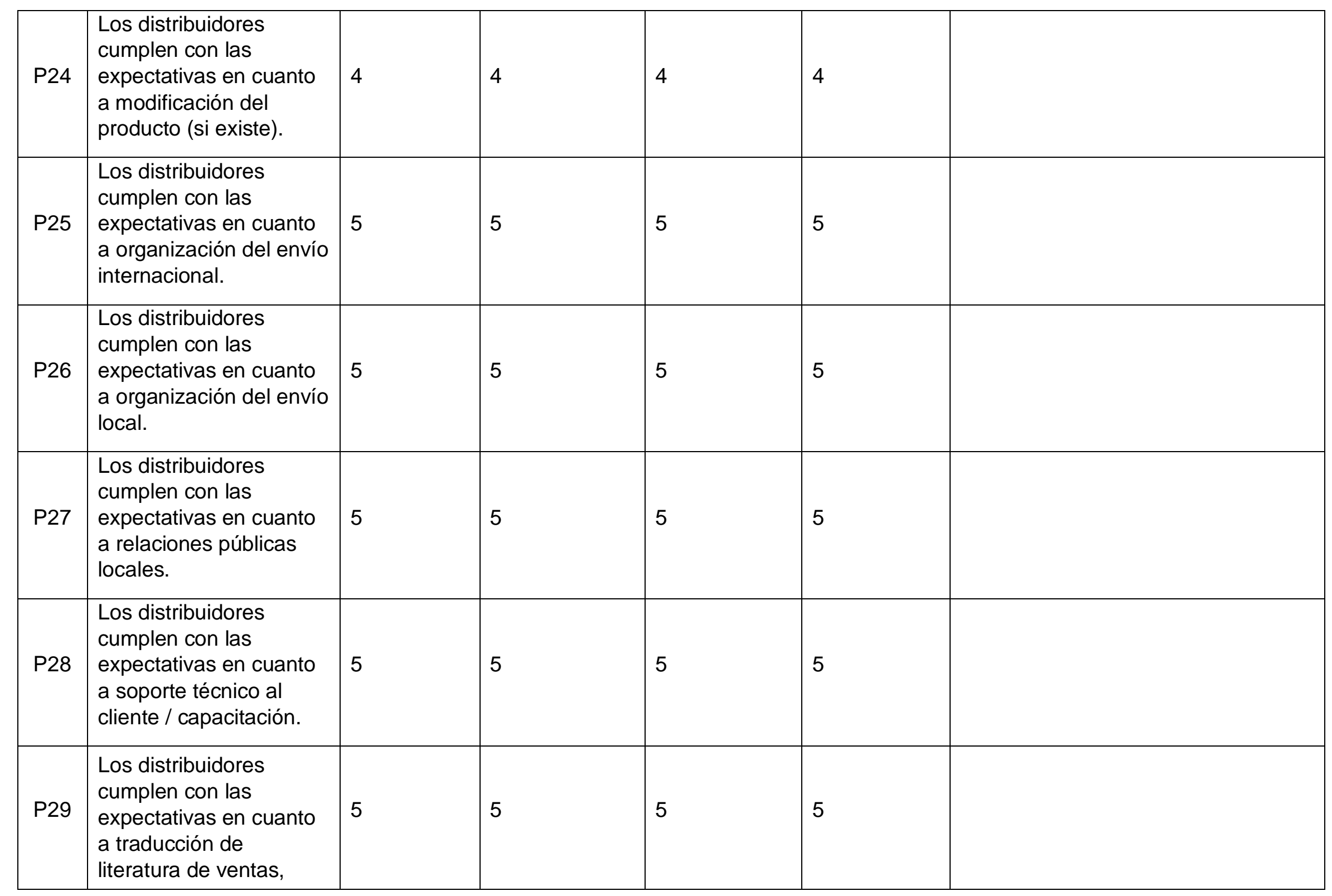




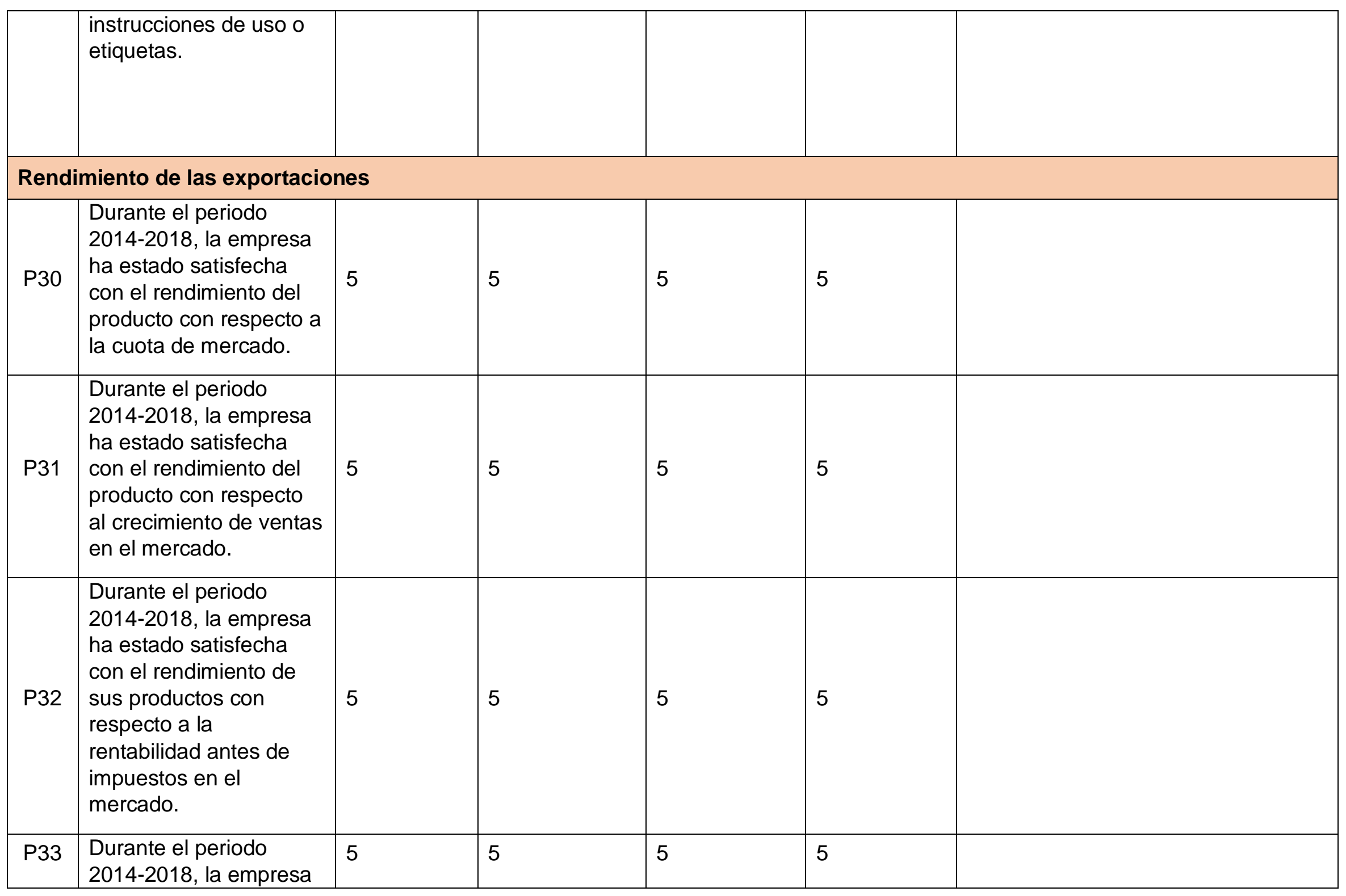




\begin{tabular}{|c|c|c|c|c|c|}
\hline & $\begin{array}{l}\text { ha estado satisfecha } \\
\text { con el crecimiento de } \\
\text { las ventas en su } \\
\text { principal mercado de } \\
\text { exportación en } \\
\text { comparación con sus } \\
\text { principales } \\
\text { competidores. }\end{array}$ & & & & \\
\hline P34 & $\begin{array}{l}\text { Durante el periodo } \\
2014-2018 \text {, la empresa } \\
\text { ha estado satisfecha } \\
\text { con el éxito de sus } \\
\text { productos en su } \\
\text { principal mercado de } \\
\text { exportación. }\end{array}$ & 5 & 5 & 5 & 5 \\
\hline P35 & $\begin{array}{l}\text { Durante el periodo } \\
2014-2018 \text {, la empresa } \\
\text { ha estado satisfecha } \\
\text { con el rendimiento total } \\
\text { de inversión (ROI) de } \\
\text { sus productos en su } \\
\text { principal mercado de } \\
\text { exportación. }\end{array}$ & 5 & 5 & 5 & 5 \\
\hline
\end{tabular}




\section{INSTRUMENTO PARA VALIDEZ DE CONTENIDO JUICIO DE EXPERTOS}

El presente instrumento tiene como finalidad validar el formulario de la relación entre las Estrategias de Negocio (competencia de tecnología global, desarrollo de productos únicos, enfoque en la calidad y aprovechamiento de competencias de distribuidores) y el Rendimiento Exportador. El mismo que será aplicado a empresas que forman parte del estudio "RELACIÓN ENTRE LAS ESTRATEGIAS DE NEGOCIO Y EL RENDIMIENTO DE LAS EXPORTACIONES DE EMPRESAS PERUANAS FABRICANTES DE MAQUINAS PARA LA INDUSTRIA PANADERA DEL 2014 AL 2018" que corresponde a un diseño de investigación cuantitativo correlacional no experimental transversal.

\section{Instrucciones}

La evaluación requiere de la lectura detallada y completa de cada uno de los ítems propuestos a fin de cotejarlos de manera cualitativa con los criterios propuestos relativos a: Claridad de la redacción, Congruencia con el contenido, Contexto correcto del ítem y Dominio del Constructo. Para ellos deberá asignar una valoración si el ítem presenta o no los criterios propuestos, y en caso necesario se ofrece un espacio para las observaciones en caso hubiese.

Fecha actual: 06/03/2020

Nombres y apellidos del evaluador: Carlos Eduardo Ossio Sal y Rosas

Puesto de trabajo: Docente de la Escuela de Postgrado

Institución donde se elabora: Universidad San Ignacio de Loyola.

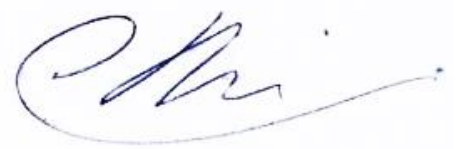

Firma o Sello 
INVENTARIO DEL CUESTIONARIO, INSTRUMENTO PARA FINES ESPECÍFICOS DE LA VALIDACIÓN DE CONTENIDOS (JUICIO DE EXPERTOS)

Calificación: Inaceptable (1) Poco aceptable (2) Regular (3) Aceptable (4) Muy aceptable (5)

\begin{tabular}{|c|c|c|c|c|c|c|}
\hline & \multirow[b]{2}{*}{ Enunciados } & \multicolumn{5}{|c|}{ Calificación } \\
\hline & & Claridad $^{9}$ & Congruencia $^{10}$ & Contexto $^{11}$ & $\begin{array}{l}\text { Dominio del } \\
\text { constructo }^{12}\end{array}$ & Sugerencias \\
\hline \multicolumn{7}{|c|}{ Competencia tecnológica global } \\
\hline $\mathrm{P} 1$ & $\begin{array}{l}\text { La empresa está a la } \\
\text { vanguardia tecnológica } \\
\text { de la industria en el } \\
\text { mercado. }\end{array}$ & 5 & 5 & 5 & 5 & \\
\hline $\mathrm{P} 2$ & $\begin{array}{l}\text { La empresa inventa } \\
\text { mucha de la tecnología } \\
\text { incorporada en sus } \\
\text { productos. }\end{array}$ & 5 & 5 & 5 & 5 & \\
\hline P3 & $\begin{array}{l}\text { En comparación con los } \\
\text { competidores locales, a } \\
\text { menudo la empresa es } \\
\text { de las primeras en } \\
\text { introducir innovaciones } \\
\text { de productos o nuevos } \\
\text { enfoques operativos. }\end{array}$ & 5 & 5 & 5 & 5 & \\
\hline
\end{tabular}

\footnotetext{
${ }^{9}$ El ítem no tiene dificultad para entenderse

${ }^{10} \mathrm{El}$ ítem tiene relación con el constructo

${ }^{11}$ En el ítem todas las palabras son usuales para nuestro contexto

${ }^{12}$ El ítem evalúa el componente o dimensión específica del constructo (bloques)
} 


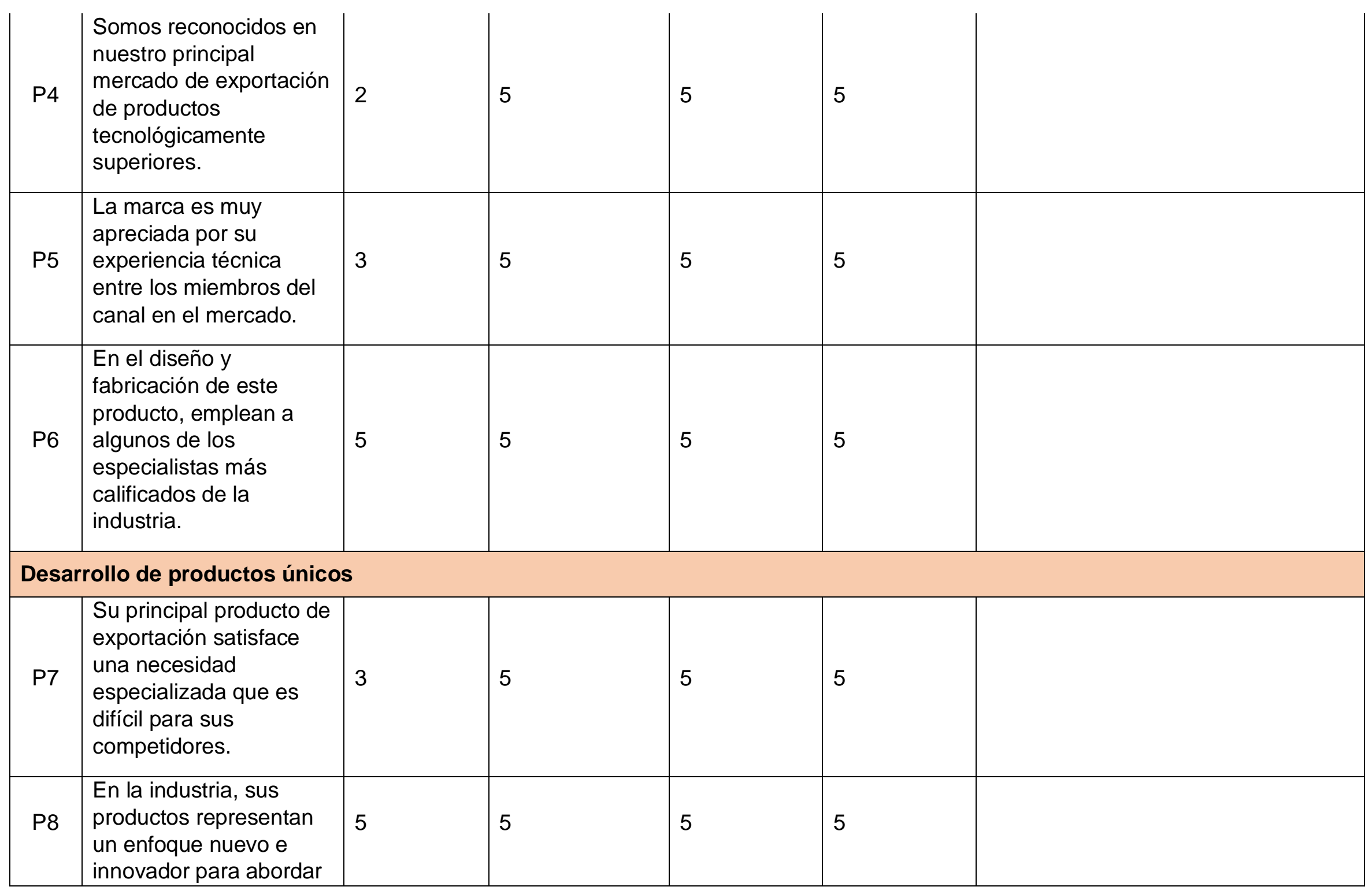




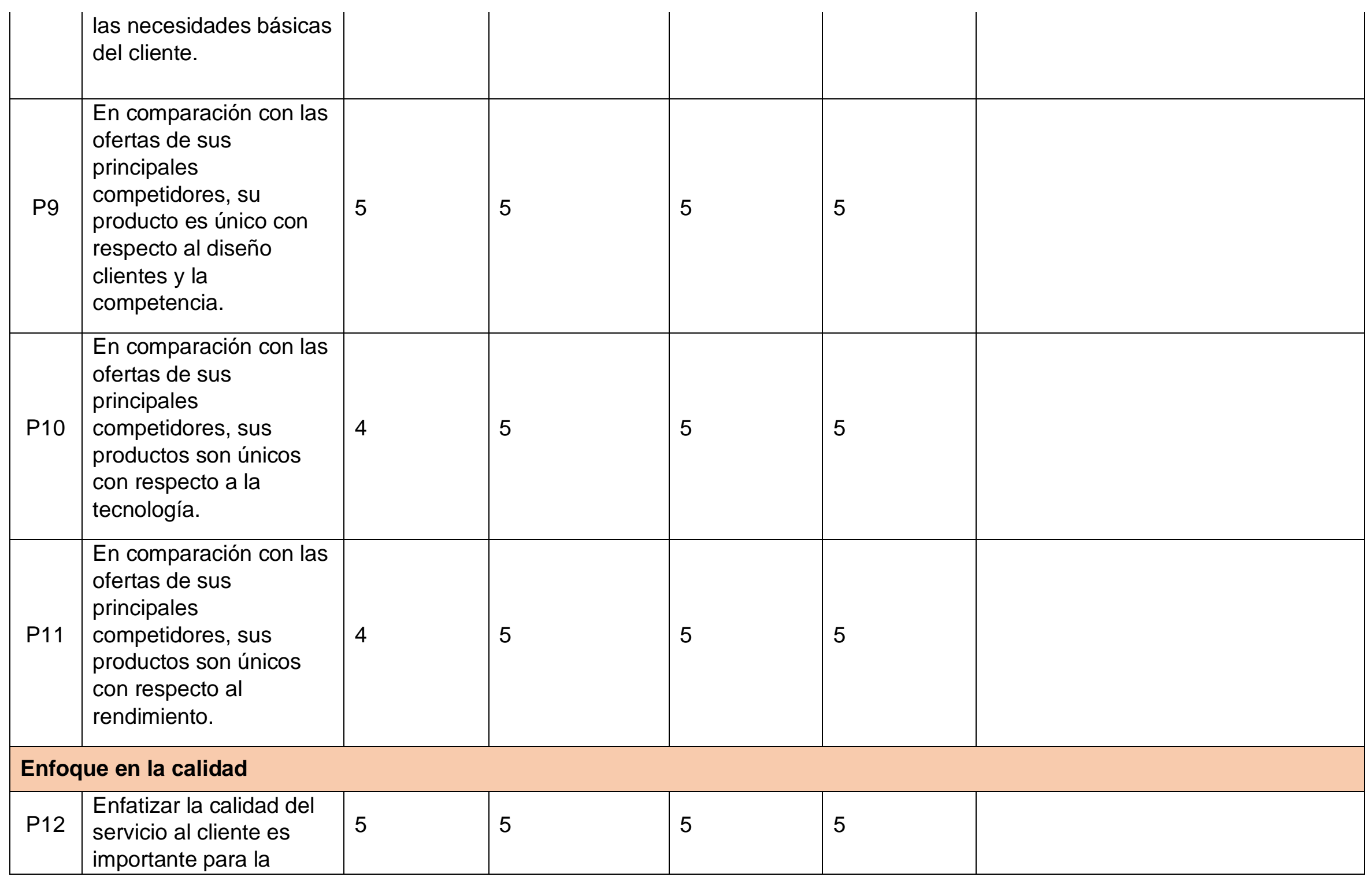




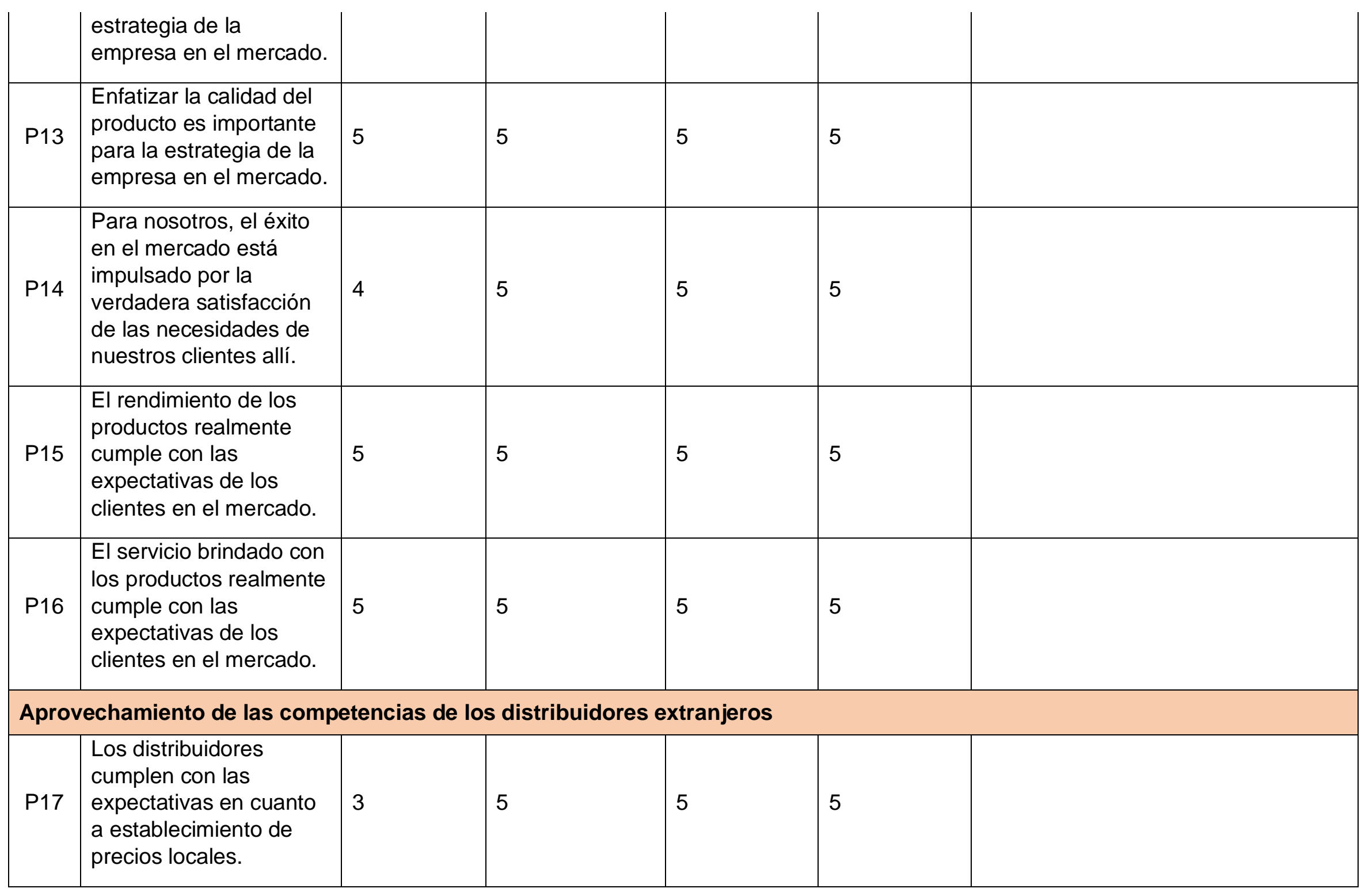




\begin{tabular}{|c|c|c|c|c|c|}
\hline P18 & $\begin{array}{l}\text { Los distribuidores } \\
\text { cumplen con las } \\
\text { expectativas en cuanto } \\
\text { a venta local. }\end{array}$ & 4 & 5 & 5 & 5 \\
\hline P19 & $\begin{array}{l}\text { Los distribuidores } \\
\text { cumplen con las } \\
\text { expectativas en cuanto } \\
\text { a publicidad local. }\end{array}$ & 4 & 5 & 5 & 5 \\
\hline P20 & $\begin{array}{l}\text { Los distribuidores } \\
\text { cumplen con las } \\
\text { expectativas en cuanto } \\
\text { a servicio. }\end{array}$ & 4 & 5 & 5 & 5 \\
\hline P21 & $\begin{array}{l}\text { Los distribuidores } \\
\text { cumplen con las } \\
\text { expectativas en cuanto } \\
\text { a recopilación de } \\
\text { información del } \\
\text { mercado local. }\end{array}$ & 4 & 5 & 5 & 5 \\
\hline P22 & $\begin{array}{l}\text { Los distribuidores } \\
\text { cumplen con las } \\
\text { expectativas en relación } \\
\text { con el gobierno local. }\end{array}$ & 4 & 5 & 5 & 5 \\
\hline P23 & $\begin{array}{l}\text { Los distribuidores } \\
\text { cumplen con las } \\
\text { expectativas en cuanto } \\
\text { a cultivar nuevos } \\
\text { negocios / expansión. }\end{array}$ & 4 & 5 & 5 & 5 \\
\hline
\end{tabular}




\begin{tabular}{|c|c|c|c|c|c|}
\hline P24 & $\begin{array}{l}\text { Los distribuidores } \\
\text { cumplen con las } \\
\text { expectativas en cuanto } \\
\text { a modificación del } \\
\text { producto (si existe). }\end{array}$ & 4 & 5 & 5 & 5 \\
\hline P25 & $\begin{array}{l}\text { Los distribuidores } \\
\text { cumplen con las } \\
\text { expectativas en cuanto } \\
\text { a organización del envío } \\
\text { internacional. }\end{array}$ & 4 & 5 & 5 & 5 \\
\hline P26 & $\begin{array}{l}\text { Los distribuidores } \\
\text { cumplen con las } \\
\text { expectativas en cuanto } \\
\text { a organización del envío } \\
\text { local. }\end{array}$ & 4 & 5 & 5 & 5 \\
\hline P27 & $\begin{array}{l}\text { Los distribuidores } \\
\text { cumplen con las } \\
\text { expectativas en cuanto } \\
\text { a relaciones públicas } \\
\text { locales. }\end{array}$ & 4 & 5 & 5 & 5 \\
\hline P28 & $\begin{array}{l}\text { Los distribuidores } \\
\text { cumplen con las } \\
\text { expectativas en cuanto } \\
\text { a soporte técnico al } \\
\text { cliente / capacitación. }\end{array}$ & 4 & 5 & 5 & 5 \\
\hline P29 & $\begin{array}{l}\text { Los distribuidores } \\
\text { cumplen con las } \\
\text { expectativas en cuanto } \\
\text { a traducción de } \\
\text { literatura de ventas, }\end{array}$ & 4 & 5 & 5 & 5 \\
\hline
\end{tabular}




\begin{tabular}{|c|c|c|c|c|c|c|}
\hline & $\begin{array}{l}\text { instrucciones de uso o } \\
\text { etiquetas. }\end{array}$ & & & & & \\
\hline \multicolumn{7}{|c|}{ Rendimiento de las exportaciones } \\
\hline P30 & $\begin{array}{l}\text { Durante el periodo } \\
2014-2018 \text {, la empresa } \\
\text { ha estado satisfecha } \\
\text { con el rendimiento del } \\
\text { producto con respecto a } \\
\text { la cuota de mercado. }\end{array}$ & 5 & 5 & 5 & 5 & \\
\hline P31 & $\begin{array}{l}\text { Durante el periodo } \\
2014-2018 \text {, la empresa } \\
\text { ha estado satisfecha } \\
\text { con el rendimiento del } \\
\text { producto con respecto } \\
\text { al crecimiento de ventas } \\
\text { en el mercado. }\end{array}$ & 5 & 5 & 5 & 5 & \\
\hline P32 & $\begin{array}{l}\text { Durante el periodo } \\
2014-2018 \text {, la empresa } \\
\text { ha estado satisfecha } \\
\text { con el rendimiento de } \\
\text { sus productos con } \\
\text { respecto a la } \\
\text { rentabilidad antes de } \\
\text { impuestos en el } \\
\text { mercado. }\end{array}$ & 5 & 5 & 5 & 5 & \\
\hline P33 & $\begin{array}{l}\text { Durante el periodo } \\
2014-2018 \text {, la empresa } \\
\text { ha estado satisfecha } \\
\text { con el crecimiento de } \\
\text { las ventas en su }\end{array}$ & 5 & 5 & 5 & 5 & \\
\hline
\end{tabular}




\begin{tabular}{|c|c|c|c|c|c|}
\hline & $\begin{array}{l}\text { principal mercado de } \\
\text { exportación en } \\
\text { comparación con sus } \\
\text { principales } \\
\text { competidores. }\end{array}$ & & & & \\
\hline P34 & $\begin{array}{l}\text { Durante el periodo } \\
2014-2018 \text {, la empresa } \\
\text { ha estado satisfecha } \\
\text { con el éxito de sus } \\
\text { productos en su } \\
\text { principal mercado de } \\
\text { exportación. }\end{array}$ & 5 & 5 & 5 & 5 \\
\hline P35 & $\begin{array}{l}\text { Durante el periodo } \\
2014-2018 \text {, la empresa } \\
\text { ha estado satisfecha } \\
\text { con el rendimiento total } \\
\text { de inversión (ROI) de } \\
\text { sus productos en su } \\
\text { principal mercado de } \\
\text { exportación. }\end{array}$ & 5 & 5 & 5 & 5 \\
\hline
\end{tabular}




\section{Anexo 9. Coeficiente V de Aiken}

\begin{tabular}{|c|c|c|c|c|c|c|c|c|c|c|c|c|c|c|}
\hline & \multicolumn{4}{|c|}{ Juez 1} & \multicolumn{4}{|c|}{ Juez 2} & \multicolumn{4}{|c|}{ Juez 3} & \multirow[b]{2}{*}{ Suma } & \multirow[b]{2}{*}{$\begin{array}{l}\text { V de } \\
\text { Aiker }\end{array}$} \\
\hline ÍTEM & Claridad & Congruencia & Contexto & $\begin{array}{c}\text { Dominio } \\
\text { del } \\
\text { constructo }\end{array}$ & Claridad & Congruencia & Contexto & $\begin{array}{c}\text { Dominio } \\
\text { del } \\
\text { constructo }\end{array}$ & Claridad & Congruencia & Contexto & $\begin{array}{c}\text { Dominio } \\
\text { del } \\
\text { constructo }\end{array}$ & & \\
\hline 1 & 5 & 5 & 5 & 5 & 4 & 4 & 4 & 4 & 5 & 5 & 5 & 5 & 46 & 0,77 \\
\hline 2 & 5 & 5 & 5 & 5 & 4 & 4 & 4 & 4 & 5 & 5 & 5 & 5 & 56 & 0,93 \\
\hline 3 & 5 & 5 & 5 & 5 & 5 & 5 & 5 & 5 & 5 & 5 & 5 & 5 & 60 & 1,00 \\
\hline 4 & 5 & 5 & 5 & 5 & 5 & 5 & 5 & 5 & 2 & 5 & 5 & 5 & 57 & 0,95 \\
\hline 5 & 5 & 5 & 5 & 5 & 5 & 5 & 5 & 5 & 3 & 5 & 5 & 5 & 58 & 0,97 \\
\hline 6 & 5 & 5 & 5 & 5 & 5 & 5 & 5 & 5 & 5 & 5 & 5 & 5 & 60 & 1,00 \\
\hline 7 & 5 & 5 & 5 & 5 & 5 & 5 & 5 & 5 & 3 & 5 & 5 & 5 & 58 & 0,97 \\
\hline 8 & 5 & 5 & 5 & 5 & 4 & 4 & 4 & 4 & 5 & 5 & 5 & 5 & 56 & 0,93 \\
\hline 9 & 5 & 5 & 5 & 5 & 5 & 5 & 5 & 5 & 5 & 5 & 5 & 5 & 60 & 1,00 \\
\hline 10 & 5 & 5 & 5 & 5 & 5 & 5 & 5 & 5 & 4 & 5 & 5 & 5 & 59 & 0,98 \\
\hline 11 & 5 & 5 & 5 & 5 & 5 & 5 & 5 & 5 & 4 & 5 & 5 & 5 & 59 & 0,98 \\
\hline 12 & 5 & 5 & 5 & 5 & 5 & 5 & 5 & 5 & 5 & 5 & 5 & 5 & 60 & 1,00 \\
\hline 13 & 5 & 5 & 5 & 5 & 5 & 5 & 5 & 5 & 5 & 5 & 5 & 5 & 60 & 1,00 \\
\hline 14 & 5 & 5 & 5 & 5 & 4 & 4 & 4 & 4 & 4 & 5 & 5 & 5 & 55 & 0,92 \\
\hline 15 & 5 & 5 & 5 & 5 & 4 & 4 & 4 & 4 & 5 & 5 & 5 & 5 & 56 & 0,93 \\
\hline 16 & 5 & 5 & 5 & 5 & 4 & 4 & 4 & 4 & 5 & 5 & 5 & 5 & 56 & 0,93 \\
\hline 17 & 5 & 5 & 5 & 5 & 5 & 5 & 5 & 5 & 3 & 5 & 5 & 5 & 58 & 0,97 \\
\hline 18 & 5 & 5 & 5 & 5 & 5 & 5 & 5 & 5 & 4 & 5 & 5 & 5 & 59 & 0,98 \\
\hline 19 & 5 & 5 & 5 & 5 & 4 & 4 & 4 & 4 & 4 & 5 & 5 & 5 & 46 & 0,77 \\
\hline 20 & 5 & 5 & 5 & 5 & 5 & 5 & 5 & 5 & 4 & 5 & 5 & 5 & 59 & 0,98 \\
\hline 21 & 5 & 5 & 5 & 5 & 4 & 4 & 4 & 4 & 4 & 5 & 5 & 5 & 55 & 0,92 \\
\hline 22 & 5 & 5 & 5 & 5 & 4 & 4 & 4 & 4 & 4 & 5 & 5 & 5 & 55 & 0,92 \\
\hline 23 & 5 & 5 & 5 & 5 & 4 & 4 & 4 & 4 & 4 & 5 & 5 & 5 & 55 & 0,92 \\
\hline 24 & 5 & 5 & 5 & 5 & 4 & 4 & 4 & 4 & 4 & 5 & 5 & 5 & 55 & 0,92 \\
\hline 25 & 5 & 5 & 5 & 5 & 5 & 5 & 5 & 5 & 4 & 5 & 5 & 5 & 59 & 0,98 \\
\hline 26 & 5 & 5 & 5 & 5 & 5 & 5 & 5 & 5 & 4 & 5 & 5 & 5 & 59 & 0,98 \\
\hline 27 & 5 & 5 & 5 & 5 & 5 & 5 & 5 & 5 & 4 & 5 & 5 & 5 & 59 & 0,98 \\
\hline 28 & 5 & 5 & 5 & 5 & 5 & 5 & 5 & 5 & 4 & 5 & 5 & 5 & 59 & 0,98 \\
\hline 29 & 5 & 5 & 5 & 5 & 5 & 5 & 5 & 5 & 4 & 5 & 5 & 5 & 59 & 0,98 \\
\hline 30 & 5 & 5 & 5 & 5 & 5 & 5 & 5 & 5 & 5 & 5 & 5 & 5 & 50 & 0,83 \\
\hline 31 & 5 & 5 & 5 & 5 & 5 & 5 & 5 & 5 & 5 & 5 & 5 & 5 & 60 & 1,00 \\
\hline 32 & 5 & 5 & 5 & 5 & 5 & 5 & 5 & 5 & 5 & 5 & 5 & 5 & 60 & 1,00 \\
\hline 33 & 5 & 5 & 5 & 5 & 5 & 5 & 5 & 5 & 5 & 5 & 5 & 5 & 60 & 1,00 \\
\hline 34 & 5 & 5 & 5 & 5 & 5 & 5 & 5 & 5 & 5 & 5 & 5 & 5 & 60 & 1,00 \\
\hline \multirow[t]{2}{*}{35} & 5 & 5 & 5 & 5 & 5 & 5 & 5 & 5 & 5 & 5 & 5 & 5 & 60 & 1,00 \\
\hline & & & & & & & & & & & & \multicolumn{2}{|c|}{ V de Aiken } & 0,95 \\
\hline
\end{tabular}

